SERVIÇO DE PÓS-GRADUAÇÃO DO ICMC-USP

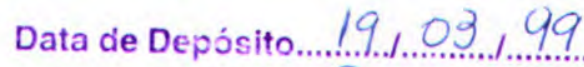

Assinatura:.........nalideudrade

\title{
Desenvolvimento e Avaliação de Algoritmos Numéricos Paralelos
}

\author{
Omar Andrés Carmona Cortés
}

Orientadora: Profa. Dra. Regina Helena Carlucci Santana

Dissertação apresentada ao Instituto de Ciências Matemáticas e de Computação - USP, como parte dos requisitos para obtenção do título de Mestre em Ciências Área: Ciências de Computação e Matemática Computacional. 
A meu irmão e a minha mãe em memória. 


\section{Agradecimentos}

A Profa. Dra. Regina Helena Carlucci Santana pela amizade, orientação e pela oportunidade de aprender tantos assuntos novos.

Ao Prof. Dr. Marcos Santana que me aceitou na pós-graduação.

À minha família, pelo carinho, apoio, paciência e por agüentar a saudade de estar tão longe.

A meu pai por acreditar em mim, a meu irmão por agüentar a saudade, a minha madrasta pela ajuda e a Iraney Colau por me apoiar.

A Porfa. Dra. Neide M. B. Franco que me ajudo muito com a parte matemática deste trabalho.

Aos amigos do LASD-PC (Aleteia, Sarita, Adriana, Paulo, Luciano, Renato, Marcio, Renata, Roberta, Andrezza, Jorge, Daniel, Kalinka, Célia, Flavio, Rita e alguém que eu esqueci) pela ajuda e pelos momentos de alegria.

Aos meus amigos especiais Cristina Endo, Marcos Alvarez e Paulo Horst pelos excelentes momentos de alegria e inclusive de tristeza compartilhados.

A meu excelente amigo Osvaldo Saavedra Mendez que teve um papel fundamental para que eu estivesse aqui.

A família Casale (Cidinha, Marcos e Elaine) que me recebeu como filho em especial a Elaine Cristina.

A Karla Conká, Cynthia M. Lima e Arturo Alejandro pela força, carinho e amor dados, a maior parte a distância, mas fundamentais para que eu conseguisse.

A meu eterno amigo Claudio Barbosa pela força e apoio.

A minha amiga Nilda que muito me ajudou.

A meu amigo Renato Haber pelo companheirismo e apoio.

Aos meus instrutores e amigo Sr. Marcos Turci e Sr. Bum Jun Kim por me mostrar o caminho da raça e do espirito forte. 
Ao CISC, LCCA e Fapema sem os quais esse trabalho não seria possível.

A Rogério T. Kondo e a Sra. Maria de Lurdes do CISC pelo otimo atendimento. Ao Francisco do LCCA pela paciência.

A todas as pessoas que contribuíram diretamente ou indiretamente para a realização deste trabalho. 


\section{Índice}

CAPITULO 1

1. INTRODUÇĀO 13

CAPITULO 2.

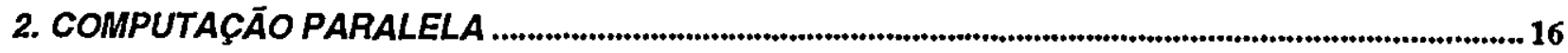

2.1 INTRODUÇÃO

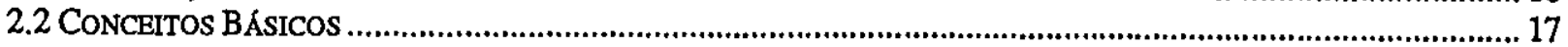

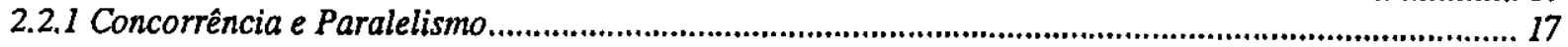

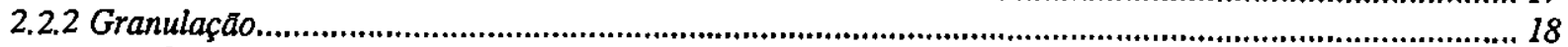

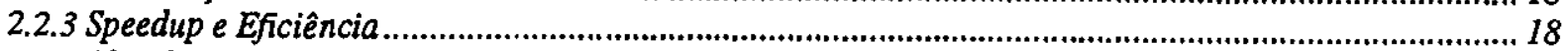

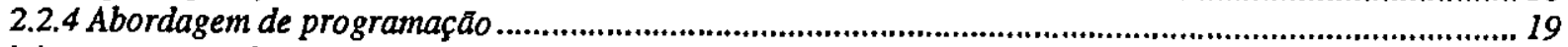

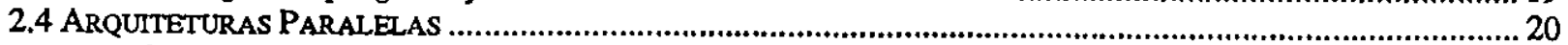

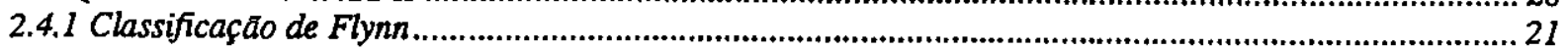

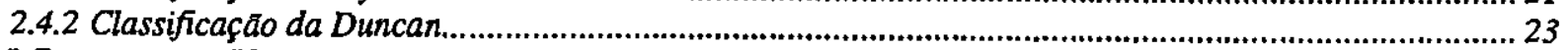

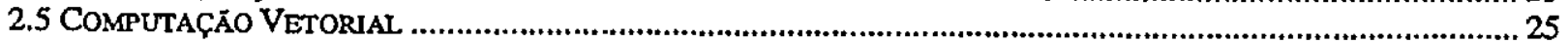

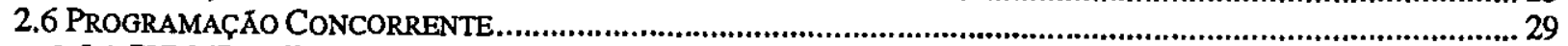

2.5.1 PVM (Parallel Virtual Machine - Máquina Paralela Virtual) ..................................................................... 30

2.5.2 MPI (Message Passing Interface - Interface de Passagem de Mensagens) .............................................. 34

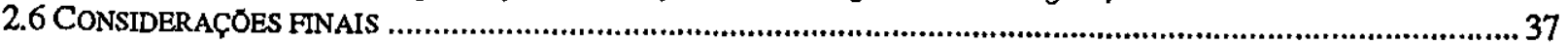

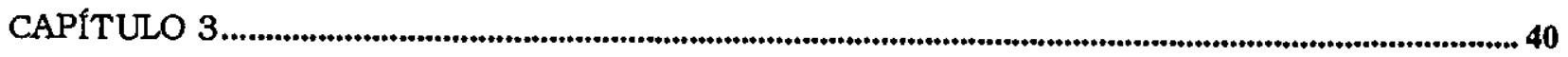

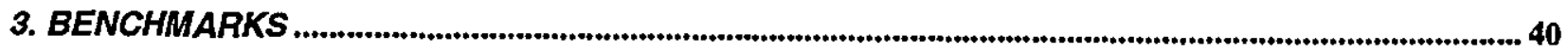

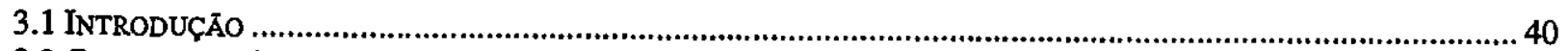

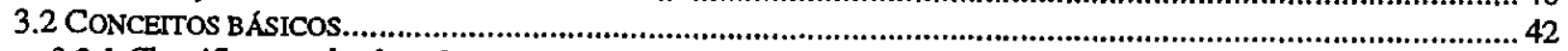

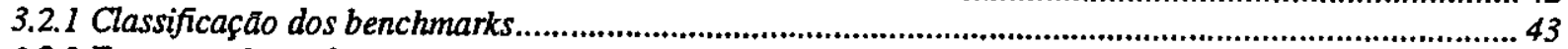

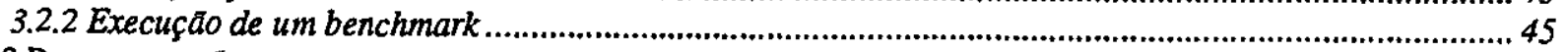

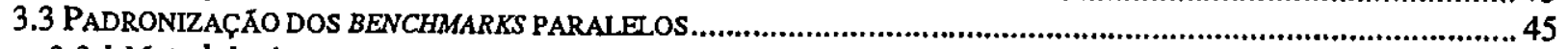

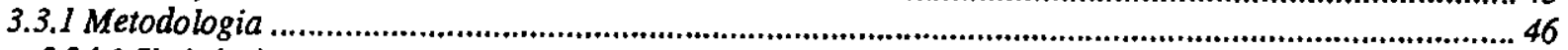

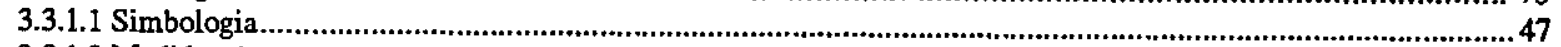

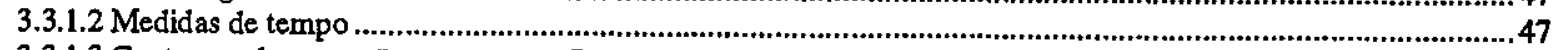

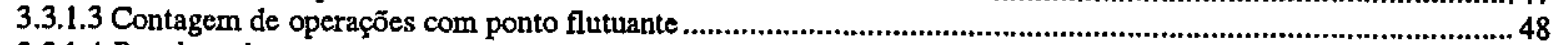

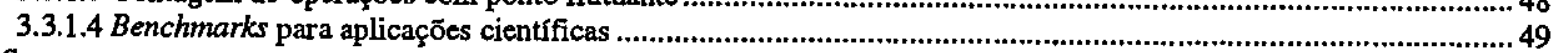

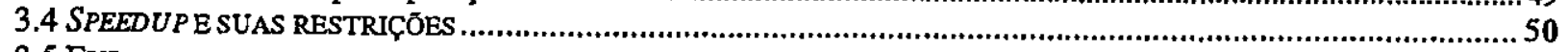

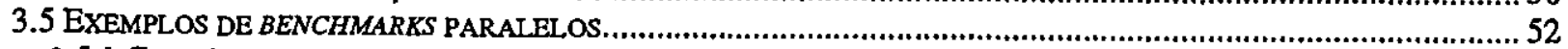

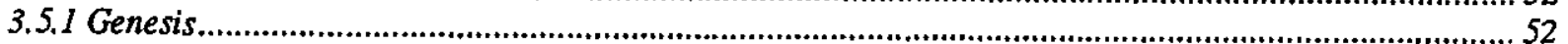

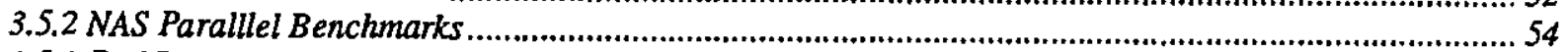

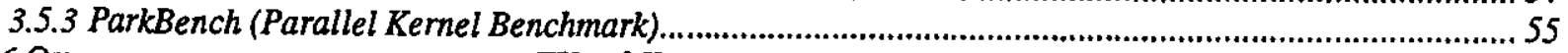

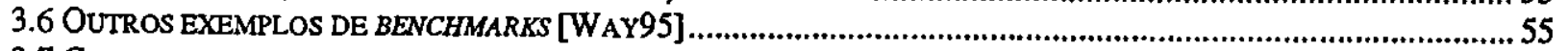

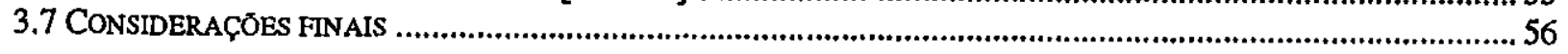

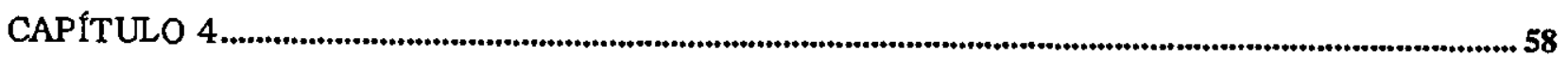

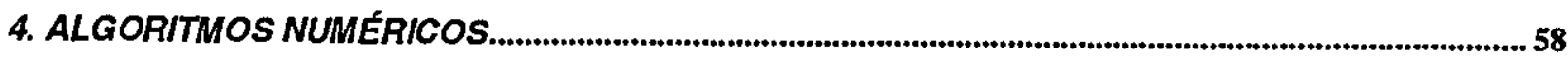

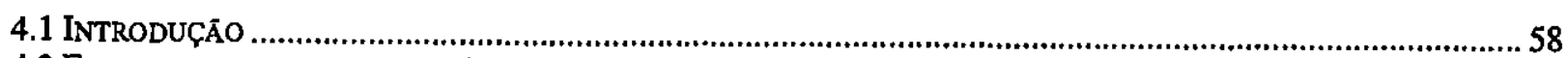

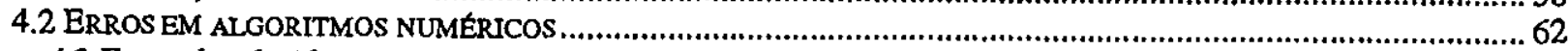

4.3 Exemplos de Algoritmos Numéricos.....................................................................................63

4.3.1. Resoluçâo de Sistemas Lineares por métodos iterativos .............................................................63

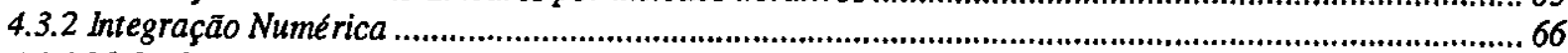

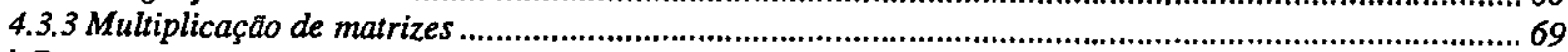

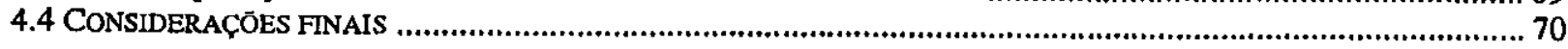




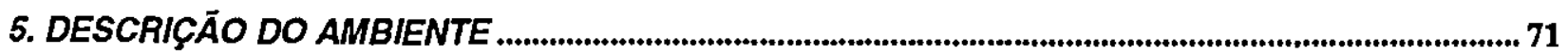

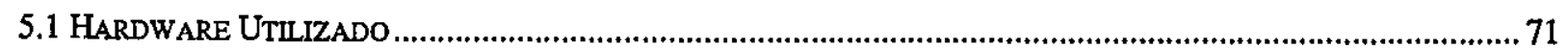

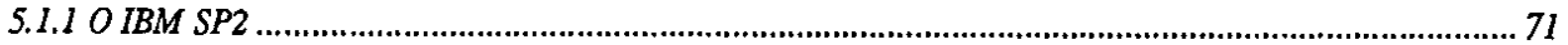

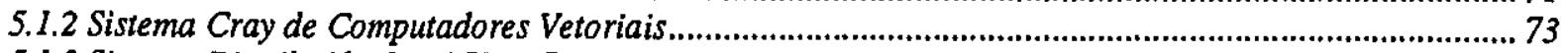

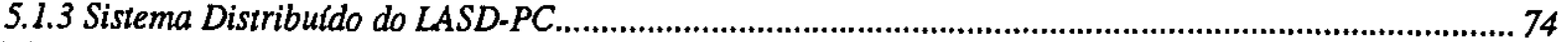

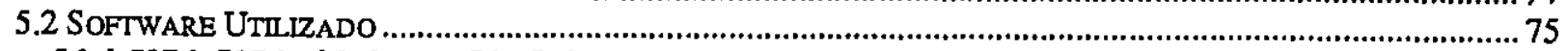

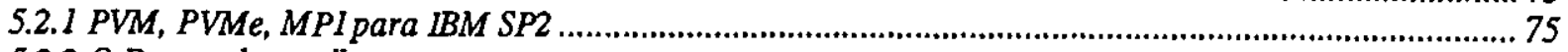

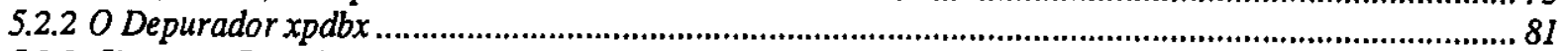

5.2.2 Sistemas Cray de Compilação e Execuçao de Programas .................................................................... 83

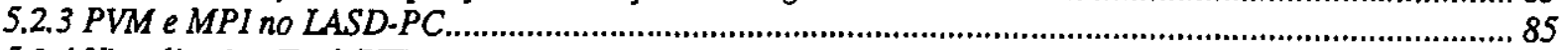

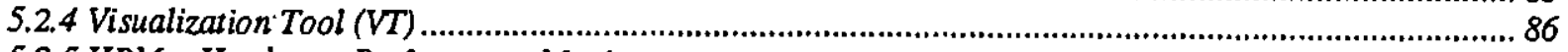

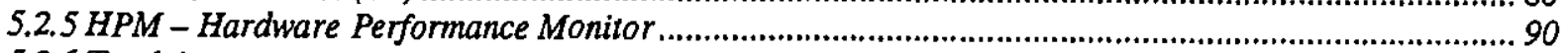

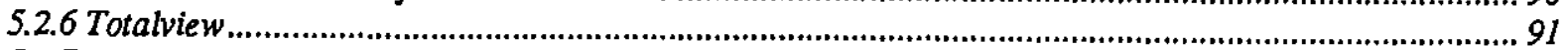

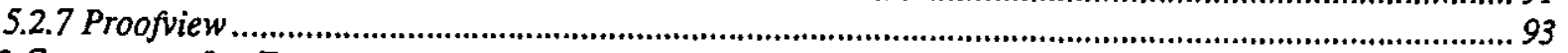

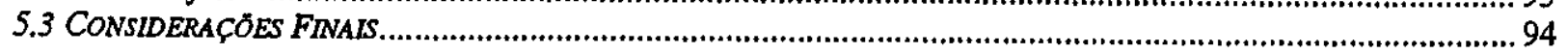

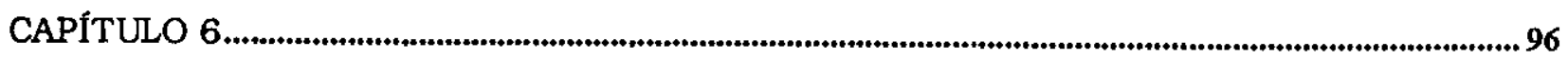

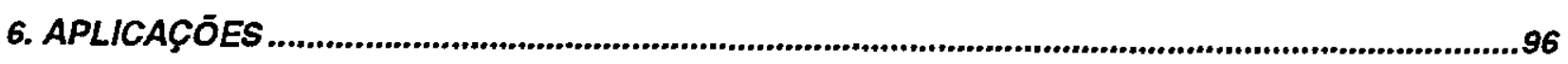

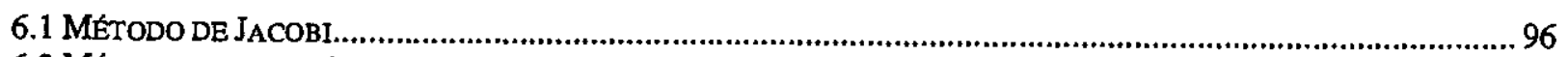

6.2 MÉTODO DOS TRAPÉZIOS COMPOSTO

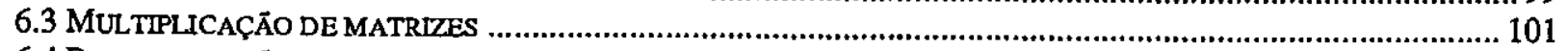

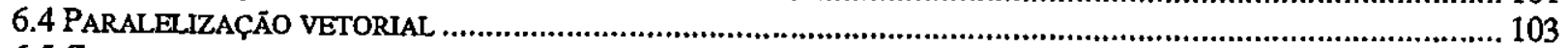

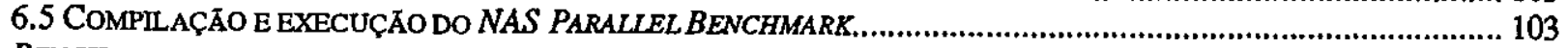

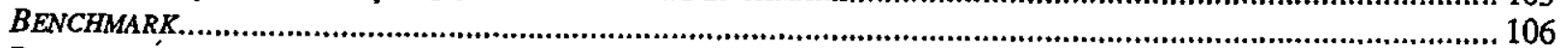

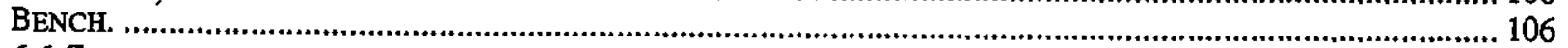

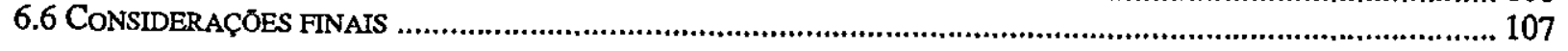

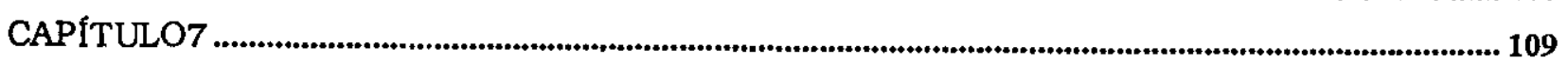

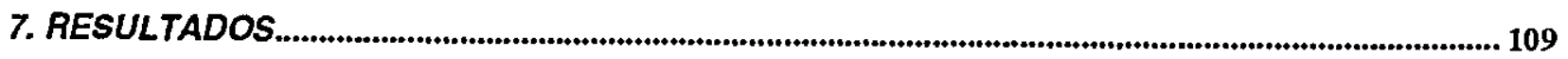

7.1 BaLANCEAMENTO de CARGA E UTILIZAÇĀo do ProcesSAdor ............................................................... 110

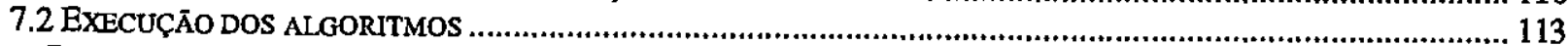

7.2.1 Resultados do programa de integração numérica ................................................................................. 113

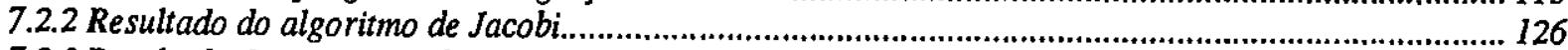

7.2.3 Resultado do programa de multiplicação de matrizes ............................................................................ 139

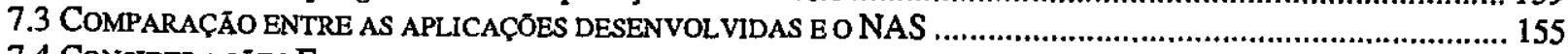

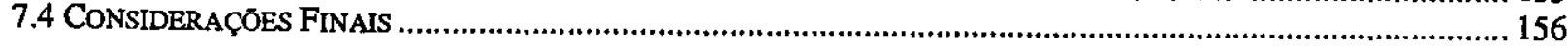

CAPITULO 8

8. CONCLUSÖES

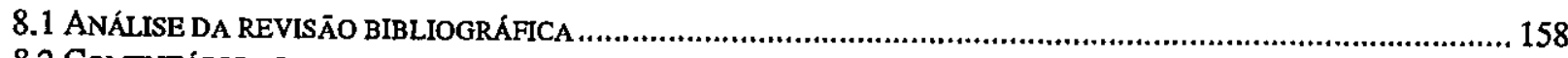

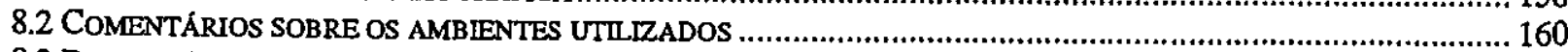

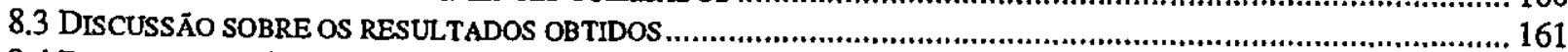

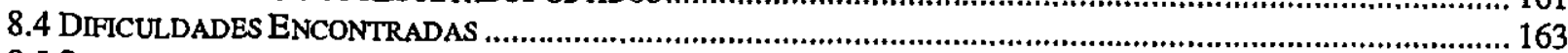

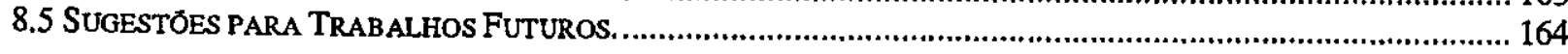

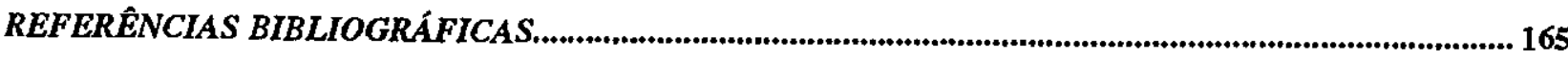




\section{Lista de Figuras}

Figura 2.1 - Exemplos de programação N-Dimensional..................................................................................... 20

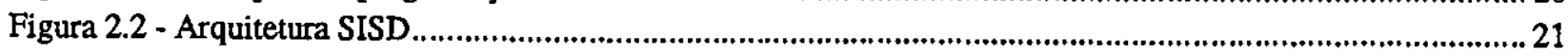

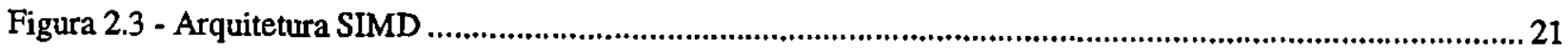

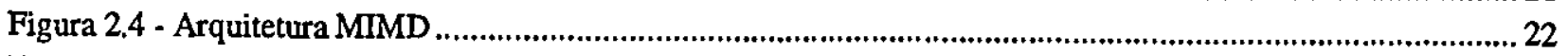

Figura 2.5 -Tentativa de caracterização da arquitetura MISD. ................................................................... 22

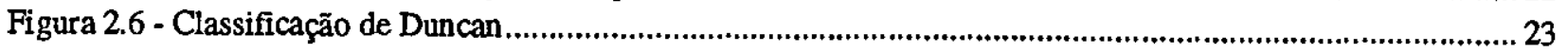

Figura 2.7 - Esquema simplificado de um computador vetorial......................................................................... 26

Figura 2.8 - Exemplos de termos utilizados na computação vetorial. ................................................................2 28

Figura 4.1 - Divisăo da Matemática Computacional. .................................................................................... 59

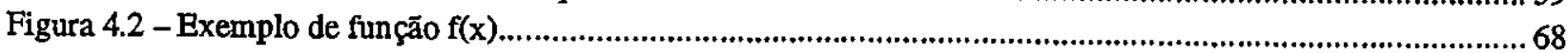

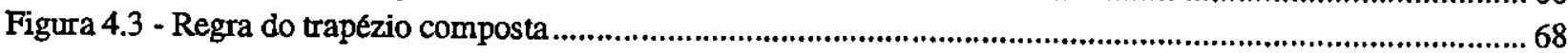

Figura 5.1 : Exemplo de conexăo do SP2 com diversos tipos de rede. ................................................................. 72

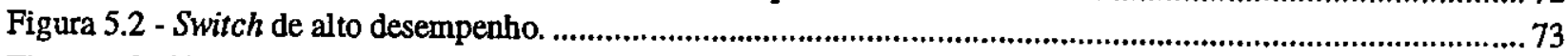

Figura 5.3 - Estrut ura básica de comunicação de um sistema Cray....................................................................... 74

Figura 5.4 - Rede LASD-PC para utilização do PVM e do MPI............................................................................ 74

Figura 5.5 - Exemplo de arquivo de comandos de tarefas. .................................................................................76

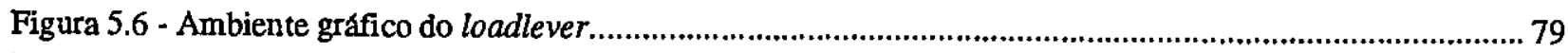

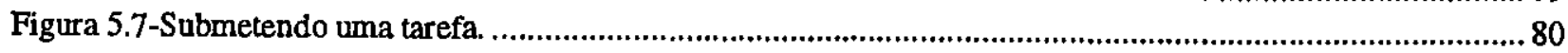

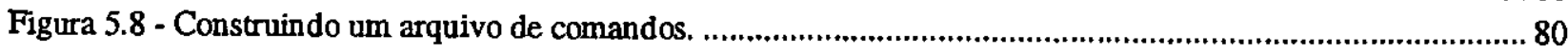

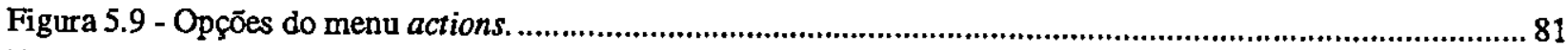

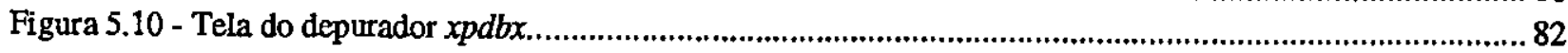

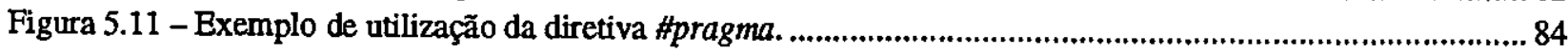

Figura 5.12 - Exemplo de um arquivo de submissão no Cray.............................................................................. 84

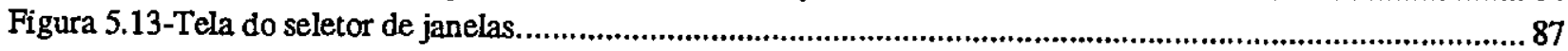

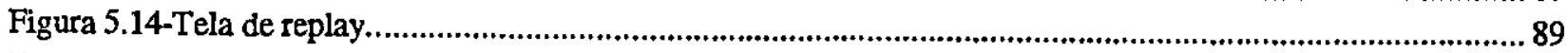

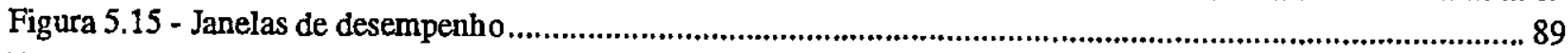

Figura 5.16 - Exemplo de um sumário emitido pelo hpm................................................................................. 91

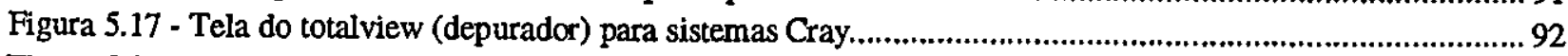

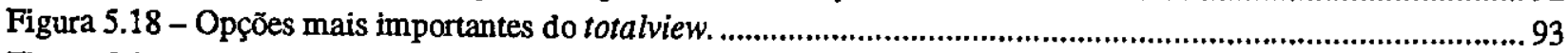

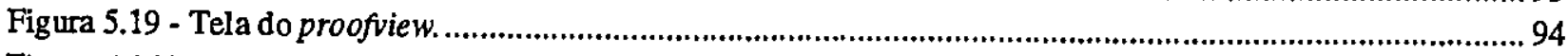

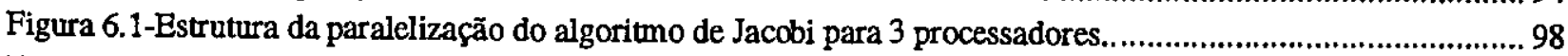

Figura 6.2 - Paralelizaf̧ăo do algoritmo do trapézio composto.................................................................... 100

Figura 6.3 - Paralelização do algoritmo de multiplicação de matrizes. .............................................................. 102

Figura 6.4 - Alteração de código no programa de multiplicação de matrizes........................................................103

Figura 7.1 - Utilização de processador por todas as aplicações. .......................................................................110

Figura 7.2 - Balanceamento de carga onde so um processador está trabalhando ................................................ 111

Figura 7.3 - Balanceamento de carga para os algoritmos no SP2 ................................................................. 112

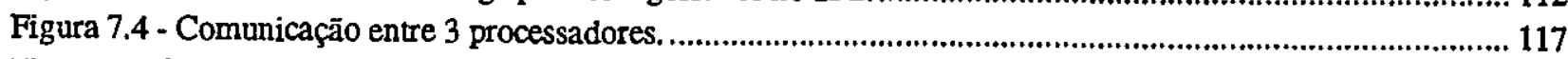

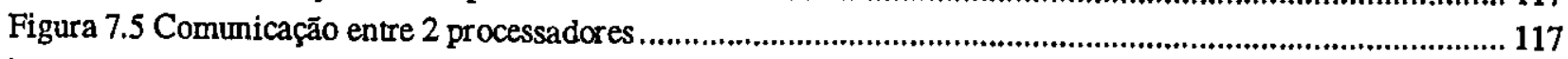

Figura 7.6 - Trecho final de comunicaşão no algoritmo de Jacobi................................................................. 128

Figura 7.7 - Execução do algoritmo de multiplicação de matrizes sem vetorização. ........................................... 149

Figura 7.8 - Execução do algoritmo de multiplicaşão de matrizes com um nivel agressivo de vetorizaçāa............... 150 


\section{Lista de Tabelas}

Tabela 2.1 - Ordem das operações no modo escalar e no modo vetorial. .............................................................. 26

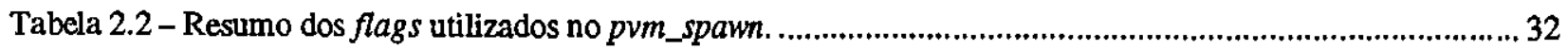

Tabela 2.3 - Funções de empacotamento de dados............................................................................................. 33

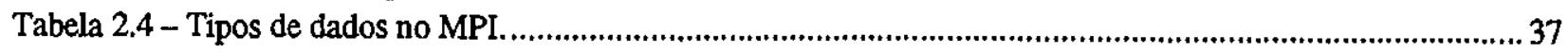

Tabela 2.5 - Resumo das características das extensőes paralelas de linguagens seriais.......................................... 38

Tabela 3.1 - Nomenclatura estipulada pelo Parkbench Comitee ........................................................................... 47

Tabela 2.2 - Contagem de operações em ponto flutuante. .................................................................................... 48

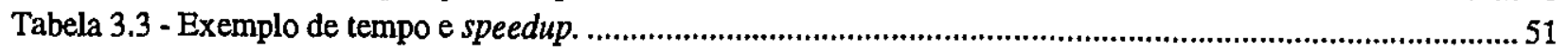

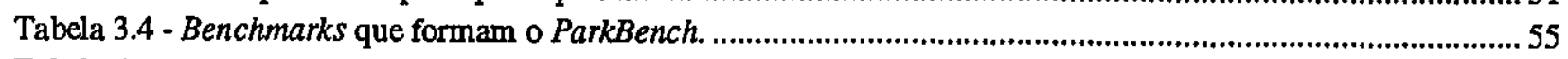

Tabela 4.1 - Resultados alcançados no processo de obtençăo das iterações. ...........................................................6 66

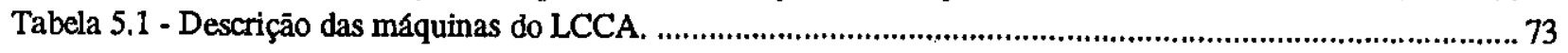

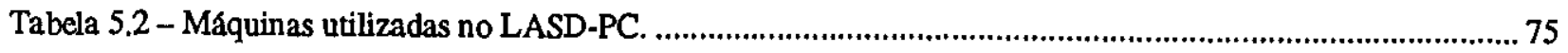

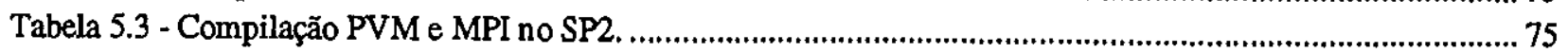

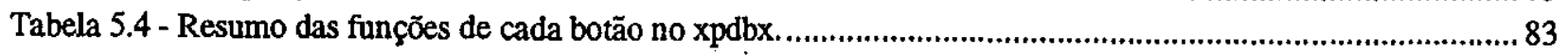

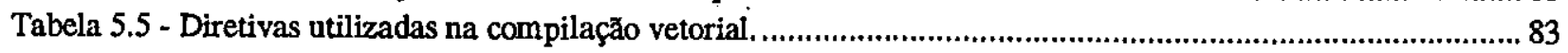

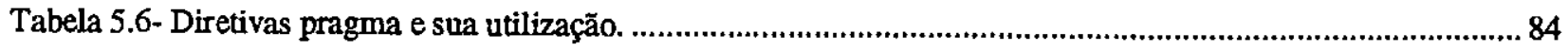

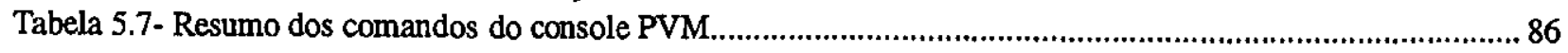

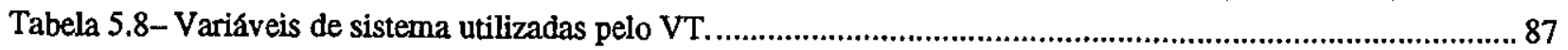

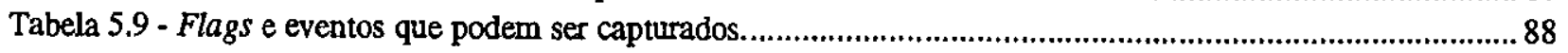

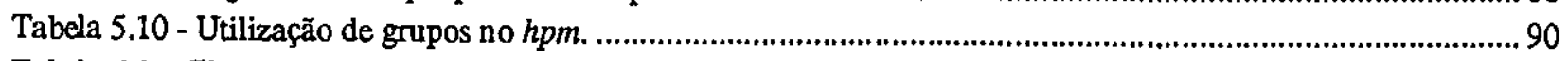

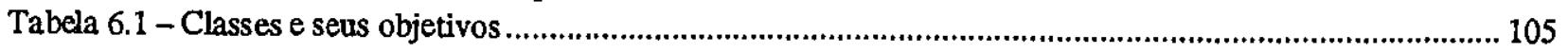

Tabela 6.2 - Benchmarks executados com as respectivas classes................................................................... 106

Tabela 6.3 - Resultados encontrados na execução do NAS Parallel Benchmark ................................................. 106

Tabela 7.1 - Resultados encontrados no SP2 utilizando MPI com 3 processadores........................................... 114

Tabela 7.2 - Resultados encontrados no SP2 utilizando MPI com 2 processadores. ......................................... 114

Tabela 7.3 - Resultados encontrados no SP2 utilizando PVMe com 3 processadores. ....................................... 116

Tabela 7.4 - Resultados encontrados no SP2 utilizando PVMe com 2 processadores.......................................... 116

Tabela 7.5 - Resultados encontrados no LASD-PC utilizando MPI com 3 processadores. ................................... 119

Tabela 7.6 - Resultados encontrados no LASD-PC utilizando MPI com 2 processadores. .................................... 119

Tabela 7.7 - Resultados encontrados no LASD-PC utilizando PVM com 3 processadores. ................................... 121

Tabela 7.8 - Resultados encontrados no LASD-PC utilizando PVM com 2 processadores.................................... 121

Tabela 7.9 - Resultados encontrados no Cray utilizando 3 processadores. ......................................................... 123

Tabela 7.10 - Resultados encontrados no Cray utilizando 2 processadores........................................................ 123

Tabela 7.11 - Comparação entre arquiteturas com 3 processadores ..................................................................... 125

Tabela 7.12 - Comparaçāo entre arquiteturas com 2 processadores ................................................................. 126

Tabela 7.13 - Resultados encontrados no SP2 utilizando MPI com 3 processadores. ........................................ 127

Tabela 7.14 - Resultados encontrados no SP2 utilizando MPI com 2 processadores. ......................................... 127

Tabela 7.15 - Resultados encontrados no SP2 utilizando PVMe com 3 processadores. ....................................... 129

Tabela 7.16 - Resultados encontrados no SP2 utilizando PVMe com 2 processadores......................................... 130

Tabela 7.17 - Resultados encontrados no LASD-PC utilizando MPI com 3 processadores. ................................. 131

Tabela 7.18 - Resultados encontrados no LASD-PC utilizando MPI com 2 processadores. .................................. 131

Tabela 7.19 - Resultados en contrados no LASD-PC utilizando PVM com 3 processadores. ................................ 133

Tabela 7.20 - Resultados encontrados no LASD-PC utilizando PVM com 2 processadores................................. 134

Tabela 7.21 - Resultados encontrados no Cray utilizando 3 processadores. ..................................................... 135

Tabela 7.22 - Resultados encontrados no Cray utilizando 2 processadores...................................................... 135

Tabela 7.23 - Desempenho do benchmark para 3 processadores..................................................................... 137

Tabela 7.24 - Desempenho do benchmark para 3 processadores................................................................... 138 
Tabela 7.25 - Resultados encontrados no SP2 utilizando MPI com 3 processadores

Tabela 7.26 - Resultados encontrados no SP2 utilizando MPI com 2 processadores.

Tabela 7.27 - Resultados encontrados no SP2 utilizando PVMe com 3 processadores.

Tabela 7.28 - Resultados encontrados no SP2 utilizando PVMe com 2 processadores.

Tabela 7.29 - Resultados encontrados no LASD-PC utilizando MPI com 3 processadores

Tabela 7.30 - Resultados encontrados no LASD-PC utilizando MPI com 2 processadores.

Tabela 7.31 - Resultados encontrados no LASD-PC utilizando PVM com 3 processadores

Tabela 7.32 - Resultados encontrados no LASD-PC utilizando PVM com 2 processadores

Tabela 7.33 - Resultados encontrados no Cray utilizando 3 processadores.

Tabela 7.34 - Resultados encontrados no Cray utilizando 2 processadores.......................................................... 147

Tabela 7.35 - Resumo do desempenho de benchmark para 3 processadores......................................................... 151

Tabela 7.36 - Resumo do desempenho de benchmark para 2 processadores ......................................................... 153

Tabela 8.1 - Resumo dos resultados obtidos na execução dos algoritmos e dos benchmarks. 


\section{Lista de Gráficos}

Gráfico 7.1 - Tempo de execução do algoritmo do trapézio composto no SP2 utilizando MPI.....................115

Grafico 7.2 - Speedup e eficiência alcan çada por 2 e 3 processadores no SP2 …........................................115

Gráfico 7.3 - Tempo de execução do algoritmo do trapézio composto no SP2 utilizando-se PVMe...............118

Gráfico 7.4 - Speedup e eficiência alcançados por 2 e 3 processadores no SP2 utilizando PVMe.................118

Gráfico 7.5 - Tempo de execuşăo do algoritmo do trapézio composto no LASD-PC utilizando MPI ............120

Gráfico 7.6 - Eficiência e speedup alcançados no LASD-PC utilizando MPI..............................................120

Gráfico 7.7 - Tempo de execução do algoritmo do trapézio composto no LASD-PC utilizando PVM..........122

Gráfico 7.8 - Eficiência e speedup alcançados no LASD-PC utilizando PVM ............................................122

Gráfico 7.9 - Tempo de execução do algoritmo do trapézio composto no sistema Cray. ...............................124

Gráfico 7.10 - Eficiência e speedup alcançados no sistema Cray................................................................124

Gráfico 7.11 - Comparaçăo entre arquiteturas com 3 processadores executando o algoritmo do trapézio. ........125

Gráfico 7.12 - Comparaçăo entre arquiteturas com 3 processadores executando o algoritmo do trapézio ........126

Gráfico 7.13 - Tempo de execuçăo do algoritmo de Jacobi no SP2 utilizando o MPI.....................................128

Gráfico 7.14- - Speedup e eficiència alcançados por 2 e 3 processadores no SP utilizando MPI.......................129

Gráfico 7.15 - Tempo de execução do algoritmo de Jacobi no SP2 utilizando PVMe. ....................................130

Gráfico 7.16 - Speedup e eficiência alcançados por 2 e 3 processadores no SP2 utilizando PVMe....................131

Gráfico 7.17 - Tempo de execuşão do algoritmo de Jacobi no LASD-PC utilizando MPI...............................132

Gráfico 7.18 - Speedup e eficiência alcançados por 2 e 3 processadores no LASD-PC utilizando MPI ...........133

Gráfico 7.19 - Tempo de execução do algoritmo de Jacobi no LASD-PC utilizando PVM. ...........................134

Gráfico 7.20 - Speedup e eficiência alcan çados por $2 \mathrm{e} 3$ processadores no LASD-PC utilizando PVM.........135

Gráfico 7.21 - Tempo de execução do algoritmo de Jacobi na sistema Cray.................................................136

Gráfico 7.22 - Speedup e eficiência alcançados no sistema Cray................................................................137

Gráfico 7.23 - Comparação entre arquiteturas com 3 processadores executando o algoritmo de Jacobi ............138

Gráfico 7.24 - Comparação entre arquiteturas com 2 processadores executando o algoritmo de Jacobi ...........139

Gráfico 7.25 - Tempo de execuşão do algoritmo de multiplicação de matrizes no SP 2 utilizando MPI. .........140

Gráfico 7.26 - Speedup e eficiência alcançados por 2 e 3 processadores no SP2 utilizando MPI......................141

Gráfico 7.27 - Tempo de execuşão do algoritmo de multiplicação de matrizes no SP2 utilizanđo PVM...........142

Gráfico 7.28 - Speedup e eficiência alcançados por 2 e 3 processadores no SP2 utilizando PVMe..................143

Gráfico 7.29 - Tempo de execução do algoritmo do trapézio composto no LASD-PC utilizando MPI. .............144

Gráfico 7.30 - Speedup e eficiência alcançados por 2 e 3 processadores no LASD-PC utilizando MPI. ...........145

Gráfico 7.31 - Tempo de execução do algoritmo de multiplicação de matrizes no LASD-PC

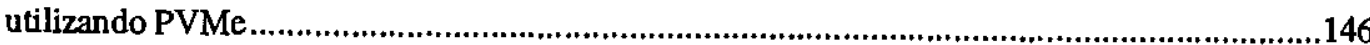

Gráfico 7.32 - Speedup e eficiência alcançados por 2 e 3 processadores no LASD-PC usando PVM ...............147

Gráfico 7.33 - Tempo de execução do algoritmo de multiplicação de matrizes no sistema Cray ......................148

Gráfico 7.34 - Speedup e eficiência encontrados no sistema Cray ...............................................................151

Gráfico 7.35 - Comparação entre arquiteturas com 3 processadores executando o algoritmo de multiplicação de matrizes

Gráfico 7.36 - Comparação entre arquiteturas com 3 processadores executando o algoritmo de multiplicação de matrizes excluindo Cray

Gráfico 7.37 - Comparação entre arquiteturas com 2 processadores executando o algoritmo de multiplicaçăo de matrizes

Gráfico 7.38 - Comparação entre arquiteturas com 2 processadores executando o algoritmo de multiplicaçāo de matrizes excluinđo Cray 


\section{Resumo}

O objetivo principal deste trabalho é o desenvolvimento e avaliação de algoritmos numéricos paralelos e sua execução em máquinas paralelas (máquinas multiprocessadas, máquinas vetoriais e máquinas paralelas virtuais). Os algoritmos desenvolvidos foram executados em diferentes condições tanto em termos de plataformas utilizadas como em termos de tamanho da aplicação considerada.

Os resultados obtidos na implementação dos algoritmos numéricos são analisados baseando-se em algumas métricas (tempo de execução e operações em ponto flutuante) comuns aos resultados apresentados nos principais benchmarks estudados. Atraves dos resultados obtidos, o desempenho das bibliotecas de passagem de mensagem MPI e PVM, o desempenho das arquiteturas consideradas e da implementação dos algoritmos numéricos são analisados. 


\section{Abstract}

The main objective of this dissertation is the development and evaluation of numerical parallel algorithms and their execution on parallel machines (multiprocessor machines, vectorial machines and parallel virtual environments).

The algorithms developed have been executed under different conditions both in terms of the hardware plataform adopted and the problem size.

The results obtained with the numerical algorithms implementation are all analyzed according to some metrics (execution time and float-point operations) available in the main benchmarks studied.

The performance reached with the message passing libraries PVM and MPI together with the performance observed from the different architectures considered and the numerical algorithms implemented are all analyzed according to the result obtained in this work. 


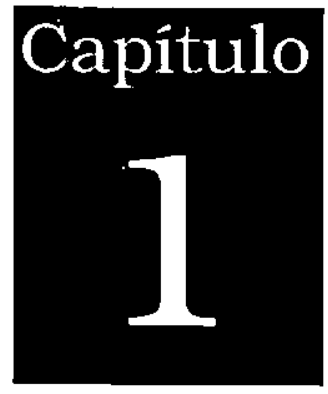

\section{Introdução}

A grande evolução dos computadores nas últimas décadas, vem sendo acompanhada de perto pelo considerável aumento, tanto em número quanto em complexidade, das aplicações que utilizam estas máquinas. Desta forma, por mais que as arquiteturas tenham apresentado um processo evolutivo intenso, ainda é necessário buscar um melhor desempenho para a execução das aplicações que crescem tanto em volume como em complexidade muito mais rapidamente que o hardware disponível. Nesse contexto surge a computação paralela que tem como objetivo principal o aumento de desempenho na execução de uma aplicação. Nessa busca por melhor desempenho os sistemas paralelos apresentam-se como uma alternativa à máquina de von Neumann, sejam esses sistemas paralelos virtuais (sistemas distribuídos) ou em arquiteturas realmente paralelas (máquinas com múltiplos processadores).

Assim como em muitas outras áreas, não só da computação, a análise de desempenho vem se tornando imprescindível, principalmente quando o objetivo é atingir a máxima qualidade de um produto ou serviço, em particular, na área de computação. Devido ao grande crescimento dos sistemas paralelos, a necessidade de avaliação de desempenho tornou-se essencial, tanto para o software como para o hardware envolvido. Segundo Heidelberg e Lavemberg [Hei84] a 
avaliação de desempenho se divide em três categorias: Modelagem Analítica de Desempenho, Simulação e Medidas de Desempenho. Sendo que, Medidas de Desempenho se divide em: Benchmarks e Monitoração.

A modelagem analítica de desempenho não envolve programação e sim análise matemática, probabilística e estatística. Este tipo de análise de desempenho nem sempre é viável, principalmente quando muitas variáveis estão envolvidas. A modelagem analítica pode ser utilizada com sucesso para verificar o desempenho de um dispositivo particular do computador, por exemplo, o sistema de disco, de E/S (Entrada/Saída), etc. A verificação do software através de modelagem analítica torna-se complicada por depender de um grande número de variáveis. Desta forma, esta abordagem tem utilização restrita.

A simulação utiliza programas que emulam o sistema em questão, executando as instruções que representam parcialmente ou totalmente um sistema real. Este tipo de análise é ideal para estimar o tempo de execução de programas, a influência de algumas características de uma arquitetura tais como utilização de memória e comunicação entre processadores entre outras.

As medidas de desempenho, podem ser efetuadas através de benchmarks ou de medidas efetuadas no programa a ser avaliado ou no hardware analisado. Os Benchmarks são programas que devem ser executados em sistemas reais para avaliar seu desempenho. O mesmo benchmark executado em diferentes sistemas, permite que os resultados e consequentemente os sistemas sejam comparados. Essas medidas podem ser a quantidade de soluções por segundo, número de operaçōes em ponto flutuante por segundo e quantidade de comunicação entre outras.

$O$ objetivo deste trabalho é verificar o desempenho de alguns algoritmos paralelos executando em diferentes plataformas. Esta avaliação é efetuada através de mediçōes durante a execução dos algoritmos. Os valores obtidos na execução são utilizados para determinar-se diferentes métricas para avaliar o desempenho do algoritmo sendo executado em uma determinada plataforma.

Os resultados obtidos nestas medições serão comparados com resultados obtidos na execução de benchmarks disponiveis comercialmente para avaliação de arquiteturas paralelas.

Três plataformas básicas foram utilizadas para a avaliação dos algoritmos. Um computador multiprocessado - SP2, executando PVM e MPI. Um sistema distribuído baseado em 
computadores tipo PC, rodando o sistema operacional linux e utilizando PVM e MPI. Uma máquina vetorial Cray com 3 processadores vetoriais.

Este trabalho está dividido em 8 capítulos. No Capítulo 2 são apresentadas as características básicas da computação paralela, tais como, conceitos, classificações e uma descrição, que permite criar programas paralelos de uma certa complexidade, das duas bibliotecas mais utilizadas em passagem de mensagens (PVM e MPI).

No Capítulo 3, são discutidas as principais características dos benchmarks, bem como os conceitos básicos, cuidados a serem seguidos, metodologia utilizada, formas de medir 0 desempenho, como devem ser construídos os benchmarks numéricos. Três benchmarks para arquiteturas paralelas (NAS, Genesis e Parkbench) e uma breve descrição de outros tipos de benchmarks são discutidos neste capítulo.

Os algoritmos numéricos que serão considerados neste trabalho são apresentados no Capítulo 4.

Os Capítulo 5 e 6 são responsáveis por descrever todo o ambiente utilizado (software e hardware) e como os algoritmos apresentados no Capítulo 4 foram paralelizados e implementados.

O Capítulo 7 mostra os resuitados obtidos durante a execução dos algoritmos numéricos nas plataformas descritas no Capítulo 5.

Finalmente, o Capítulo 8 apresenta as conclusões, as dificuldades encontradas e as sugestões para trabalhos futuros. 


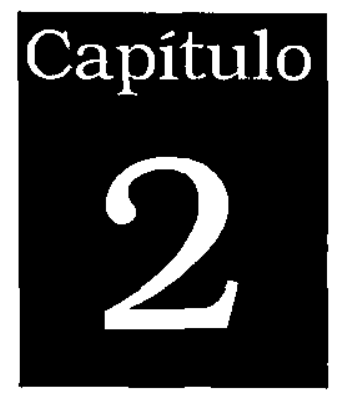

\section{Computação Paralela 2.1 Introdução}

Com o advento do VLSI (Very Large System Integration) em circuitos integrados, as regras para construção de computadores mudaram totalmente. Um resultado indiscutível foi a remoção da barreira criada pelo paradigma de von Neumman que impunha as CPUs um procedimento serial. Com essa barreira quebrada, os projetistas de computadores podem agora voltar-se a solucionar problemas utilizando arquiteturas paralelas, problemas estes que antes exigiriam longos períodos de computação se utilizada uma arquitetura serial.

Considerando os problemas a serem solucionados, origina-se a seguinte questão: qual a relação custo-beneficio de se utilizar um sistema paralelo vetorial, como por exemplo uma máquina Cray, versus utilizar um sistema de passagem de mensagem num sistema distribuído ou em uma máquina multiprocessada? A resposta mais intuitiva seria a de utilizar-se a arquitetura de mais baixo custo, mas se for feita uma análise mais profunda, observa-se que a resposta é bem mais complicada do que se imagina. Outras questões devem entrar na análise, tais como: tempo exigido para conclusão de uma tarefa, periodicidade de resolução, se vários tipos de problemas 
devem ser solucionados pela máquina, qual a sincronização exigida pelo problema, qual a linguagem ou biblioteca de comunicação mais adequada para implementar o algoritmo, e assim por diante. Um ponto que nunca deve ser esquecido, é se a instituição ou empresa tem recursos suficientes para implantar e manter a estrutura necessária funcionando [Ve194].

Neste capítulo serão discutidos alguns tópicos que devem ser considerados na utilização da computação paralela. A próxima seção introduz alguns conceitos básicos da área e conceitos referentes a computação paralela.

\subsection{Conceitos Básicos}

Devido ao surgimento relativamente recente da computação paralela, não existe uma terminologia unificada como a encontrada em algumas outras áreas da ciência da computação. Desta forma apresentam-se alguns conceitos que serão observados através deste trabalho.

\subsubsection{Concorrência e Paralelismo}

Estes dois conceitos sẫo constantemente confundidos pelos usuários menos experientes por estarem intimamente ligados. O termo "paralelismo" é designado a múltiplos processadores executando processos ao mesmo tempo. Entende-se por processo como um programa qualquer em execução em um determinado instante de tempo.

O termo "concorrência" indica que mais de um processo está sendo executado, ou seja, vários processos já iniciaram e ainda não terminaram. O pseudo-paralelismo ocorre quando vários programas (processos) são executados em uma máquina que possui somente um processador. Neste caso, em um determinado instante de tempo somente um processo pode estar sendo executado. Cada um desses processos recebe uma porção de tempo para sua execução, esse determinado tempo pode ser denominado de time-slice ou quantum. Quando seu quantum termina, caso ele não tenha concluído sua execução, seu estado é salvo para uma posterior execução e um outro processo é executado. Desta forma o usuário tem a impressão de que todos os programas estão sendo executados ao mesmo tempo. 


\subsubsection{Granulação}

A granulação representa o nível de paralelismo apresentado por uma aplicação, sendo que de maneira simplificada a granulação pode ser dividida em: grossa, média e fina. $O$ conceito de granulação é largamente discutido em [Hwa84] [Nav89] [Kir91] [Alm94].

Pode-se dizer que quando os processadores tem grande carga de trabalho, dividida em poucos processos, e pouca comunicação entre eles a granulação é grossa. Geralmente, este tipo de granulação aplica-se a arquiteturas com poucos processadores.

A granulação fina por sua vez lida com paralelismo em nível de instruções ou operações e geralmente é utilizada com uma grande quantidade de processadores.

E por fim, pode-se dizer que a granulação média está situada entre as duas granulações anteriores. Geralmente é difícil distinguir onde aplicações de granulação média se situam dentre essas três classificações.

\subsubsection{Speedup e Eficiência}

O principal motivo da utilização da computação paralela é o aumento da velocidade de processamento o que consequentemente pode levar ao aumento da eficiência na resolução de um determinado problema.

Speedup (Sp) É uma medida utilizada para calcular o quanto um programa paralelo utilizando $p$ processadores é mais rápido do que sua execução seqüencial. Onde, $T_{\text {seq }}$ é o tempo de execução seqüencial e $T_{p a r}$ representa o tempo de execução em paralelo [Hwa93][Alm94] como na equação a seguir:

$$
S p=T_{\text {seq }} / T_{p a r}
$$

Pela fórmula pode-se observar que $S p=p$ representa a situação ideal em termos de ganho. Mas, essa situação dificilmente é alcançada pois outros fatores influenciam nos cálculos, tais como: sobrecarga na comunicação, balanceamento de carga inadequado, algoritmos com um nível pequeno de paralelismo e granulação inadequada. Em casos raros, pode ocorrer uma anomalia, 
onde $S p>p$, esse caso é chamado de anomalia de speedup ou speedup super linear [Fos95]. Isto normalmente ocorre devido a um grande aumento de memória, quando vários processadores são considerados.

Para quantificar a utilização do processador é usada uma métrica denominada eficiência $(E p)$ e é calculada através do speedup $(S p)$ e do número de processadores $(p)$ :

$$
E p=S p / p
$$

A máxima eficiência do processador é dada por $E p=1$, que significa que sua capacidade do foi totalmente aproveitada (100\%). Os valor encontrados devem variar entre 0 (zero) e 1 (um) e dificilmente atinge o valor 1 (um). Quando ocorre a anomalia de speedup também ocorre uma exceção onde os valores de $E p$ serão maiores do que um.

\subsubsection{Abordagem de programação}

Existem duas abordagens de programação conhecidas como SPMD (Simple Program Multiple Data - Programa Único Múltiplos Dados) e MPMD (Multiple Program Multiple Data - Vários Programas Múltiplos Dados). O primeiro tipo utiliza um único programa, ou seja, o mesmo código executa em diferentes processadores utilizando diferentes dados. O segundo tipo utiliza diferentes programas usando diferentes dados.

Além das abordagens de programação, existem alguns paradigmas que podem ser classificado em: Processor Farm também conhecido como Mestre-Escravo, Pipeline, e N-dimensional.

No paradigma Mestre-Escravo é designado um processador, chamado de mestre, para distribuir o trabalho entre os demais processadores escravos. É apropriado para aplicações com pouca comunicação e no final de cada tarefa os escravos enviam os resultados do seu processamento ao mestre. Esta abordagem é de fácil implementação, uma vez que não depende totalmente da arquitetura. [Meg97] A programação SPMD torna-se mais simples devido a capacidade das linguagens de iniciar vários processos iguais de uma só vez.

No modo Pipeline uma tarefa é dividida em várias tarefas menores com um certo grau de dependência entre elas, ou seja, a segunda tarefa depende do resultado da primeira, a terceira 
depende do resultado da segunda e assim por diante sendo que as mesmas devem ser uma diferente da outra.

O paralelismo $N$-Dimensional caracteriza-se pela forma de como os processos trocam informações entre si. Por exemplo, o paralelismo de uma dimensão comunica-se com os processos vizinhos que seguem o mesmo caminho, já o de duas dimensões permite duas linhas de comunicação entre os dados, o de três dimensões possuem três linhas de comunicação formando um cubo e assim por diante [Des87]. A Figura 2.1 mostra um exemplo dos três tipos descritos.

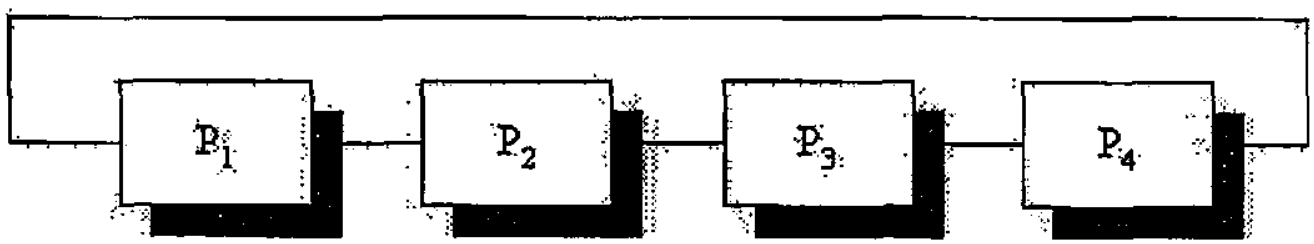

(a) Unidimensional

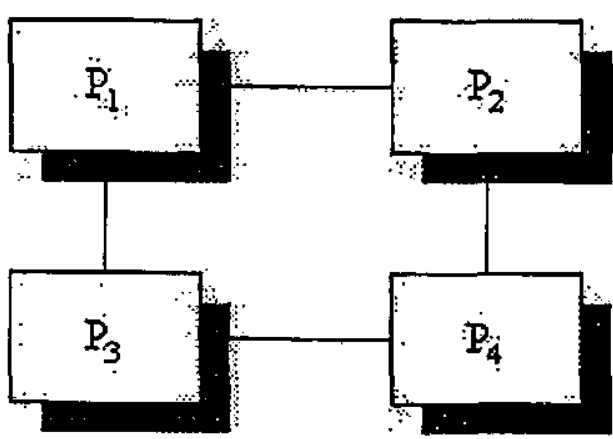

(b) Bidimensional

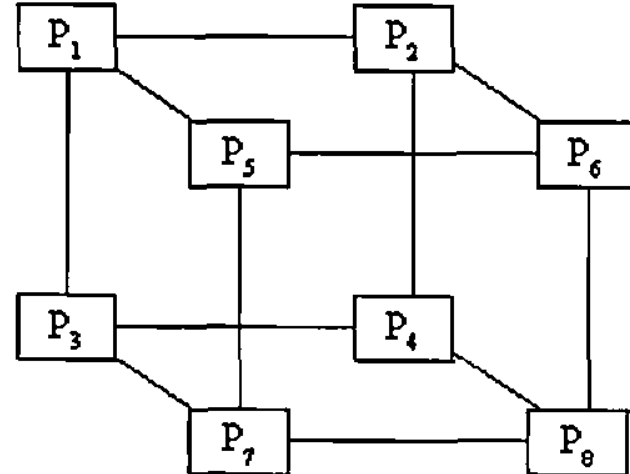

(c) Tridimensionai

Figura 2.1 - Exemplos de programação $N$-Dimensional.

\subsection{Arquiteturas Paralelas}

Um grande número de arquiteturas paralelas vem sendo propostas ao longo dos últimos anos . Para organizar a apresentação destas arquiteturas, são utilizadas algumas classificações, a de Flynn e de Duncan foram adotadas por abrangerem a grande maioria das arquiteturas disponíveis. 


\subsubsection{Classificação de Flynn}

A primeira tentativa de classificação das arquiteturas paralelas foi a classificação de Flynn que a dividia em quatro categorias [Hwa93]:

SISD - Única Instrução e Único Dado.

É o computador de von Neumman, ou seja, os computadores puramente seqüenciais. Executa as instruções seqüencialmente a cada operação atua sobre um único elemento de dados. Os computadores sequienciais estão enquadrados nesta categoria, esta arquitetura é apresentada na Figura 2.2.

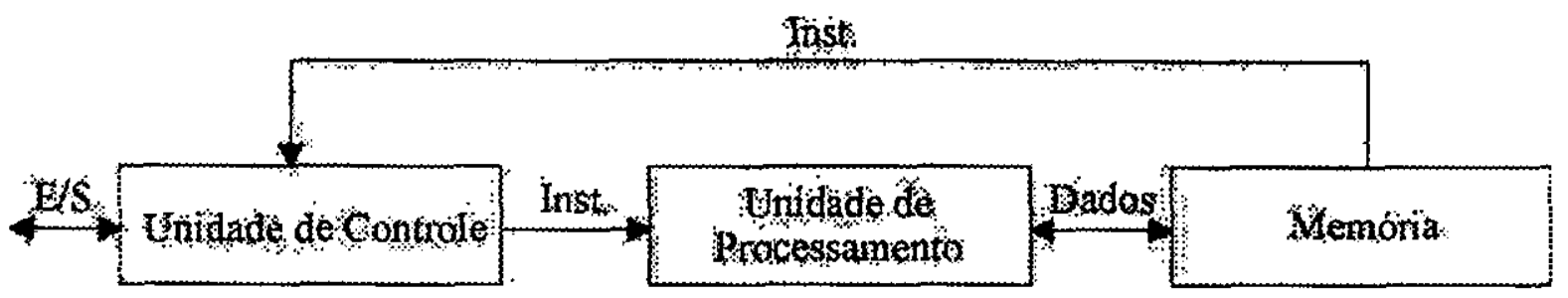

Figura 2.2 - Arquitetura SISD

SIMD - Única Instruções e Múltiplos Dados

Este tipo de arquitetura é síncrona e determinística, conveniente para paralelismo em nível de instrução/operação. Nesta categoria estão os computadores vetoriais como o IBM 9000 e o Cray YMP [Hwa94]. A figura 2.3 mostra a estrutura deste tipo de arquitetura.

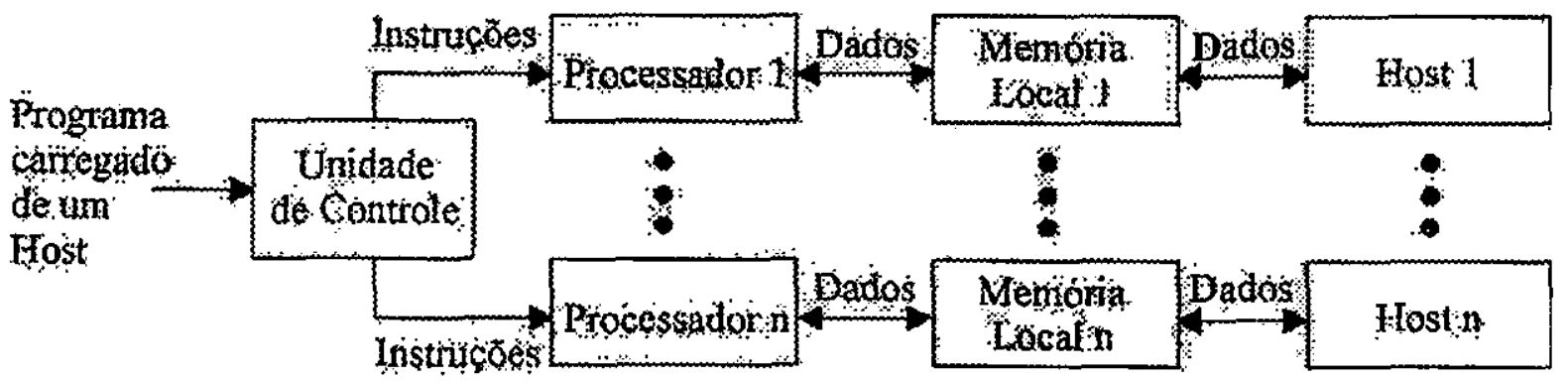

Figura 2.3 - Arquitetura SIMD

\section{MIMD - Múltiplas Instruções e Múltiplos Dados}

Este tipo de arquitetura é assíncrona e conveniente para paralelismo de blocos, "loops" e subrotinas [Hwa93]. O código pode ser igual ou diferente para todos os processadores (SPMD ou 
MPMD). Seus principais representantes são: IBM ES/9000-900 e o IBM-SP2. A Figura 2.4 mostra a estrutura de uma arquitetura MIMD.

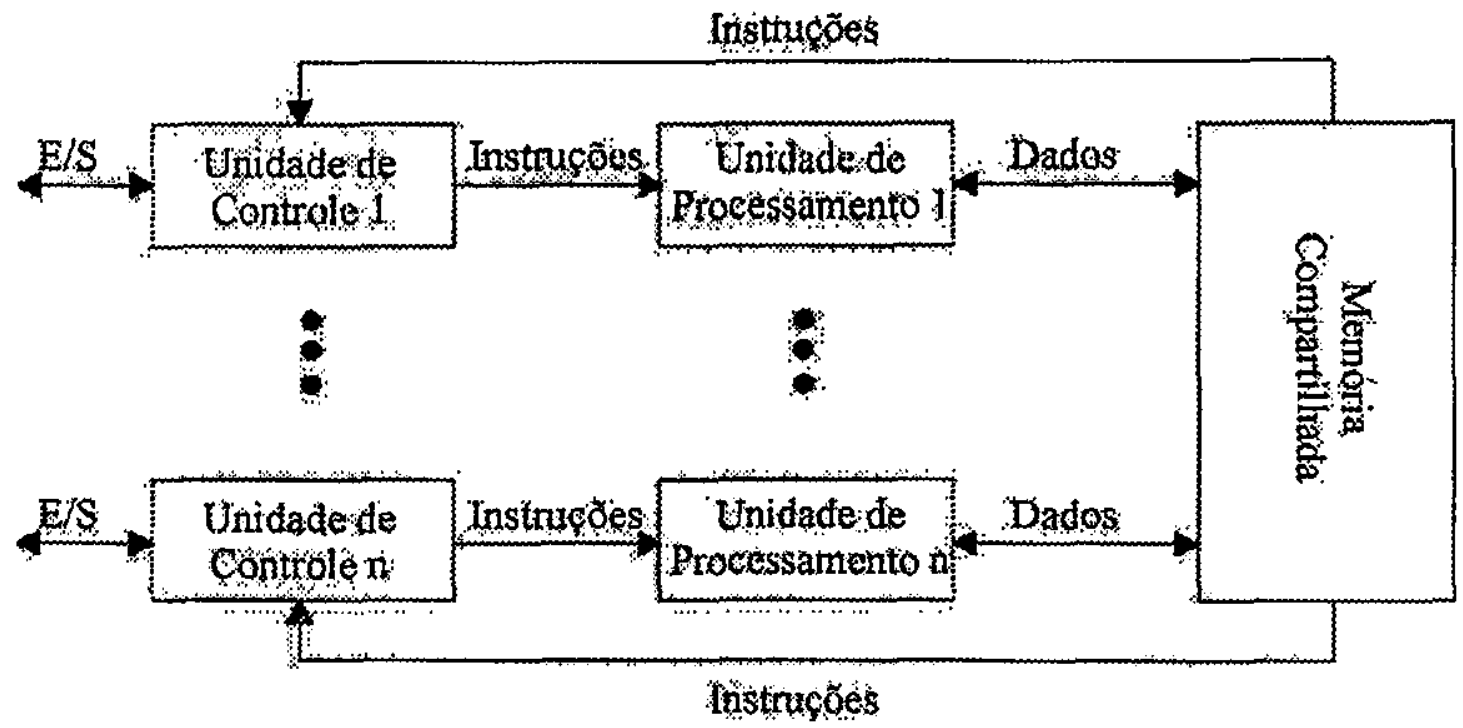

Figura 2.4 - Arquitetura MIMD

\section{MISD - Múltiplas Instruções e Dados Simples}

Apesar de nesta categoria não existirem exemplos práticos a Figura 2.5 tenta demonstrar como seria esse sistema.

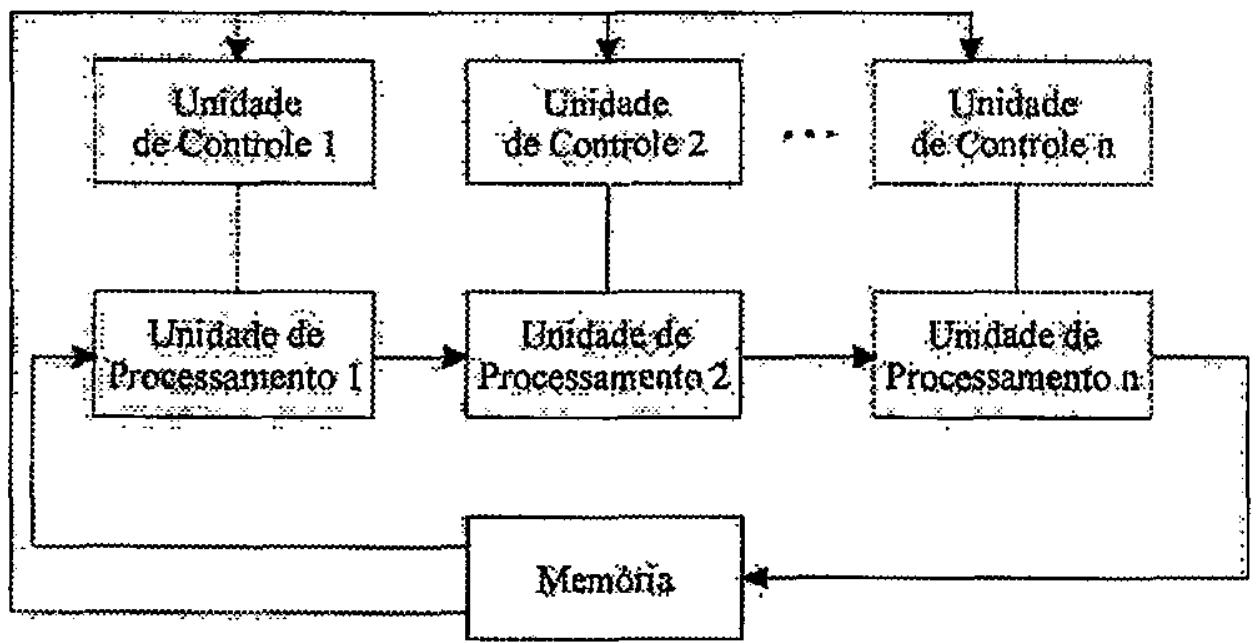

Figura 2.5 -Tentativa de caracterização da arquitetura MISD.

Analisando-se a classificação de Flynn observa-se a existência de apenas dois tipos de arquiteturas paralelas: SIMD e MIMD, o que não é suficiente para abranger a grande quantidade de arquiteturas existentes. A classificação de Duncan, apresentada resumidamente na próxima seção, expande estes tipos de arquiteturas, ela é amplamente discutida em [Dun90]. 


\subsubsection{Classificação da Duncan}

Com a crescente evolução das arquiteturas paralelas a classificação de Flynn tornou-se obsoleta e pouco genérica. A seguir na Figura 2.6 apresenta-se a classificação de Duncan que aproveitou os conceitos de Flynn e generalizou sua classificação [Dun90]. Basicamente elas são divididas em dois tipos (síncronas e assíncronas) e a partir destes as demais arquiteturas são detalhadas

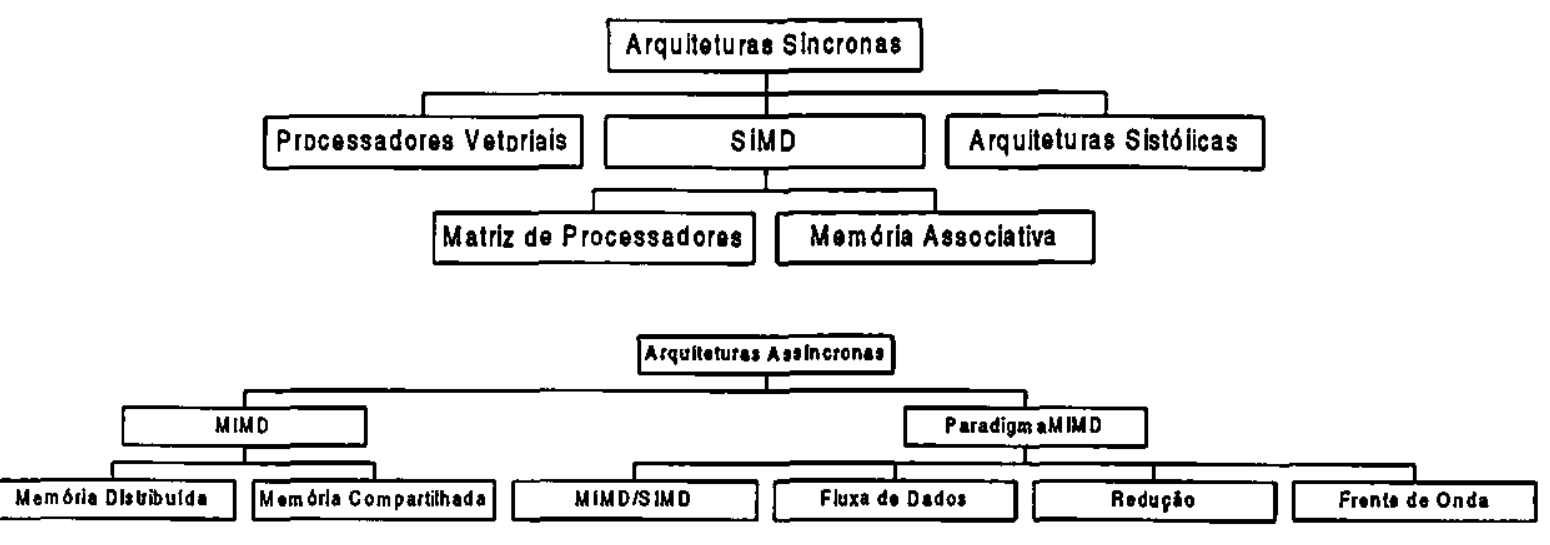

Figura 2.6 - Classificação de Duncan

As Arquiteturas Síncronas são baseadas em relógios globais, uma unidade central de controle e quando cabível, em unidades vetoriais de controle. Podem ser subdivididas em:

- Processadores vetoriais - possuem um hardware especializado em operações vetoriais e pipelines múltiplos os quais podem trabalhar com operações aritméticas e logicas em vetores e escalares.

- SIMD - utiliza uma unidade central de controle para diversos processadores, onde a mesma efetua um broadcast de uma instrução para todas as unidades de processamento. As conexőes permitem que os resultados dos cálculos sejam trocados entre processadores para que estes sirvam como operadores em novos cálculos. As máquinas SIMD podem ser divididas em duas categorias:

- Matriz de processadores - utilizada em larga escala em aplicações científicas, processamento de imagens e modelagem de energia nuclear. Os processadores são conectados em forma de matrizes. 
- Memória associativa - é uma arquitetura basicamente utilizada em bancos de dados orientados a objetos, permitindo o acesso simultâneo a memória através de padrōes.

- Sistólica - surgiu aproximadamente em 1980 para solucionar problemas de propósito específico que exigem uma grande quantidade de Entrada e Saída (E/S), usa basicamente processadores pipelined e possui um relógio global.

Seguindo a Figura 2.6 encontram-se as arquiteturas assíncronas que são caracterizadas por possuírem relógios e unidades de controles próprios para cada processador e são classificadas como a seguir:

- Arquiteturas MIMD utilizam vários processadores, ativados por unidades de controle próprias, que executam instruções independentes. Apesar dessa independência os processadores podem ser sincronizados através de passagens de mensagens. Quanto a organização da memória, as arquiteturas MIMD podem ser divididas em dois tipos:

- Memória Distribuída - são processadores com memória independente, ou seja, cada processador tem seu espaço de endereçamento e podem comunicar-se por troca de mensagens. A conexão entre processadores pode dar-se através de diferentes formas, tais como: anel, árvore, hypercubo, malha, árvores mapeadas, etc. A desvantagem desta arquitetura é que uma mensagem pode ser perdida, no entanto, para solucionar esse problema as bibliotecas de passagem de mensagem geralmente tem funções que detectam esse tipo de inconveniente.

- Memória Compartilhada - na memória compartilhada, todos os processadores compartilham o mesmo espaço de memória. Neste caso, não existem os problemas da memória distribuída (perda de mensagens, eliminando a necessidade de novas trocas), mas outros problemas podem surgir tais como: a sincronização de acesso e coerência de cache. Os processadores e a memória podem ser conectados de diferentes formas, tais como: barramento, crossbar e omega. Neste caso a conexão entre memória e processador é a região mais crítica e deve ser cuidadosamente implementada com um meio veloz de comunicação. 
Paradigma MIMD - Cada uma das arquiteturas é baseada nos princípios de operações assíncronas e manipulação concorrente de múltiplas instruçōes da arquitetura MIMD. Alguns tipos de MIMD não convencional são:

- Híbrida - MIMD/SIMD - nesta arquitetura alguns processadores MIMD são designados como mestres que controlam outros processadores escravos que se utilizam da arquitetura SIMD, isso dá a aparência de uma árvore a arquitetura.

- Fluxo de Dados - neste paradigma diz-se que as instruçōes podem ser executadas tão logo seus operadores estejam disponíveis. Isto implica numa dependência de dados que permite uma concorrência de tarefas, rotinas e instruções. [Dun90]

- Redução - neste paradigma uma instrução é executada somente quando uma segunda instrução que depende da primeira já está pronta para execução apenas dependendo dos resultados da primeira. Este paradigma é ideal para expressões grandes e complexas.

- Frente de Onda - esta arquitetura é uma mistura da arquitetura sistólica com o paradigma Fluxo de Dados.

Na próxima seção serāo apresentados alguns tópicos concernentes a programaçāo de arquiteturas paralelas de modo geral.

\subsection{Computação Vetorial}

Um computador vetorial é uma máquina que tem uma grande capacidade para trabalhar com vetores, ou seja, o processamento de elementos de um vetor é feito em grupos. A diferença entre uma entidade escalar e uma vetorial, é que a escalar é uma entidade de 16,32 , ou 64 bits que pode ser um número em ponto flutuante, um número inteiro ou um valor lógico (verdadeiro ou falso). Essa entidade escalar é processada através de registradores e pipelines escalares. Uma entidade vetorial é uma coleção de entidades escalares, por exemplo: uma coleção de entidade de 64 bits para números em ponto flutuante ou uma coleção de entidades de 128 bits para números complexos. As entidades vetoriais são processadas através de registradores e pipelines vetoriais. A Figura 2.7, mostra como trabalha uma máquina vetorial. 


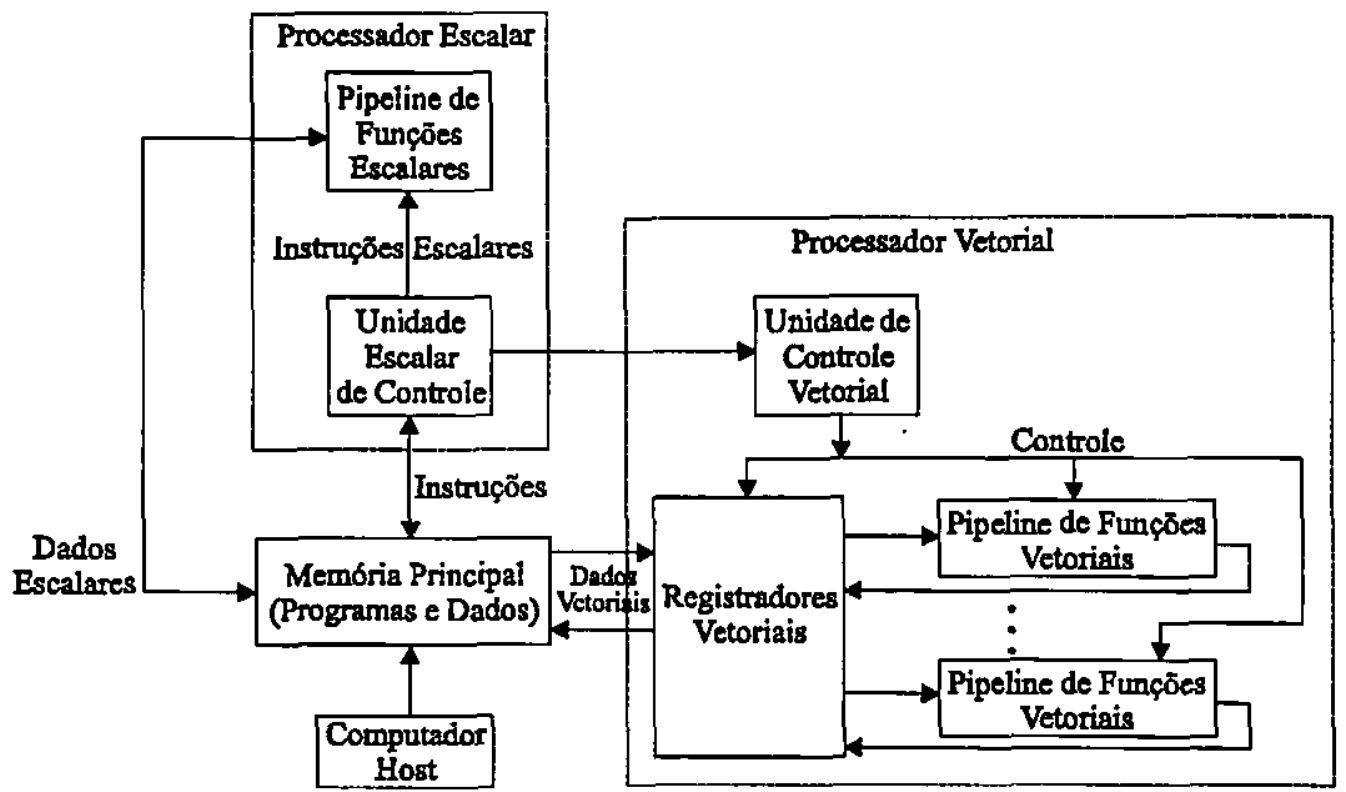

Figura 2.7 - Esquema simpllficado de um computador vetorial.

Através de um host (computador remoto) compila-se um programa, em seguida e necessário submete-lo a uma fila de execução através de um script (arquivo de comandos) quando houverem processadores disponíveis o programa é enviado para a memória principal. Se a instrução a ser executada for escalar, ela será enviada ao processador escalar, se a instrução for vetorial ela será direcionada ao processador vetorial.

O pequeno código a seguir e a Tabela 2.1 mostram a diferença entre como um processador escalar e um processador vetorial tratam os dados.

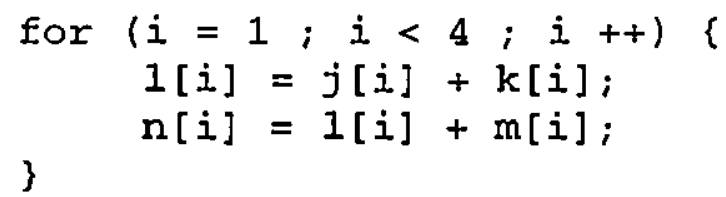

Tabela 2.1 - Ordem das operações no modo escalar e no modo vetorlal.

\begin{tabular}{|c|r|}
\hline \multicolumn{1}{|c|}{ Modo escalar } & Modo vetorial \\
\hline $1[1]=j[1]+k[1]$ & $1[j[1]+k[1]$ \\
\hline$n[1]=1[1]+m[1]$ & $1[2]=j[2]+k[2]$ \\
\hline $1[2]=j[2]+k[2]$ & $1[3]=j[3]+k[3]$ \\
\hline$n[2]=1[2]+m[2]$ & $n[1]=1[1]+m[1]$ \\
\hline $1[3]=j[3]+k[3]$ & $n[2]=1[2]+m[2]$ \\
\hline$n[3]=1[3]+m[3]$ & $n[3]=1[3]+m[3]$ \\
\hline
\end{tabular}


Note que no processador escalar os dados são tratados item por item. No caso vetorial cada vetor é tratado de uma vez só. Note também que se a máquina tiver mais de um processador e no código a variável $n$ não dependesse de $l$ todas as instruções seriam tratadas de uma só vez.

\section{Condições que impedem a vetorização}

A seguir são relacionadas as principais circunstâncias que impedem a vetorização:

- Dependência de dados - se existir uma dependência de dados, ou seja, se o valor que está sendo gerado depende do valor anterior ou posterior como em $a[i]=b[i-1]+j$ e $a[i]=b[i+1]$ $+\mathrm{j}$, respectivamente;

- Se existirem chamadas a funções do usuário dentro do laço;

- Comandos de entrada e saída;

- Dependência de dados como em $a[i]=b[i+1]+c$ ou $a[i]=b[i-1]+c$;

- Comandos de quebra de laço, tais como: break e exit;

- Teste de condições: if, switch;

- Manipulação de bits;

- Diretivas de compilação.

Em programas científicos as condições acima são pouco encontradas, com exceção das chamadas as funções de usuários e da dependência de dados. Apesar disso, outras regras devem ser observadas. Nos sistemas Cray, na existência de laços aninhados, somente o mais interno é vetorizado. Isso é válido também para os comandos while e do...while. A seguir é dada uma breve descrição do jargão utilizado na computação vetorial com alguns exemplos na Figura 2.8 .

- Laço invariável - é uma variável constante que é referenciada no corpo do laço mas não é alterada por ele.

- Laço variável induzida - é uma variável que é incrementada ou decrementada por uma expressão invariável. 
- Vetor candidato - é um elemento referenciado por um índice que pode variar no corpo do laço.

- Vetor candidato temporário - é uma variável escalar que é referenciada em cada passo do laço.

- Expressão vetorizável - é uma expressão logica ou aritmética que consiste na combinação de qualquer dos itens acima

- Laço vetorizável - é um laço que contem apenas expressões vetorizáveis.

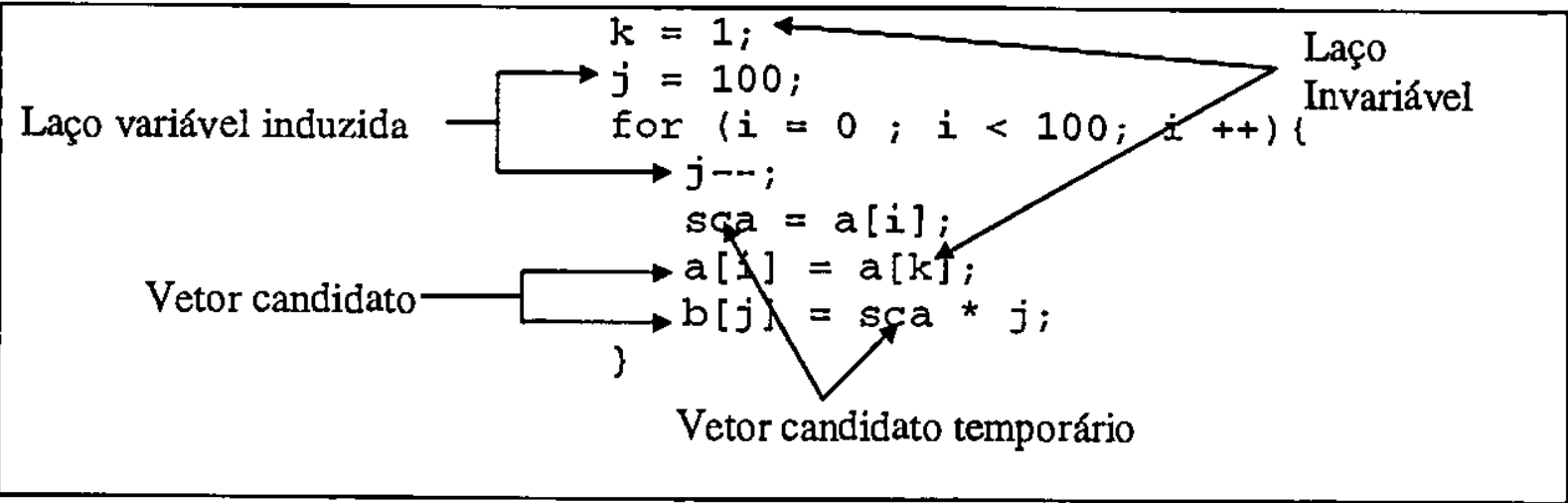

Figura 2.8 - Exemplos de termos utilizados na computação vetorial.

Dadas as definições utilizadas na vetorização, a seguir serăo mostrados os diferentes tipos de vetorização.

Vetorização total - utiliza somente expressões vetorizáveis dentro do laço. O código gerado é extremamente eficiente.

$$
\begin{aligned}
& \text { for }(i=0 ; i<101 ; i++)( \\
& \quad c[i]=a[i]+b[i] / 2.0 ; \\
& \quad m 3[i]=m 1[i]-m 2[i] ; \\
& \operatorname{trig}[i]=\cos (c[i]) ;
\end{aligned}
$$

Vetorização especial - é um laço que contém variáveis escalares e vetoriais, onde há uma transformação de elementos vetoriais para escalares.

$$
\text { for }(i=0 ; i<101 ; i++) \text { sum }+=a[i] \text {; }
$$


Pesquisa de laços - são laços que contém comandos que podem transferir o controle para fora do mesmo. Este tipo de código não é vetorizável.

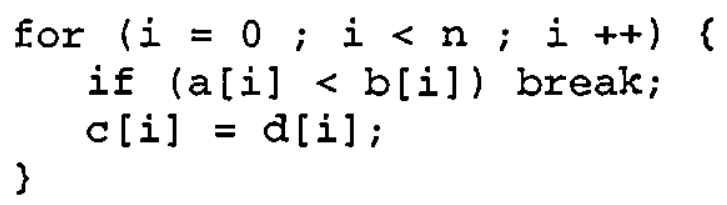

\subsection{Programação Concorrente}

Atualmente a Programação Concorrente não tem uma terminologia padronizada, desta forma considera-se que a programação concorrente é dividida em duas categorias: programação concorrente com memória compartilhada e com passagem de mensagens (comandos Send e Receive).

Quando a memória compartilhada é usada, ou melhor dizendo, quando são usadas variáveis compartilhadas, dois tipos de sincronização são necessários: exclusão mútua e condição de sincronização (também chamado de condição de concorrência). Para solucionar esses problemas existem diversas técnicas, tais como: busy-waiting, semáforos e monitores [Mis89].

Usando a passagem de mensagens, tem-se os comandos Send e Receive que enviam e recebem mensagens respectivamente. Dependendo da organização deste comandos pode-se ter comunicação ponto-a-ponto, rendevouz ou RPC [Mis89].

A programação concorrente vem sendo de fundamental importância para todos os tipos de programação, incluindo sistemas de gerenciamento de dados, computação científica, sistemas de tempo real e sistemas de controle [Geh89], sendo largamente utilizada para a computação numérica.

A vinte anos atrás os programas eram desenvolvidos para utilizar a máxima capacidade de uma determinada arquitetura. Atualmente, além desta abordagem, pode-se desenvolver programas para explorar ao máximo o paralelismo existente no problema a ser solucionado. Para programas paralelos é necessário a utilização de uma ferramenta que possibilite representar os processos paralelos, a comunicação e o sincronismo entre eles [Tan95]. Os ambientes de passagem de mensagens são largamente utilizados porque suprem com relativa facilidade essas necessidades. 
Uma grande vantagem dos ambientes de troca de mensagens é que são compostas por bibliotecas que podem ser implementadas em diversas arquiteturas, tornando os programa portáveis entre essas arquiteturas. Exemplos de ambiente de passagem de mensagem são: MPI e PVM.

Nos dias atuais tem-se tornado viável a utilização da computação paralela, principalmente devido ao surgimento de bibliotecas que permitem simular um máquina virtual paralela em ambientes distribuídos. Já não é mais necessário investir milhares de dólares em máquinas, basta ter uma pequena rede de estações de trabalho (até mesmo de PC's) para desfrutar das vantagens da programação paralela.

Na programação paralela, um dos primeiros objetivos é desenvolver programas tão independente quanto possivel das arquiteturas preocupando-se apenas com a eficácia e com a eficiência. Alguns problemas, exigem uma preocupação com a arquitetura devido a sua natureza principalmente onde questões como desempenho são críticas (sistemas de tempo real). Como em alguns algoritmos numéricos a convergência de uma solução em máquinas monoprocessadas é muito lenta, vê-se claramente a aplicação da computação paralela nesses casos.

A seguir são apresentados os ambientes de passagem de mensagem mais conhecidos atualmente e que serāo utilizados no desenvolvimento deste trabalho.

\subsubsection{PVM (Parallel Virtual Machine - Máquina Paralela Virtual)}

O PVM é uma biblioteca que oferece ferramentas de software necessárias para programar um sistema computacional paralelo de propósitos gerais [Beg94]. Inicialmente foi escrito em Fortran, mas, já possui versões em C e C++. Seu projeto teve início em 1989 no Oak Ridge National Laboratory - ORNL nos EUA, atualmente envolvendo diversos institutos de pesquisa. Sua primeira versão (PVM 1.0) foi implementada por Vaidy Sunderman e Al Geist sendo que atualmente o PVM encontra-se na versão 3.0 (1993).

\section{Utilizando o PVM}

O PVM é formado por duas partes básicas. A primeira é um daemon que deve residir em cada máquina, ou em cada processador, no caso de um máquina multiprocessada, para formar o ambiente paralelo virtual. A segunda parte é composta pela biblioteca de interface PVM, que 
contém todas as primitivas necessárias para a montagem das tarefas que compõe a aplicação. As funções ou primitivas existentes permitem realizar as seguintes operações:

- Iniciar, sincronizar e terminar processos;

- Empacotar, enviar, receber e desempacotar mensagens;

- Alterar o número de cada no, criar, manipular e apagar grupos de processos.

A menor unidade em uma aplicação PVM chama-se tarefa e os programas em PVM podem utilizar tanto a abordagem de programação SPMD ou MPMD. Segundo [Gei94], as principais características do PVM são:

- Fila configurável de máquinas - As tarefas de uma aplicação são executadas por um conjunto de máquinas que podem ser selecionadas pelo usuário.

- Acesso transparente ao hardware - Os programas PVM podem ter acesso ao hardware como se ele fosse um conjunto de processadores dentro de uma mesma máquina, ou, podem explorar ao máximo as capacidades de um determinado equipamento realmente multiprocessado.

- Tolerância a falhas - Se uma das máquinas do sistema paralelo virtual falhar, ela é imediatamente retirada da fila pelo sistema. Mas, cabe ao usuário realocar o processo em outra máquina e executar novamente a aplicação.

- Suporte a máquinas heterogêneas - O PVM permite a passagem de mensagem entre máquinas de diferentes arquiteturas com diferentes tipos de representação de dados.

Antes de rodar qualquer programa PVM é necessário assegurar-se de que a máquina paralela virtual está configurada corretamente. No caso do SP2, isso não é necessário porque a alocação de tarefas é feita automaticamente pelo sistema.

\section{Principais Primitivas}

O primeiro comando PVM que geralmente é utilizado é o pvm_mytid(), que devolve um número que identifica a tarefa em execução. Todas as tarefas são iniciadas através de uma tarefa mestre, a função que se encarrega de iniciar os processos é a pum_spawn e tem o seguinte formato: 
int pvm_spawn(char *task, char **argv, int flag, char *where, int ntask, int * tids)

Sendo que os parâmetros têm os seguintes significados:

- char *task - nome da tarefa a ser executada;

- char **argv - ponteiro para argumentos de tarefas, geralmente utilizado com o valor NULL.

- int flag - opçðes de distribuição seguindo a Tabela 2.2.

- char *where - nome da máquina onde será executada a tarefa, null no caso do SP2.

- int ntask -representa a quantidade de escravos que devem ser iniciados;

- int *tids - vetor que conterá a identificação das tarefas iniciadas.

Tabela 2.2 - Resumo dos flags utilizados no pvm_spawn.

\begin{tabular}{|l|l|l|}
\hline Valor & Opção & Significado \\
\hline 0 & PvmTaskDefault & O PVM escolhe onde iniciar os processos. \\
\hline 1 & PvmTaskHost & O usuário escolhe onde os processos serão iniciados. \\
\hline 2 & PvmTaskArch & Os processos serão iniciados através de um arquivo. \\
\hline 4 & PvmTaskDebug & Inicia os processos num depurador. \\
\hline 8 & PvmTaskTrace & Cria um arquivo de rastreamento. \\
\hline 16 & PvmMppFront & Inicia as tarefas a partir de uma máquina front-end. \\
\hline 32 & PvmHostCompl & Dados complementares sobre onde será iniciada uma tarefa. \\
\hline
\end{tabular}

Para terminar uma tarefa no PVM utiliza-se a função $p v m \_k i l l()$. Outros comandos importantes são:

- pvm_parent - retorna a identificação de quem criou a tarefa.

- $p v m$ tidtohost - retorna um vetor com a identificação de todas as tarefas que estão sendo executadas numa máquina.

- pvm_addhost - permite adicionar máquinas a Máquina Paralela Virtual.

Os comandos mais utilizados no PVM são os responsáveis por enviar e receber mensagens. Para enviar uma mensagem é necessário seguir alguns passos. O primeiro é inicializar o buffer de envio de mensagens através do comando pvm_initsend(codificação). Onde codificação, refere-se a como os dados serão codificados para o envio, sendo de três maneiras diferentes:

- PvmDataDefault - utiliza o formato padrão do PVM que é o XDR. 
- PvmDataRaw - não utiliza nenhuma forma de codificação e é utilizado onde a máquina paralela virtual é homogênea, ou seja, todas as máquinas são do mesmo tipo.

- PvmDatainPlace - simplesmente mostra onde os dados a serem empacotados estão, lá só estarão contidas as informações de tamanho e ponteiros, quando o procedimento de envio se iniciar os dados serão buscados diretamente na memória, isto é, não é utilizado um buffer para armazenar temporariamente os dados que se desejam enviar.

Depois de inicializado o buffer de envio é necessário empacotar os dados que se desejam enviar. Para cada tipo de dados existe uma função no PVM, conforme mostra a Tabela 2.3, mas todas elas apresentam os mesmos argumentos que são: pvm_pktipo(dado, qitens, stride)

- dado - endereço onde se encontra o dado a empacotar;

- qitens - quantidade de dados que se deseja enviar;

- stride - tempo de acesso a memória, geralmente é utilizado o valor 1.

Tabela 2.3 - Funções de empacotamento de dados.

\begin{tabular}{|l|l|}
\hline Funçäo & Tipo de dado empacotado em C \\
\hline pvm_pkint() & int \\
\hline pvm_pkshort() & unsigned \\
\hline pvm_pklong() & long int \\
\hline pvm_pkfloat() & float \\
\hline pvm_pkdouble() & double \\
\hline pvm_pkcplx() & complex \\
\hline pvm_pkdcplx() & double complex \\
\hline pvm_pkbyte() & byte \\
\hline
\end{tabular}

Umas das restrições do PVM é que ele não pode empacotar dados do tipo estrutura. Cada dado deve ser empacotado individualmente em buffers auxiliares e a estrutura deve ser remontada na tarefa que recebeu a mensagem. Quando todo esse processo estiver completo o PVM já está pronto para enviar os dados. Nota-se que todos os dados empacotados são transmitidos de uma só vez. O comando que envia uma mensagem a uma determinada tarefa é o pvm_send( ) e apresenta o seguinte formato:

$$
\text { int info }=\text { pvm_send }(\text { tid, } \operatorname{tag})
$$

onde info é um inteiro que identifica um erro caso ele ocorra, tid é a identificação da tarefa que irá receber os dados e tag é uma etiqueta que identifica a mensagem enviada. 
O processo de recebimento é feito de modo inverso ao processo de envio, só que não é necessário inicializar um buffer de recebimento. $O$ comando que recebe uma mensagem é:

$$
\text { int bufid }=\text { pvm_recv(tid, tag) }
$$

onde bufid é um inteiro que identifica um erro caso ele ocorra, tid é o identificador da tarefa que enviou e tag é uma etiqueta que identifica a mensagem. Depois de recebida a mensagem o primeiro passo a ser seguido é desempacotá-la. A sintaxe do comando de desempacotamento é semelhante a de empacotamento, e é definida como:

$$
\text { int info }=\text { pvm_upktipo(buffer, qitem, stride })
$$

onde info recebe o código de retorno de erro, buffer é o endereço de memória que receberá o dado desempacotado, qitem é a quantidade de itens a desempacotar e stride é o tempo de acesso a memoria.

Com a teoria apresentada nesta seção é possível desenvolver programas paralelos com um certo nível de complexidade . A próxima seção descreve outra das mais importantes bibliotecas de passagem de mensagem.

\subsubsection{MPI (Message Passing Interface - Interface de Passagem de Mensagens)}

De maneira geral um algoritmo seqüencial pode ser portado para qualquer arquitetura desde que está tenha o compilador adequado e o algoritmo não utilize funções especiais de hardware de uma determinada arquitetura. Atualmente uma das maiores exigências dos usuários é o alto grau portabilidade que um programa/algoritmo deve possuir.

$\mathrm{O}$ mesmo deve ocorrer com programas que utilizam o sistema de passagem de mensagens. $\mathrm{O}$ MPI tenta suprir essa necessidade estendendo linguagens como o FORTRAN, C e C++, para que estas tenham a capacidade de executar programas paralelos.

A idéia do MPI surgiu por volta de 1990, quando 60 pessoas de diferentes organizações (usuários, vendedores e construtores de arquiteturas e programas paralelos da Europa e do Estados Unidos) formaram o que ficou conhecido como "Forum MPI". Os debates ocorriam entre pessoas experientes, o que incluía especialistas em PVM, PARMACS e EPCC, entre outros 
[Mac94]. Os documentos gerados desses debates e discussōes deu origem a uma nova proposta a qual originou a primeira versão do MPI. Na verdade, o processo de desenvolvimento do MPI iniciou-se em abril de 1992, sendo que em novembro do mesmo ano a primeira versão foi apresentada [Wa194].

A questão da portabilidade em sistemas de passagens de mensagens é recente. No entanto, diversas plataformas de portabilidade foram propostas (PVM, PARMACS, etc). O MPI foi a primeira tentativa de se construir um sistema padrão, sendo que seus objetivos e seu escopo podem ser resumidos em: [Mac94]

- Prover alta portabilidade de código - atendendo a reivindicação dos usuários por portabilidade;

- Permitir a implementação eficiente em um grande número de arquiteturas - ou seja, permitir que um programa seja desenvolvido numa arquitetura de cluster (rede de estações de trabalho ou PC's) e depois portada para uma máquina paralela especial de alto desempenho;

- Suporte a arquiteturas paralelas heterogêneas - permitir que programas sejam executados em redes, independentemente das arquiteturas que se encontram nela;

- Facilidade de uso - permitir um aprendizado rápido da linguagem, sem envolver altos custos.

Apesar das facilidades que o MPI apresenta, alguns recursos foram deixados de lado, tais como:

- Iniciar processos dentro de outros processos;

- Iniciar processos durante a execução do programa;

- Funções de depuração;

- Entrada e Saída paralela.

Novas versões do MPI têm surgido e essas facilidades, inicialmente ausentes, vêm sendo introduzidas. 


\section{Passagem de mensagem utilizando o MPI}

Para utilizar o sistema de passagem de mensagem em MPI, a primeira rotina que deve ser chamada num programa é MPI_Init (int *argc, char **argv), que definirá quantos processos serão criados. No caso do SP2 não são necessários argumentos pois a quantidade de processos é definida no arquivo de comandos de tarefas que será detalhado no Capítulo 5. Essa rotina também define o que se chama de communicator, quando não especificado o padrão é chamado de MPI_COMM_WORLD. Os processos s6 podem se comunicar se compartilharem um mesmo communicator, ou seja, a programação obrigatoriamente tem que se basear em grupos.

Para terminar um programa MPI são definidas duas funções básicas: a MPI_Finalize( ), que geralmente é utilizada no final do programa, caso hajam processos ainda em execução esta função não surte efeito. E a MPI_Abort(communicator, errcode), que termina abruptamente um programa caso ocorra o erro definido em errcode.

Como o MPI trabalha com a abordagem SPMD de programação, todos os processadores executam o mesmo código, dessa forma, para ter as informações sobre cada processo existem as rotinas MPI_Comm_size e MPI_Comm_rank. A primeira retorna a quantidade de processos que compartilham um mesmo communicator. A segunda retorna para cada processo a sua identificação que é um número inteiro.

As principais rotinas de envio e recepção de mensagens são:

\section{MPI_Send(buf, count, datatype, dest, tag, comm)}

onde:

buf - é o endereço onde se encontra o dado a ser enviado;

count - é a quantidade de dados a serem enviados;

datatype - é o tipo de dado a ser enviado. A Tabela 2.5 mostra mais detalhes sobre como são definidos os tipos em MPI.

dest - é um número que identifica o processo destino.

tag - é como uma etiqueta que identifica a mensagem que está sendo enviada; 
comm - é o communicator que os processos compartilham;

MPI_Recv(buf, count, data type, source, tag, comm, status)

onde:

buf - é o endereço onde o dado recebido deve ser armazenado;

count - é a quantidade de dados que será armazenada;

datatype - é o tipo de dado a ser armazenado, que também segue a Tabela 2.4;

source - é o número que identifica quem está mandando a mensagem;

tag - é a etiqueta que identifica a informação que foi enviada, ela deve ser a mesma especificada no comando de envio.

comm - é o communicator que os processos compartilham;

status - armazena o código de erro se houver algum na recepção.

Tabela 2.4 - Tipos de dados no MPI.

\begin{tabular}{|c|c|}
\hline Tipo do dado & $\begin{array}{c}\text { Representaçäo } \\
\text { em C }\end{array}$ \\
\hline MPI_CHAR & char \\
\hline MPI_SHORT & short int \\
\hline MPI_INT & Int \\
\hline MPI_LONG & long int \\
\hline MPI_UNSIGNED_CHAR & unsigned char \\
\hline MPI_UNSIGNED_SHORT & unsigned short int \\
\hline MPI_UNSIGNED & unsigned \\
\hline MPI_UNSIGNED_LONG & unsigned long \\
\hline MPI_DOUBLE & double \\
\hline MPI_FLOAT & float \\
\hline MPI_LONG_DOUBLE & long double \\
\hline MPI_BYTE & 8 dígitos binários \\
\hline MPI_PACKED & $\begin{array}{l}\text { structure,vetores e } \\
\text { matrizes }\end{array}$ \\
\hline
\end{tabular}

\subsection{Considerações finais}

Com a constante queda dos preços, os computadores vem se tornado cada vez mais acessíveis, seja a empresas ou a pessoas físicas. Atualmente a construção de computadores com múltiplos 
processadores já não é um desejo impossível. Com as novas ferramentas disponíveis no mercado, montar uma pequena rede de baixo custo que consiga simular uma máquina paralela virtual torna-se acessível a um número considerável de pessoas, ou seja, a computação paralela tornouse economicamente viável.

Muitas áreas da computação vem necessitando cada vez mais de poder computacional, sendo que a matemática computacional também está incluída. A computação paralela veio exatamente tentar suprir essa necessidade. Principalmente no que diz respeito aos problemas que possuem um paralelismo natural.

Atualmente existem três tipos de ferramentas que dão suporte a programação paralela: ambientes de paralelização automática (computadores vetoriais), extensões paralelas para linguagens sequienciais (PVM e MPI) e linguagens concorrentes (Ada) [Alm94].

Neste trabalho serão utilizadas as extensões paralelas para linguagens seqüenciais MPI e PVM pois elas são caracterizadas pela simplicidade, eficiência e são independentes de máquina. As características principais dessas linguagens são resumidas na Tabela 2.5.

Tabela 2.5 - Resumo das características das extensōes paralelas de linguagens seriais.

\begin{tabular}{|c|c|c|}
\hline Característica & PVM & MPI \\
\hline Manipulaçāo de Mensagens & $\begin{array}{l}\text { - Empacota dados; } \\
\text { - } \quad \text { Não permite a passagem de } \\
\text { mensagens formadas por } \\
\text { estruturas e vetores nāo } \\
\text { contíguos. }\end{array}$ & $\begin{array}{l}\text { - } \quad \text { Não empacota dados; } \\
\text { - } \quad \text { Permite a passagem de } \\
\text { estruturas complexas. }\end{array}$ \\
\hline Portabilidad $\theta$ & $\begin{array}{l}\text { Portável sem nenhuma } \\
\text { modificaçāo de código } \\
\text { dependendo da arquitetura. }\end{array}$ & $\begin{array}{l}\text { Portável sem nenhuma } \\
\text { modificaçāo de código } \\
\text { dependendo da arquitetura. }\end{array}$ \\
\hline Máquina Virtual & $\begin{array}{l}\text { Permite uma rede } \\
\text { heterogênea; } \\
\text { Interrompe processos em } \\
\text { tempo de execução; } \\
\text { Manipulaçăo individual de } \\
\text { processos ou em grupos } \\
\text { realizada manualmente. }\end{array}$ & $\begin{array}{l}\text { Não possui o conceito de } \\
\text { máquinas virtual; } \\
\text { - Não interrompe processos } \\
\text { em tempo de execução; } \\
\text { Possui um bom nivel de } \\
\text { abstração em relação a } \\
\text { topologias trabalhando apenas } \\
\text { com grupos. }\end{array}$ \\
\hline Toleråncia a Falhas & $\begin{array}{l}\text { Esquema básico de } \\
\text { notificação de falhas; } \\
\text { - Não interrompe a aplicação. } \\
\text { E possível que outras } \\
\text { máquinas ainda recebam } \\
\text { mensagens. }\end{array}$ & $\begin{array}{l}\text { As falhas devem ser } \\
\text { controladas no código do } \\
\text { programa. }\end{array}$ \\
\hline
\end{tabular}


Baseado na Tabela 2.5 pode-se concluir que o MPI é mais adequado para sistemas homogêneos que necessitam de muita comunicação e o desempenho é fator decisivo. Já o PVM é perfeito para sistemas heterogêneos ou que possuem uma granulação grossa com muito pouca comunicação.

O próximo capítulo apresenta um resumo dos conceitos básicos e das principais características desejadas em benchmarks. 


\section{Capitulo}

\section{Benchmarks}

\subsection{Introdução}

Analisar o desempenho de máquinas paralelas é uma tarefa relativamente complexa devido ao não determinismo dessas máquinas, ou seja, elas nunca executam uma mesma tarefa da mesma forma em instantes consecutivos de tempo. Dentro desse contexto surgiram os benchmarks como uma poderosa ferramenta. Ainda não existe um benchmark que avalie completamente um sistema paralelo, seja ele multiprocessado ou um sistema distribuído. No entanto, podem dar uma boa idéia das capacidades do sistema em questão. Pela pouca sedimentação desse tipo de ferramenta, uma forma comum e errônea de medir-se desempenho é através da freqüência em que trabalha o processador, há de notar-se que Megahertz (Mhz) não é sinônimo de desempenho. Acatar essa afirmação é como medir a velocidade de um carro por sua RPM (Rotações por Minutos) [Int98]. A RPM simplesmente mede o quão rápido é uma engrenagem mecânica. Muitas pessoas comparam processadores apenas pela sua velocidade de clock. Existem outras questões que também influenciam diretamente, por exemplo, em programas numéricos de 
cálculos intensivos, o que mais influenciará é como a unidade em ponto flutuante foi implementada e quão rápidos são seus registradores. Em termos de programação, deve-se considerar a forma de como o algoritmo matemático foi implementado e as ferramentas utilizadas.

Outra forma errônea de se medir desempenho é através dos MIPS (Milhões de Instruções por Segundo) os quais estão sujeitos a eficiência do compilador, ao nível de otimização utilizado e ao tipo de programa gerado. Segundo [Wei91], compiladores para o sistema operacional VAX produzem um código trinta porcento mais rápido que os compiladores para Unix da Berkeley. Com relação a quantiḑade de instruções executadas, um programa que tenha somente operações NOOP (que não fazem absolutamente nada) atinge o pico máximo de instruções por segundo, 0 que leva a conclusão que está-se sujeito a quantos ciclos de clock são necessários para executar uma instrução.

A questão de qual tipo de processador está sendo utilizado também influencia diretamente na análise. No caso de processadores RISC (Reduce Instruction Set Code) são executadas apenas instruções simples que não exigem muito trabalho do processador o que permite um alto grau de pipeline. Se comparado a um processador CISC (Complex Instructions Set Code) de mesma velocidade com certeza o RISC terá vantagem, mas não significa que será o mais rápido, isso irá depender diretamente do tipo de programa em questão.

Uma das abordagens corretas que começam a ser utilizadas para avaliação de desempenho é através de benchmarks os quais podem ser divididos por camadas [Emi96]. Nessa abordagem o benchmark é executado em diversos níveis de complexidade. No primeiro nível, chamado de baixo nível, são medidas as propriedades da máquina, tais como bandwidth e tempo para começar a executar. As informações obtidas nesse nível podem ser passadas para um nível mais alto conhecido como nível de kernel (núcleo). Neste nível são executadas pequenas porções de código que geralmente são utilizadas em simulações científicas, tais como resoluções de: integrais, equações diferenciais, multiplicação de matrizes, sistemas lineares, etc. $O$ último nível é chamado de nível de aplicação ou aplicações compactas onde são realizadas complexas simulações que se utilizam do código em nível de núcleo, dentre essas simulações estão: a: cromo-dinâmica, a termodinâmica, a meteorologia, a mecânica de fluídos, etc. 
A análise de desempenho também depende muito das considerações que são feitas sobre 0 sistema analisado tais como: número de processadores, velocidade dos processadores utilizados, nível de otimização do compilador e biblioteca de comunicação.

Um dos grandes problemas nesta área é a falta de ferramentas de suporte a benchmarks as quais são necessárias para avaliar com precisão o potencial de paralelismo. Dentre essas ferramentas pode-se citar os monitores de desempenho de hardware que são encontrados com mais facilidade para computadores vetoriais, e quando encontrados para máquinas com memória distribuída geralmente tem que ser executados com privilégios de administrador inviabilizando sua utilização por usuários comuns.

Na próxima seção são apresentados alguns conceitos básicos sobre benchmarks e como estes podem ser utilizados para medir o desempenho de uma máquina paralela.

\subsection{Conceitos básicos}

Benchmarks envolvem a execução de programas em ambientes reais [Don87], sendo uma das abordagens mais utilizadas para a avaliação de desempenho de sistemas. A execução de programas reais pode avaliar todos os aspectos necessários tais como a arquitetura do sistema, a eficiência do compilador, sobrecarga do sistema operacional, sobrecarga de comunicação, etc. A verificação do desempenho de um único componente do sistema não permite uma avaliação precisa de desempenho global, uma vez que não se conhece o impacto que a interação entre esses componentes irá causar no sistema.

Segundo a Intel Corporation [Int98], um benchmark é um programa o qual mede o desempenho de um computador, de uma parte do mesmo ou de um outro programa os quais executam sempre a mesma tarefa de tempos em tempos. Assim, benchmarks são usados para medir o desempenho de um sistema ou sub-sistema em uma tarefa bem definida ou conjunto de tarefas. [Wai95]

Cada benchmark testa um tipo diferente de trabalho. Alguns testam quão rápido um computador pode gerar um documento. Outros, o quão rápido um programa pode desenhar uma figura na tela. Alguns benchmarks podem testar tudo isso ao mesmo tempo. Na realidade um benchmark reflete a forma de como se está utilizando um programa, algoritmo ou computador.

A seguir apresenta-se como os benchmarks podem ser divididos e classificados. 


\subsubsection{Classificação dos benchmarks}

Existem dois níveis de benchmarks, de componentes e sistemas. Os de componentes testam partes individuais de um computador, tais como, processador, memória, placas de vídeo, entre outros. Dessa forma pode-se avaliar o impacto de um componente no desempenho geral de um sistema. Dois representantes desse tipo de benchmarks são o SPECint95 e o CPUmark36. O primeiro é um dos benchmarks mais conhecidos para ambiente Unix. Seus testes refletem o desempenho de um processador e da arquitetura de memória de um sistema em computação intensiva em aplicaçōes de 32 bits. O CPUmark36 é um benchmark para ambiente Windows 95/NT e foi desenvolvido para testar aplicações de 32 bits [Int98].

Os benchmarks de sistemas testam todos os componentes juntos. Eles são utilizados para responder questões tais como: $O$ sistema $X$ é mais rápido que o sistema $Y$ ? Quanto vou ganhar em desempenho se uma aplicação for executada num sistema com processador com $Z$ Mhz? Dessa forma, se dois sistemas que tenham somente um componente diferente um do outro, podese usar um benchmark de sistema para avaliar o impacto no desempenho do sistema devido a esse componente. Um exemplo de benchmark de sistema é o SYSmark 4.0 [Int98] para Windows NT que pode ser executado em qualquer plataforma que aceite o sistema NT.

Além da classificação por níveis, os benchmarks podem ser subdivididos quanto a sua origem em: de aplicações e sintéticos. Os de aplicações medem o desempenho de programas reais, ou seja, o benchmark tenta modelar o comportamento do usuário em um determinado programa utilizando "scripts", isto é, todas as ações (mudança de janelas, abertura de arquivos, etc) do usuários são gravadas em um arquivo e depois o benchmarks as repete como se fosse o proprio usuário. A desvantagem de se utilizar um benchmark de aplicações é que ele pode levar muito tempo para ser concluído e é muito suscetível ao modo de como o usuário utiliza os recursos do programa em análise. Além disso, esse tipo de benchmark é mais apropriado para aplicaçōes comerciais e não científicas. O SYSmark 4.0 e o SPECint95 são representantes dos benchmarks de aplicaçōes.

Os benchmarks sintéticos são programas criados especialmente para analisar o desempenho das aplicações através de estatísticas, ou seja, ele mostra a porcentagem de memória utilizada, a quantidade de disco utilizada em swap e mudanças de contexto, velocidade de comunicação entre processadores e a porcentagem de uso do processador entre outras. De maneira geral essas 
estatísticas são mostradas em forma de gráfico. O CPUmark36 encaixa-se dentro dos benchmarks sintéticos, dentro desse tipo também encaixa-se o NORTON SI32 [Int98] para Windows 95 que compara sub-sistemas (CPU, memória e cache) executando aplicações de 32 bits.

Os benchmarks ainda podem ser divididos nas seguintes categorias: [Wai95].

Benchmarks proprietários - é um tipo mais antigo, onde os desenvolvedores de programas e máquinas criavam seus próprios benchmarks e os utilizavam em produtos concorrentes. Claro que este beneficiava somente a empresa que o projetou. Atualmente esse tipo de benchmark não é mais considerado.

Benchmarks de subsistemas padronizados - este tipo mede alguns aspectos particulares de um subsistema. Ele provê informaçōes sobre o desempenho alcançado em diferentes áreas do produto testado. Essas informações irão determinar a aplicabilidade e a importância do subsistema em seu ambiente.

Benchmarks de aplicações padronizadas - este benchmark constitui um tipo que simula aplicações ou executa uma série de testes em programas que são muito difundidos na comercio e na indústria. Novamente as informações provenientes desses testes ou simulaçōes vão determinar a aplicabilidade do programa em seu ambiente.

Benchmarks de aplicações personalizadas - neste tipo as aplicações funcionam como seu próprio benchmark, ou seja, desenvolve-se a aplicação e o benchmark dentro da mesma para testar seu desempenho. Isso aumenta o custo de desenvolvimento, mas, por outro lado pode ajudar a criar um produto com maior qualidade e depois submete-lo a benchmarks padronizados para validar os testes já realizados.

Os tipos de código utilizados também podem caracterizar uma divisão dos benchmarks, podendo ser classificados em: sintéticos, núcleo, algoritmos e aplicações. Os Sintéticos são códigos pequenos e representam situações reais. Os de núcleo são segmentos utilizados em programas que representam situações reais tais como simulações. Algoritmos representam modos de programação bem definida como a computação numérica. E os de aplicações são programas que resolvem problemas científicos bem definidos. [Ber91] 
Finalmente, pode-se dividir os benchmarks atuais em: benchmarks para arquiteturas seqüenciais e benchmarks para arquiteturas paralelas. Os benchmarks para arquiteturas seqüenciais visam analisar o desempenho de uma máquina com um único processador. Esses benchmarks já foram largamente pesquisados e existem alguns representantes que são amplamente utilizados, dentre eles cabe citar: Linpack (que atualmente também tem versões para máquinas vetoriais), drystone, whetstone, Sysmark, etc. Os benchmarks para arquiteturas paralelas são relativamente recentes representando o foco de recentes pesquisas. Alguns exemplos de benchmarks são apresentados na seção 3.6.

\subsubsection{Execução de um benchmark}

Para executar um benchmark algumas questões devem estar bem definidas, tais como:

- Em termos de máquina deve-se saber onde o benchmark irá ser executado. Isso inclui, saber qual o processador da máquina, velocidade, cache, memória, disco rígido, periféricos e número de CPUs. É ainda necessário conhecer seu estado, isto é, mono-usuário ou multiusuário.

- Em termos de software deve-se saber qual sistema operacional será utilizado, qual a versão do benchmark que está sendo executado, quais os compiladores e/ou interpretadores usados na compilação do benchmark ou do programa que será avaliado.

A utilização de benchmarks para computação paralela é um tópico relativamente recente e não tão sedimentado quanto os benchmarks seqüenciais. Os benchmarks paralelos devem considerar, adicionalmente aos benchmarks seqüenciais, problemas de comunicação, sincronismo, ativação de processos, etc. Desta forma, surgiu a necessidade de uma padronização tanto na criação, como na execução e na representação dos dados obtidos. A próxima seção descreve toda a metodologia que deve ser utilizada.

\subsection{Padronização dos benchmarks paralelos}

Para estudar a padronização de benchmarks paralelos foi criada uma comissão chamada Parkbench (PARallel Kernels and Benchmarks) Commitee que tem os seguintes objetivos [Hoc96]: 
- Estabelecer um conjunto de benchmarks que são aceitos tanto pelos usuários como pelos fabricantes.

- Direcionar as atividades dos benchmarks paralelos para impedir a duplicação de esforços e impedir a proliferação desnecessária de benchmarks.

- Padronizar a metodologia utilizada em benchmarks paralelos e seus resultados através de um banco de dados de benchmarks e seus resultados.

- Tornar os resultados e os benchmarks de domínio público.

O relatório do Parkbench Comitee é composto de cinco capítulos. O primeiro diz respeito a metodologia e padronização do jargão utilizado. O segundo aos benchmarks de baixo nível que são responsáveis por medir o desempenho de componentes de hardware, como comunicação, latência, velocidade de processadores, etc. O terceiro capítulo diz respeito aos benchmarks de núcleo ("kernel benchmarks") que descrevem um conjunto de subrotinas cientificas, isso inclui, manipulação de matrizes, transformada de Fourrier e solução de sistemas de equações diferenciais parciais. O quarto capítulo comprem-se dos codigos compactos dos benchmarks apresentados e algumas questões das áreas abrangidas pelo benchmark tais como, modelagem climática, sismologia, química computacional e física qüântica. E no último capítulo algumas questões relevante a linguagem HPF (High Performance Fortran), como por exemplo, usá-la como interface em diversos computadores paralelos e alguns blocos de código para testar compiladores de HPF.

Na próxima seção são apresentadas algumas das conclusões do Parkbench Comitee, que consideram a metodologia e padronização dos benchmarks paralelos.

\subsubsection{Metodologia}

Nesta seção é apresentado o padrão do Parkbench Comitee para apresentação de relatórios, tais como, a simbologia e as métricas que expressam os resultados de um determinado benchmark dando ênfase a computação científica. 


\subsubsection{Simbologia}

Como já foi mencionado, o Parkbench Comitee é um associação criada para padronizar a aplicação de benchmarks e estabeleceu uma nomenclatura padrão para sua utilização. Ela será utilizada através de todo o trabalho e está descrita na Tabela 3.1.

Tabela 3.'1 - Nomenclatura estlpulada pelo Parkbench Comitee

\begin{tabular}{|l|l|}
\hline Termo & Significado \\
\hline flop & operação em ponto flutuante. \\
\hline inst & uma instrução qualquer. \\
\hline intop & Operaçōes inteiras. \\
\hline vecop & Operaçōes vetoriais. \\
\hline send & operação send (enviar dado para outro processador/processo). \\
\hline iter & iteração de um "loop" (laço). \\
\hline mref & Referência a memória (leilura/escrita). \\
\hline barr & operação de barreira (sincronização entre processos). \\
\hline b & digito binário. \\
\hline b & Byte (8 bits). \\
\hline sol & solução ou uma única execução de um benchmark. \\
\hline w & palavra binária (2 Bytes). \\
\hline tstep & tempo para solucionar um problema. \\
\hline
\end{tabular}

\subsubsection{Medidas de tempo}

A primeira avaliação que um benchmark deve fazer é a avaliação de tempo. O Parkbench Comitee estipulou dois benchmarks de baixo nível para isso. São eles:

TICK1 - é definido como o intervalo entre sucessivos ticks de relógio. Esse benchmark chama uma subrotina de tempo dentro de um laço que é executado muitas vezes. O relógio do UNIX, por exemplo, tem um tick típico de $10 \mu \mathrm{s}$, e um computador Cray tem um tick médio de $2 \eta$ s. [Hoc96] Isso significa que o Cray possuiu um relógio bem mais preciso.

TICK2 - verifica se o valor retornado pelo TICK1 é correto.

O tempo num benchmark pode ser entendido como uma função $T(N, p)$, onde, $\mathrm{N}$ é um vetor de tamanho variável que descreve o tamanho do problema e $p$ é o número de processadores usados na resolução do problema.

Essa métrica é utilizada para medir o desempenho de algoritmos que realizam a mesma função. Por exemplo, comparar o algoritmo do trapézio composto e o algoritmo de Simpson para solução 
de integrais numéricas. De posse dessa medida é possível encontrar o desempenho temporal que é representado por $\mathrm{R}_{\mathrm{T}}$, definido como o inverso do tempo de execução, como mostra a equação abaixo:

$$
R_{T}(N, p)=T^{1}(N, p)
$$

A unidade desta medida é soluções por segundo (sol/s), ou melhor dizendo, timesteps/s (tstep/s). Nota-se que com esta equação é possível encontrar o melhor algoritmo para solucionar um determinado problema.

\subsubsection{Contagem de operações com ponto flutuante}

Um primeiro passo na avaliação de um programa científico é determinar o número de operações em ponto flutuante que são realizadas. Isso pode ser contado através da análise do algoritmo ou do seu código fonte. Em MacMahon sugere a Tabela 3.2 para contagem de operaçōes em ponto flutuante:[Mah88]

Tabela 2.2 - Contagem de operaçōes em ponto flutuante.

\begin{tabular}{|l|l|}
\hline Operações & Quantidade de flop \\
\hline Adição, subtração, multiplicação & 1 flop \\
\hline Divisão e raiz quadrada flop \\
\hline $\begin{array}{l}\text { Exponencial, serıo, coseno e outras operações } \\
\text { trigonométricas }\end{array}$ & 8 flop \\
\hline Operação if & 1 flop \\
\hline
\end{tabular}

A avaliação inicial, através do código ou algoritmo, é chamada de nominal e representada por $F_{B}(N)$. Por exemplo, seguindo a Tabela 3.2, a execução das instruçōes:

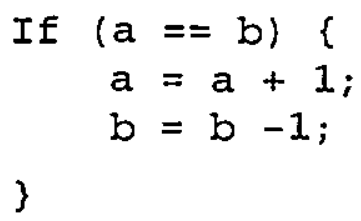

tem um $F_{B}(N)=3$. Outra notação também pode ser encontrada em arquiteturas paralelas a $F_{h}(N, p)$, onde $p$ é o numero de processadores e $N$ é o tamanho do problema. Essa notação representa a quantidade real de operaçōes em ponto flutuante executadas por uma máquina paralela. Este deve ser bem maior que a quantidade nominal devido ao credito dado as operaçōes redundantes. Este valor só é encontrado através da utilização de monitores de performance. 
Para analisar o desempenho de um benchmark num determinado computador e depois comparálo com outros, é necessário solucionar algum tipo de problema matemático e medir os flop encontrados [Hoc96]. Usando a contagem de operações em ponto flutuante obtém-se a seguinte equação:

$$
R_{B}(N, p)=F_{B}(N) / T(N, p)
$$

onde, a quantidade de operações em ponto flutuante é divida pelo tempo de execução em $p$ processadores. A unidade encontrada será de Mflop/s (megaflops por segundo) e também pode ser representada como $\mathrm{Mflop}^{-1}$. Deve notar-se, que $\mathrm{F}_{B}(\mathrm{~N})$ é seqüencial, mas é utilizado porque a faixa de execução de operações em ponto flutuante é mantida. $O$ objetivo desta métrica é comparar diferentes implementações e algoritmos em diferentes máquinas e arquiteturas para solucionar o mesmo problema, sendo que o que será levado em consideração é o tempo de execução.

A utilização de $\mathrm{F}_{\mathrm{B}}(\mathrm{N})$ (que é seqüencial), pode ser utilizado devido as arquiteturas com memória distribuída executarem uma quantidade diferente de operações em ponto flutuante em cada processador, mantendo a faixa dos resultados. O objetivo deste benchmark é comparar diferentes implementações e algoritmos em diferentes máquinas e arquiteturas para solucionar o mesmo problema.

\subsubsection{Benchmarks para aplicações cientificas}

Alguns benchmarks tais como o Linpak e o Whetstone que se utilizam de grande quantidade de operações em ponto flutuante são mais apropriados para máquinas seqüenciais [Gus86]. Com o aumento crescente de máquinas paralelas esses benchmarks já não conseguem representar muito bem o desempenho alcançado pelas aplicações científicas nesse tipo de máquina. Um dos principais requisitos que um benchmark deve considerar é que ele possa rodar em uma grande variedade de arquiteturas. O NAS Parallel Benchmark tenta suprir essa necessidade pois pode rodar tanto em máquinas vetoriais vetorial, como em paralelo e pipeline.

Todo benchmark cientifico deve ser acompanhado das seguintes informaçôes:

- Formato numérico utilizado;

- Sistema Operacional e sua versão; 
- Linguagem utilizada;

- Tamanho da memória, cache, discos e outras informações de armazenamento;

- Número de processadores, velocidade de comunicação e velocidade dos processadores;

- Forma de medir o desempenho.

Estes requisitos são a base para a reprodução do experimento. Quando um benchmark é executado deve-se assumir que nenhum outro usuário está usando a máquina para outros benchmarks ou mesmo para outras aplicaçōes[Gus86].

Quando um benchmark científico é implementado algumas regras devem ser seguidas. Algumas delas são especificadas pela IEEE, a qual, propõem que:

- Todos os números em ponto flutuante devem ser de 64 bits;

- Os números complexos devem ser formado por 128 bits, isto $e$, dois números em ponto flutuante;

- Para medir o tempo de execução, o tempo de inicialização de variáveis, vetores e matrizes deve ser desconsiderado sendo desaconselhado a tomada de tempos intermediários, ou seja, o primeiro instante de tempo medido deve iniciar-se junto com os cálculos e o último instante de tempo deve ser tomado quando os cálculos terminarem;

- Finalmente devem ser computados os Mflop (lê-se "megaflops"), onde a quantidade total de operações com ponto flutuante deve ser dividida pelo tempo de execução dos cálculos.

Na próxima seção serão apresentadas as principais restrições e erros cometidos na utilização de uma das métricas mais conhecidas para a análise de desempenho o speedup.

\subsection{Speedup e suas restrições}

Dentro da computação paralela o speedup é uma medida muito popular e utilizada para avaliar o desempenho de programas paralelos. Sendo que uma das coisas esquecidas por esses avaliadores é a velocidade dos processadores. Isso quer dizer que analisar o speedup sem analisar a velocidade dos processadores leva a conclusōes irreais [Hoc96]. Por isso o Parkbench Comitee 
tem lutado contra a publicaçẫo de speedup em relatórios de publicação de resultados de benchmarks.

Como explicado no Capitulo 2, speedup relaciona o $T_{1}$ que é o tempo de execução em um processador e $T_{P}$ que é o tempo de execução em vários processadores, assim, entram as seguintes questões: [Hoc96]

- Se o algoritmo continua o mesmo, qual é a probabilidade de haver sobrecarga desnecessária na computação paralela?

- Deve ser usado o melhor algoritmo serial para solucionar o problema?

- Se é usado outro algoritmo serial, qual a possibilidade de comparação entre esses algoritmos ?

Uma análise errônea sobre os resultados obtidos no speedup seria: Supondo que existem dois algoritmos que solucionam o mesmo problema denominados por $A$ e $B$ respectivamente. A Tabela 3.3 mostra um exemplo de tempos de execução dos algoritmos seriais e paralelo e o speedup alcançado.

Tabela 3.3 - Exemplo de tempo e speedup.

\begin{tabular}{|l|c|c|c|}
\hline Algoritmo & Tempo Serial (s) & Tempo em Paralelo(s) & speedup \\
\hline A & 10 & 5 & 2 \\
\hline B & 7 & 4 & 1.75 \\
\hline
\end{tabular}

$O$ algoritmo A teve um tempo de execução serial de 10 segundos e de 5 segundo em paralelo obtendo um speedup de 2. O algoritmo B teve um tempo de execução serial de 7 segundos e de 4 segundos em paralelo obtendo um speedup de 1.75. Se for levado em consideração somente 0 speedup o algoritmo escolhido como o melhor seria o $\mathrm{A}$, que é uma conclusão totalmente equivocada. A melhor escolha seria o algoritmo B, não pelo speedup alcançado, e sim porque ele soluciona o mesmo problema mais rápido.

Devido a esses problemas o Parkbench Comitee tomou as seguintes decisões:

- Nenhuma estatística ou resultados envolvendo speedup poderá ser mantida nos bancos de dados de Parkbench Comitee; 
- Estatísticas baseadas em speedup nunca podem ser consideradas como figura de mérito quando sistemas diferentes estão sendo comparados.

- Speedup pode ser usado em estudos de desempenho quando estão sendo avaliadas as características de um único sistema. Sendo que a base de $\mathrm{T}_{1}$ deve ser bem especificada.

- O valor de $T_{1}$ (tempo inicial) deve ser baseado numa implementação monoprocessada eficiente. Nenhum código de sincronização ou de passagem de mensagem pode estar presente.

- Como muitos problemas não se encaixam facilmente em algoritmos monoprocessados, ou seja possuem um paralelismo natural, é permitido que algumas estatísticas utilizando speedup possam ser utilizadas, desde que para um número pequeno de nós e que o número de processos não seja superior ao número de processadores.

A seguir são apresentados alguns exemplos de benchmarks que serão utilizados neste trabalho.

\subsection{Exemplos de benchmarks paralelos}

\subsubsection{Genesis}

Este benchmark foi criado para avaliar o desempenho de sistemas com memória distribuída. Seu foco principal é a avaliação de programas científicos e das engenharias [Gle94]. Foi desenvolvido em HPF e em Fortran 77. Em Fortran 77 trabalha com PARMACS e com PVM, sendo que uma versão que trabalha com MPI está em desenvolvimento. Ele é dividido em três categorias: benchmarks de baixo nível, kernel benchmarks (benchmarks de núcleo) e aplicações.

No benchmark de baixo nível são medidos os parâmetros básicos de um máquina, tais como tempo de comunicação, custo de sincronização e capacidade de vetorização. Este nfvel apresenta as seguintes funçōes [Gle94]:

- TICK1 - mede a resolução do relógio do sistema

- TICK2 - confirma a precisão encontrada pelo TICK1.

- RINF1 - mede a capacidade de vetorização. 
- COMMS1 - benchmark de ping-pong, ou seja, troca de mensagens entre dois processadores.

- COMMS2 - benchmark onde dois processadores trocam mensagens de forma bidirecional.

- COMMS3 - benchmark que mede bandwidth.

- SYNCH1 - mede o custo de sincronização (barreiras).

- POLY1 - mede a saturação de entrada da memória cache

- POLY2 - mede a saturação de saída da memória cache, tanto POLY2 como POLY1 são versões monoprocessadas.

- POLY 3 - tem a mesma função de POLY1, com a diferença que os dados necessários estão armazenados em outros processadores.

O benchmark de núcleo, é o que apresenta o código mais complexos [Gle94] e representa um núcleo com computação intensiva de diferentes aplicações. Suas principais funções são:

- TRANS1 - calcula a transposta de uma matriz.

- IO1 - mede a taxa de transferência paralela onde cada processador escreve $12.5 \mathrm{Mb}$ de dados e depois efetua sua leitura.

- FFT1 - FFT (Fast Fourrier Transformation - Transformação Rápida de Fourrier) de uma dimensão.

- SOLVER - solução de um sistema linear pelo método do gradiente conjugado.

- PDE1 - resolve uma equação tridimensional de Poisson .

- PDE2 - resolve uma equação bidimensional de Poisson .

Nos benchmarks de aplicações são realizadas algumas simulações, a saber [Gle94]:

- QCD1 - simulação de chromo dinâmica utilizando o método de Monte Carlo.

- GR1 - simulação de relatividade.

- LPM1 - simulação de dispositivos eletrônicos.

- MD1 - simulação de dinâmica molecular. 


\subsubsection{NAS Parallel Benchmarks}

O NAS (Numerical Aeronautical Simulation) foi criado pelo NASA Ames Laboratory que fica localizado na California. O NAS surgiu devido a necessidade de avaliar sistemas paralelos de alto desempenho que não fossem vetoriais [Bai94a], além da necessidade de verificar a portabilidade das máquinas, característica de fundamental importância. Este benchmark é construído com oito algoritmos (denominados por duas letras), onde cinco são do tipo kernel e três simulações:

- EP (Embarrassingly Parallel) - utilizando o algoritmo de Monte-Carlo, consegue medir o desempenho de uma máquina em ponto flutuante. Este núcleo não utiliza comunicação entre processos.

- MG (Multigrid) - algoritmo que soluciona equaçōes de Poisson. Mede o desempenho de comunicação utilizando mensagens longas e curtas.

- CG (Conjugate Gradient) - calcula o gradiente conjugado. Faz cálculos em matrizes esparsas, simétricas e positivas. Utilizado para medir o desempenho de comunicação de longa distância.

- FT - soluciona equações diferenciais parciais. Faz um teste rigoroso com a comunicação de dados.

- IS (Integer Sorting) - é o único que não utiliza operaçōes em ponto-flutuante. Testa a capacidade do sistema em trabalhar com números inteiros e ao mesmo tempo testa a comunicação utilizando os mesmos.

As simulações utilizam três métodos para solucionar equações. O primeiro é o LU (lower-upper) que fatora uma matriz regular-esparsa até sua solução utilizando blocos de $5 \times 5$. Este algoritmo apresenta um nível baixo de paralelismo se comparado aos outros dois [Bai94b].

O segundo SP (scalar pentadiagonal), faz a multiplicação de sistemas independentes nãodiagonais dominantes e resolve equações escalares pentadiagonais. $\mathrm{O}$ terceiro método utilizado é o BT (block tridiagonal) que é muito semelhante ao SP sendo que a diferença está na quantidade de transmissão [Bai94b]. 


\subsubsection{ParkBench (Parallel Kernel Benchmark)}

Este benchmark consiste de 4 pacotes distintos, onde todos eles requerem que o PVM ou o MPI estejam adequadamente instalados e configurados. A Tabela 3.4 mostra um resumo dos pacotes que o compõem, alguns deles foram extraídos de outros benchmarks tais como o NAS e o Genesis.

Tabela 3.4 - Benchmarks que formam o ParkBench.

\begin{tabular}{|l|l|l|l|}
\hline Baixo-Nivel & Kernel & \multicolumn{2}{l|}{ NPB2.1 } \\
\hline Comms1 & FT & BT & BT \\
\hline Comms2 & LU_solver & FT & LU \\
\hline Comms3 & MATMUL & LU & SP \\
\hline Poly1 & TRANS & MG & PSTSWM \\
\hline Poly2 & QR & SP & \\
\hline Poly3 & TRD & & \\
\hline Rinf1 & & & \\
\hline Synch1 & & & \\
\hline Tick1 & & & \\
\hline Tick2 & & & \\
\hline
\end{tabular}

A primeira coluna mostra os benchmarks de baixo nível, sendo que todos eles foram extraídos do Genesis. A segunda coluna exibe os benchmarks de kernel (núcleo). Eles foram retirados do Genesis e do NAS versão 2.1 com exceção do MATMUL e do TRD. Na terceira coluna é mostrado quais algoritmos foram tirados no NAS versão 2.1 para formar o pacote. E finalmente a quarta coluna mostra quais são os benchmarks de aplicação, que com exceção do PSTSWM também foram retirados do NAS.

Todos os pacotes estão disponíveis tanto para PVM como para MPI.

\subsection{Outros exemplos de benchmarks [Way95]}

\section{Linpack}

Este é um benchmark para aplicações que se utilizam de rotinas de álgebra linear, mais precisamente com rotinas de manipulação de matrizes. É encontrado tanto em Fortran como em C. Todo o tempo do benchmark é gasto em duas rotinas básicas, a saxpy para precisão simples, e a daxpy para precisão dupla, as quais dão a solução de um sistema linear pelo método da triangularização de Gauss com pivoteamento. Ambas trabalham com operações matriciais do 
tipo $y(i)=y(i)+a^{*} x(i)$. A versão padrão trabalha com matrizes de $100 \times 100$, mas existem versões que trabalham com matrizes de $300 \times 300$ e de $1.000 \times 1.000$. Sua principal desvantagem é que ele trabalha apenas com aplicações matriciais. Até algum tempo atrás esse benchmark era específico para máquinas seriais, atualmente sua aplicação se dá também em máquinas vetoriais.

\section{Whetstone}

É um dos primeiros benchmarks sintéticos criados, foi desenvolvido para analisar o desempenho de programas numéricos que se utilizam intensamente de ponto flutuante. Foi desenvolvido pela National Physical Lab baseado totalmente em estatística e foi escrito inicialmente em Algol 60, atualmente possui versões em Fortran77/90 e em linguagem C.

\section{Nhfsstone}

Este benchmark é utilizado para medir o desempenho de servidores de arquivos que utilizam o protocolo NFS. Este benchmark é complementado com o SPEC e com o LADDIS.

\section{Drhystone}

É um benchmark sintético que avalia o desempenho de sistemas de programação inteira. Também baseia-se em estatísticas. Foi originalmente desenvolvido em Ada e atualmente é mais encontrado em linguagem $C$.

\subsection{Considerações finais}

Os benchmarks paralelos são relativamente recentes no mercado, sejam eles acadêmicos ou comerciais. As pesquisas nessa área vem crescendo lentamente, sendo que o alvo dos benchmarks paralelos é a computação paralela científica que vem exigindo cada vez mais poder computacional. Essa é a razão da maioria dos benchmarks estar escrito em Fortran com suas extensões paralelas. Apesar de que, atualmente versões em $\mathrm{C}$ vem sendo criadas devido a crescente otimização dos compiladores.

Um bom benchmark deve ser portável entre máquinas e escrito numa linguagem popular de alto nível como $\mathrm{C}$ ou Fortran. Deve utilizar bibliotecas conhecidas de passagem de mensagem como o PVM ou MPI que permitem uma mudança de plataforma praticamente sem nenhuma mudança 
de código, ou utilizar a linguagem HPF que atualmente está bem sedimentada na área da computação científica.

Além das características descritas acima ele deve representar algum tipo de programação em especial tais como: sistemas operacionais, compiladores, programação numérica, programação comercial, etc.

Com relação a padronização, graças ao Parkbench Comitee não existe uma confusão generalizada de benchmarks. Este comitê criou padrōes de medição e centralizou o controle sob suas mãos, validando resultados e armazenando-os em um banco de dados centralizado. A cada período de tempo, o Parkbench Comitee lança um relatório contendo as novas criações na área de benchmarks e os resultados obtidos nas avaliações de desempenho, isso inclui os resultados da utilização de benchmarks já conhecidos. 


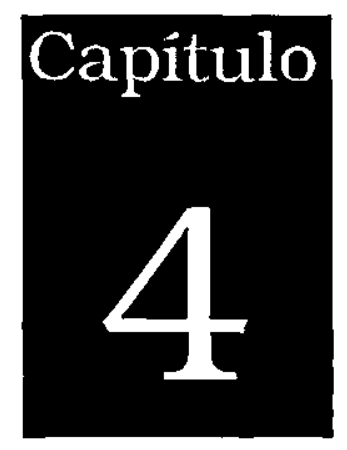

\section{Algoritmos Numéricos}

\subsection{Introdução}

Devido ao grande esforço de cálculo exigido pelos métodos numéricos, antes do advento dos computadores estes métodos sofriam grandes restrições. A partir da década de 40 quando começaram a surgir os computadores, muitos problemas passaram a ser resolvidos a contento [Cla94]. Nos últimos tempos, a capacidade de processamento dos computadores vem crescendo vertiginosamente melhorando a exatidão e aumentando a velocidade de processamento.

A matemática numérica, no ponto de vista da computação, faz parte de uma área maior denominada Matemática Computacional. Dessa forma, alguns fatores devem ser considerados. O primeiro é que algumas propriedades básicas da aritmética não valem no mundo digital, principalmente se forem considerados os números infinitos. Um computador só pode representar números finitos porque as palavras de memória também são finitas. A Matemática Computacional pode ser subdividida em várias sub-áreas conforme mostra a Figura 4.1 [Cla94]. 


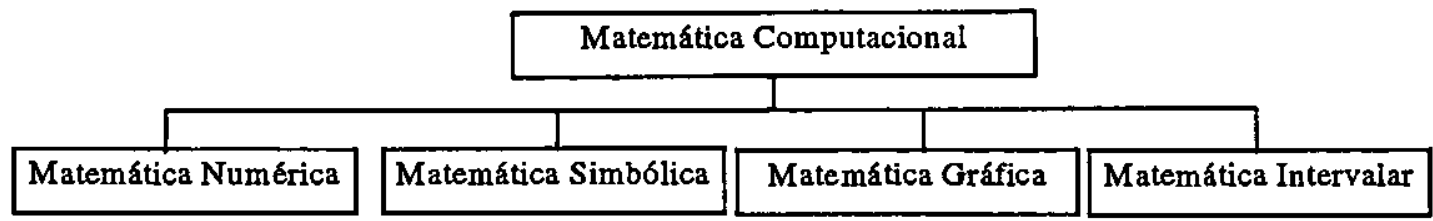

Figura 4.1 - Divisão da Matemática Computacional.

A Matemática Numérica procura encontrar soluçōes aproximadas de problemas através da representação do mesmo por um modelo matemático. A Simbólica trata das formas literais. A Matemática Gráfica estuda os problemas através de uma forma gráfica e tenta solucioná-los através da mesma técnica. E finalmente, a Matemática Intervalar trata os dados na forma de intervalos controlando os limites de erro dos processos da Matemática Numérica de forma $100 \%$ confiável.

O objetivo da Matemática Numérica é estudar processos numéricos, ou seja, algoritmos para a solução de problemas visando a máxima confiabilidade e economia. Como esses algoritmos são implementados em computadores, alguns fatores devem ser considerados. O primeiro deles é, como já foi mencionado, que os computadores só podem representar números finitos. Outro fator está relacionado com o tempo de execução. Neste caso encaixa-se a computação paralela (multiprocessada ou distribuída) que tem como principal objetivo o aumento de desempenho na execução de uma aplicação.

Para solucionar um problema através de um computador é necessário executar uma série de passos preestabelecidos de modo formal, onde esses passos dão origem ao que se chama de algoritmo, no caso da matemática computacional, algoritmo numérico. Um algoritmo numérico de boa qualidade deve apresentar as seguintes características [Cla94]:

- Inexistência de erros lógicos;

- Inexistência de erro operacional;

- Quantidade finita de cálculos;

- Existência de um critério de exatidão;

- Independência de máquina;

- Eficiência.

Cada uma destas características será comentada a seguir. 
Inexistência de erros lógicos vale para qualquer algoritmo, seja ele numérico ou não. Sendo que nos algoritmos numéricos faz-se necessário uma previsão completa de todas as possibilidades, considerando as características das operações aritméticas que serão utilizadas. Por exemplo, qual seria 0 algoritmo correto para encontrar o valor de $x$ na equação $a x=b$ ?

Intuitivamente pode-se pensar que $x=b / a$ seria a solução correta. Mas, se esta solução for analisada pelo ponto de vista dos algoritmos numéricos ela está incompleta. $\mathrm{O}$ algoritmo correto seria:

Se $a=0$ então

Se $b=0$ então Imprima ("Não existe soluçâo") senão Imprima ("Erro -Divisâo por zero")

Fim_se

Senäo

Se $b=0$ então Imprima ("Soluçâo identidade $(x=0)$ ")

Senão $x \leftarrow b / a$

Fim_se

\section{Inexistência de Erros Operacionais}

Corrigidos todos os erros lógicos parte-se para a análise de restrições, ou seja, verificar se 0 algoritmo não está violando as restrições da máquina, como por exemplo, se a precisão dos múmeros não ultrapassa a capacidade em ponto flutuante da máquina. Esses erros são geralmente detectados em tempo de execução e caracterizam os erros operacionais. A representação matemática das restrições é dada por [Cla94]:

- Seja $\mathrm{T}=\Re$ (conjunto dos reais) e $\mathrm{x} \in \Re$

- $\forall \mathrm{x} \in \mathrm{T},-\mathrm{x} \in \mathrm{T}$

- $\mathrm{t}_{1}=$ limite_inferior $\{\mathrm{x} / \mathrm{x} \in \mathrm{T}$ e $\mathrm{x}>\mathrm{n}\}$

- $\mathrm{t}_{2}=$ limite_superior $\{\mathrm{x} / \mathrm{x} \in \mathrm{T}$ e $\mathrm{x}<\mathrm{z}$ e $\mathrm{x}>\mathrm{n}\}$ onde $\mathrm{z}>\mathrm{t}_{1}$

$t_{1}$ representa o limite inferior, ou seja, o menor valor de $x$ que pode ser utilizado. E $t_{2}$ representa o limite superior, isto é, o maior valor que $x$ pode alcançar. Se existir algum valor de $y$, de forma 
que, $y<t_{1}$ ou $y>t_{2}$ tem-se dois erros chamados de underflow e overflow respectivamente. Isso caracteriza um erro operacional.

\section{Quantidade finita de cálculos e existência de critérios de exatidão}

Existem muitos métodos para resolução de problemas numéricos que são iterativos, isto é, repetitivos. Dessa forma, tem-se a necessidade de estabelecer um critério de parada, ou seja, uma quantidade finita de cálculos (repetições). Um dos principais motivos que leva a quantidade finita de cálculos é a capacidade finita de uma máquina representar números em ponto flutuante. Levando isso em consideração, todo resultado obtido em um computador deve estar dentro de um critério de exatidão fornecido antes de iniciado o cálculo. Deste modo o resultado pode ser escrito na forma de:

\section{Resultado = Valor aproximado \pm Limite de erro}

onde valor aproximado é o resultado encontrado pela máquina e o limite de erro é a diferença entre o que foi encontrado pela máquina e o valor real.

\section{Independência de máquina}

Quando o algoritmo estiver pronto para ser implementado, este não pode ser dependente de uma máquina, a não ser que seu propósito seja muito específico. De maneira geral os algoritmos numéricos devem ter independência de máquina visando a máxima portabilidade.

\section{Eficiência do algoritmo}

$\mathrm{Na}$ solução de qualquer problema, uma grandeza comum sempre aparece. Essa grandeza é conhecida como economizar os recursos envolvidos na solução, ou seja, aumentar ao máximo a relação custo/benefício. $E$ isso só é conseguido com a eficiência do algoritmo. Tem-se que deixar bem claro a diferença entre eficiência e eficácia. A eficácia é a capacidade do algoritmo de produzir uma resposta correta. E a eficiência é a capacidade do algoritmo em obter uma resposta correta no menor tempo possível. Por exemplo, o algoritmo de Crammer para resolução de sistemas lineares é muito eficaz, mas é extremamente ineficiente para um certo número $n$ de elementos, por exemplo, $\operatorname{com} n=10$ o sistema já se torna extremamente lento. 
Analisando-se as características discutidas, observa-se que um ponto crucial no desenvolvimento e execução de um algoritmo numérico é o tratamento de erros. Desta forma, a próxima seção é "destinada" ao estudo de erros em algoritmos numéricos.

\subsection{Erros em algoritmos numéricos}

Dentro dos algoritmos numéricos existem três tipos básicos de erros: os inerentes, os de discretização e os de arredondamento. Os inerentes aparecem quando um modelo matemático é criado ou simplificado. Os valores de, por exemplo, tempo, temperatura, distância e intensidade luminosa são medidos através de aparelhos que também são limitados em sua representação numérica. Dessa forma, esses erros não podem ser evitados ou minimizados.

Os erros de discretização, também conhecidos como erros de aproximação ou de truncamento, são erros que ocorrem quando um processo infinito de cálculo é substituído por um processo finito, ou seja, por um processo discretizado que o torne computacionalmente viável. Por exemplo, qual seria a solução computacionalmente viável para a série:

$$
e=\sum_{i=0}^{\infty} \frac{1}{i !}
$$

Nota-se que é uma série infinita e para torná-la computacionalmente viável tem-se que transformá-la numa série discretizada, isto é, efetuar somente algumas parcelas do somatório. Com isso, cria-se um erro causado pelo abandono das parcelas que não foram somadas.

Os erros de arredondamento surgem quando se trabalha com máquinas digitais representando números reais [Cla94]. De maneira geral o arredondamento é feito com números em ponto flutuante para o mais próximo do número real. Neste caso entram mais dois tipos de erro: o erro absoluto e o erro relativo. O erro absoluto é caracterizado pela diferença entre o número real e o valor arredondado.

$$
\mathrm{E}_{\mathrm{A}}=\left|x^{*}-x\right| \text {; onde } x^{*} \text { é o número real e } \mathrm{x} \text { é o número arredondado }
$$

Seguindo a mesma representação, tem-se o erro relativo que é caracterizado:

$$
E_{r}=\frac{\left|x^{*}-x\right|}{|x|} \text { ou } E_{r}=\frac{\left|x^{*}-x\right|}{\left|x^{*}\right|}
$$


Tanto o erro relativo como o erro absoluto são utilizados nos algoritmos numéricos como critério de parada.

A seguir são apresentados alguns exemplos de algoritmos numéricos. Para cada algoritmo é desenvolvido o método de solução considerando o teste de parada, baseado em alguma forma de erro.

\subsection{Exemplos de Algoritmos Numéricos}

A maioria dos algoritmos numéricos utiliza métodos iterativos para resolver o problema considerado. Os métodos iterativos estão divididos em quatro partes:

- Estimativa inicial: onde apresenta-se uma ou mais aproximações da solução desejada;

- Atualização: considera-se uma fórmula que atualize a solução aproximada;

- Critério de parada: é uma regra que permite a parada do processo iterativo quando uma solução é encontrada ou quando a solução converge;

- Estimador de exatidão: é associado ao critério de parada e provê uma estimativa do erro cometido em relação a solução real.

\subsubsection{Resolução de Sistemas Lineares por métodos iterativos}

Nesta seção mostra-se o método iterativo de Jacobi para resolução de sistemas lineares por ser naturalmente paralelo, ou seja, não há dependência entre as equações utilizadas no sistema.

A classe dos métodos iterativos de Gauss-Seidel e Jacobi, resolvem o sistema convertendo um vetor $x^{(k)}$ em outro, $x^{(k+1)}$, que depende de $x^{(k)}$ ( $x$ no passo $k$ ). A idéia central dos métodos iterativos para solução de sistemas lineares pode ser colocada na seguinte forma[Rug96]:

Seja o sistema linear $A x=b$, onde:

$A$ : matriz dos coeficientes, $\mathrm{n} \times \mathrm{n}$;

$x$ : vetor de variáveis, $\mathrm{n} \times 1$;

$b:$ vetor dos termos independentes, $\mathrm{n} \times 1$. 
Inicia-se o passo em $x^{(0)}$, onde $x^{(0)}$ é o vetor de aproximação inicial.

De um modo geral, as próximas iteraçōes $(k+1)$ são dependentes da iteração no passo $k$.

\section{Teste de Parada}

O processo de iteração repete-se até que o vetor $x^{(k+1)}$ esteja próximo do vetor $x^{(k)}$, dado um determinado erro ou precisão $(\varepsilon)$ de modo que $M_{R}{ }^{(k)}<\varepsilon$, onde:

$$
M_{R}^{(k)}=\frac{\left\|x^{(k+1)}-x^{(k)}\right\|_{\infty}}{\left\|x^{(k+1)}\right\|_{\infty}} \text { ou } \quad M_{R}^{(k)}=\frac{\left\|x^{(k+1)}-x^{(k)}\right\|_{\infty}}{\left\|x^{(k)}\right\|_{\infty}}
$$

sendo que $\|x\|_{\infty}=\max _{1 \leq i \leq n}\left|x_{i}\right|$. A seguir mostra-se o método iterativo de Jacobi para solucionar sistemas de equações lineares [Rug96].

\section{Método iterativo de Jacobi}

Considere-se o seguinte sistema:

$$
\left[\begin{array}{c}
a_{11} x_{1}+a_{12} x_{2}+\ldots+a_{1 n} x_{n}=b_{1} \\
a_{21} x_{1}+a_{22} x_{2}+\cdots+a_{2 n} x_{n}=b_{2} \\
a_{31} x_{1}+a_{32} x_{2}+\cdots+a_{3 n} x_{n}=b_{3} \\
\vdots \quad \vdots \quad \vdots \quad \vdots \\
a_{n 1} x_{1}+a_{n 2} x_{2}+\cdots+a_{n n} x_{n}=b_{n}
\end{array}\right.
$$

Isolando o termo $x_{i}$, onde, $i=1,2, \ldots, n$, em cada equação tem-se:

$$
\left[\begin{array}{l}
x_{1}=\frac{1}{a_{11}}\left(b_{1}-a_{12} x_{2}-a_{13} x_{3}-\cdots-a_{1 n} x_{n}\right) \\
x_{2}=\frac{1}{a_{22}}\left(b_{2}-a_{21} x_{1}-a_{23} x_{3}-\cdots-a_{2 n} x_{n}\right) \\
\vdots \\
x_{n}=\frac{1}{a_{n n}}\left(b_{n}-a_{n 1} x_{1}-a_{n 2} x_{2}-\cdots-a_{n, n-1} x_{n-1}\right)
\end{array}\right.
$$


$\mathrm{O}$ método de Jacobi consiste em, dado uma aproximação inicial $\mathrm{x}^{(0)}$, encontrar $\mathrm{x}^{(1)}, \ldots, \mathrm{x}^{(\mathrm{k})}$, através de um relação recursiva, ou seja, usar o valor de $x^{(k)}$ para encontrar a próxima aproximação $x^{(k+1)}$ através das equações:

$$
\left[\begin{array}{l}
x_{1}^{(k+1)}=\frac{1}{a_{11}}\left(b_{1}-a_{12} x_{2}^{(k)}-a_{13} x_{3}^{(k)}-\cdots-a_{1 n} x_{n}^{(k)}\right) \\
x_{2}^{(k+1)}=\frac{1}{a_{22}}\left(b_{2}-a_{21} x_{1}^{(k)}-a_{23} x_{3}^{(k)}-\cdots-a_{2 n} x_{n}^{(k)}\right) \\
\vdots \\
x_{n}^{(k+1)}=\frac{1}{a_{n n}}\left(b_{n}-a_{n 1} x_{1}^{(k)}-a_{n 2} x_{2}^{(k)}-\cdots-a_{n, n-1} x_{n-1}^{(k)}\right)
\end{array}\right.
$$

A aproximação inicial $\mathrm{x}^{(0)}$, que geralmente é usada nos métodos iterativos é:

$$
\mathrm{x}^{(0)}=\left(\begin{array}{c}
0 \\
0 \\
\vdots \\
0
\end{array}\right)
$$

No método de Jacobi, essa aproximação conduz a segunda iteração como sendo:

$$
x^{(1)}=\left(\begin{array}{l}
\frac{b_{1}}{a_{11}} \\
\frac{b_{2}}{a_{22}} \\
\vdots \\
\frac{b_{n}}{a_{n n}}
\end{array}\right)
$$

neste caso pode-se utilizar a iteração $\mathrm{x}^{(1)}$ diretamente como sendo a aproximação inicial $\mathrm{x}^{(0)}$. Computacionalmente, devido a velocidade de cálculo, pode-se adotar como aproximação inicial 0 vetor de zeros (I)

Exemplo: Resolver o seguinte sistema com $\varepsilon=0.05$ :

$$
\left\{\begin{aligned}
10 x_{1}+2 x_{2}+x_{3} & =7 \\
x_{1}+5 x_{2}+x_{3} & =-8 \\
2 x_{1}+3 x_{2}+10 x_{3} & =6
\end{aligned}\right.
$$


Pela equação dada acima e considerando-se a opção 2 para escolha da primeira iteração, tem-se que $x^{(0)}=\left(\begin{array}{c}0.7 \\ -1.6 \\ 0.6\end{array}\right)$

O processo para a obtenção das iterações é:

$$
\left\{\begin{array}{l}
x_{1}^{(k+1)}=-0.2 x_{2}^{(k)}-0.1 x_{3}^{(k)}+0.7=0.96 \\
x_{2}^{(k+1)}=-0.2 x_{1}^{(k)}-0.2 x_{3}^{(k)}-1.6=-1.86 \text { para } \mathrm{k}=0,1, \ldots, \text { ate } \mathrm{M}_{\mathrm{R}}^{(k)}<\varepsilon . \\
x_{3}^{(k+1)}=-0.2 x_{1}^{(k)}-0.3 x_{2}^{(k)}+0.6=0.94
\end{array}\right.
$$

A Tabela 4.1, mostra os valores utilizados para $k$ e os respectivos resultados para $\mathrm{x}_{\mathrm{i}}$ quando utilizado o processo de obtenção das iterações, a última linha apresenta o erro relativo correspondente.

Tabela 4.1 - Resultados alcançados no processo de obtenção das iteraçōes.

\begin{tabular}{|l|l|l|l|l|}
\hline \multicolumn{2}{|c}{ k 0 } & $\mathbf{1}$ & $\mathbf{2}$ & $\mathbf{3}$ \\
\hline $\mathrm{X} 1$ & 0,7 & 0,96 & 0,978 & 0,9994 \\
\hline $\mathrm{X} 2$ & $-1,6$ & $-1,86$ & $-1,98$ & $-1,9888$ \\
\hline $\mathrm{X3}$ & 0,6 & 0,94 & 0,699 & 0,9984 \\
\hline Erro $\left(\mathrm{M}_{\mathrm{R}}^{(\mathrm{k})}\right)$ & - & 0,1828 & 0,0606 & 0,0163 \\
\hline
\end{tabular}

Nota-se que na terceira iteração obteve-se um $\mathrm{M}_{\mathrm{R}}{ }^{(\mathrm{k})}<\varepsilon$ o que ocasiona a parada do processo.

Este método possui um paralelismo natural, ou seja, não existem dependências entre as equações. Dessa forma o paralelismo pode ser feito mandando-se um conjunto de equações para cada processo/processador.

\subsubsection{Integração Numérica}

Existem quatro abordagens para se solucionar uma integral. Pelos métodos analíticos, mecânicos, gráficos e por métodos numéricos. Olhando pelo ponto de vista analítico existem inúmeras regras a serem seguidas, mas nem sempre essas regras são fáceis de se processar. Por exemplo, calcule:

$$
f(x)=\int x^{2} d x
$$


Uma resposta simples e rápida pođe ser dada, ou seja, $f(x)=x^{3} / 3$. Mas a solução de:

$$
f(x)=\int \frac{1}{x} d x
$$

já não é tão trivial assim, sua solução seria $f(x)=\ln x$. Alguns softwares como o Reduce e o Formac utilizam-se de técnicas de inteligência artificial para produzirem tais primitivas, mas elas exigem muita memória da máquina. [Cla94]

O método mecânico utiliza instrumentos para determinar uma área delimitada por uma curva qualquer, que podem ser planos simples. O método gráfico é baseado em segmentos de reta e utiliza basicamente o plano cartesiano. Por não ser de interesse neste trabalho estes métodos não serão detalhados.

No método numérico será calculado uma integral definida de mođo que será utilizado uma combinação linear de valores de uma função $f$ em certos pontos de $x_{1}$, onde $\mathrm{a} \leq x_{1} \leq \mathrm{b}$, chamados de nós e certos valores $\omega_{1}$ que constituem os pesos, isto é:[Cla94]

$$
\int_{a}^{b} f(x) d x \cong \omega_{1} f\left(x_{1}\right)+\omega_{2} f\left(x_{2}\right)+\ldots+\omega_{n} f\left(x_{n}\right)+\omega_{n+1} f\left(x_{n+1}\right)
$$

\section{Regra dos trapézios}

Suponha que $f$ seja uma função cujo gráfico é mostrado na Figura 4.2. Se $f$, for aproximada, por um polinômio de $1^{\circ}$ grau $\left(f^{*}\right)$, chega-se a seguinte fórmula:

$$
f(x) \cong f^{*}(x)=f(a) \frac{(x-a)}{(b-a)}+f(b) \frac{(x-b)}{a-b}
$$

Integrando ( III ) de a até b obtém-se:

$$
\begin{aligned}
\int_{a}^{b} f(x) d x & \cong \int_{a}^{b} f^{*}(x) d x=\frac{f(a)}{b-a} \int_{a}^{b}(x-a) d x+\frac{f(b)}{a-b} \int_{a}^{b}(x-b) d x \\
\int_{a}^{b} f(x) d x & \cong \frac{b-a}{2}[f(a)+f(b)]
\end{aligned}
$$

Esta equação é conhecida como regra đo trapézio pois sua expressão final irá conđuzir à área do trapézio, como mostra a área em cinza na Figura 4.2. 


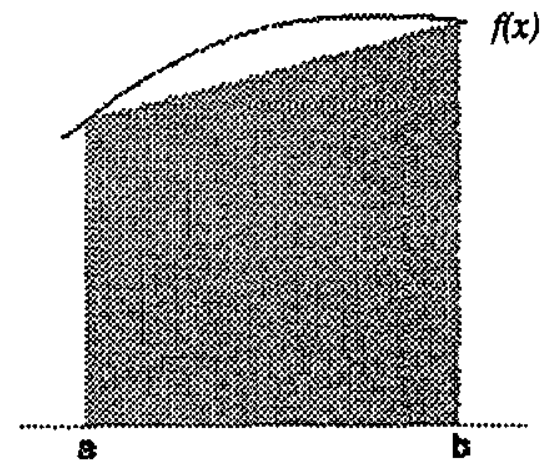

Figura 4.2 -Exemplo de função $f(x)$.

A área entre o trapézio e a curva é o erro cometido.

Se o intervalo $[\mathrm{a}, \mathrm{b}]$ for subdivido em $n$ subintervalos e em cada um deles for feita uma aproximação da função $f$ utilizando a regra do trapézio tem-se o que se chama de regra dos Trapézios Composta, conforme mostra a Figura 4.3. Note que a área não coberta pelo trapézio agora é bem menor, isso significa uma maior precisão nos cálculos.

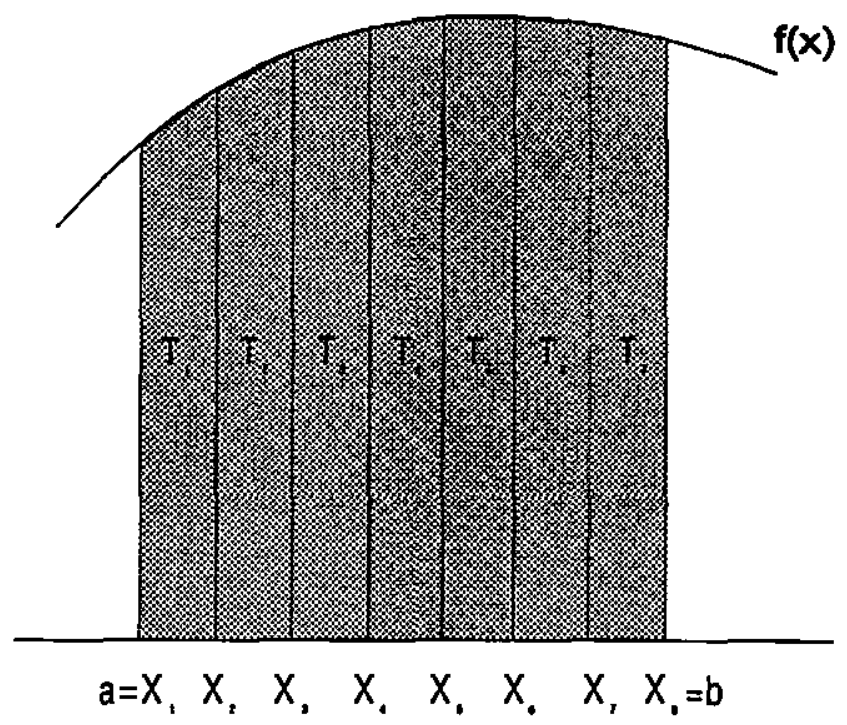

Figura 4.3 - Regra do trapézio composta

Para obter-se a regra do trapézio composta, basta a aplicação da regra do trapézio em cada subintervalo $\left[X_{j}, X_{j+1}\right], j=1, \ldots, n$. Com isso tem-se a seguinte equação:

$$
T(h)=\frac{h}{2}\left[f\left(x_{1}\right)+2\left(f\left(x_{2}\right)+f\left(x_{3}\right)+\cdots+f\left(x_{n}\right)\right)+f\left(x_{n+1}\right)\right]
$$

onde $\mathrm{f}\left(\mathrm{x}_{\mathrm{i}}\right)$ é a função calculada no ponto inicial de cada subintervalo e $h=\frac{b-a}{n}$. 
Exemplo: Encontre a soluçāo de:

$$
\int_{0}^{1} e^{-x^{2}} d x
$$

utilizando $\mathrm{n}=4$, onde $h=(b-a) / n$.

$h=(1-0) / 4=0.25$, dessa forma $x_{1}=0.0, x_{2}=0.25, x_{3}=0.5, x_{4}=0.75, x_{5}=1.0$

$T(0.25)=\frac{0.25}{2}\left[f\left(x_{1}\right)+2 f\left(x_{2}\right)+2 f\left(x_{3}\right)+2 f\left(x_{4}\right)+f\left(x_{5}\right)\right]$

$T(0.25)=0.125[1+2 * 0.939413063+2 * 0.778800783+2 * 0.569788+0.367879441]=0.742984098$

Para realizar a paralelização deste algoritmo basta dividir o intervalo pelo número de processos ou processadores que se quer sendo que um $n$ grande pode ser usado para aumentar a precisão e a carga de processamento em cada processo/processador, este procedimento é descrito com detalhes no Capítulo 6.

\subsubsection{Multiplicação de matrizes}

Apesar desse algoritmo não ser numérico, ele está sendo apresentado neste capítulo por exigir um grande esforço de processamento apresentando uma complexidade $\mathrm{n}^{3}$, ou seja, o crescimento de custo computacional é relativamente grande e rápido.

O algoritmo é simples onde a matriz resultante da multiplicação é obtida através do pequeno algoritmo a seguir:

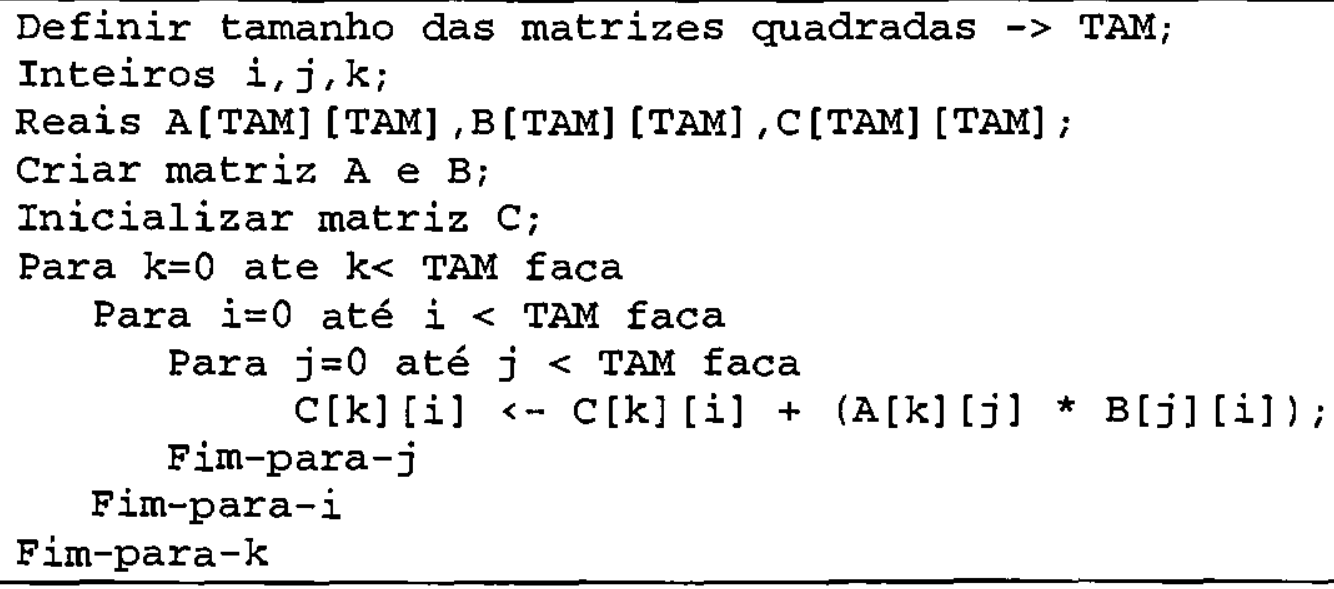

Como nos demais algoritmos sua paralelização é também mais detalhada no Capítulo 6. 


\subsection{Considerações finais}

A busca pelo alto desempenho é o que leva a grande utilização do processamento paralelo [Alm94]. As diversas áreas na qual a computação paralela pode ser aplicada, seja na computação científica, na indústria ou em aplicações militares requerem cada vez mais poder computacional em virtude dos algoritmos cada vez mais complexos.

No projeto de algoritmos paralelos vários fatores, que não são considerados nos algoritmos seqüenciais, devem ser considerados, tais como: arquitetura onde o algoritmo será implementado, se o mesmo possui muita comunicação, se o algoritmo possui dependência em seus cálculos e o sincronismo imposto pelo problema.

$\mathrm{Na}$ matemática computacional existem muitos algoritmos que são intrinsecamente paraklos e podem ser implementados tanto seguindo a abordagem MPMD como SPMD, explorando granulação grossa e atingindo valores de speedup e eficiência atrativos. Os algoritmos descritos neste capítulo podem ser desenvolvidos tanto em computadores multiprocessados como em sistemas paralelos virtuais.

O próximo capítulo descreve todo o ambiente utilizado no desenvolvimento dos algoritmos numéricos aqui descritos. 


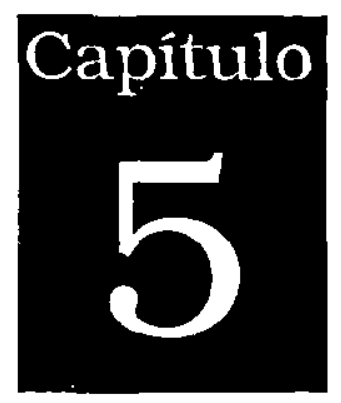

\section{Descrição do Ambiente}

Este capítulo descreve os ambientes utilizados no desenvolvimento deste trabalho começando pelo hardware e em seguida detalhando o software que auxiliou o desenvolvimento e a execução das aplicações.

\subsection{Hardware Utilizado}

\subsubsection{O IBM SP2}

IBM SP2 (IBM Scalable PowerParallel System), é uma máquina paralela de memória distribuída, adequada tanto para o processamento de programas seqüências como paralelos que demandem grande potência computacional e/ou grande quantidade de memória. O sistema é composto de nós (processadores com memória e disco proprios) e interligados por um switch de alto desempenho que proporciona alta velocidade de comunicação entre os processadores e também entre outras máquinas SP2. Seu sistema flexível de interligação também permite que ele seja conectado a outros tipos de tecnologia de redes tais como: Ethernet, FDDI, ATM, etc. A Figura 5.1 mostra um sistema SP2 onde os nós estão interligados a dois servidores de arquivos, 
estes servidores estão interligados por uma rede token-ring, que por sua vez está interligada ao SP2 através de uma rede Ethernet e quatro dos processadores do SP2 estão ligados a três servidores por uma rede FDDI.

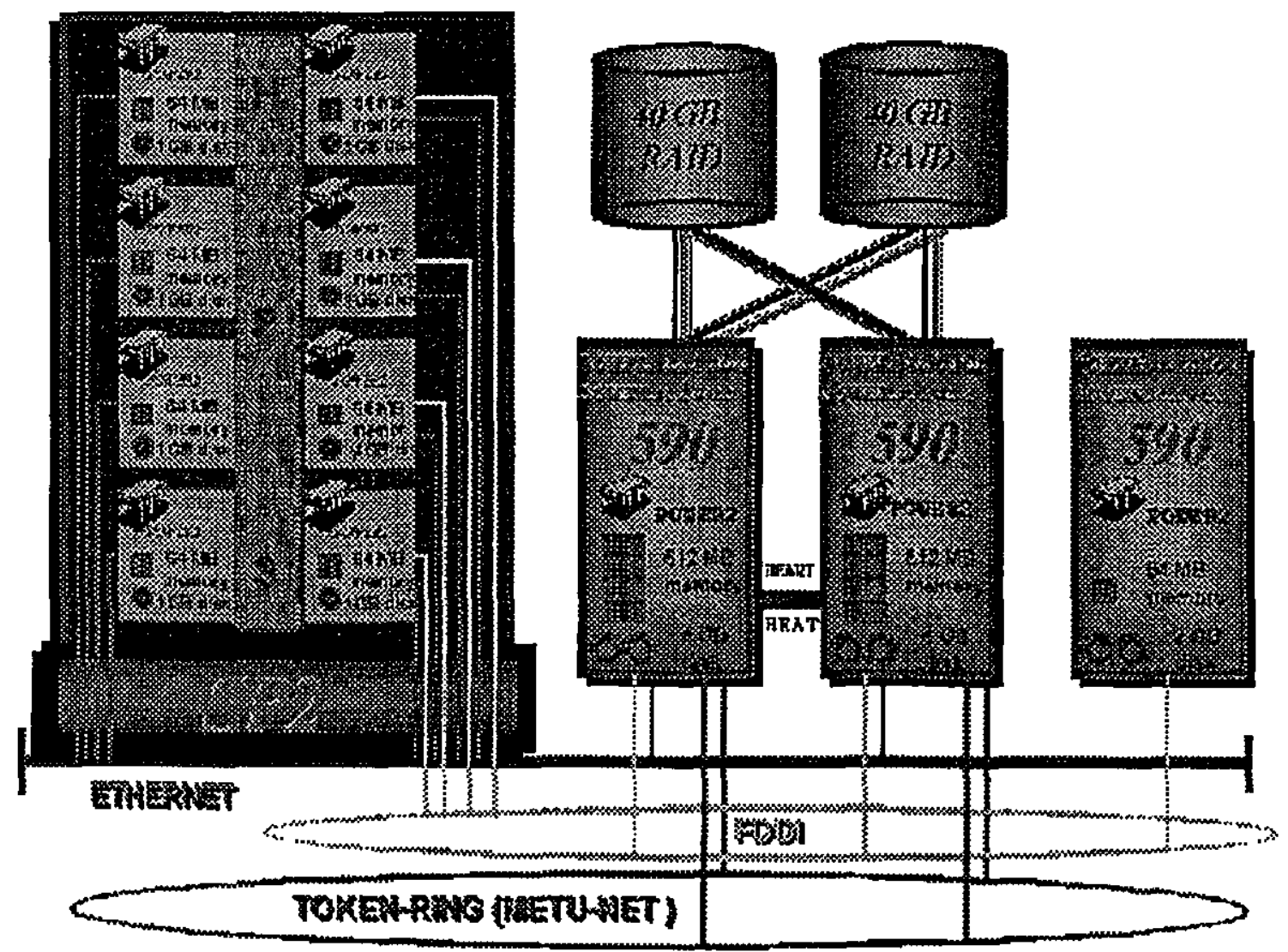

Figura 5.1 - Exemplo de conexāo do SP2 com diversos tipos de rede.

A característica mais marcante dos sistemas SP2 é o switch de alto desempenho. Ele consiste de dois elementos básicos: uma placa principal e um adaptador de rede. Estes elementos permitem a utilização de passagem de mensagens entre todos os nós do sistema ao mesmo tempo. O SP2 possui ainda um sistema de segurança que impede a perda das mensagens. Como possui diversos caminhos disponíveis para roteamento (como pode ser visto na Figura 5.2) caso um deles apresente defeito ou esteja sendo utilizado, o adaptador se encarrega de encontrar um novo caminho para a mensagem. [Ibm98]

Dois tipos de nós estão disponíveis para o SP2:0 do tipo thin e do tipo wide. Os nós do tipo thin apresentam um barramento de 64 bits e o segundo um barramento de 128 bits. A máquina é basicamente vista como uma espécie de estante, chamada de rack, onde são colocados os nós. Em cada gaveta é possível colocar dois nós do tipo thin ou um nó do tipo wide. 


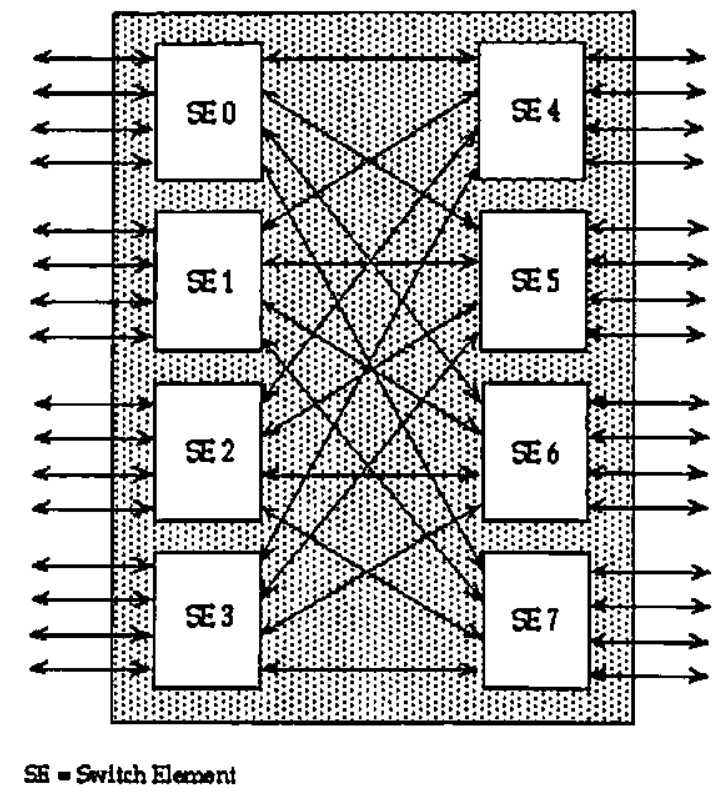

Figura 5.2 - Switch de alto desempenho.

O IBM SP2 do CISC está equipado com três processadores sendo dois do tipo thin e um do tipo wide com as seguintes configurações: o do tipo wide possui processador POWER2 de 66,7 Mhz, 256 Mbytes de memória RAM, 256 Kbytes de cache, barramento de 128 bits e 9 Gbytes de disco rígido; os do tipo thin possuem processador POWER2 de 66,7 Mhz, 128 Mbytes de memória RAM, 128 Kbytes de cache, barramento de 64 bits e 9 Gbytes de disco. Os três nós perfazem um total de 27 Gbytes de disco para aplicações, sistema operacional, etc. [Cis98]

\subsubsection{Sistema Cray de Computadores Vetoriais}

O sistema Cray de computadores foi criado pela Silicon Graphics sendo um dos principais representantes na computação vetorial. O LCCA possui duas máquinas deste tipo sendo que suas características são apresentadas na Tabela 5.1.

Tabela 5.1 - Descrição das máquinas do LCCA.

\begin{tabular}{|c|c|c|c|}
\hline Nome da máquina & Modelo & Nome & Configuração \\
\hline boto.lcca.usp.br & J90 & dolphin.lcca.usp.br & $\begin{array}{l}12 \text { processadores, } 1024 \text { MB de memória } \\
\text { RAM, } 55 \text { GB de disco rígido, pico máximo } \\
\text { de operaçōes em ponto flutuante } 2.4 \text { Gflop. }\end{array}$ \\
\hline dolphin.lcca.usp.br & EL98 & boto.lcca.usp.br & $\begin{array}{l}6 \text { processadores, } 512 \mathrm{MB} \text { de memória RAM, } \\
13 \mathrm{~GB} \text { de disco rígido, pico máximo de } \\
\text { operaçóes em ponto flutuante de } 2.4 \text { Gflop. }\end{array}$ \\
\hline
\end{tabular}

A Figura 5.3 mostra a estrutura interna básica de comunicação entre os processadores [Hwa93]. 


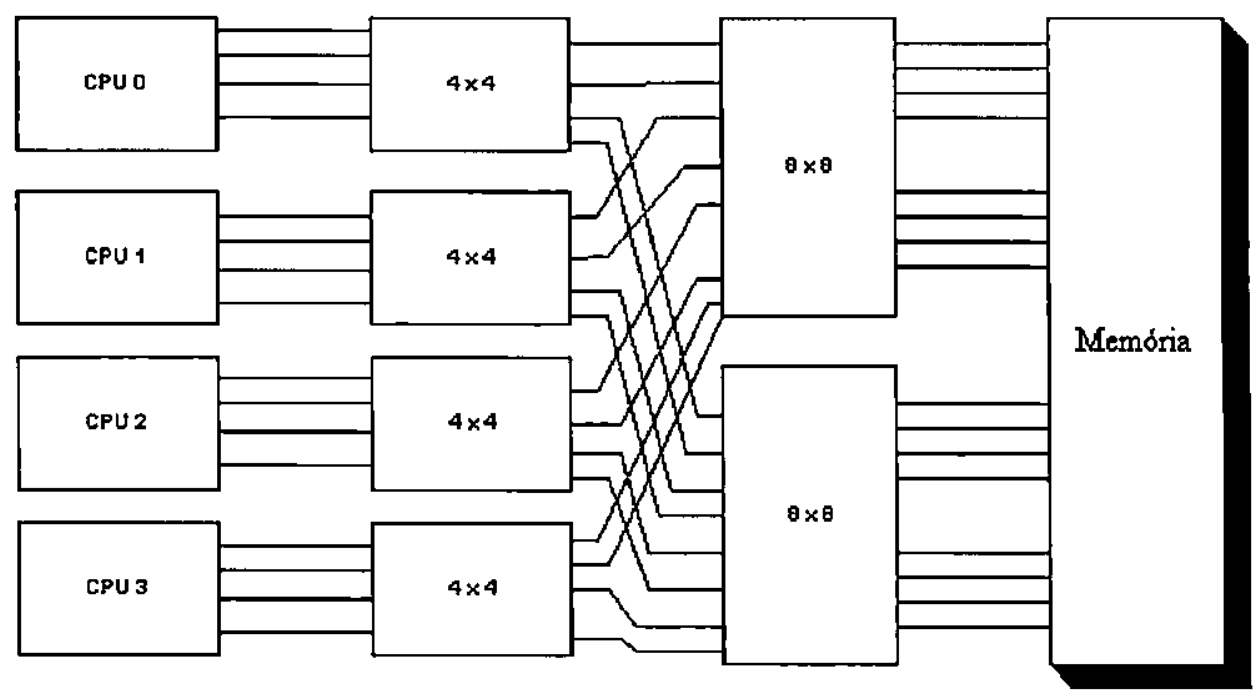

Figura 5.3 - Estrutura básica de comunicação de um sistema Cray.

A comunicação entre processadores e memória é feita por uma rede crossbar de múltiplos estágios. Como a memória é compartilhada os processadores não precisam estar conectados um com outro. O primeiro estágio da rede é formada por blocos de 4 entradas por 4 saídas e o segundo estágios da rede é formada por blocos de 8 entradas por oito saídas.

\subsubsection{Sistema Distribuído do LASD-PC ${ }^{1}$}

Os computadores utilizados no LASD-PC compõem-se de três máquinas compatíveis com o IBM-PC. As três possuem o sistema operacional Linux Slackware, seus respectivos nomes e configuraçōes são apresentados na Tabela 5.2, sendo que todas elas possuem o PVM e o MPI instalados. Todas as máquinas estão interligadas a uma rede ethernet de 10Mbits como mostra a Figura 5.4.

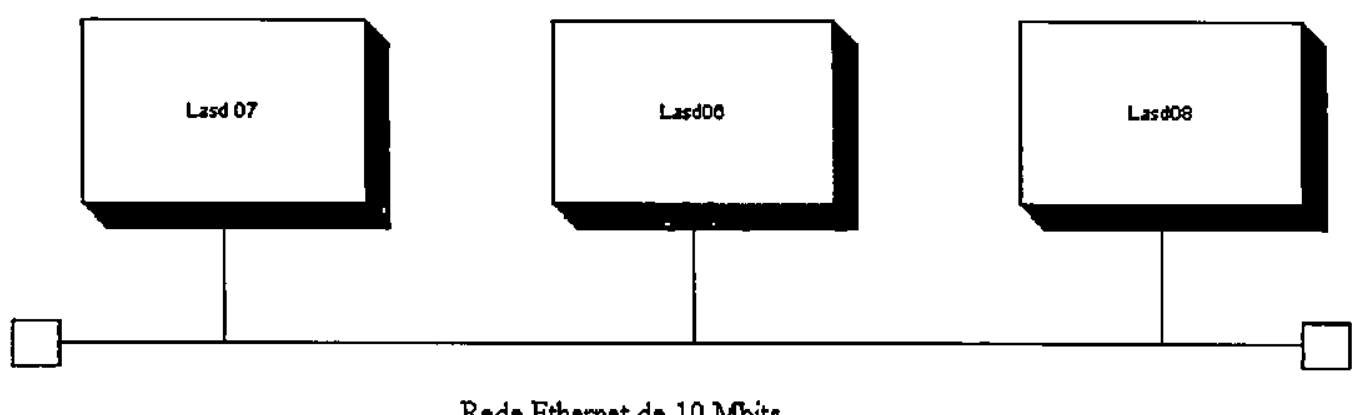

Figura 5.4 - Rede LASD-PC para utilização do PVM e do MPI.

\footnotetext{
${ }^{1}$ LASD-PC representa a abreviação de Laboratório de Sistemas Distribuídos e Programação Concorrente de Instituto de Ciências Matemática e de Computação da Universidade de São Paulo no campus de São Carlos.
} 
Tabela 5.2 - Máquinas utilizadas no LASD-PC.

\begin{tabular}{|l|l|}
\hline Nome & Configuraçōes \\
\hline Lasd06 & LASD 6 - Pentium $100 \mathrm{MHz}, 32$ Mbytes, 512 de cahce L2 \\
\hline Lasd07 & LASD 7 - Pentium $200 \mathrm{MMX}, 32$ MBytes, 512 de cache L2 \\
\hline Lasd08 & LASD 8 - Pentium $166 \mathrm{MHz}, 32$ Mbytes, 512 de cache L2 \\
\hline
\end{tabular}

\subsection{Software Utilizado}

\subsubsection{PVM, PVMe, MPI para IBM SP2}

No IBM SP2 do CISC estão disponíveis quatro tipos de bibliotecas de passagem de mensagens o PVM3, o PVMe, o MPI e o MPL. O PVM3 não é utilizado por funcionar através de uma camada do MPI, oferendo desta forma, um desempenho bem pobre. O PVM3 e o PVMe utilizam a mesma biblioteca de funções diferindo apenas pelo seu deamon e pelo desempenho já que o PVMe utiliza-se do switch de alto desempenho e o PVM3 não, por esse motivo ele não foi utilizado neste trabalho. O MPL foi descartado por ser uma biblioteca proprietária da IBM para o SP2 impedindo a portabilidade. A seguir é descrito como os programas são executados neste tipo de arquitetura.

\section{Submetendo tarefas (jobs) em máquinas SP2 - LoadLever}

Antes de mais nada é necessário compilar o programa. A Tabela 5.3 apresenta os comandos necessários tanto para o MPI quanto para o PVMe.

Tabela 5.3 - Compilação PVM e MPI no SP2.

\begin{tabular}{|c|c|}
\hline Biblioteca & Comando para compilação \\
\hline MPI & mpCC $\multimap<$ nome_do_executável $><$ nome_do_arquivo.cpp $>$ \\
\hline PVMe - arquivo mestre & $\begin{array}{l}\text { x|C -O3 -lpvm3 -Impci -L/usr/lpp/ssp/css/libus -b|:/usr/lib/pvm3e.exp - } \\
\text { o <executável><arquivo_mestre.cpp> }\end{array}$ \\
\hline PVMe - arquivo escravo & $\begin{array}{l}\text { xlC -O3 -lpvm3 -Impci - L/usr//pp/ssp/css/libus -bl:/usr/lib/pvm3e.exp - } \\
\text { o <executável> <arquivo_escravo.cpp> }\end{array}$ \\
\hline
\end{tabular}

Como o MPI no SP2 só trabalha com programas com abordagem SPMD sua compilação torna-se mais simples.

Para o PVMe destaca-se a diretiva de compilação $-L /$ usr/lpp/ssp/css/libus que indica que o switch de alto desempenho não será compartilhado com outros usuários, como será visto mais adiante nos arquivos de comando de tarefas, durante a execução da aplicação. Para testar 0 
funcionamento da aplicação pode-se usar a diretiva $-L / u s r / p p / s s p / c s s / i b i p$ que permite o compartilhamento do switch.

Depois do processo de compilação, para executar uma tarefa nesse tipo de máquina é necessário submeter os programas a uma fila através de um sistema de gerenciamento de tarefas chamado LoadLever. Seu trabalho consiste, basicamente, em alocar todos os recursos necessários a execução de um job. As tarefas devem ser submetidas através de um arquivo de comandos chamado de arquivo de comando de tarefas onde serão especificados todos os parâmetros necessários a sua execução. Este arquivo é composto por duas partes: [Ibm95c]

-Palavras chaves - passam informações ao LoadLever e são precedidas pelos caracteres \#@.

- Comentários - são simples comentários e são precedidos pelo símbolo \#.

A Figura 5.5 mostra um exemplo de arquivo de comandos de tarefas e a descrição de cada um dos comandos.

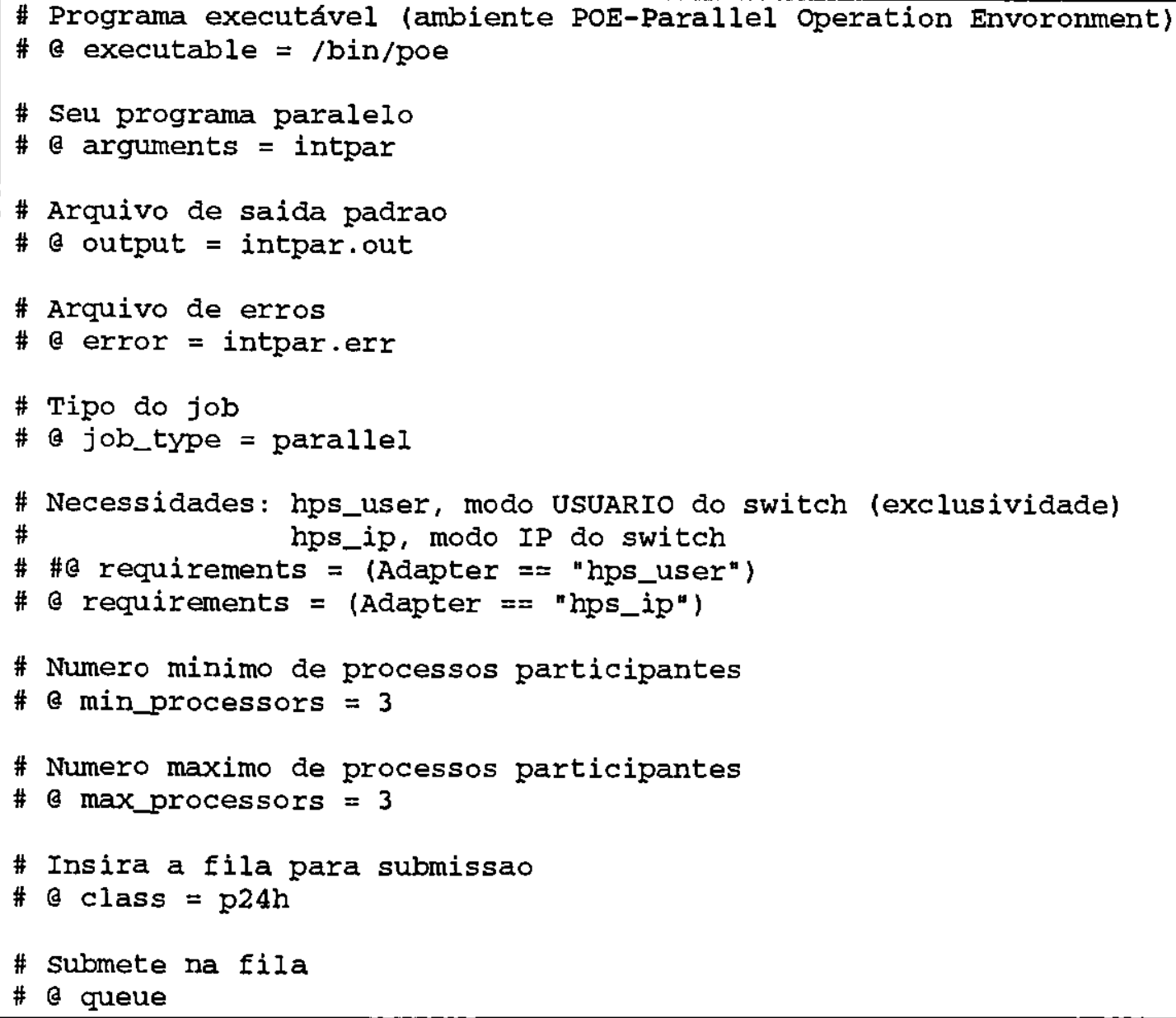

Figura 5.5 - Exemplo de arquivo de comandos de tarefas. 
O primeiro comando encontrado é o executable que deve receber o nome do programa que será executado, geralmente é um programa chamado POE (Parallel Operation Environment Ambiente Paralelo de Operações) que é responsável por gerenciar o ambiente do SP2. Em alguns sistemas é permitido que o nome do programa a ser executado seja colocado diretamente como no caso do LCCA (Laboratório de Computação Científica Avançada), mas no CISC (Centro de Informática de São Carlos) só é permitido a execução de programas via POE. Quando esse sistema é utilizado o comando arguments é necessário para especificar o nome do programa que se deseja executar.

Como não existe interface com o usuário, faz-se necessário o uso de mais alguns comandos. $\mathrm{O}$ output define um arquivo com extensão “.out” que conterá as saídas do programa. O comando error define um arquivo com extensão “.err" que conterá todas as mensagens de erro. Ainda existe o comando input que deve conter as entradas necessárias para o programa, como se fosse um usuário digitando. Os arquivos de input devem ter a extensão inp.

Job_type define se o programa a ser executado é serial ou paralelo. Requirements determina se o switch de comunicação será disponibilizado somente para o usuário que esta executando ( $\left.h p \_u s e r\right)$ ou se será compartilhado $\left(h p \_i p\right)$.

Os comandos min_processor e max_processor definem a quantidade mínima e máxima, respectivamente, de processadores que devem ser alocados para a execução do programa.

O comando class define o nome da fila em que o programa será colocado, isso varia de sistema para sistema, no LCCA existem vários tipos de fila, tais como: short, long, extra e very long. No CISC são definidas duas filas paralelas chamadas p24h e p168h e uma fila serial denominada s168h. E finalmente, o comando queue que envia o programa para execução.

Para programas PVMe, o comando de arquivo de tarefas é semelhante. A diferença é que este tipo de programa não é executado no ambiente POE e sim por um deamon próprio do PVMe. Como será visto mais adiante isso impede a depuração através do depurador gráfico.

Além do arquivo de comandos de tarefa, que deve ter a extensão “.cmd”, o LoadLever apresenta alguns comandos básicos para submissão e controle das tarefas na fila de execução. São eles: 
llsubmit - submete um programa a fila de execução através do respectivo arquivo de comando (arquivo.cmd).

llcancel - cancela a execução de um programa.

$l l q$ - exibe o estado da fila de execução.

llprio - aumenta ou diminui a prioridade do processo na fila, entretanto este comando só afeta os processo do mesmo usuário.

llstatus - exibe o estado atual das máquinas que compõem o sistema.

llclass - exibe quais filas estão disponíveis para utilização.

Para submeter um processo deve-se digitar o comando llsubmit <arquivo.cmd>. Este exibirá uma mensagem dizendo que a tarefa foi submetida e um número que corresponde a identificação do job no sistema como mostrado a seguir.

submit: the job "hades01.1432" has been submitted.

Esse número deve ser utilizado no comando llcancel caso se deseje cancelar a execução, ou no comando llprio caso seja necessário aumentar a prioridade da tarefa.

Após a submissão pode-se utilizar o comando $l l q$, para exibir qual o estado de todas as tarefas que foram submetidas ao sistema. Caso se queira verificar somente o estado dos jobs submetidos por um só usuário, usa-se o comando:

\section{$l l q-u<$ nome do usuário $>$}

Todo esse controle é feito a partir de duas máquinas, uma denominada front-end que é responsável por manter os arquivos dos usuários e executar os principais comandos e outra chamada de controle que é responsável por manipular o status das tarefas. Por exemplo, quando o comando llcancel <número da tarefa> é executado, a máquina front-end envia uma mensagem a máquina de controle que se responsabiliza por retirar o job da execução ou somente da fila caso este não esteja sendo executado. 
Para facilitar a utilização do Loadlever existe uma interface gráfica para o programa conforme mostra a Figura 5.6.

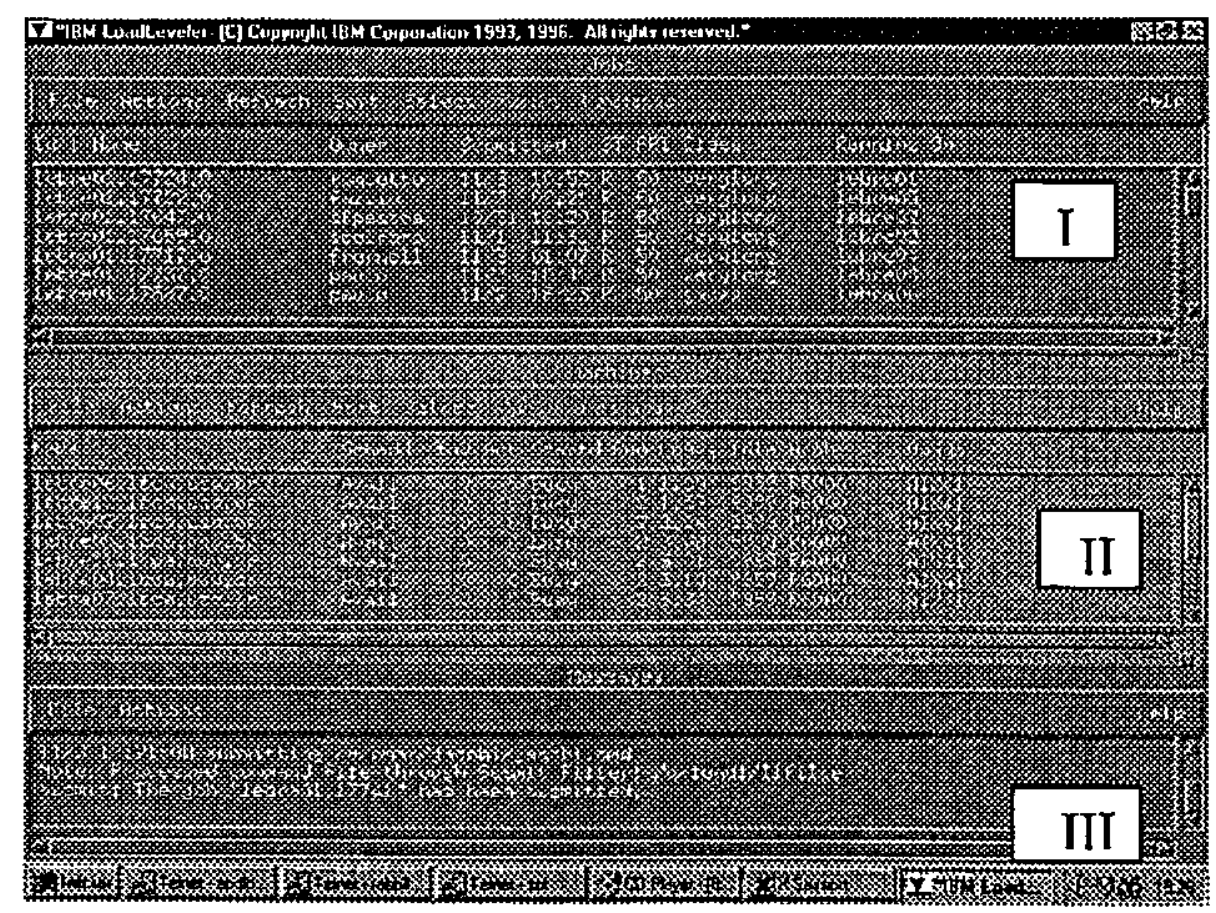

Figura 5.6 - Ambiente gráfico do loadlever.

A tela é dividida em três partes. A primeira, apresentada em I da Figura 5.4, mostra todas as tarefas que estão na fila, esteja ou não em execução, correspondendo ao comando $l l q$. A parte II, apresenta o estado de cada máquina e substitui o comando llstatus. A última parte, identificada por III, exibe as mensagens do sistema.

Para submeter uma tarefa, basta escolher o comando de menu File da Figura 5.4 e em seguida escolher o comando submit-job o qual vai originar a tela mostrada na Figura 5.7, bastando escolher o arquivo e dar um clique no botão Submit. 


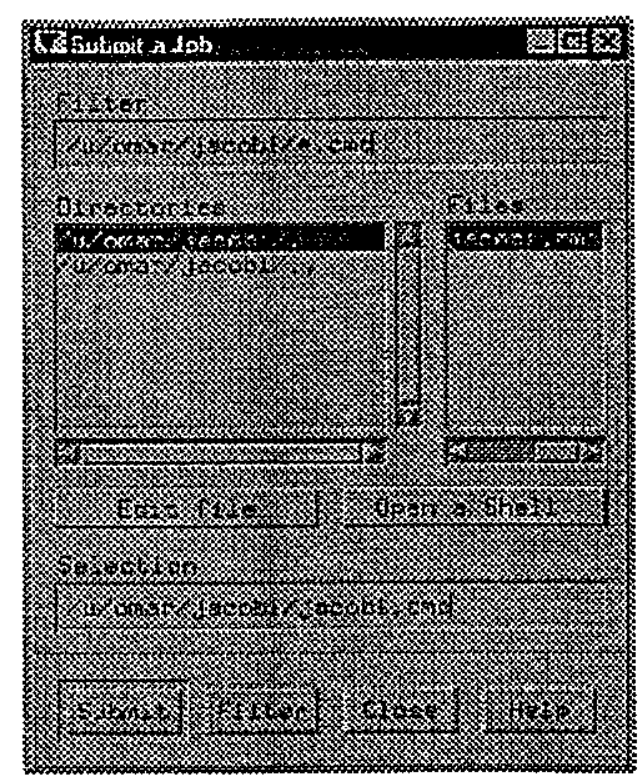

Figura 5.7-Submetendo uma tarefa.

Existe ainda outra facilidade que é a de criar de maneira mais simplificada e rápida o arquivo de comando para submissão de tarefas, estando na opção File do menu na sub-opção chamada de build_job como mostra a Figura 5.8. Os demais comandos encontram-se no menu actions como pode ser visto na Figura 5.9.

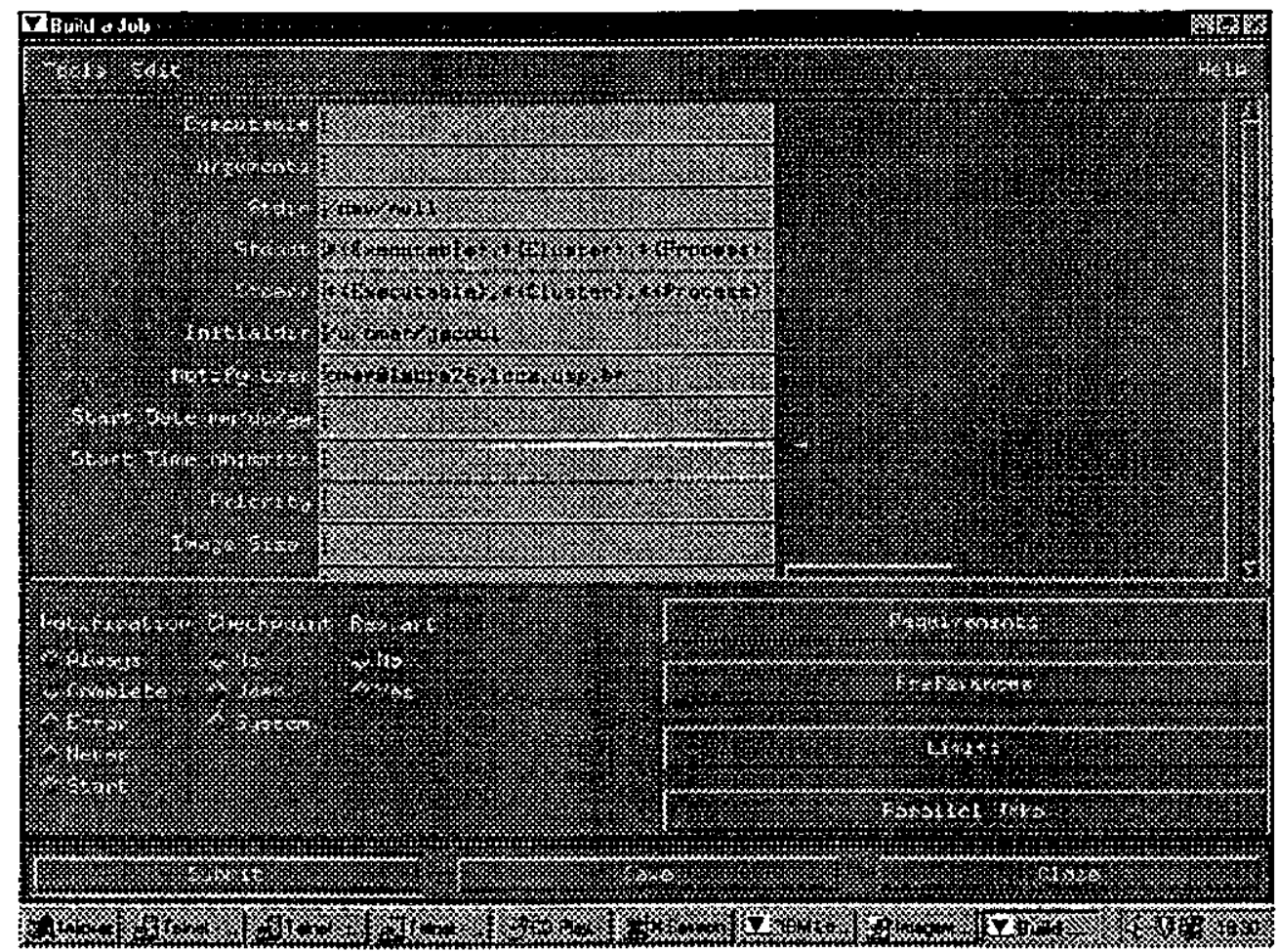

Figura 5.8 - Construindo um arquivo de comandos. 


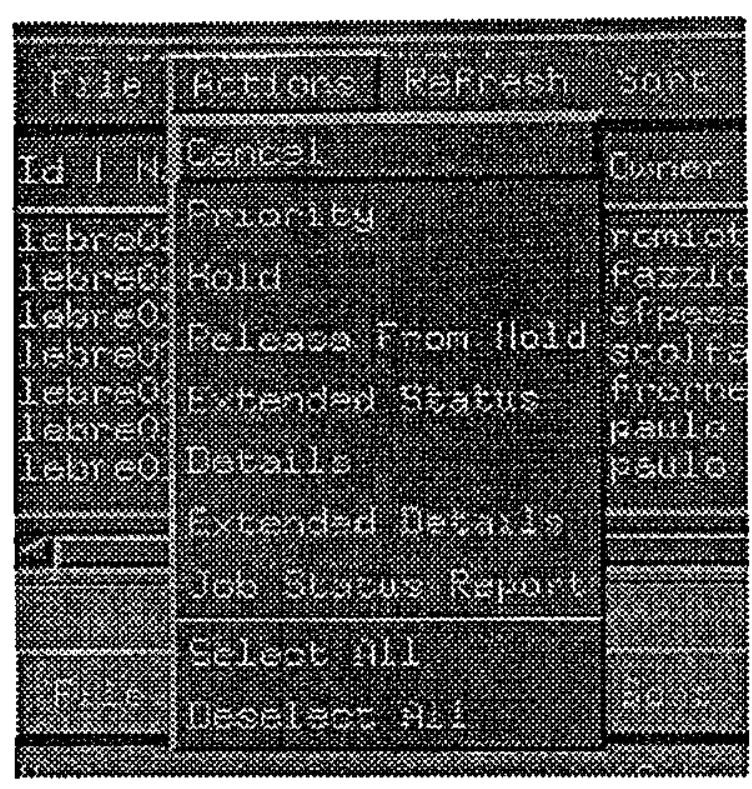

Figura 5.9 - Opçöes do menu actions.

As duas primeiras sub-opções do menu actions na figura 5.9 são as mais importantes pois substituem os comandos llcancel e llprio, respectivamente.

\subsubsection{O Depurador $x p d b x$}

O $x p d b x$ é um depurador gráfico específico para máquinas do tipo SP2 que utilizam o sistema POE, isto quer dizer que só é possível depurar programas feitos em plataformas que rodem sobre POE, por exemplo o MPI. Para iniciá-lo é necessário que se esteja conectado em um dos nós de um computador SP2 (não funciona se executado pela máquina front-end), compilar o programa desejado com a diretiva " $-\mathrm{g}$ " e executar o depurador com o comando:

$x p d b x<$ nome_executóvel $>$-procs $n$

procs $\mathrm{n}$ indica o número de processadores que serão utilizados na depuração. A Figura 5.10 mostra o xpdbx em execução. 


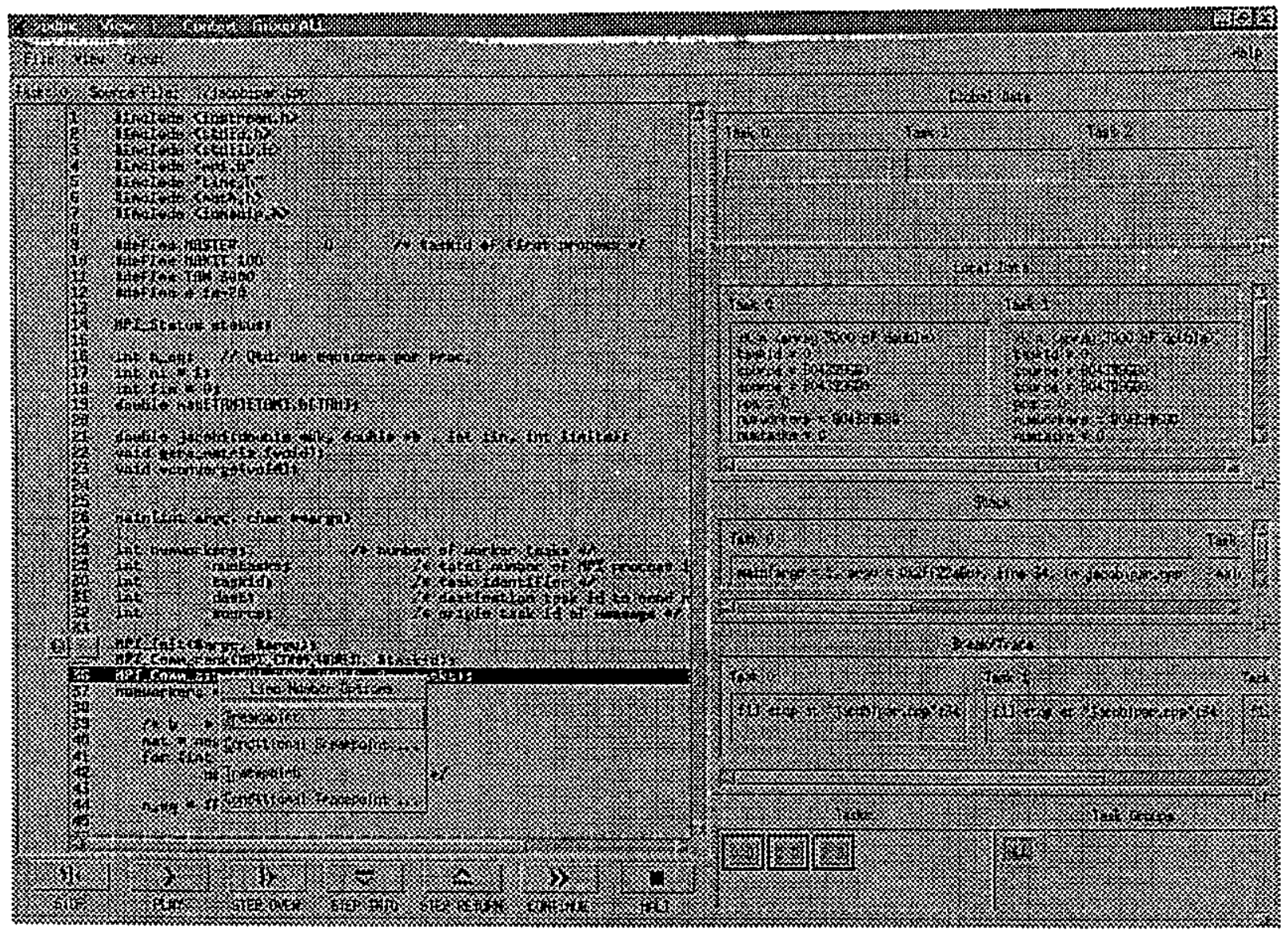

Figura 5.10 - Tela do depurador $x p d b x$.

A parte esquerda da tela exibe o código do programa e seus respectivos pontos de parada. Ao pressionar o botão esquerdo do mouse em uma das linhas exibe-se o menu Line Number Options cuja a principal opção é a de inserir um ponto de parada no programa (Breakpoint).

A parte direita da tela exibe informaçōes sobre as variáveis, sobre a pilha e sobre grupos de processos. A pequena janela denominada de Tasks controla qual processo está sendo depurado e exibe seu respectivo código do lado esquerdo do vídeo. Os processos também podem ser agrupados e sua exibição é controlada pela janela Task Group.

Logo abaixo da região que exibe o código estão os botões de controle e suas respectivas funções que são resumidas na Tabela 5.4. 
Tabela 5.4 - Resumo das funçōes de cada botão no xpdbx.

\begin{tabular}{|l|l|l|}
\hline Botão & Nome & Funçāo \\
\hline & Stop & $\begin{array}{l}\text { Executa o programa até um ponto de parada definido. Se o ponto não for } \\
\text { especificado executa o programa inteiro. }\end{array}$ \\
\hline & Step Over & Executa o programa linha por linha. \\
\hline
\end{tabular}

\subsubsection{Sistemas Cray de Compilação e Execução de Programas}

Os computadores do sistema Cray do LCCA não utilizam bibliotecas de passagem de mensagem, o responsável pelo aumento de desempenho é o compilador que se encarrega de vetorizar o código de acordo com a teoria apresentada no Capítulo 2. Neste contexto, cabe definir algumas diretivas de compilação que foram muito úteis no desenvolvimento deste trabalho e são apresentadas na Tabela 5.5.

Tabela 5.5 - Diretivas utilizadas na compilação vetorial.

\begin{tabular}{|c|c|}
\hline Diretiva & Descriçäo \\
\hline-0 & Utilizada para definir o nivel de otimização da compilação. \\
\hline$-g$ & Cria um executável que pode ser depurado. \\
\hline$\cdot h$ & $\begin{array}{l}\text { Esta diretiva está diretamente relacionada a vetorização, algumas das suas } \\
\text { funçōes são: } \\
\text {-h report = flags: flags podem ser } f, V, s \text {. Quando fé utilizado, o compilador } \\
\text { gera um arquivo com todo o processo de compilação. } V \text { especifica ao } \\
\text { compilador para gerar o relatório somente com os trechos que foram ou não } \\
\text { vetorizados. E finalmente } s \text {, diz ao compilador para verificar a otimização } \\
\text { feita no código escalar. } \\
\text {-h vectorN: } N \text { especifica o grau de vetorização, que pode ser } 0,1,2 \text { ou } 3 . \\
\text { Zero indica que o compilador não deve executar nenhum tipo de } \\
\text { vetorização. Um define um baixo nivel de vetorização. Dois determina um } \\
\text { nivel médio e três especifica um grau alto de vetorização. } \\
\text { OBS: Caso seja necessário impedir a vetorização a diretiva -O não deve } \\
\text { ser utilizada pois ela também indica automaticamente níveis de vetorização. }\end{array}$ \\
\hline
\end{tabular}

A utilização do compilador é relativamente simples e segue a seguinte sintaxe:

$C C-o<$ nome do executável $><$ nome do programa.C $>$-diretivas 
Existem ainda as diretivas de compilação definidas como \#pragma. Elas são utilizadas junto ao código de uma aplicação, devem estar sempre antes do laço a ser analisado e instruem o compilador a ignorar dependências de dados quando possível, evitar as pesquisas de laços, forçar a tentativa de vetorização, etc. A Tabela 5.6 [Cra98] resume as principais características da diretiva e a Figura 5.11 mostra um exemplo de sua utilização. Em seguida é apresentado como os programas são submetidos as máquinas do tipo Cray.

Tabela 5.6- Diretivas pragma e sua utilização.

\begin{tabular}{|l|l|}
\hline Diretiva & Funçāo \\
\hline \#pragma_CRI ivdep & $\begin{array}{l}\text { Utilizado para ignorar as dependéncias de dados. Geralmente utilizado } \\
\text { quando o laço está trabalhando com variáveis ponteiro ou com matrizes. } \\
\text { No caso de matrizes o laço é substituído por uma biblioteca de funçöes } \\
\text { do próprio Cray. }\end{array}$ \\
\hline \#pragma_CRI novector & Utilizado para ignorar a vetorização do laço a seguir. \\
\hline \#pragma_CRI prefervector & $\begin{array}{l}\text { Dentro de laços aninhados esta diretiva especifica qual ó o laço que } \\
\text { deve ter preferéncia na vetorização. Deve ser utilizada antes do primeiro } \\
\text { laço e a diretiva \#pragma_CRl ivdep deve estar precedendo o laço } \\
\text { preferencial. }\end{array}$ \\
\hline
\end{tabular}

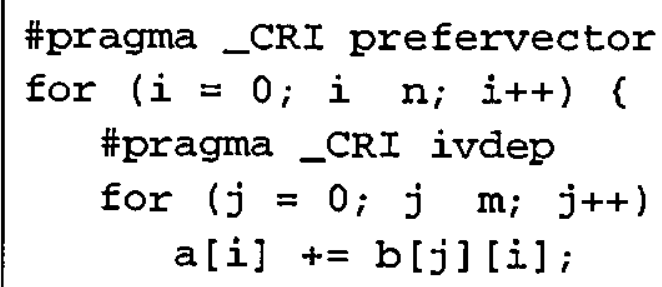

Figura 5.11 - Exemplo de utilização da diretiva \#pragma.

\section{Submetendo programas ao sistema Cray}

Para executar tarefas num computador Cray, mais especificamente nas máquinas disponíveis no LCCA, é necessário utilizar um pequeno script como mostra a Figura 5.12.

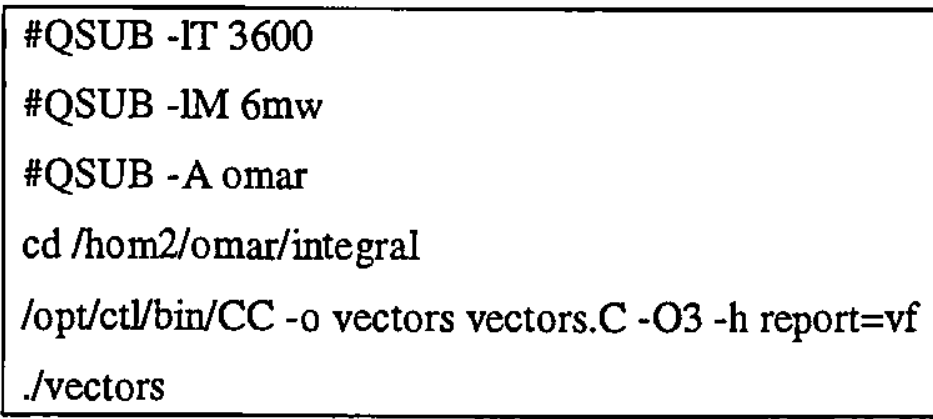

Figura 5.12 - Exemplo de um arquivo de submissão no Cray. 
Na primeira linha é solicitado 3600 segundos de execução que equivale a uma hora de utilização, caso esse limite seja ultrapassado será gerado um arquivo informando o erro ocorrido. A segunda e a terceira linha, alocam 6 Megawords de memória para o usuário omar. A quarta linha vai até o diretório onde o programa se encontra. A quinta linha compila o programa gerando o relatório de vetorização. E finalmente a última linha submete o programa a execução. Esse script deve ser submetido com o comando qsub <nome do arquivo>. Os principais comandos de controle são:

$q s u b<$ arquivo.sh > : submete um job na fila de execução.

qstat - $a$ : mostra a fila de execução e seu estado

$q d e l-k<$ numero_do_processo $>$ : retira um job da sua execução

Como as máquinas do LCCA possuem 12 (dolphin) e 4 (boto) processadores cada uma, é necessário também configurar uma variável de ambiente chamada NCPU e por se tratar de um sistema operacional Solaris a configuração é feita com o comando setenv $N C P U N$, onde $N$ é a quantidade de processadores que se deseja utilizar. Para o caso deste trabalho o valor de $N$ pode ser 2 ou 3. A próxima seção trata de como o PVM e o MPI estão configurados no LAASD-PC.

\subsubsection{PVM e MPI no LASD-PC}

No LASD-PC estão disponíveis o PVM 3.0 nas versões para Linux e Windows 95 e o MPI (MPICH) para Linux. Neste trabalho só foram utilizadas as versões para Linux.

Com relação ao MPI basta compilar o programa com um arquivo Makefile que contém todos os caminhos e diretivas necessárias para a compilação. Depois basta executar a aplicação com o comando:

$$
\text { mpirun-np } 3<\text { arquivo_executável> }
$$

Para utilizar o PVM, também compila-se o programa utilizando um arquivo Makefile. A execução pode-se dar através da utilização do console do PVM. Para iniciar o console basta digitar-se $p v m$, o que fará surgir o prompt "pvm>". A partir desse prompt os programas são executados. Para iniciar uma aplicação digita-se o seguinte comando:

$$
\text { spawn }->/ \text { caminho/<arquivo_executavel> }
$$


Se o caminho não for especificado, o arquivo executável deve estar no caminho indicado pela variável PVM_ARCH que é configurada quando o PVM é instalado. O símbolo de menos seguido pelo símbolo de maior indica ao console que a saída de todos os programas incluindo a saída dos escravos será direcionada para o vídeo.

Os programas podem também ser executados fora do console, sendo necessário neste caso que o deamon do PVM esteja rodando. Isso é feito inicializando o console e saindo do mesmo com o comando quit. Além disso, dentro do código é necessário uma pequena alteração, a adição do comando pvm_addhosts que tem a seguinte sintaxe:

$$
\text { info = pvm_addhosts(hosts, qm, infos) }
$$

hosts é uma variável ponteiro que contém o nome das máquinas que serão adicionadas a máquina paralela virtual, no caso deste trabalho todas as aplicações terão nessa variável algo do tipo:

$$
\text { char *hosts[]=("lasd06","lasd08") }
$$

A máquina lasd07 não precisa ser adicionada pois é nela que as tarefas mestres estão sendo executadas. A variável qm indica quantas máquinas serão adicionadas e infos é um endereço de memória que contém o status de cada máquina iniciada. Caso esta linha não seja adicionada, o programa retornara um erro chamado "pvm_send error". A Tabela 5.7 resume os principais comandos do console do PVM.

Tabela 5.7- Resumo dos comandos do console PVM.

\begin{tabular}{|l|l|}
\hline Comando & Descriçäo \\
\hline conf & Exibe quais hosts fazem parte da máquina paralela virtual \\
\hline add & Adiciona um host à máquina paralela virtual. \\
\hline delete & Retira um host da máquina paralela virtual. \\
\hline spawn & Inicia um programa na máquina em que o console está sendo executado. \\
\hline quit & Sai do console mantendo o deamon rodando. \\
\hline halt & Sai do console e retira o deamon do pvm de execução. \\
\hline
\end{tabular}

\subsubsection{Visualization Tool (VT)}

A Visualization Tool é uma ferramenta de apoio a analise de desempenho. Através dela é possível analisar aspectos importantes da programação concorrente tais como o balanceamento de carga, utilização do processador, utilização da máquina pelos usuários, tempo de espera do processador e comunicação entre processos. A Figura 5.13 mostra a tela inicial onde são 
escolhidos os modos de exibição de desempenho. No andamento deste trabalho somente foram observados o balanceamento de carga e a utilização do processador.

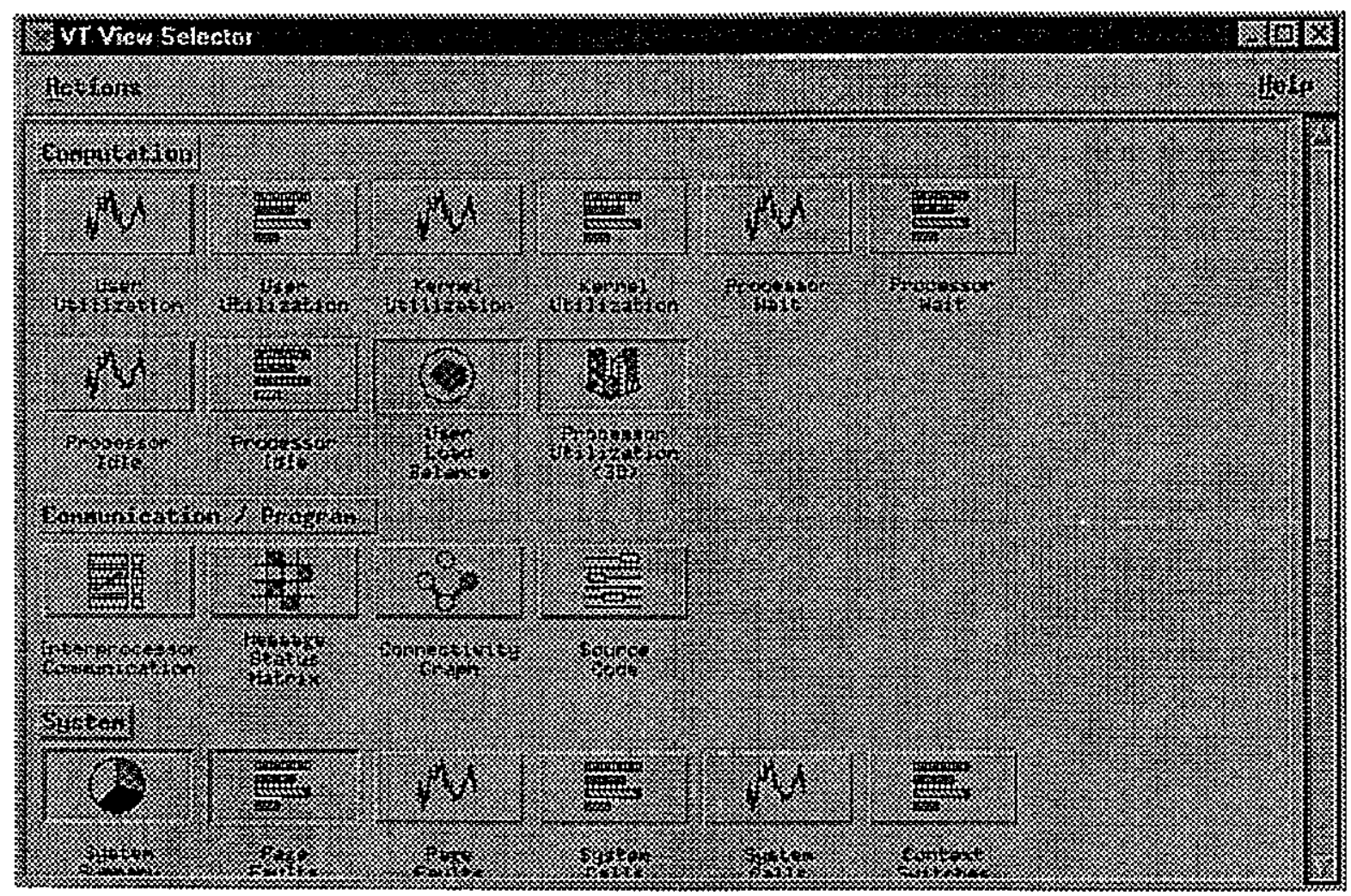

Figura 5.13-Tela do seletor de fanelas.

Esta ferramenta pode reproduzir a execução de um programa repetindo todos os eventos que ocorreram desde seu início até seu término. Para realizar esse replay são salvos todos os estados do sistema de tempo em tempo. Antes de sua execução são necessários alguns ajustes nas variáveis de sistema. Ao todo são quatro variáveis que são mostradas na Tabela 5.8 e para definilas é utilizada sempre a mesma sintaxe mostrada abaixo:

\section{setenv VARIAVEL valor ou export VARIÁVEL=valor}

Tabela 5.8- Variáveis de sistema utilizadas pelo VT.

\begin{tabular}{|l|l|l|}
\hline Variävel & \multicolumn{1}{l}{ Valores } & \multicolumn{1}{l|}{ Funçäo } \\
\hline MP_TRACELEVEL & $0,1,2,3,9$ & Especifica o nivel de captura de eventos. \\
\hline MP_SAMPLEFREQ & $\mathrm{N}$ & Configura o intervalo de tempo para captura. \\
\hline MP_PROCS & $\mathrm{N}$ & Define a quantidade de processadores utilizados. \\
\hline RM_POOL & $\mathrm{N}$ & $\begin{array}{l}\text { Determina quantos processos são executados por } \\
\text { processador }\end{array}$ \\
\hline
\end{tabular}


O comando setenvé utilizado em sistemas Solaris e o export no IBM-AIX.

A primeira variável a ser configurada é a MP_TRACELEVEL que define quais tipos de capturas de eventos são possíveis. A Tabela 5.9 mostra os flags que podem ser usados e o que cada um deles permite capturar. Geralmente o mais utilizado é o flag com valor nove pois com ele tem-se uma gama maior de possibilidades na análise de desempenho.

Tabela 5.9 - Flags e eventos que podem ser capturados.

\begin{tabular}{|l|c|c|c|c|}
\hline Flag & $\begin{array}{c}\text { Passagem de } \\
\text { Mensagem }\end{array}$ & $\begin{array}{c}\text { Comunicação } \\
\text { Coletiva }\end{array}$ & $\begin{array}{c}\text { Estatisticas do } \\
\text { Núcleo }\end{array}$ & $\begin{array}{c}\text { Marcas em } \\
\text { Programas }\end{array}$ \\
\hline 0 & & & & \\
\hline 1 & & & $\mathrm{X}$ & $\mathrm{X}$ \\
\hline 2 & & & $\mathrm{X}$ & $\mathrm{X}$ \\
\hline 3 & $\mathrm{X}$ & $\mathrm{X}$ & $\mathrm{X}$ & $\mathrm{X}$ \\
\hline 9 & $\mathrm{X}$ & $\mathrm{X}$ & $\mathrm{X}$ & \\
\hline
\end{tabular}

Ainda seguindo a Tabela 5.8, a segunda variável que deve ser configurada é a MP_SAMPLEFREQ que define a frequiência com que os eventos devem ser capturados, sendo que o intervalo mais utilizado é o de dez mili-segundos, ou seja, de dez em dez mili-segundos ocorre a captura de um estado do sistema.

A terceira variável que deve ser especificada é a MP_PROCS que simplesmente determina quantos processadores serão utilizados na execução do programa.

E, finalmente, a variável RM_POOL especifica quantos processos vão ser iniciados em cada processador da máquina.

Com tudo definido, basta executar o programa que vai gerar um arquivo com o mesmo nome adicionando-se um ".trc". Por exemplo, se for executado um programa chamado teste.executavel será criado um arquivo chamado teste.executavel.trc que contém todos os eventos que ocorreram durante sua execução. Nota-se que a execução não pode se dar por filas de LoadLever porque isso impedirá a criação do arquivo ".trc".

Após todo esse processo a tela da Figura 5.14 estará liberada para utilização, ou seja, para reproduzir a execução de um programa. Ela funciona de maneira análoga a um painel de videocassete sendo de fácil utilização. 


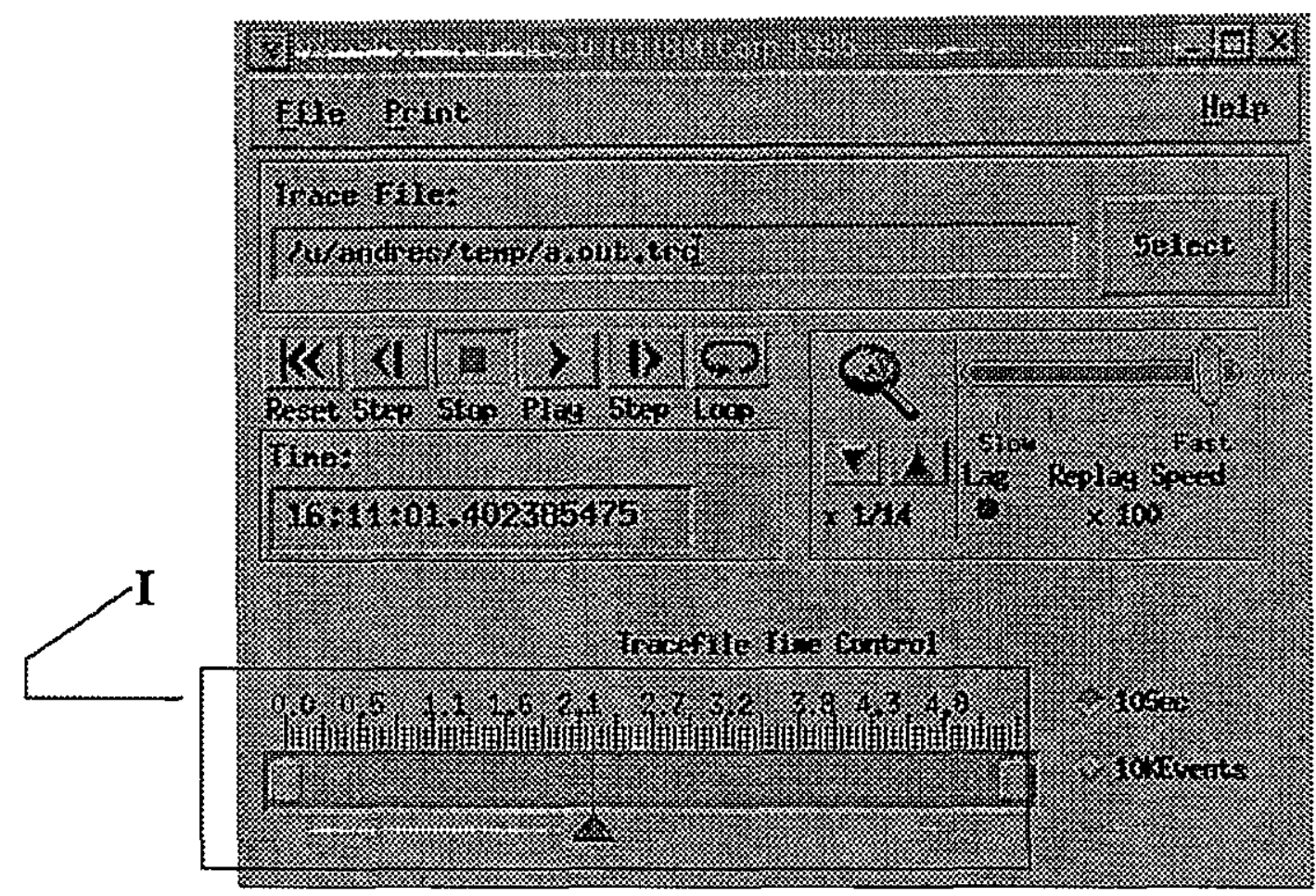

Figura 5.14-Tela de replay.

Destaca-se a parte I, Figura 5.14, onde através dela pode-se posicionar o cursor em forma de triângulo e visualizar o desempenho desejado naquele instante de tempo. A Figura 5.15 mostra as janelas que serão utilizadas neste trabalho, porcentagem de uso do processador (a), balanceamento de carga (b) e comunicação entre processadores (c) quando necessário.

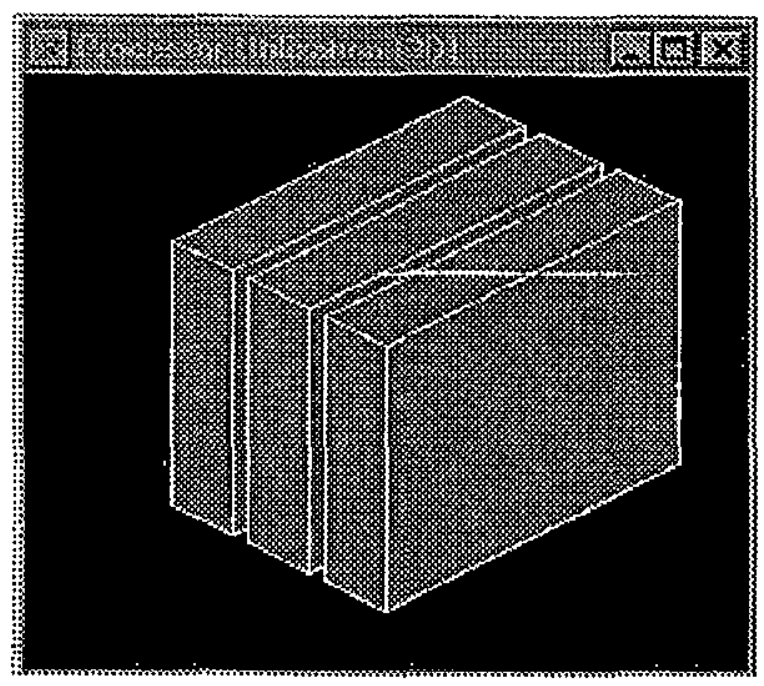

(a)

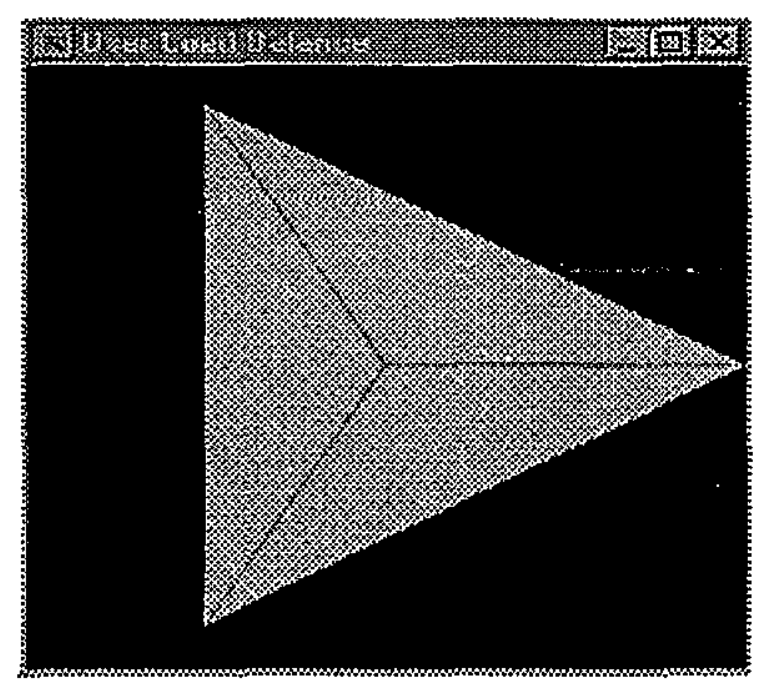

(b)

Figura 5.15 - Janelas de desempenho 


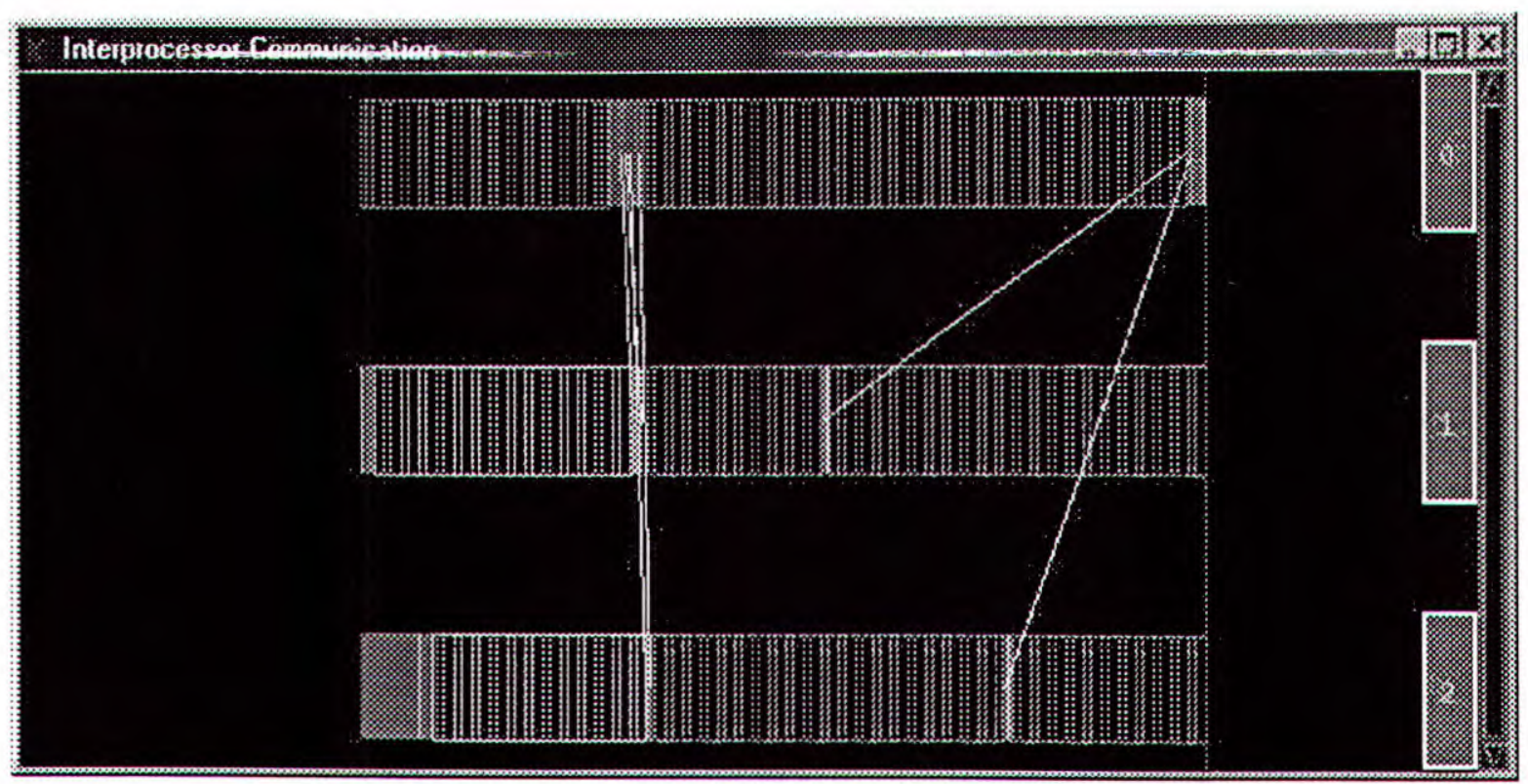

(c)

Figura 5.15 - Janelas de desempenho

\subsubsection{HPM - Hardware Performance Monitor}

Para validar os dados encontrados em $F_{B}(N)$, ou seja, para ter uma idéia aproximada de quantas operações em ponto flutuante foram realizadas pela aplicação, foi utilizado um software chamado hpm para sistemas Cray. Seu funcionamento é extremamente simples e para ativa-lo basta usar a seguinte sintaxe:

$$
\text { hpm-gn <nome do executável > }
$$

Sendo que n representa o grupo de hardware ao qual o programa será analisado, a Tabela 5.10 mostra a utilização de cada grupo.

Tabela 5.10 - Utilização de grupos no $\mathrm{hpm}$.

\begin{tabular}{|l|l|}
\hline Grupo & Elementos \\
\hline 0 & Sumário da execução, este grupo é considerado o padrão. \\
\hline 1 & Mantém algumas condições pré-definidas \\
\hline 3 & Atividade de memória. \\
\hline 4 & Eventos vetorias e sumário da execução. \\
\hline
\end{tabular}

Dara efetuar uma medição das operações em ponto flutuante foi utilizado o grupo zero (os mais grupos não são permitidos para usuários sem permissão de administrados) sendo que o ograma foi compilado sem nenhum grau de vetorização pois o valor procurado é o de $F_{B}(N) o$ 
qual pode ser aproximado. A Figura 5.16 apresenta um sumário emitido pelo hpm para um dos programas desenvolvidos.

$\begin{array}{llrlr}\text { Group 0: CPU seconds : } & 135.41 & \text { CP executing } & : & 13540954818 \\ \text { Milion inst/sec (MIPS) : } & 47.95 & \text { Instructions } & : & 6492793799 \\ \text { Avg. clock periods/inst : } & 2.09 & & \\ \text { \& CP holding issue } & : & 40.59 & \text { CP holding issue : } & 5496496936 \\ \text { Inst.buffer fetches/sec : } & 0.00 \mathrm{M} & \text { Inst.buf. fetches : } & 1338 \\ \text { Floating adds/sec } & : & 6.93 \mathrm{M} & \text { F.P. adds } & 938533815 \\ \text { Floating multiplies/sec : } & 4.79 \mathrm{M} & \text { F.P. multiplies : } & 648891104 \\ \text { Floating reciprocal/sec : } & 0.00 \mathrm{M} & \text { F.P. reciprocals : } & 2 \\ \text { I/O mem. references/sec : } & 1.37 \mathrm{M} & \text { I/O references : } & 186054973 \\ \text { CPU mem. references/sec : } & 4.76 \mathrm{M} & \text { CPU references : } & 645200027 \\ \text { Floating ops/CPU second : } & 11.72 \mathrm{M} & & \end{array}$

Figura 5.16 - Exemplo de um sumário emitido pelo hpm.

\subsubsection{Totalview}

O totalview é um poderoso depurador para sistemas Cray. Para utilizá-lo basta compilar o programa com a diretiva $-\mathrm{g}$ e executá-lo com a instrução totalview <nome_do_programa>, a Figura 5.14 mostra a tela de execução do depurador.

A utilização dos botões encontrados logo acima do código do programa é semelhante a dos botões apresentados na Tabela 5.4. Este depurador é mais fácil de utilizar do que o xpdbx, pois a execução é vista numa única tela, sem a necessidade de criar grupos de processos e janelas para visualizar cada processo/processador. A opção mais importante é a display variable que é mostrada na Figura 5.18(a). Essa op̧̧ão abre uma janela exibida na Figura 5.18(b) onde serão inseridas as variáveis que se deseja visualizar, estas devem ser inseridas uma por uma. $\mathrm{E}$ finalmente, a Figura 5.18(c) apresenta como os dados das variáveis desejada são exibidos. Não existe um limite para a quantidade de variáveis que se deseja depurar. 


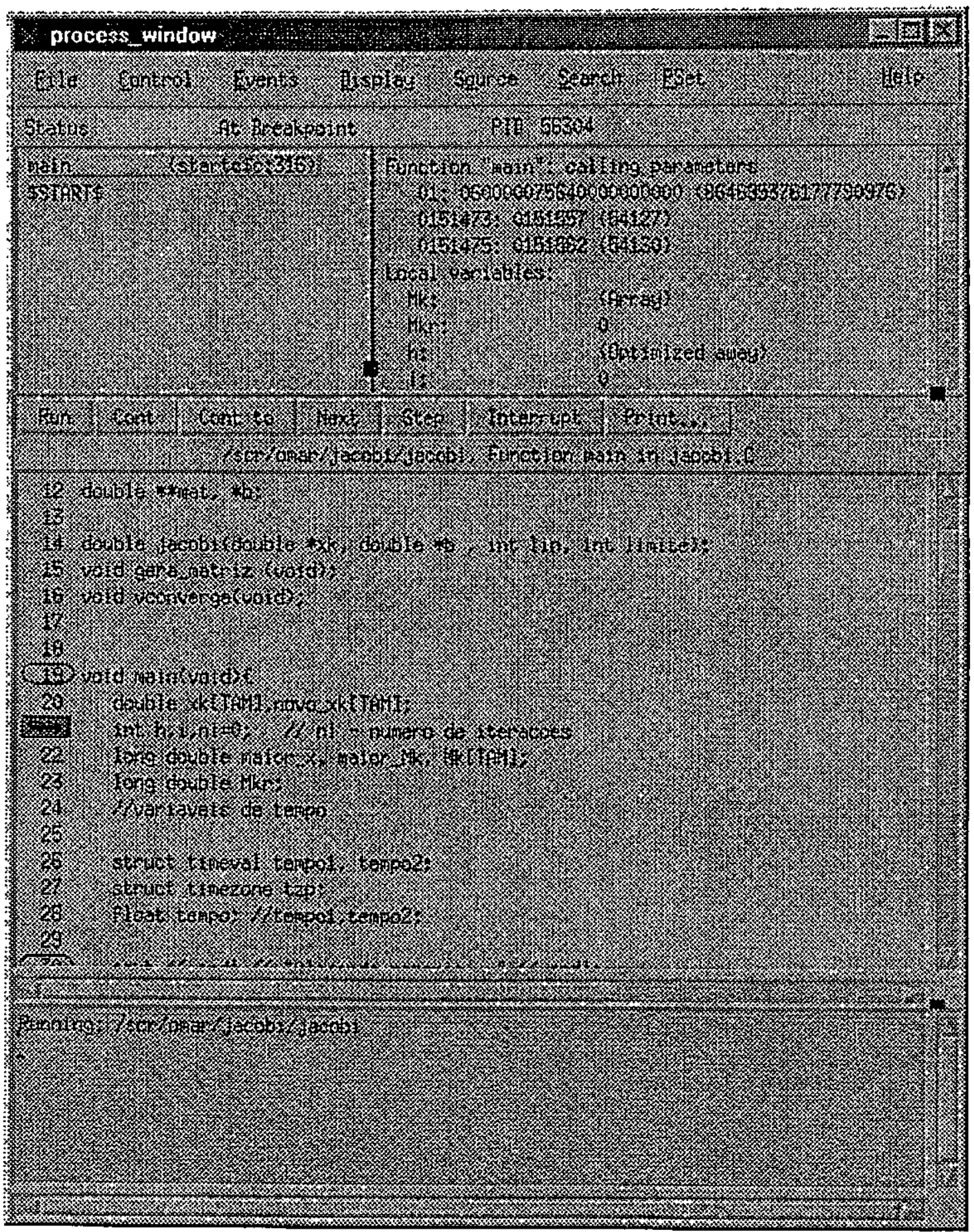

Figura 5.17 - Tela do totalview (depurador) para sistemas Cray. 


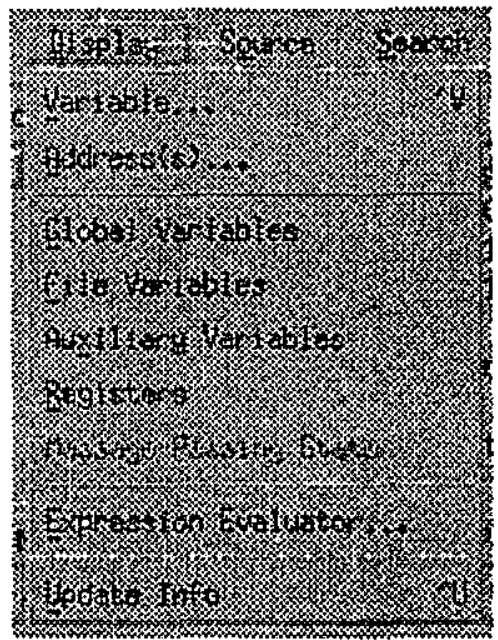

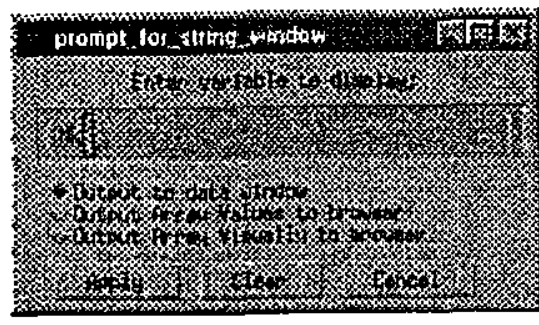

(b) - Janela onde são inseridas as variáveis.

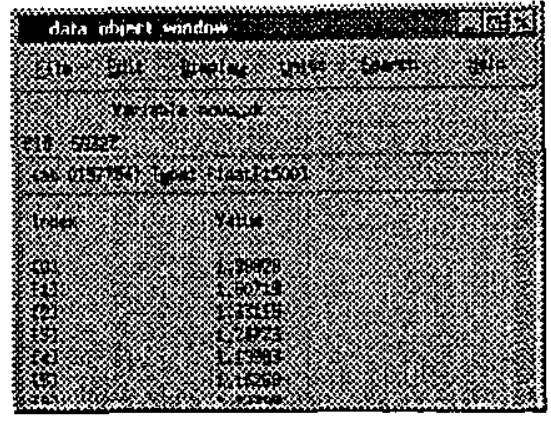

(c) - Apresentação de variáveis.

(a) - Opção display-variable.

Figura 5.18 - Opf̧̃̃es mais importantes do totalview.

\subsubsection{Proofview}

Este é um programa que de maneira geral pode fornecer uma visão aproximada da vetorização alcançada num programa quando os gráficos de ambos (sequiencial e vetorizado) são comparados. Para visualizar as informações desejadas é necessário executar os seguintes comandos:

Compilar o programa com: $C C-G p-l$ prof $-l$ sci matrix. $C$, que indica que o profview será utilizado;

Em seguida é necessário executar o programa;

Executar o comando prof com a seguinte sintaxe: prof $-x$ a.out $>$ prof.raw, que irá gerar uma saída contendo as informações sobre a execução no arquivo prof.raw;

E finalmente executar o profview com o seguinte comando: profview prof.raw, que exibirá uma tela como mostrada na Figura 5.19. 


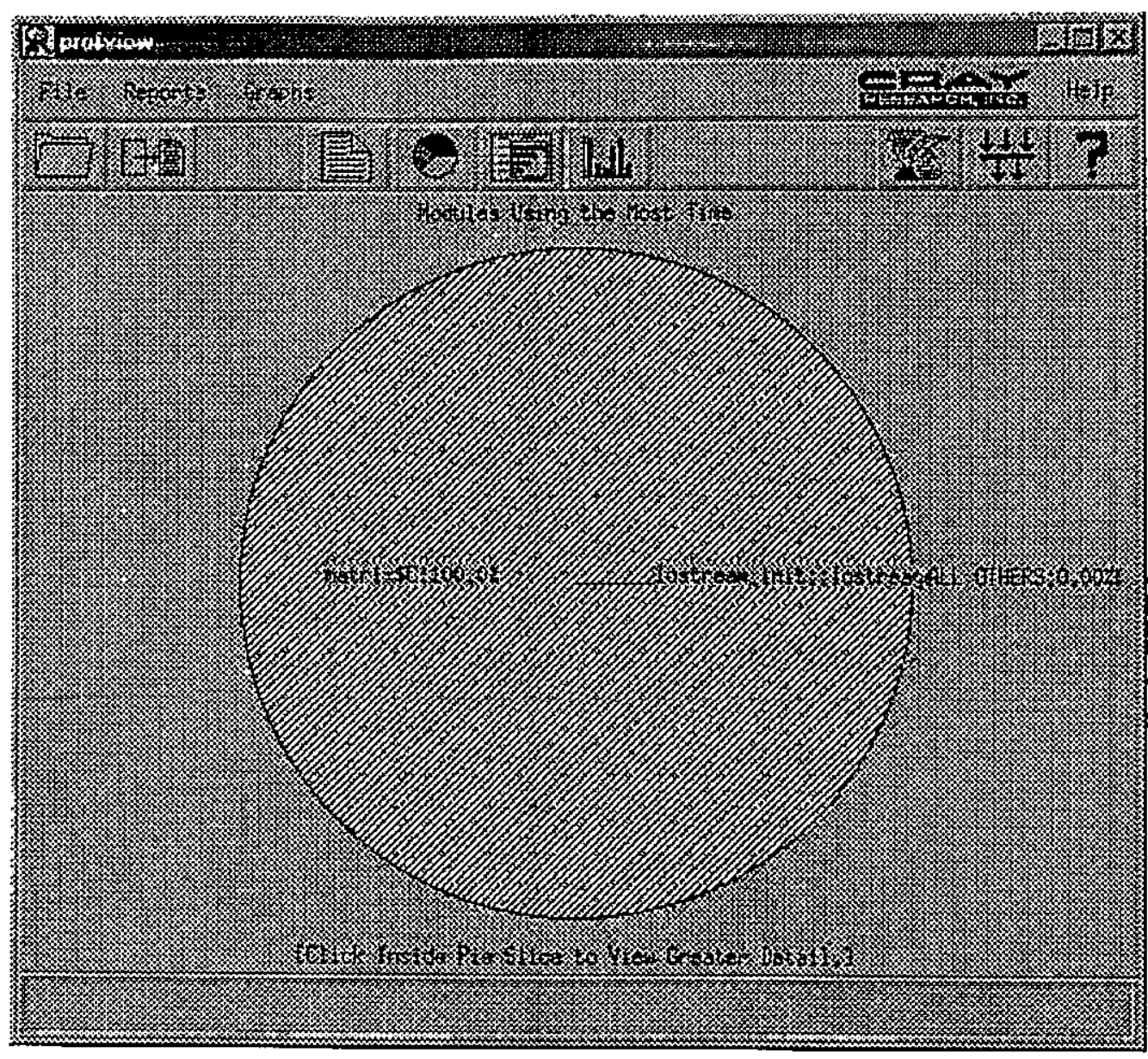

Figura 5.19 - Tela do proofview.

Nesta figura vê-se a execução do programa de multiplicação de matrizes sem vetorização, essa informação é dada no centro do gráfico com o nome de matrix\$C:100\%. Quando a vetorização é realizada o gráfico é dividido em mais pedaços como será visto na seção 7.3 do Capítulo 7 .

\subsection{Considerações Finais}

Neste capítulo foi descrito todo o ambiente utilizado para o desenvolvimento e execução das aplicações numéricas. Nota-se ainda uma falta considerável de programas. Por exemplo, foi encontrado um monitor de desempenho para sistemas SP2 que s6 é executado no modo supervisor, caso ocorra um travamento no programa, todo o sistema seria parado e a máquina deveria ser reiniciada inviabilizando sua utilização. Por esse motivo não se tem exatamente a quantidade de operações em ponto flutuante dessa máquina. Além de que falta um depurador gráfico para o PVMe.

Com relação ao hpm, geram-se informações sobre toda a execução do programa o que não é interessante no caso de benchmarking pois só um trecho do programa deve ser levado em 
consideração, além de que as operações de divisão não são registradas pelo monitor devido a sua pouca utilização. Esses fatos levaram o hpm a ser utilizado apenas para ter uma noção da quantidade de operações em ponto flutuante utilizadas o que muitas vezes pode se distanciar da quantidade encontrada pelos contadores dentro do código.

O VT apesar de prover uma grande quantidade de informações só foi utilizado para verificar se o balanceamento de carga foi feito adequadamente e se os processadores estão ociosos em algum instante de tempo.

O próximo capítulo apresenta, em detalhes, como os algoritmos mostrados no Capítulo 4 foram paralelizados e implementados em MPI, PVM e nas máquinas Cray. 


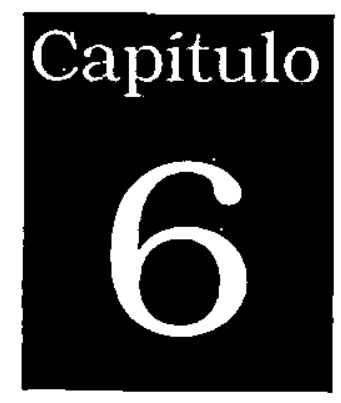

\section{Aplicações}

Neste capítulo apresenta-se como os algoritmos numéricos mostrados no Capítulo 4 foram paralelizados e implementados utilizando as bibliotecas de passagem de mensagem MPI e PVM. Foram utilizados dois e três processadores em todo desenvolvimento. A compilação e execução do NAS Parallel Benchmark também é discutida.

\subsection{Método de Jacobi}

Neste método o primeiro passo é criar as matrizes que serão utilizadas, a mesma geração é feita por todos os processadores utilizados. Isto é feito utilizando-se uma função encontrada no LINPACK benchmark que sofreu pequenas alterações para produzir apenas números positivos. Em seguida foi criada uma função denominada vconverge() que transforma a matriz gerada numa matriz convergente que segue as regras descritas a seguir:

- Ser diagonalmente dominante, isto é, que não exista nenhum número nulo na sua diagonal principal. Esta regra é satisfeita logo na geração das matrizes que não permite a criação de números nulos. 
- que a soma dos números em linhas ou colunas seja menor que o valor da sua respectiva diagonal principal como mostrado a seguir:

$$
a_{n n}>\sum_{m=1}^{n} a_{n m}
$$

Para satisfazer essa condição, a função vconverge( ) atribui ao elemento diagonal de cada linha o somatório de todos os elementos da linha somando seu resultado com o respectivo elemento da diagonal principal. Por exemplo, se a linha de índice 2 fosse $\{2,4,5,7\}$ após a execução da função ela corresponderia a $\{2,18,5,7\}$. A seguir é dada a demonstração matemática dessa regra.

$$
\begin{aligned}
& a_{22}>\sum_{m=1}^{4} a_{2 m}, m \neq 2 \\
& a_{22}>2+5+7 \\
& a_{22}>14 \\
& \text { Depois da execução da função vconverge() } \\
& a_{22}=18 \Rightarrow a_{22}>14
\end{aligned}
$$

Após a geração da matriz e de efetuada a convergência, é criado o vetor b. Nessa operação é feita uma soma de todos os elementos de cada linha e atribuído a respectiva posição do vetor $b$. Dessa forma as equações geradas sempre terão a solução $x[1]=x[2]=x[3]=\ldots=x[n]=1$. A aproximação inicial é dada por um vetor de zeros, e esta pode ser configurada facilmente alterando-se apenas uma linha de código.

A abordagem de programação utilizada foi a SPMD e segue a estrutura da Figura 6.1. A quantidade de equações tem que ser divisível por três e por dois processadores ao mesmo tempo para que possa ser efetuada uma comparação dos speedups encontrados. 


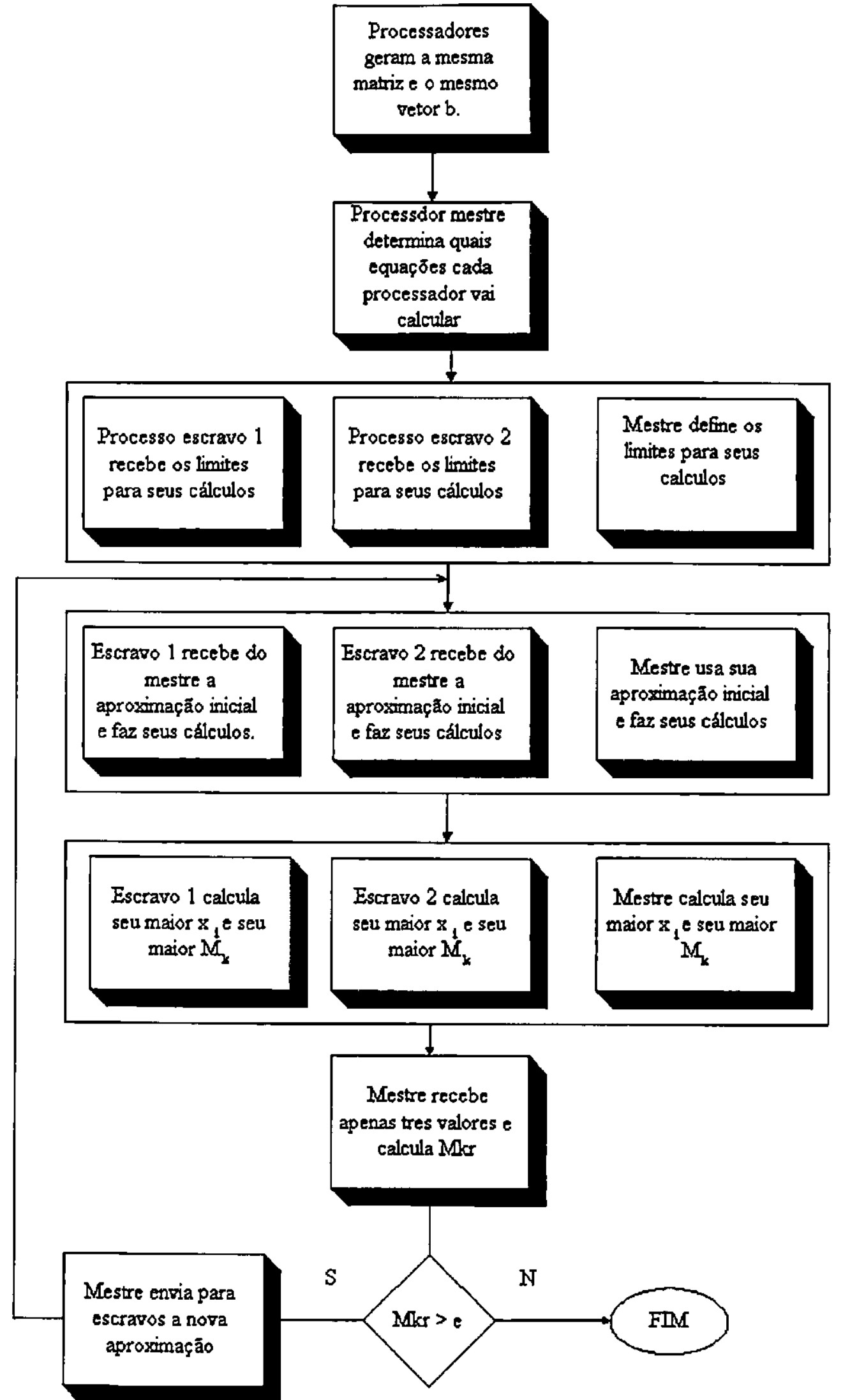

Figura 6.1-Estrutura da paralelização do algoritmo de Jacobí para 3 processadores.. 


\subsection{Método dos trapézios composto}

Este método soluciona uma integral definida pela aproximação de diversos trapézios. Este algoritmo é considerado pouco preciso quando são utilizadas poucas divisões, por esse motivo, as integrais foram divididas em um número grande e crescente de trapézios.

A paralelização foi realizada através de uma pequena propriedade das integrais, onde, dada uma função qualquer $\mathrm{f}(\mathrm{x})$ que pode ser integrada nos pontos de a até $\mathrm{b}$, ela pode ser divida na soma de duas outras integrais definidas como mostrado a seguir:

$$
\int_{a}^{b} f(x) d x=\int_{a}^{b / 2} f(x) d x+\int_{b / 2}^{b} f(x) d x
$$

Por exemplo:

$$
\int_{0}^{1} \frac{1}{x} d x=\int_{0}^{0.5} \frac{1}{x} d x+\int_{0.5}^{1} \frac{1}{x} d x
$$

Dessa mesma forma essa integral pode ser dividida no somatorio de $\mathrm{n}$ outras integrais definidas, onde cada uma delas pode ser calculada por um processo ou processador, como no SP2 do CISC está-se limitado em um processo por processador essa integral foi inicialmente dividida em três e posteriormente somente em duas. A Figura 6.2 mostra um diagrama de paralelização para 3 processadores. Pode-se considerar possível a divisão em um processo tornando o cálculo como de uma integral tradicional, mas os comandos de passagem de mensagem irão interferir no tempo de execução, desta forma nesse caso é aconselhável utilizar o programa seqüencial.

De forma análoga ao método de Jacobi a quantidade de trapézios dentro da área desejada também deve ser divisível por 2 e por 3 ao mesmo tempo. Por exemplo, uma integral que no modo seqüencial foi dividida em 9 milhões de trapézios em três processadores cada um foi responsável por calcular uma integral com 3 milhões de divisões e em 2 processadores cada um usou 4,5 milhões de trapézios.

A região para cálculo, ou seja, a diferença entre a e b, também deve apresentar essa propriedade de ser divisível por 2 e por 3 ao mesmo tempo. O intervalo utilizado na execução foi de $a=0$ e $b$ $=1,2$. As integrais ficaram divididas da seguinte forma: 


$$
\begin{gathered}
\int_{0}^{1,2} f(x) d x=\int_{0}^{0,6} f(x) d x+\int_{0,6}^{1,2} f(x) d x: \text { para } 2 \text { processadores; } \\
\int_{0}^{1,2} f(x) d x=\int_{0}^{0,4} f(x) d x \int_{0,4}^{0,8} f(x) d x \int_{0,8}^{12} f(x) d x \text { : para } 3 \text { processadores. }
\end{gathered}
$$

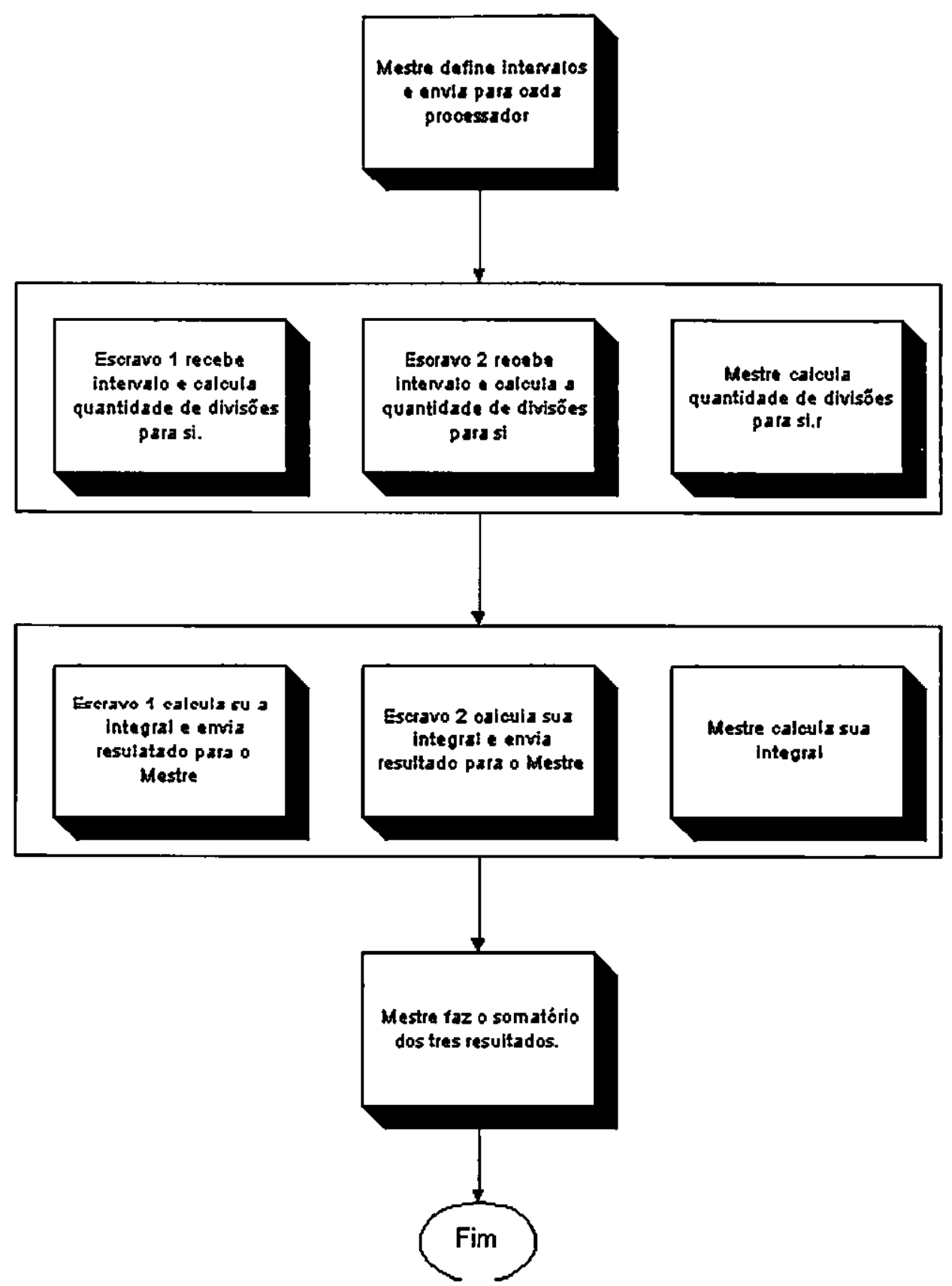

Figura 6.2 - Paralelização do algoritmo do trapézlo composto. 


\subsection{Multiplicação de matrizes}

O terceiro e último algoritmo desenvolvido foi o de multiplicação paralela de matrizes. Sua escolha deve-se a grande quantidade de operações em ponto flutuante exigida para a solução utilizando o algoritmo tradicional de complexidade $\mathrm{n}^{3}$.

A paralelização foi feita da seguinte maneira:

A geração das matrizes A e B é feita de forma semelhante ao do método de Jacobi, criando-se duas matrizes quadradas. $\mathrm{O}$ processo mestre gera a matriz $\mathrm{A}$, e ao mesmo tempo os processos escravos geram a mesma matriz B. Ao terminarem o processo, o mestre manda a sua matriz gerada A para os processos escravos, e um dos processos escravos envia a matriz B para 0 mestre. De posse dos dados o mestre envia aos escravos a posição da linha onde cada processo iniciará a sua parte da multiplicação. Todos os processadores executam a multiplicação incluindo o mestre. No final do processamento os escravo mandam os respectivos pedaços calculados para o mestre. A Figura 6.3 mostra um diagrama da paralelização.

Por exemplo, se as matrizes geradas tiverem o tamanho de $90 \times 90$ ocorrerá o seguinte processamento:

- Mestre gera uma matriz A90x90 e escravos geram a matriz B90x90 ao mesmo tempo;

- Mestre envia matriz A para escravos;

- Mestre e escravos calculam a quantidade de linhas que cada um irá trabalhar;

- Escravo 1 envia a matriz B para o mestre;

- Mestre envia a posição zero para escravo 1;

- Mestre envia a posição 30 para escreavo2;

- Escravo 1 realiza a multiplicação da linha 0 até a linha 29;

- Escravo 2 realiza a multiplicação da linha 30 até a linha 59;

- Mestre realiza a multiplicação da linha 60 até a linha 89;

- Escravo 1 envia da linha 0 a linha 29 da matriz C; 
- Escravo 2 envia da linha 30 a linha 59 da matriz C;

- Mestre recebe as respectivas linhas e as junta a seu resultado.

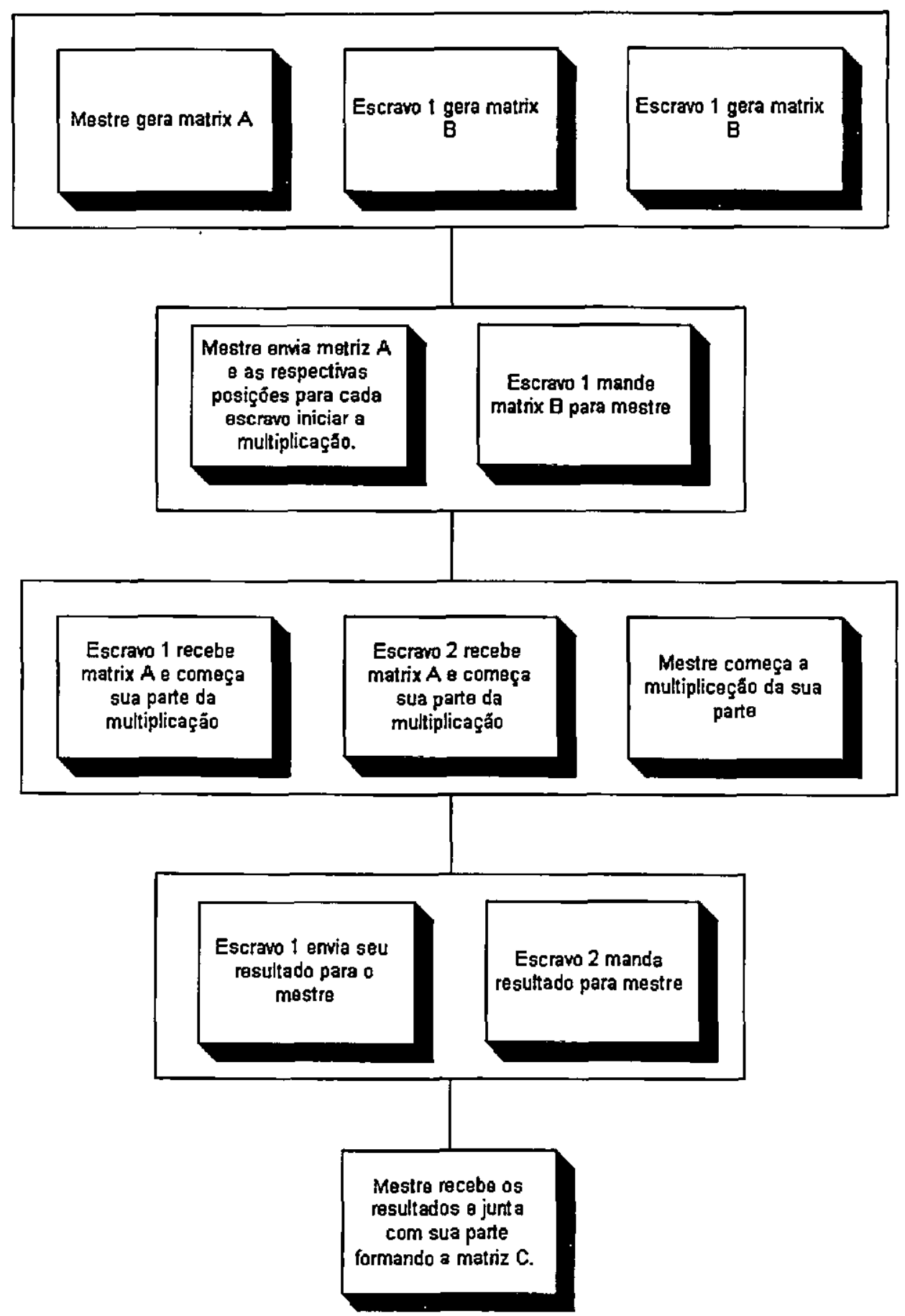

Figura 6.3 - Paralelização do aigoritmo de multiplicação de matrizes. 


\subsection{Paralelização vetorial}

Para todas as aplicações desenvolvidas no sistema Cray foram utilizadas as versōes seriais implementadas de modo a se atingir um bom grau de vetorização. Cabe uma observação ao programa de multiplicação de matrizes que teve no seu código uma diretiva \#pragma adicionada para forçar a vetorização como pode ser visto no pequeno trecho de código da Figura 6.4.

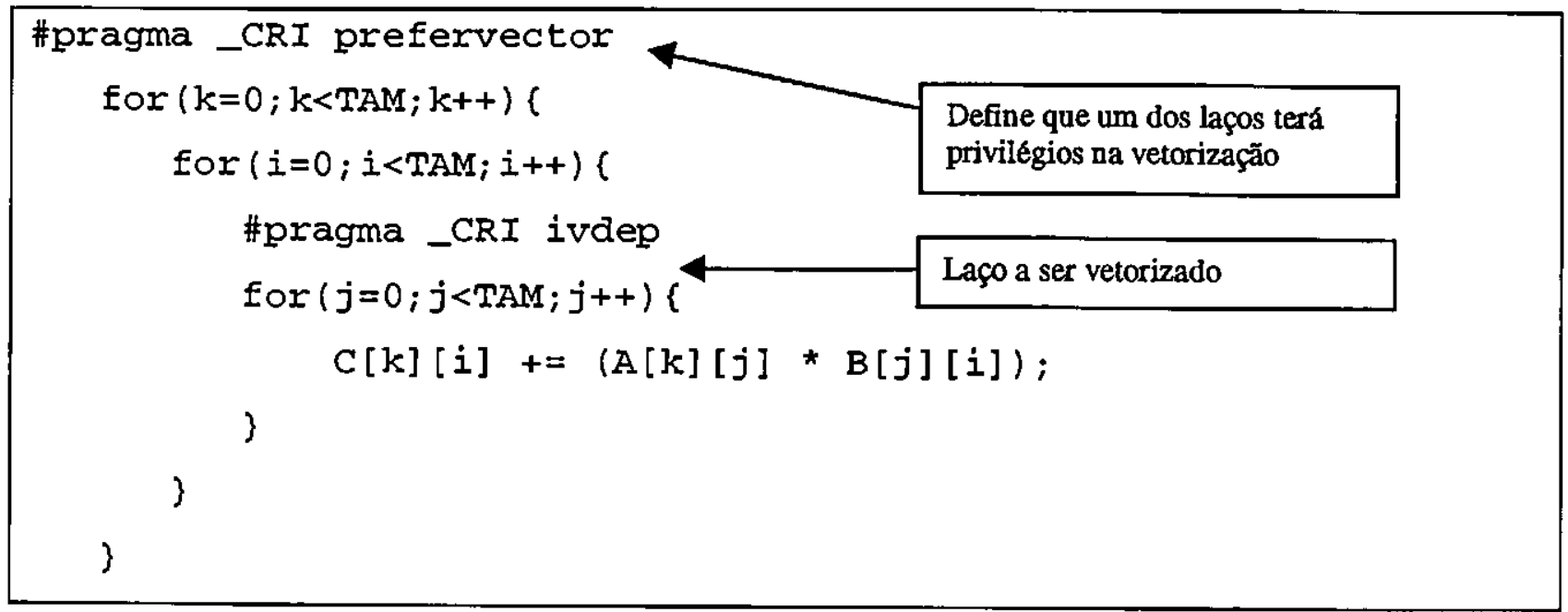

Figura 6.4 - Alteração de código no programa de multiplicação de matrizes.

Na próxima seção é apresentada uma descrição mais detalhada sobre a execução do NAS Parallel Benchmark.

\subsection{Compilação e execução do NAS Parallel Benchmark}

O processo de compilação do NAS no SP2 é relativamente simples, basta seguir o roteiro que acompanha o benchmark no diretório /NPB2.3/Doc. O primeiro passo é criar um arquivo de nome make.def onde são definidos os parâmetros de compilação. Essa criação é feita geralmente através da cópia de um arquivo chamado make.def.template que se encontra no diretório /config do NAS.

Caso a máquina a ser utilizada seja muito específica, como por exemplo, uma Fujistsu, existem arquivos no diretório /config/NAS.samples já prontos para serem copiados. 
Em seguida é necessário editar o arquivo make.def. No caso deste trabalho só foi necessário a configuração de algumas variáveis as quais definem quais compiladores e link editores serão utilizados como mostrado a seguir:

MPIF77 $=$ mpxlf

FLINK = mpxlf

MPICC $=\mathrm{mpCC}$

CLINK $=\mathrm{mpCC}$

Existem também outras variáveis que podem ser configuradas como as mostradas a seguir:

FFLAGS - define opções de compilação tais como: o parâmetro "O" que otimiza o código; ou o parâmetro "g" que diz ao compilador para gerar um código que pode depurado através de ferramentas auxiliares.

CLINKFLAGS e FLINKFLAGS - especifica os flags utilizados pelo link editor para $\mathrm{C}$ e Fortran respectivamente.

Para compilar o benchmark desejado usa-se o comando:

$$
\text { make }<\text { benchmark }>\text { NCLASS }=<\text { classe }>\text { NPROCS }=<\text { numero de processadores }>
$$

onde benchmark especifica qual deles será compilado, por exemplo, ft corresponde ao benchmark que utiliza Fast Fourrier Transformation para solucionar equações diferenciais (o significado das abreviações estão na seção 3.5.2 do Capítulo 3), o parâmetro NCLASS especifica qual classe de benchmark será utilizado (A, B, C, S ou W), a Tabela 6.1 mostra a equivalência de cada uma das classes. $O$ parâmetro NPROCS define o número de processadores que serão utilizado na execução do benchmark. $O$ processo de compilação gera um arquivo executável com o seguinte nome:

$$
<\text { nome_do_benchmark>.classe.num_de_processadores }
$$

dessa forma, o comando make sp CLASS $=A$ NPROCS $=1$, gera um arquivo executável de nome sp.A.l. 
Tabela 6.1 - Classes e seus objetivos

\begin{tabular}{|l|l|}
\hline Classe & Objetivo \\
\hline S & Exemplificar os resultados do benchmark. \\
\hline W & Para execução em Workstations. \\
\hline A & Para pequenos sistemas paralelos. \\
\hline B & Para máquinas paralelas de médio porte. \\
\hline C & Para máquinas paralelas de grande porte (acima 128 processadores) \\
\hline
\end{tabular}

Existem algumas restrições para o processo de compilação. O valor de NPROCS para os benchmarks de núcleo tem que ser obrigatoriamente uma potência de dois, ou seja, a quantidade de processadores utilizados deve ser $1,2,4,8$ e assim por diante. No caso das simulaçöes a quantidade de processadores tem que ser o quadrado de um número, isto é, $1,4,9,16$, etc.

Caso seja necessário gerar vários arquivos executáveis de um só vez, é possível a utilização de um arquivo chamado suite.def, que também encontra-se no diretório /config, contendo as especificações desejadas. As linhas a seguir mostram um exemplo de arquivo suite.def.

$\begin{array}{lll}\text { sp } & \text { A } & 4 \\ \mathrm{sp} & \mathrm{B} & 9 \\ \mathrm{ft} & \text { W } & 2 \\ \mathrm{mg} & \mathrm{C} & 8 \\ \mathrm{mg} & \text { A } & 16\end{array}$

Este arquivo deverá ser compilado com o comando make suite.def que gerará os seguintes arquivos executáveis:

sp.A.4

sp.B.9

ft.W.2

mg.C.8

mg.A.16

Todos os arquivos gerados pelo utilitário make são armazenados no diretório Bin, a não ser, que no Makefile seja definido um outro diretório.

\section{Coleta de dados}

Existem duas formas possíveis de se executar os benchmarks do NAS Parallel Benchmark dentro do SP2. A primeira é a forma tradicional de execução de programas paralelos, onde um código fonte é compilado e depois submetido a fila de execução através do comando llsubmit do LoadLever. 
A segunda forma de executar um benchmark é estando conectado diretamente em um dos nós do SP2, nesse caso é utilizado o seguinte comando:

\section{poe <nome do programa> -procs <número de processadores $>$}

Em qualquer uma das formas é necessário assegurar-se que nenhum dos nós está sendo utilizado por outro usuário para não afetar o desempenho na execução dos benchmarks. Devido a grande quantidade de recursos que os mesmo exigem em determinadas classes, alguns deles não puderam ser executados por falta de memória. A Tabela 6.2 a seguir mostra os benchmarks e as classes que puderam ser executadas.

Tabela 6.2 - Benchmarks executados com as respectivas classes

\begin{tabular}{|l|l|}
\hline Benchmark & Classes \\
\hline CG & S,W,A \\
\hline EP & S,W,A,B \\
\hline FT & S,W \\
\hline MG & S,W \\
\hline
\end{tabular}

O IS não foi incluído nesta tabela pois o mesmo não trabalha com nenhum algoritmo numérico e sim com um algoritmo de ordenação de vetores. A tabela 6.2 mostra os resultados obtidos na execução dos mesmos.

Tabela 6.3 - Resultados encontrados na execução do NAS Parallel Benchmark

\begin{tabular}{|l|c|c|c|c|c|c|c|}
\hline Bench. & \multicolumn{7}{c}{ Classe NP } \\
\hline MG & S & 2 & $0.4861 \times 10^{-16}$ & $32 \times 32 \times 32$ & 4 & 0,15 & 50,18 \\
\hline MG & W & 2 & $0.1624 \times 10^{-18}$ & $64 \times 64 \times 64$ & 40 & 7,9 & 76,22 \\
\hline EP & S & 2 & - & 33554432 & 0 & 25,10 & 1,34 \\
\hline EP & W & 2 & - & 67108864 & 0 & 50,18 & 1,34 \\
\hline EP & A & 2 & - & 536870912 & 0 & 447,86 & 1,20 \\
\hline EP & B & 2 & - & 2147483648 & 0 & 1612,32 & 1,33 \\
\hline FT & S & 2 & - & $64 \times 64 \times 64$ & 6 & 2,72 & 65,13 \\
\hline FT & W & 2 & - & $128 \times 128 \times 32$ & 6 & 5,98 & 62,30 \\
\hline CG & S & 2 & $0.8888 \times 10^{-14}$ & 1400 & 15 & 1,47 & 45,40 \\
\hline CG & W & 2 & 0.0 & 7000 & 15 & 7,64 & 55,02 \\
\hline CG & A & 2 & $0.8989 \times 10^{-12}$ & 14000 & 15 & 23,77 & 62,96 \\
\hline
\end{tabular}

A primeira coluna da Tabela 6.3 indica qual das diversas opções de benchmark oferecidas pelo NAS foi utilizado. A segunda refere-se as classes de execução conforme apresentado na Tabela 
6.1. Como o NAS so funciona com $2^{n}$ processadores e o SP2 do CISC contém 3 processadores, a coluna 3 indica que todos os benchmarks foram executado em 2 processadores. A quarta coluna indica o erro utilizado na respectiva classe quando o benchmark utiliza um algoritmo iterativo. A coluna Tamanho indica o da tamanho do problema, ou seja, da estrutura utilizada no cálculo (matrizes e vetores). Quando o algoritmo é numérico a quinta coluna indica a quantidade de iterações realizadas. As duas últimas colunas indicam o tempo de execução em segundos de cada benchmark seguido do desempenho do benchmark $\left(R_{B}(N, p)\right)$.

No benchmark MG apresentado na primeira e segunda linhas, o tamanho do problema praticamente dobra, o numero de iteração é 10 vezes maior e o tempo de execução que teoricamente deveria também ser multiplicado por 10 devido a quantidade de iteraçōes é multiplicado praticamente por 52. Isso ocorre pelo fato do benchmark executar muita comunicação e testar a capacidade de enviar grandes e pequenas mensagens. A quantidade Mflop/s aumenta devido ao aumento do número de iterações.

O benchmark EP, não realiza comunicação durante o processo de cálculo, isso induz que o tempo de execução está diretamente relacionado ao tamanho do problema, sendo que o desempenho de benchmark deve continuar constante.

Em todos os benchmarks a quantidade de Mflop/s é alterada devido ao contador de operações em ponto flutuante estar diretamente ligado ao tamanho do problema. $O$ erro mostrado na quarta coluna para o benchmark CG não é o erro desejado para que ocorra a finalização das iterações e sim o erro encontrado após a execução das 15 iterações. Esse número é constante para todo os tamanhos de problema.

\subsection{Considerações finais}

Dentre os problemas encontrados, destaca-se encontrar as condições de corrida que aconteciam durante a execução. Para ajudar nessa tarefa foi utilizado o depurador gráfico $x p d b x$ apresentado no Capitulo 5.

A Tabela 6.1 de classes é muito vaga e não define adequadamente o tamanho dos problemas, ou seja, esse tamanho deveria ser definido com a quantidade mínima de memória RAM e cache para a execução de todos os programas. 
Quanto aos demais benchmarks eles continham muito pouca informação para sua compilação e não tinham arquivos make.def específicos para o SP2 nem gerais como foi o caso do NAS Parallel Benchmark.

O próximo capítulo apresenta em detalhes todos os resultados encontrados na execução dos programas desenvolvidos em todas as plataformas já descritas. 


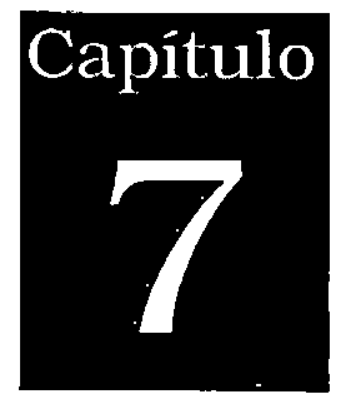

\section{Resultados}

Este capítulo descreve os resultados encontrados nos três ambientes utilizados: SP2, Cray e Sistema Distribuído (LASD-PC). No SP2, os programas seqüenciais são executados num nó chamado cronus que tem as mesmas características do nó wide (hades03). No sistema Cray, a versão seqüencial foi executada sem vetorização. E no Sistema Distribuído a execução serial deu-se na máquina mais rápida da rede a lasd07 (Pentium $200 \mathrm{Mhz}$ ). Todos os aplicativos foram rodados várias vezes e os tempos de execução considerados foram os mais altos obtidos.

A primeira seção deste capítulo apresenta o balanceamento de carga e a porcentagem de utilização de CPU para cada aplicação, observa-se que esta característica vale apenas para programas que rodam sobre o ambiente POE, como por exemplo o MPI. Apesar disso, o balanceamento de carga e a utilização de CPU podem ser estendidas para os programas em PVM já que o algoritmo e a forma como são enviadas as mensagens são as mesmas. Estas informações foram obtidas através da execução da ferramenta Visualization Toolkit. 
A segunda seção apresenta os resultados obtidos na execução dos algoritmos. O desempenho do benchmark $\left(R_{B}(N, p)\right)$ só será utilizado no final de cada subseção para comparar as arquiteturas. $O$ desempenho temporal $\left(R_{T}(N, p)\right)$ é utilizado para fazer uma comparação entre algoritmos do mesmo tipo, ou seja, comparar algoritmos que resolvem o mesmo problema de forma diferente. Pelo fato de que neste trabalho não foram implementados algoritmos diferentes para o mesmo problema, o desempenho temporal só é utilizado de forma ilustrativa para demonstrar a teoria apresentada no Capitulo 3.

Nos resultados da arquitetura Cray, a máquina boto (configuração apresentada no Capítulo 5) não é considerada por ter um desempenho muito pobre. Os programa seqüenciais demoram muito para terminar sua execução e a maioria das vezes extrapolam o tempo permitido de execução. Mesmo nos algoritmos que foram vetorizados o tempo de execução as vezes é ultrapassado.

\subsection{Balanceamento de Carga e Utilização do Processador}

Em todas as aplicações desenvolvidas para o SP2 utilizando a biblioteca de passagem de mensagem MPI houve $100 \%$ de utilização de processador, ou seja, nenhum processador ficou ocioso tempo suficiente capaz de ser detectado pelo VT. A Figura 7.1 mostra o gráfico de utilização para todas as aplicações.

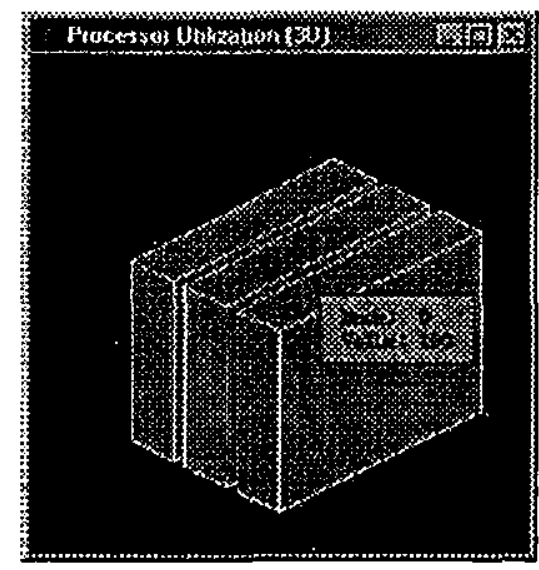

Figura 7.1 - Utilização de processador por todas as apllcações.

Em seguida foi testado o balanceamento de carga para cada aplicação. A Figura 7.2 (a) mostra um instante em que o balanceamento de carga tende para um só processador. $O$ triângulo mais escuro indica que o $N o ́$ O está trabalhando e os demais esperando. Este instante é muito rápido e 
foi de difícil captura já que ele ocorre quando outros processadores estão esperando por uma mensagem.

A Figura 7.2 (b) mostra um quadro de informações sobre o balanceamento de carga que será exibido juntamente com a Figura 7.2 (a). Neste quadro, o primeiro dado é o instante de tempo em que os dados foram obtidos. Esse valor não é relevante pois é baseado no intervalo configurado na variável MP_SAMPLEFREQ apresentada no Capítulo 5. O Node, indica qual nó está sendo avaliado (neste exemplo o nó 2). Instantaneous indica a porcentagem de execução do programa quando a informação foi obtida, o valor 100 indica que as informações foram obtidas no término de execução. E Average, indica a média de balanceamento de carga, neste caso, a média 99 indica que o processador teve uma carga média de $99 \%$.

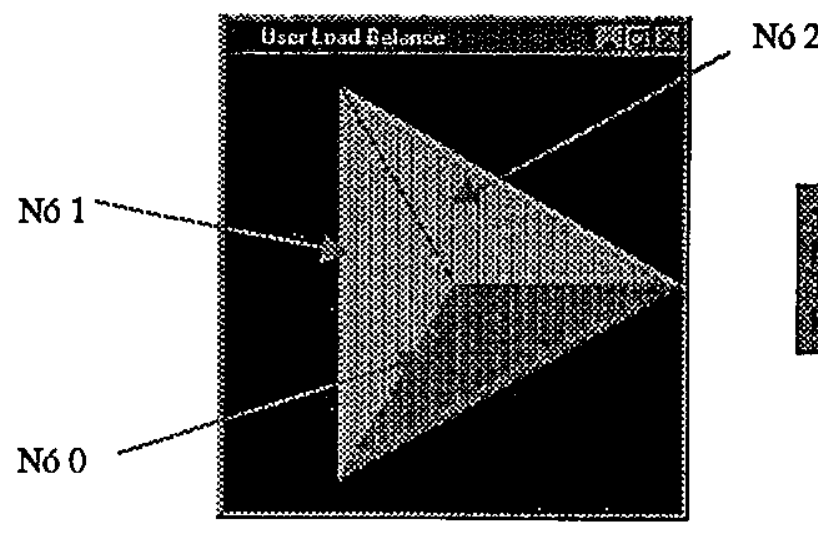

(a)

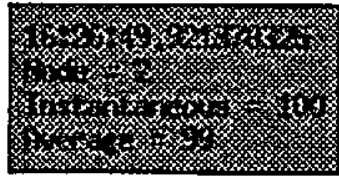

(b)

Figura 7.2 - Balanceamento de carga onde só um processador está trabalhando.

A Figura 7.3 mostra o balanceamento de carga para cada aplicação e para cada nó utilizado, a Figura 7.3 (a) apresenta o balanceamento para 0 algoritmo do trapezio, a (b) para o algortimo de Jacobi e a (c) para o algoritmo de multiplicação de matrizes. Um pequeno retângulo como o mostrado na Figura 7.2 (b), é mostrado em cada figura. Essa média é feita automaticamente pelo VT no final da execução do programa. 

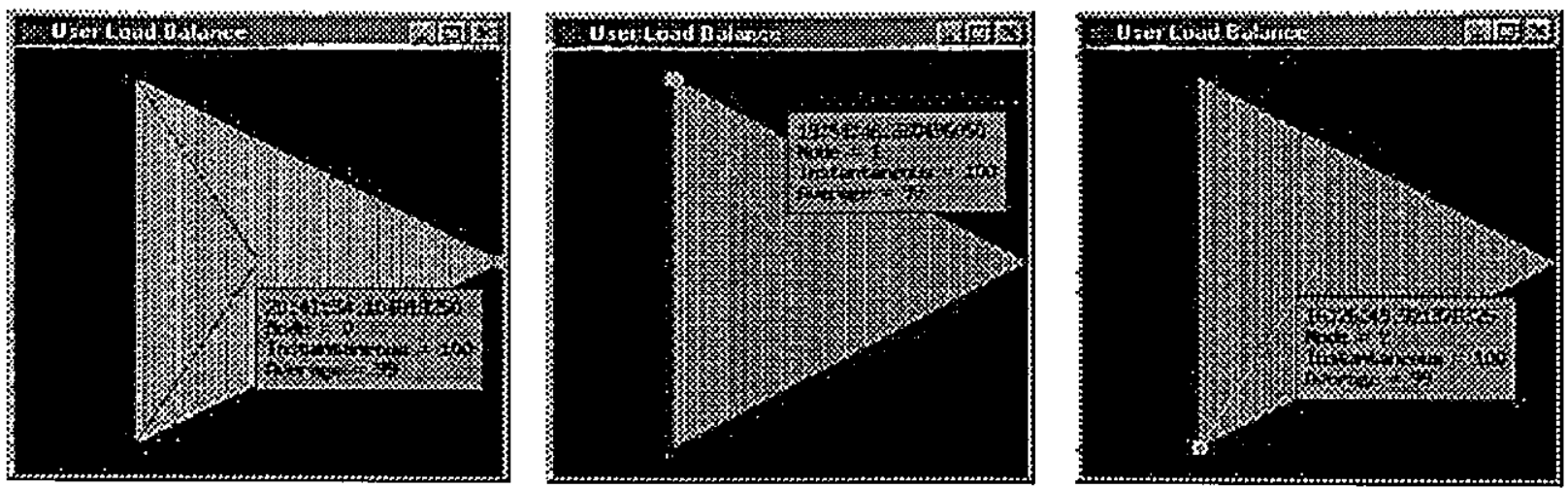

(a) Balanceamento de carga para o algoritmo do trapézio.
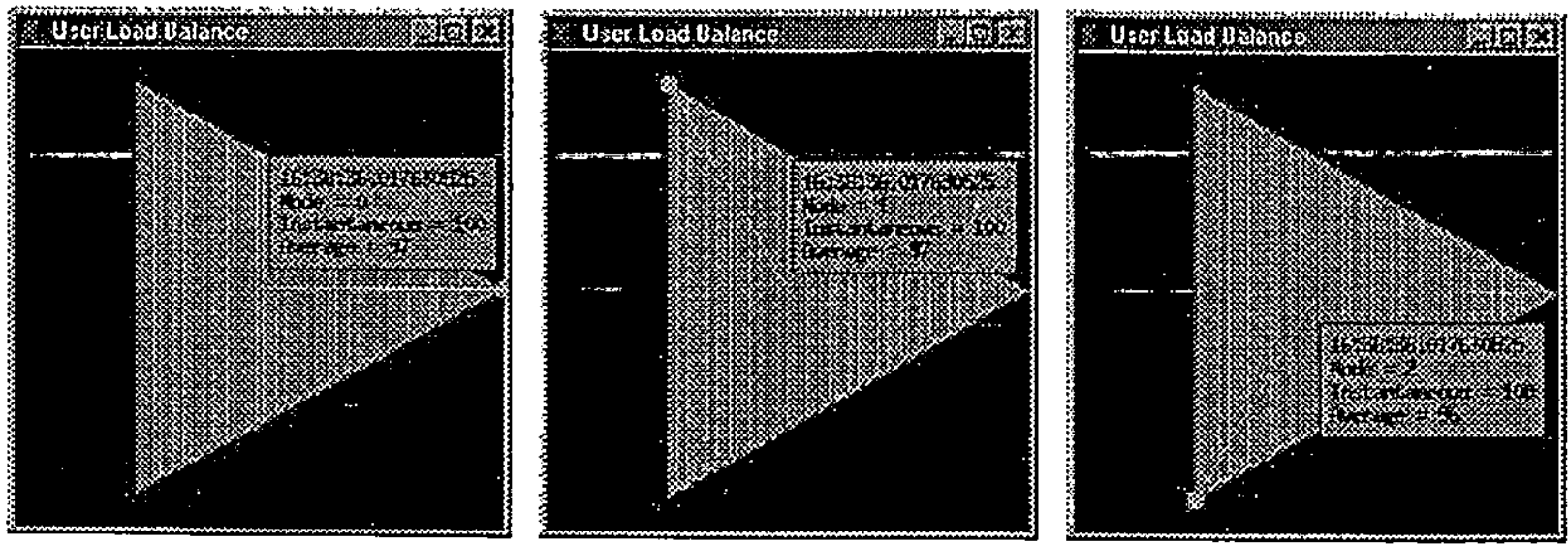

(b) Balanceamento de carga para o algoritmo de Jacobi.
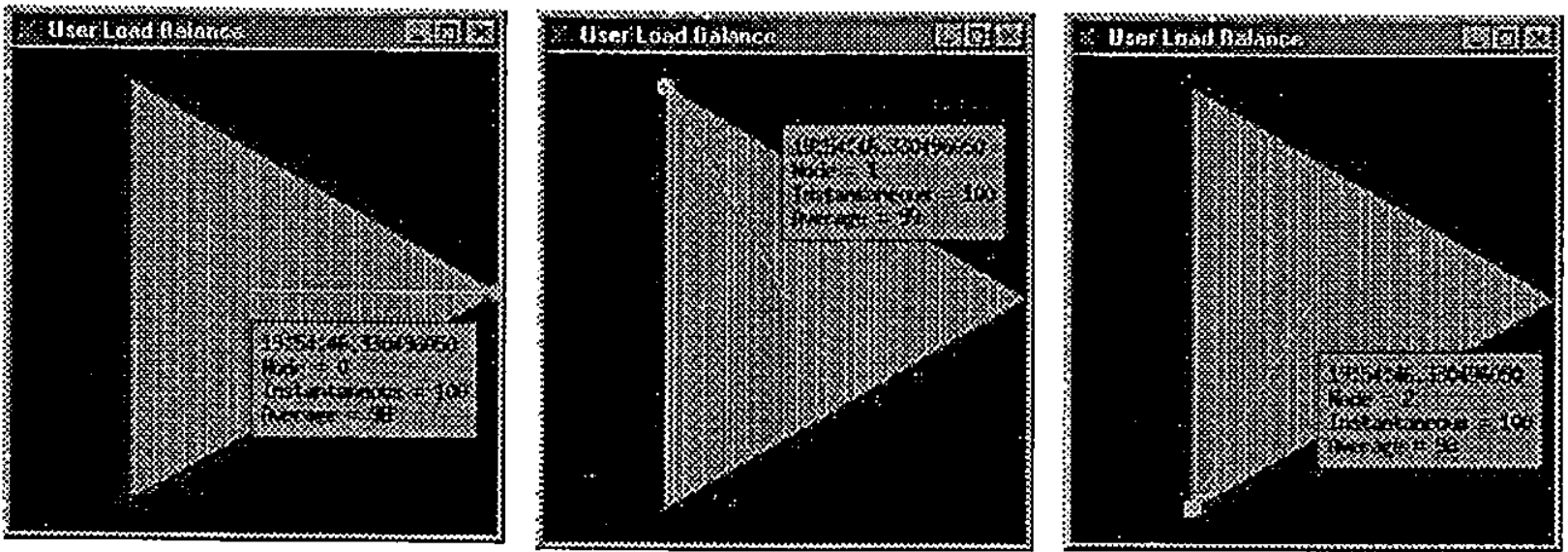

(c) Balanceamento de carga para o algoritmo de multiplicação de matriz.

Figura 7.3 - Balanceamento de carga para os algoritmos no SP2.

Dos três algoritmos, o que apresentou melhor média foi o algoritmo de multiplicação de matrizes, seguido do algoritmo do trapézio. Isso ocorreu porque ambos só fazem duas comunicações durante todo o processo, uma no inicio do programa para especificar os limites e passar as matrizes para os respectivos processadores quando necessário, e uma comunicação no final da execução para juntar o resultado. 


\subsection{Execução dos algoritmos}

Os algoritmos foram implementados conforme o apresentado nos Capítulos 4 e 6. Na arquitetura Cray foi utilizado um nível agressivo de vetorização. Para realizar todos os cálculos foram executados os seguintes passos:

- Primeiro é executado a versão serial do algoritmo guardando o tempo de execução;

- Em seguida é executado o algoritmo paralelo armazenando o tempo de execução;

- Calcula-se o speedup;

- Calcula-se a eficiência;

- Executa-se uma versão do programa serial com contadores para encontrar o número de operações em ponto flutuante $\left(F_{B}(N)\right)$;

- Calcula-se o desempenho temporal $\left(R_{T}(N, p)\right)$ seguindo a teoria apresentada no Capítulo 3, neste capítulo o $R_{T}(N, p)$ também será referenciado como simplesmente $R_{T}(N)$;

- Calcula-se o desempenho do benchmark $\left(R_{B}(N, p)\right)$ também seguindo o explicado no Capítulo3.

\subsubsection{Resultados do programa de integração numérica}

As Tabela 7.1 e 7.2 mostram os resultados encontrados no SP2 utilizando o MPI. As Tabelas 7.3 e 7.4 mostram os resultados obtidos utilizando o PVMe, também no SP2. As duas primeiras linhas expressam o tempo de execução em segundos para 3,2 e 1 processador respectivamente. A terceira e quarta linhas mostram o resultado do cálculo do speedup e da eficiência . A quinta linha ilustra o desempenho temporal que é calculado a título de demonstração pois não foram implementados vários algoritmos para solucionar o mesmo problema. A penúltima linha mostra o resultado obtido com o programa contador de operações em ponto flutuante. $E$ a última linha exibe o resultado encontrado no desempenho do benchmark. A última linha de todas as tabelas, geralmente só é comentada no final de cada subseção onde as arquiteturas são comparadas. $\mathrm{O}$ cabeçalho das tabelas indicam a quantidade total de divisões da integral em milhões. Por exemplo, o valor 9 indica que a integral foi dividida em 9 milhões de pedaços. 
Tabela 7.1 - Resultados encontrados no SP2 utilizando MPI com 3 processadores.

\begin{tabular}{|c|c|c|c|c|c|c|}
\hline & 9 & 18 & 36 & 72 & 144 & 288 \\
\hline 3 proc. (s) & 5,20 & 10,38 & 20,82 & 41,55 & 83,00 & 175,80 \\
\hline Serial (s) & 14,55 & 29,17 & 58,29 & 116,59 & 233,16 & 473,93 \\
\hline Speedup & 2,7981 & 2,8102 & 2,7997 & 2,806 & 2,8092 & 2,6958 \\
\hline Eficiência & 0,9327 & 0,9367 & 0,9332 & 0,935 & 0,9364 & 0,8986 \\
\hline$R_{T}(N, p)^{*}-$ sols $/ s$ & 0,19 & 0,1 & 0,05 & 0,02 & 0,01 & 0,0057 \\
\hline$F_{B}(N)^{* *}-$ Mflop & 198 & 396 & 792 & 1584 & 3168 & 6336 \\
\hline$R_{B}(N, p)^{*+*}-$ Mflop/s & 38,08 & 38,15 & 38,04 & 38,12 & 38,17 & 36,04 \\
\hline
\end{tabular}

Tabela 7.2 - Resultados encontrados no SP2 utillzando MPI com 2 processadores.

\begin{tabular}{|c|c|c|c|c|c|c|}
\hline & 9 & 18 & 36 & 72 & 144 & 288 \\
\hline 2 proc.(s) & 7,27 & 14,52 & 29,12 & 58,16 & 116,29 & 232,67 \\
\hline Serial (s) & 14,55 & 29,17 & 58,29 & 116,59 & 233,16 & 473,93 \\
\hline Speedup & 2,0014 & 2,009 & 2,0017 & 2,0046 & 2,005 & 2,0369 \\
\hline Eficiência & 1,0007 & 1,0045 & 1,0085 & 1,0023 & 1,0025 & 1,018 \\
\hline $\mathrm{R}_{\mathrm{T}}(\mathrm{N})-\mathrm{sols} / \mathrm{s}$ & 0,14 & 0,07 & 0,03 & 0,02 & 0,01 & 0,0043 \\
\hline$F_{B}(N)-$ Mflop & 198 & 396 & 792 & 1584 & 3168 & 6336 \\
\hline$R_{B}(N, p)-$ Mflop/s & 27,24 & 27,27 & 27,2 & 27,24 & 27,24 & 27,23 \\
\hline
\end{tabular}

O resultado da execução das três versōes do algoritmo pode ser melhor visto no Gráfico 7.1, onde a execução em 3 processadores obteve o menor tempo de execução. Como a granulação desta aplicação é grossa e a quantidade de processadores é pequena a Lei de $A h m d a l^{2}$ não se aplica. Houve uma pequena anomalia de speedup na versão com 2 processadores devido a grande quantidade de memória disponível nos processadores do SP2 (256 Mbytes para o nó wide e $128 \mathrm{Mbytes}$ para o nó thin), consequentemente houve uma anomalia na eficiência. Nota-se que apesar da ocorrer a anomalia com 2 processadores o desempenho de benchmark $\left(R_{B}(N)\right)$, ou seja, a quantidade de operações em ponto flutuante por segundo com dois processadores foi menor. A eficiência alcançada ficou por volta de $93 \%$ bem semelhante ao balanceamento de carga mostrado na Figura 7.3 (a). Essa diferença entre a eficiência e o balanceamento de carga deu-se pelo fato de que o balanceamento de carga é feito no programa inteiro e a eficiência é baseada somente no tempo de cálculo da integral.

\footnotetext{
${ }^{2}$ A lei de Ahmdal diz que a partir de um número $n$ de processadores ( $n$ representa a quantidade de processadores que toma a aplicação a mais rápida possível) a velocidade de execução diminui a medida que novos processadores são adicionados.
} 


\section{Gráfico 7.1 - Tempo de execução do algoritmo do trapézio composto no SP2 utilizando MPI.}

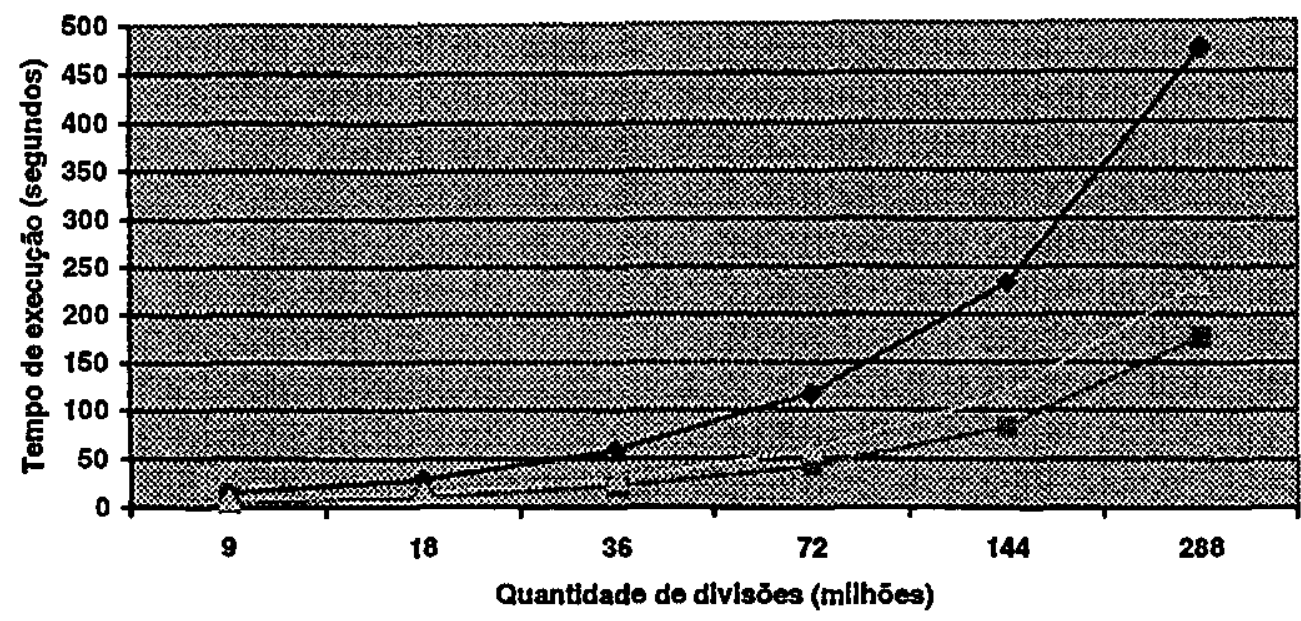

$\rightarrow$ Serial (s) - -3 - 3 proc. (8) …..... 2 proc. (8)

O Gráfico 7.2 apresenta o speedup e a eficiência alcançado nas versões para 2 e 3 processadores. Nota-se que apesar de haver uma nítida diferença de speedup a eficiência para 2 processadores é ligeiramente maior que para 3 processadores, isso não implica que deve-se utilizar 2. processadores no lugar de 3, pois o tempo de execução em 3 processadores é menor. Aqui o que deve ser considerado é o speedup tomando o cuidado de se observar o tempo de execução para que não ocorram os problemas do speedup apresentadas na seção 3.4 do Capítulo 3 , que considera que nem sempre o algoritmo que tem o maior speedup é o mais rápido.

\section{Gráfico 7.2 - Speed-up e eficiência alcançada por 2 e 3} processadores no SP2.

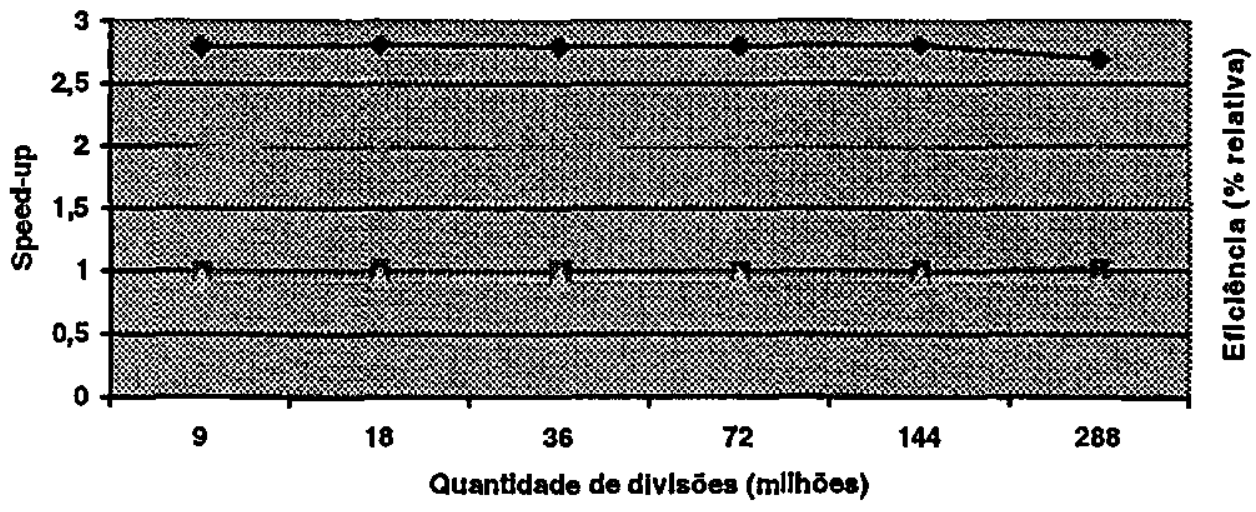


As Tabelas 7.3 e 7.4 apresentam os resultados encontrados no SP2 utilizando-se o PVMe. Como esperado, o comportamento foi semelhante ao da execução com MPI, já que ambos se utilizam do switch de alto desempenho para efetuar a comunicação entre processadores.

Tabela 7.3 - Resultados encontrados no SP2 utilizando PVMe com 3 processadores.

\begin{tabular}{|c|c|c|c|c|c|c|}
\hline & 9 & 18 & 36 & 72 & 144 & 288 \\
\hline 3 proc. & 5,076 & 9,9131 & 19,67 & 39,21 & 78,1961 & 156,246 \\
\hline Serial & 14,55 & 29,17 & 58,29 & 116,59 & 233,16 & 473,93 \\
\hline Speedup & 2,8664 & 2,9426 & 2,9634 & 2,9735 & 2,9817 & 3,0332 \\
\hline Eficiência & 0,9555 & 0,9809 & 0,9878 & 0,9912 & 0,9939 & 1,0111 \\
\hline $\mathrm{R}_{\mathrm{T}}(\mathrm{N})-\mathrm{sols} / \mathrm{s}$. & 0,197 & 0,1009 & 0,05 & 0,03 & 0,0128 & 0,0064 \\
\hline $\mathrm{F}_{\mathrm{B}}(\mathrm{N})-$ Mflop & 198 & 396 & 792 & 1584 & 3168 & 6336 \\
\hline$R_{B}(N, p)-$ Mflop/s & 39,007 & 39,9471 & 40,26 & $40, \overline{4}$ & 40,5135 & 40,551 \\
\hline
\end{tabular}

Tabela 7.4 - Resultados encontrados no SP2 utillzando PVMe com 2 processadores.

\begin{tabular}{|l|ll|l|l|l|l|}
\hline \multicolumn{2}{|c|}{9} & $\mathbf{9}$ & 36 & 72 & 144 & 288 \\
\hline 2 proc. & 7,0865 & 14,038 & 27,64 & 55,0672 & 111,148 & 219,91 \\
\hline Serial & 14,55 & 29,17 & 58,29 & 116,59 & 233,16 & 473,93 \\
\hline Speedup & 2,0532 & 2,0779 & 2,1089 & 2,117231 & 2,0977 & 2,1551 \\
\hline Eficiéncia & 1,0266 & 1,039 & 1,0545 & 1,058616 & 1,0489 & 1,0776 \\
\hline $\mathrm{R}_{\mathrm{T}}(\mathrm{N})-$ sois/s. & 0,14 & 0,07 & 0,03 & 0,02 & 0,01 & 0,0043 \\
\hline $\mathrm{F}_{\mathrm{B}}(\mathrm{N})-$ Mflop & 198 & 396 & 792 & 1584 & 3168 & 6336 \\
\hline$R_{B}(N, p)-$ Mflop/s & 38,08 & 38,15 & 38,04 & 38,12 & 38,17 & 36,04 \\
\hline
\end{tabular}

A medida que a quantidade de divisōes aumenta, o PVMe tem uma nítida vantagem sobre a versão em MPI, principalmente na execução com 3 processadores. Isso acontece porque os dois processadores escravos no MPI, tem que esperar que o mestre esteja pronto para receber a mensagem final que faz o somatório dos cálculos, isso pode ser visualizado na Figura 7.4 obtida através da utilização do VT. As barras indicam a execução da aplicação. Os retângulos numerados do lado direito, indicam os respectivos nós, sendo que 0 (zero) representa o mestre e os demais representam os escravos. As linhas que interligam as barras representam a comunicação entre os processadores. A faixa do $R_{B}(N, p)$ é mantida porque o problema tem uma complexidade $n$. Isso faz com que o crescimento do problema seja linear, ou seja, se o tamanho do problema dobra, a quantidade de operaçōes em ponto flutuante e o tempo de execução também dobram. Conseqüentemente, a faixa de operaçōes em ponto flutuante por segundo $\left(R_{B}(N, p)\right)$ se mantém quase que constante, já que $R_{B}(N, p)=F_{B}(N) / T(N, p)$, onde $T(N, p)$ é o 
tempo de execução em paralelo com processadores e $F_{B}(N)$ é a quantidade de operações em ponto flutuante.

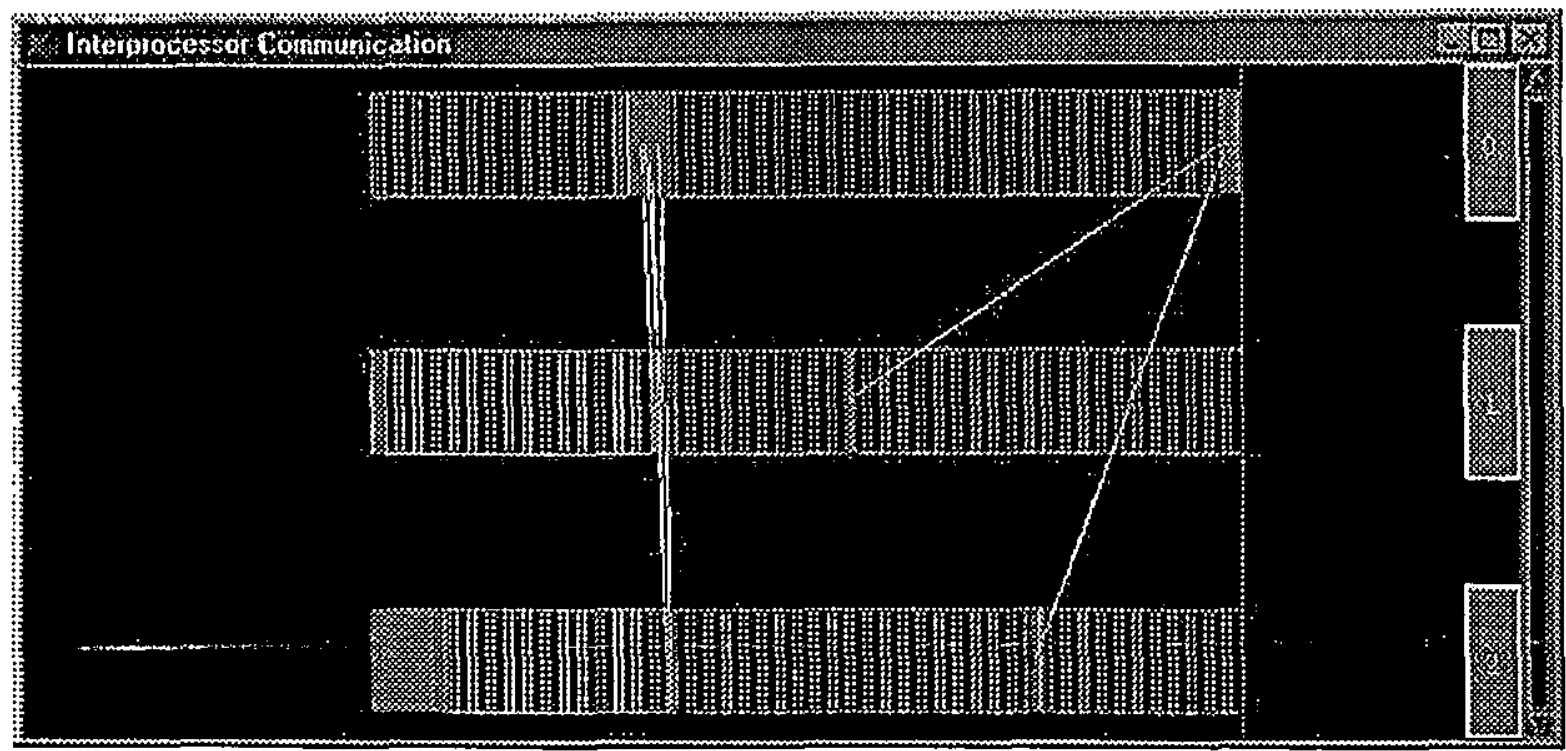

Figura 7.4 - Comunicação entre 3 processadores.

A Figura 7.5 mostra a execução do algoritmo do trapézio para 2 processadores. Nota-se que a espera pela comunicação com o mestre é nitidamente menor que a da Figura 7.4 levando a maior eficiência encontrada para 2 processadores.

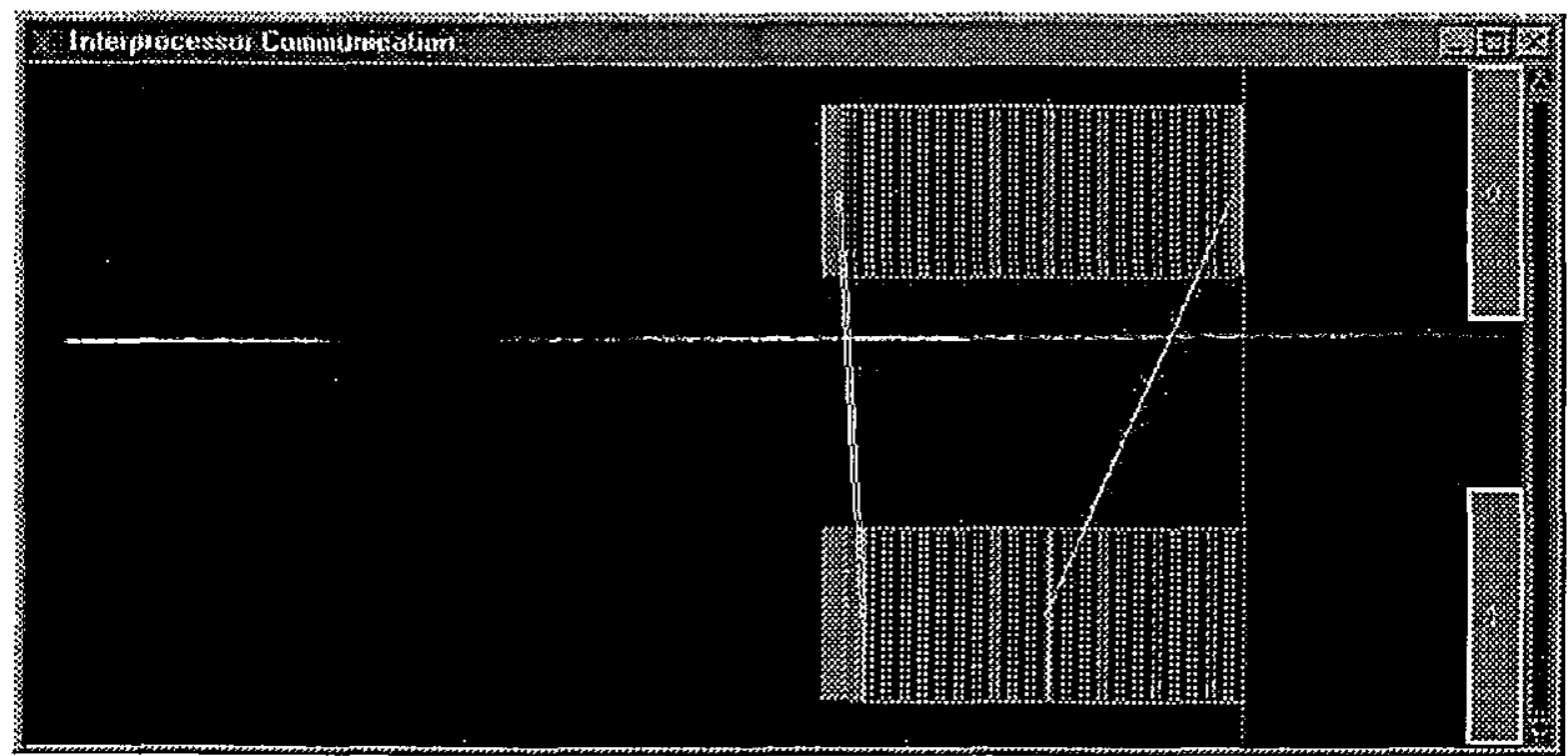

Figura 7.5 Comunicação entre 2 processadores 
O Gráfico 7.3 mostra a execução utilizando PVMe. Se comparado ao Gráfico 7.1 a escala do gráfico não permite uma visualização clara, mas se os tempo de execução forem comparados entre as Tabelas 7.3 a $7.4 \mathrm{e}$ as Tabelas 7.1 a 7.2 essa diferença será rapidamente notada.

\section{Gráfico 7.3 - Tempo de execução do algoritmo do trapézio composto no SP2 utlizando-se PVMe.}

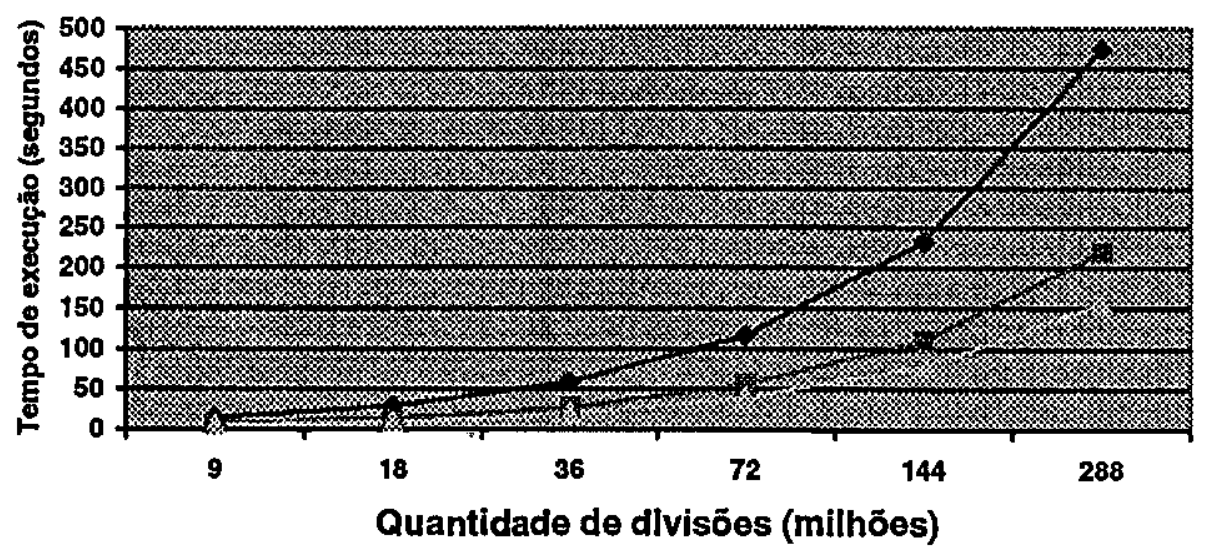

$$
- \text { Serial }-m-2 \text { proc. …*.... } 3 \text { proc. }
$$

A seguir o Gráfico 7.4 mostra o speedup e a eficiência alcançada. Como esperado, o comportamento foi semelhante ao do Gráfico 7.2 pois a faixa de speedup e de eficiência foi mantida devido a linearidade dos resultados.

Grafico 7.4 - Speed-up e eficiência alcançados por 2 e 3 processadores no SP2 utilizando PVMe

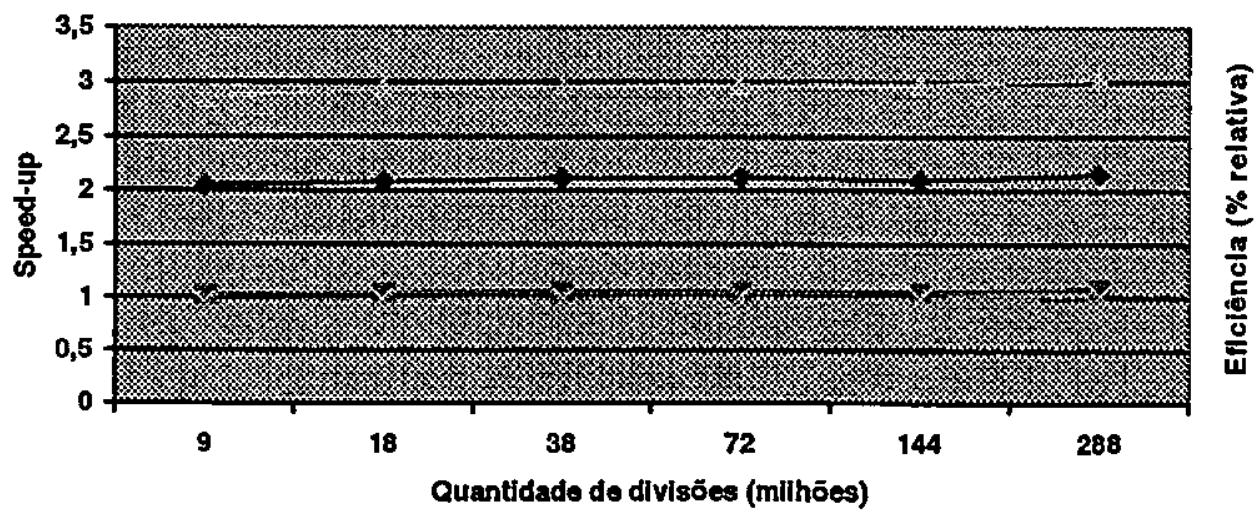


As Tabelas 7.5 e 7.6 mostram os resultado encontrados na execução do algoritmo do trapézio no sistema distribuído do LASD-PC utilizando-se o MPI.

Tabela 7.5 - Resultados encontrados no LASD-PC utillzando MPI com 3 processadores.

\begin{tabular}{|c|c|c|c|c|c|c|}
\hline & 9 & 18 & 36 & 72 & 144 & 288 \\
\hline 3 proc. & 10,078 & 20,1103 & 40,1806 & 80,5113 & 160,59 & 321,148 \\
\hline Serial & 16,29 & 35,51 & 65,01 & 130,22 & 260,10 & 520,16 \\
\hline Speedup & 1,6164 & 1,7658 & 1,7658 & 1,6174 & 1,6197 & 1,6197 \\
\hline Eficiência & 0,5388 & 0,5886 & 0,5886 & 0,5391 & 0,5399 & 0,5399 \\
\hline$R_{T}(N)-$ sols $/ s$ & 0,07 & 0,0497 & 0,0249 & 0,0124 & 0,01 & 0,0031 \\
\hline$F_{B}(N)-$ Mflop & 198 & 396 & 792 & 1584 & 3168 & 6336 \\
\hline$R_{B}(N, p)-$ Mflop/s & 19,6468 & 19,6914 & 19,711 & 19,6743 & 19,73 & 19,729 \\
\hline
\end{tabular}

Tabela 7.6 - Resultados encontrados no LASD-PC utilizando MPI com 2 processadores.

\begin{tabular}{|c|c|c|c|c|c|c|}
\hline & 9 & 18 & 36 & 72 & 144 & 288 \\
\hline 2 proc. & 15,20 & 30,37 & 60,711 & 121,41 & 242,771 & 485,519 \\
\hline Serial & 16,29 & 35,51 & 65,01 & 130,22 & 260,10 & 520,16 \\
\hline Speedup & 1,0717 & 1,1692 & 1,1692 & 1,0726 & 1,0714 & 1,0713 \\
\hline Eficiência & 0,5359 & 0,5846 & 0,5846 & 0,5363 & 0,5357 & 0,5357 \\
\hline $\mathrm{R}_{\mathrm{T}}(\mathrm{N})$ - sols/s. & 0,06 & 0,03 & 0,02 & 0,01 & 0,0038 & 0,0019 \\
\hline$F_{B}(N)-M f l o p$ & 198 & 396 & 792 & 1584 & 3168 & 6336 \\
\hline$R_{B}(N, p)-$ Mflop/s & 13,03 & 13,04 & 13,045 & 13,05 & 13,049 & 13,05 \\
\hline
\end{tabular}

Os tempos de execução apresentados nas Tabelas 7.5 e 7.6 foram coerente, dado novamente a linearidade do problema. Apesar da velocidade dos processadores ser maior no sistema distribuído se comparado aos processadores do SP2, o sistema distribuído leva desvantagem pela pouca eficiência da unidade de ponto flutuante das máquinas do tipo PC que realizam cálculos mais lentamente e também leva desvantagem pela quantidade de memória RAM e pela quantidade de memória cache. A métrica tempo de execução não deve ser utilizada para comparar as arquiteturas. O Gráfico 7.5 mostra melhor os tempos alcançados pelo sistema distribuído utilizando o MPI (Mpich). 


\section{Gráfico 7.5 - Tempo de execuçāo do aigoritmo do trapézlo composto no LASD-PC utilizando MPI.}

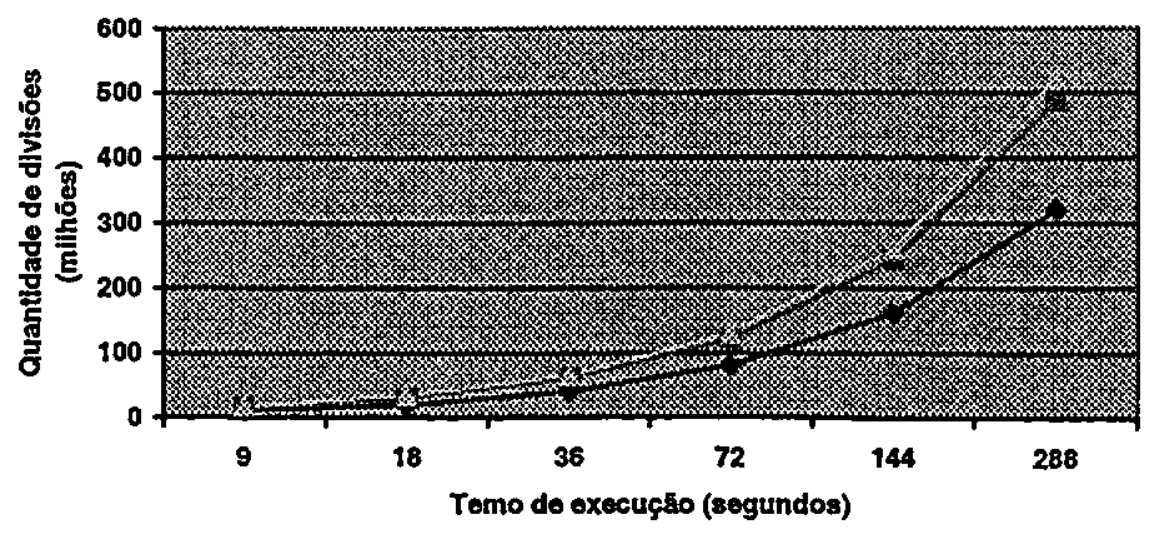

-3 proc. min-2 proc. mosemnserlal

O mestre que tem uma carga um pouco maior sempre foi executado no processador de $200 \mathrm{Mhz}$ (Lasd07), como os demais processadores são mais lentos isso acarretou numa espera do mestre pelas mensagens finais. Para dois processadores essa afirmação torna-se mais clara, por exemplo, dividir 288 milhões de trapézios em dois processadores, o mestre vai calcular uma integral de 144 milhões de divisões bem mais rápido que o escravo e vai ter que esperar até este terminar para obter o resultado final.

O Gráfico 7.6 apresenta a eficiência e o speedup alcançados pelo algoritmo do trapézio utilizando MPI no LASD-PC.

Grafico 7.6 - Eficiência e speed-up alcançados no LASDPC utilizando MPI.

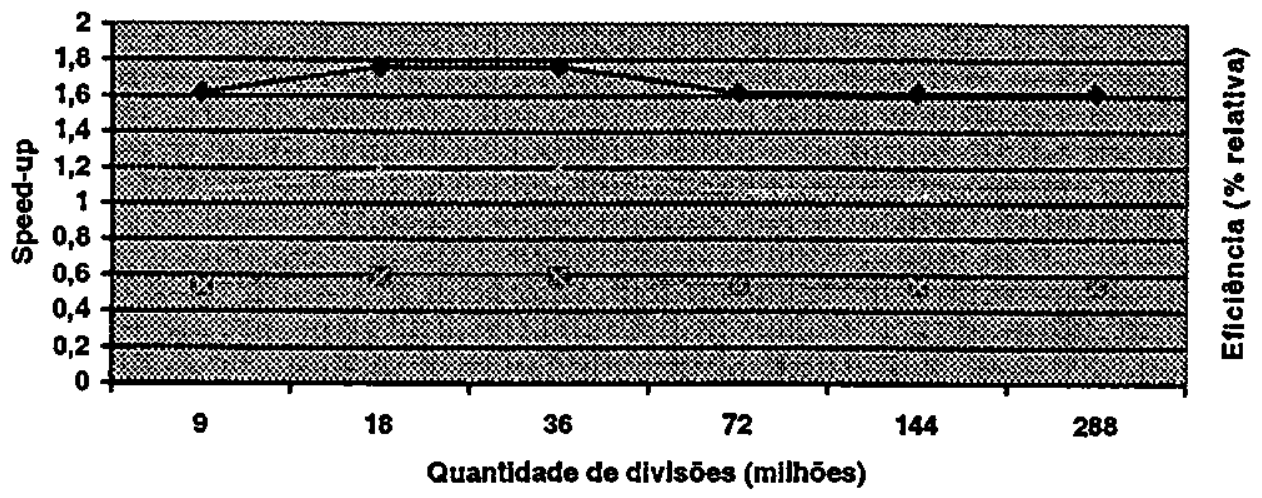

- Speed-up 3 proc. - E- Eficiência 3 proc.

......... Speed-up 2 proc. 
Analisando-se o Gráfico 7.6 e as Tabelas 7.5 e 7.6, novamente pode-se cair na armadilha da eficiência e do speedup. O fato da eficiência com 2 processadores estar extremamente próxima da com 3 processadores e dos speedups serem não muito distantes um do outro, não seria aconselhável, a utilização de um sistema distribuído com 2 nós para resolver esse tipo de problema.

As Tabelas 7.7 e 7.8 a seguir mostram os resultados encontrados na execução do algoritmo do trapézio no LASD-PC utilizando o PVM.

Tabela 7.7 - Resultados encontrados no LASD-PC utillzando PVM com 3 processadores.

\begin{tabular}{|c|c|c|c|c|c|c|}
\hline & 9 & 18 & 36 & 72 & 144 & 288 \\
\hline 3 proc. & 10,89 & 18,685 & 37,1429 & 74,5757 & 149,60 & 297,337 \\
\hline Serial & 16,29 & 35,51 & 65,01 & 130,22 & 260,10 & 520,16 \\
\hline Speedup & 1,4959 & 1,9005 & 1,9005 & 1,7461 & 1,7386 & 1,7494 \\
\hline Eficiência & 0,4986 & 0,6335 & 0,6335 & $0,5 \overline{82}$ & 0,5795 & 0,5831 \\
\hline$R_{T}(\mathrm{~N})-$ sols $/ \mathrm{s}$ & 0,06 & 0,03 & 0,02 & 0,01 & 0,0038 & 0,0019 \\
\hline$F_{B}(N)-$ Mflop & 198 & 396 & 792 & 1584 & 3168 & 6336 \\
\hline$R_{B}(N, p)-$ Mflop/s & 18,18 & 21,193 & 21,3231 & 21,2402 & 21,18 & 21,309 \\
\hline
\end{tabular}

Tabela 7.8 - Resultados encontrados no LASD-PC utilizando PVM com 2 processadores.

\begin{tabular}{|c|c|c|c|c|c|c|}
\hline & 9 & 18 & 36 & 72 & 144 & 288 \\
\hline 2 proc. & 14,2739 & 28,5584 & 57,1901 & 114,0264 & 228,0590 & 456,1955 \\
\hline Serial & 16,29 & 35,51 & 65,01 & 130,22 & 260,10 & 520,16 \\
\hline Speedup & 1,1412 & 1,2434 & 1,2434 & 1,142 & 1,1405 & 1,1402 \\
\hline Eficiência & 0,5706 & 0,6217 & 0,6217 & 0,571 & 0,5703 & 0,5701 \\
\hline$R_{T}(\mathrm{~N})-\mathrm{sols} / \mathrm{s}$ & 0,06 & 0,03 & 0,02 & 0,01 & 0,0038 & 0,0019 \\
\hline$F_{B}(N)-M f l o p$ & 198 & 396 & 792 & 1584 & 3168 & 6336 \\
\hline$R_{B}(N, p)-2$ proc. Mflop/s & 13,8715 & 13,8663 & 13,8486 & 13,8915 & 13,8911 & 13,8888 \\
\hline
\end{tabular}

No caso do LASD-PC usando PVM, a velocidade relativamente pobre de execução foi gerada novamente pela diferença de velocidade entre os processadores, essa diferença acontece quando o mestre (lasd07 - $200 \mathrm{Mhz}$ ) termina a execução dos seus cálculos e fica esperando pelo resultado dos escravos (lasd06 - $166 \mathrm{Mhz}$ e lasd08 - $133 \mathrm{Mhz}$ ), que com certeza ainda não terminaram. Somado a isso existe o problema de que a velocidade da rede é de apenas $10 \mathrm{Mbits} / \mathrm{s}$ causando uma maior sobrecarga na comunicação.

O Gráfico 7.7 mostra o tempo de execução para cada quantidade de processadores. A linha que representa a execução em dois processadores se aproxima muito da linha seqüiencial. Esse 
desempenho relativamente pobre deve-se novamente ao fato da velocidade dos processadores ser desigual e pela baixa velocidade de comunicação da rede. As três linhas quase se juntam no inicio devido a pouca quantidade de divisōes efetuadas, quanto menor a quantidade de divisōes há uma maior utilização da memória cache o que torna a execução muito mais rápida do que se a aplicação tivesse que usar a memória RAM. Aliado a isso, encontra-se a diferença de velocidade entre os processadores e a baixa velocidade de transmissão de dados da rede (10 Mbits/s).

\section{Gráflco 7.7 - Tempo de execuçāo do algoritmo do trapézlo composto no LASD-PC utilizando PVM.}

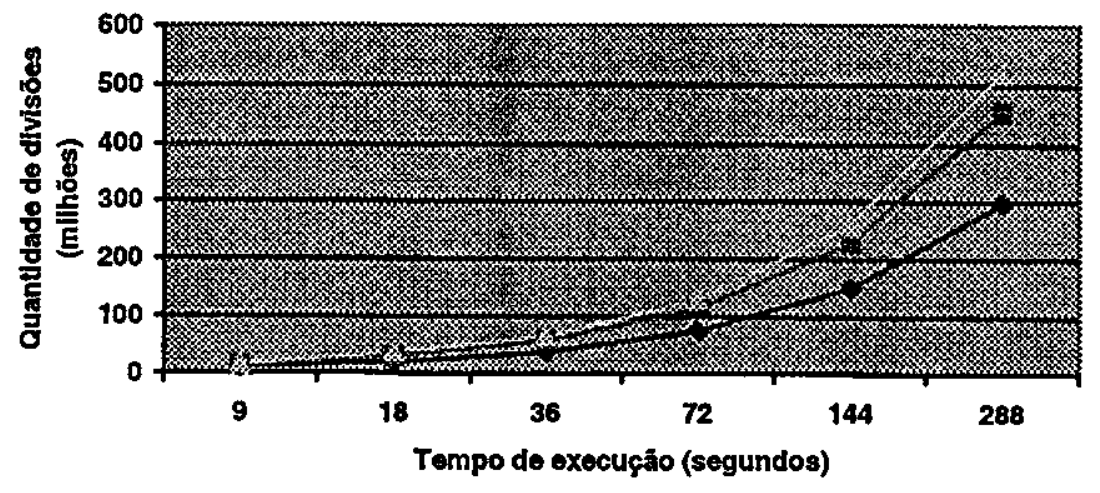

-3 proc. manis 2 proc. $m$ Serial

Usando-se três processadores a computação paralela começa a ficar interessante a partir de 36 milhões de divisões. Com dois processadores a utilização da computação paralela não é muito interessante pois seu ganho é muito pequeno, a utilização de uma única máquina com processador de $300 \mathrm{Mhz}$, por exemplo, tornaria a execução mais rápida e o custo mais baixo.

\section{Gráflco 7.8 - Eficiêncla $\theta$ speed-up alcançados no LASD-PC} utilizando PVM

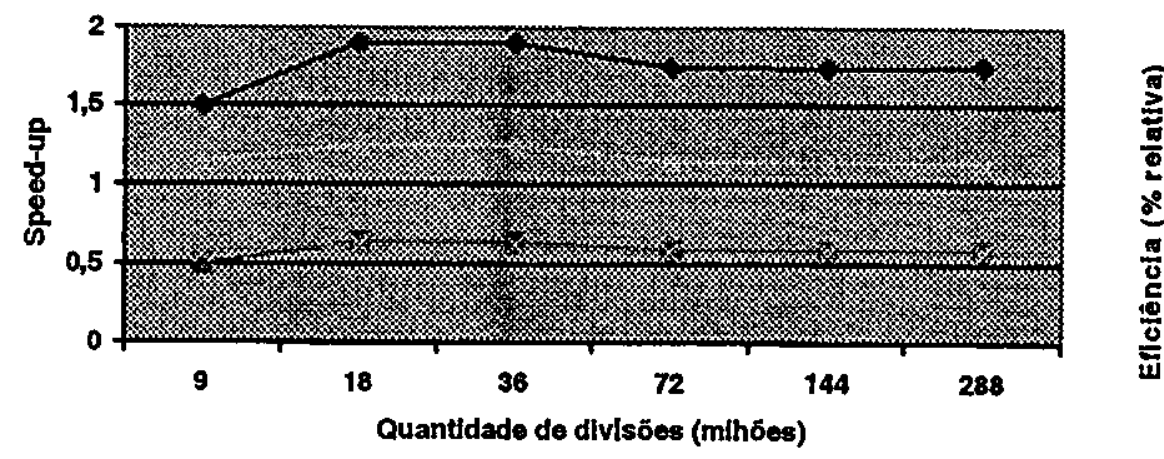


No gráfico 7.8 observa-se uma diferença maior entre o speedup/eficiência para 2 e 3 processadores. Neste caso elas podem ser adotadas como medida de desempenho, mas apenas para comparação do mesmo algoritmo na mesma arquitetura e ainda com muita cautela. Observa-se também o baixa speedup para 2 processadores que se encontra próximo ao valor 1. Isso indica que sua velocidade de processamento foi próxima a de um único processador.

Os resultados para a arquitetura Cray são mostrados nas Tabelas 7.9 e 7.10.

Tabela 7.9 - Resultados encontrados no Cray utilizando 3 processadores.

\begin{tabular}{|c|c|c|c|c|c|c|}
\hline & 9 & 18 & 36 & 72 & 144 & 288 \\
\hline 3 proc. & 8,81 & 17,34 & 34,78 & 70,94 & 141,44 & 284,04 \\
\hline Serial vetorizado & 8,47 & 16,80 & 33,42 & 67,32 & 134,26 & 269,21 \\
\hline Serial não vetorizado & 44,79 & 89,85 & 180,74 & 358,35 & 717,70 & 1439,95 \\
\hline Speedup & 5,084 & 5,1817 & 5,1817 & 5,0515 & 5,0742 & 5,0695 \\
\hline Eficiência & 1,695 & 1,7272 & 1,7272 & 1,6838 & 1,6914 & 1,6898 \\
\hline$R_{T}(N)-s o l s / s$ & 0,1135 & 0,0577 & 0,0288 & 0,0141 & 0,0071 & 0,0035 \\
\hline$F_{B}(N)-M$ flop & 198 & 396 & 792 & 1584 & 3168 & 6336 \\
\hline$R_{B}(N, p)-$ Mflop $/ \mathrm{s}$ & 22,47 & 22,84 & 22,77 & 22,33 & 22,4 & 22,31 \\
\hline
\end{tabular}

Tabela 7.10 - Resultados encontrados no Cray utilizando 2 processadores.

\begin{tabular}{|l|l|l|l|l|l|l|}
\hline \multicolumn{2}{|c|}{9} & 18 & 36 & 72 & 144 & 288 \\
\hline 2 proc. & 8,50 & 17,15 & 34,18 & 68,44 & 137,55 & 274,37 \\
\hline Serlal vetorizado & 8,47 & 16,80 & 33,42 & 67,32 & 134,26 & 269,21 \\
\hline Serial não vetorizado & 44,79 & 89,85 & 180,74 & 358,35 & 717,70 & 1439,95 \\
\hline Speedup & 5,2694 & 5,2391 & 5,2391 & 5,236 & 5,2177 & 5,2482 \\
\hline Eficiência & 2,6347 & 2,6196 & 2,6196 & 2,618 & 2,6089 & 2,6241 \\
\hline$R_{\mathrm{T}}(\mathrm{N})$ - sols/s & 0,1176 & 0,0583 & 0,0293 & 0,0146 & 0,0073 & 0,0036 \\
\hline $\mathrm{F}_{\mathrm{B}}(\mathrm{N})-$ Mflop & 198 & 396 & 792 & 1584 & 3168 & 6336 \\
\hline$R_{B}(N, p)-$ Mflop/s & 23,29 & 23,09 & 23,17 & 23,14 & 23,03 & 23,09 \\
\hline
\end{tabular}

Nota-se um desempenho bem pobre para a execução seqüencial não vetorizada. A versão vetorizada teve uma ligeira vantagem sobre as demais devido ao fato de esta utiliza-se intensivamente de registradores vetoriais, pipelines vetoriais e memoria cache local para comunicação e acesso aos dados. O mesmo não ocorre com diversos processadores já que estes tem que efetuar a comunicação via memória compartilhada inviabilizando o uso de cache local para comunicação e inserindo problemas de sincronização (acesso concorrente). O Gráfico 7.9, apresenta a execução das quatro versões. 


\section{Gráfico 7.9 - Tempo de execução do algoritmo do trapézio composto no slstema Cray.}

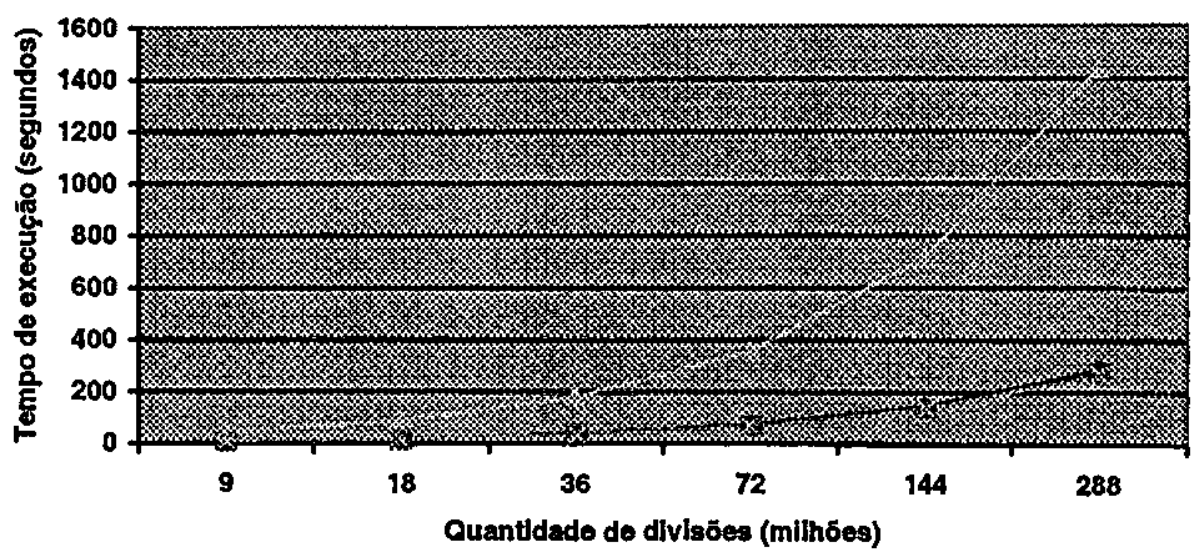

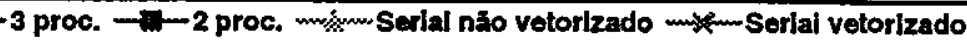

Os tempos de execução entre 3,2 , e 1 processador usando vetorização foi praticamente igual. A execução com 1 processador vetorial levou um pequena vantagem pelos motivos já mencionados como o acesso concorrente a memória.

O Gráfico 7.10 mostra o speedup e a eficiência alcançados no sistema Cray.

Grafico 7.10 - Eficiência e speed-up alcançados no sistema Cray.

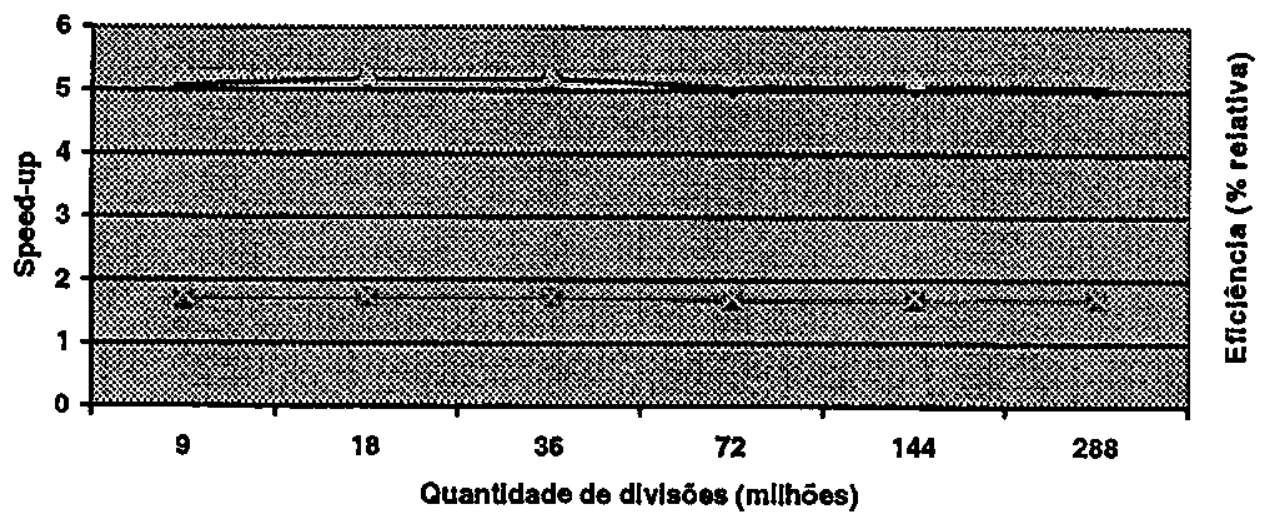

- Spoed-up 3 proc. minneEfliêncla 3 proc.

Speed-up 2 proc mixumenciência 2 proc.

Novamente encontra-se uma anomalia de speedup e de eficiência, não só pelo fato da máquina possuir muita memória, mas sim pelo fato de que a vetorização proporciona uma alta velocidade de processamento e pelo fato de que a execução seqüiencial foi extremamente pobre. 


\section{Comparação de arquiteturas}

A Tabela 7.11 seguida do Gráfico 7.11 apresentam um apanhado dos desempenhos benchmark encontrados nas três arquiteturas. A métrica utilizada para comparação será o Mflop/s, isto é, qual máquina consegue executar mais operações em ponto flutuante por segundo.

Tabela 7.11 - Comparação entre arquiteturas com 3 processadores

\begin{tabular}{|l|l|l|l|l|l|l|}
\hline$R_{B}($ N,p) & 9 & 18 & 36 & 72 & 144 & 288 \\
\hline SP2 - MPI & 38,08 & 38,15 & 38,04 & 38,12 & 38,17 & 36,04 \\
\hline SP2 - PVMe & 39,007 & 39,9471 & 40,26 & 40,4 & 40,5135 & 40,551 \\
\hline LASD - MPI & 19,6468 & 19,6914 & 19,711 & 19,6743 & 19,73 & 19,729 \\
\hline LASD - PVM & 18,18 & 21,193 & 21,3231 & 21,2402 & 21,18 & 21,309 \\
\hline Cray & 22,47 & 22,84 & 22,77 & 22,33 & 22,4 & 22,31 \\
\hline
\end{tabular}

Gráfico 7.11 - Comparação entre arquiteturas com 3 processadores executando o aigoritmo do trapézio.

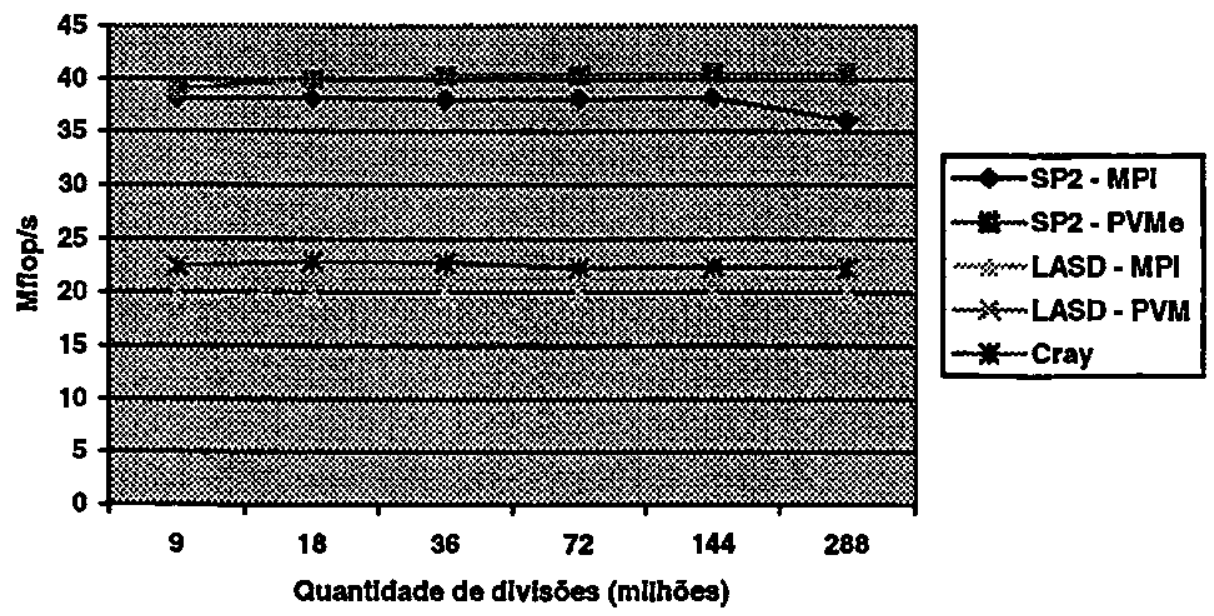

Como apresentado no Capítulo 3, devido a linearidade do problema, a métrica $R_{B}(N, p)$ pode ser usada para comparar arquiteturas sem nenhuma restrição. Pelo Gráfico 7.11 nota-se que a arquitetura SP 2 utilizando-se PVMe foi superior as demais. Apesar da arquitetura Cray ter tido um desempenho superior a do sistema distribuído, em termos de custo, não valeria a pena adquiri-la para utilizá-la com esse algoritmo. Um sistema distribúdo com mais memória (RAM e cache) seria mais rápido e extremamente mais barato.

A Tabela 7.12 e o Gráfico 7.12 apresentam os resultados obtidos no desempenho de benchmark para as três arquiteturas utilizando dois processadores. 
Tabela 7.12 - Comparação entre arquiteturas com 2 processadores

\begin{tabular}{|c|c|c|c|c|c|c|}
\hline & 9 & 18 & 36 & 72 & 144 & 288 \\
\hline$R_{B}(N, p) S P 2-M P I$ & 27,24 & 27,27 & 27,2 & 27,24 & 27,24 & 27,23 \\
\hline$R_{B}(\mathrm{~N}, \mathrm{p}) \mathrm{SP} 2$ - PVM $\theta$ & 38,08 & 38,15 & 38,04 & 38,12 & 38,17 & 36,04 \\
\hline$R_{B}(N, p)$ LASD-PC PVM & 13,8715 & 13,8663 & 13,8486 & 13,8915 & 13,8911 & 13,8888 \\
\hline$R_{B}(N, p)$ LASD-PC MPI & 13,03 & 13,04 & 13,045 & 13,05 & 13,049 & 13,05 \\
\hline $\mathrm{R}_{\mathrm{B}}(\mathrm{N}, \mathrm{p})$ Cray & 23,29 & 23,09 & 23,17 & 23,14 & 23,03 & 23,09 \\
\hline
\end{tabular}

Comparando a Tabela 7.12 com os tempos de execução encontrados, nota-se a mesma ordem ganho, ou seja, SP2 utilizando PVMe executou a aplicação em menor tempo seguido do SP2 utilizando MPI e assim por diante.

Gráfico 7.12 - Comparação entre arquiteturas com 3 processadores executando o algoritmo do trapézio.

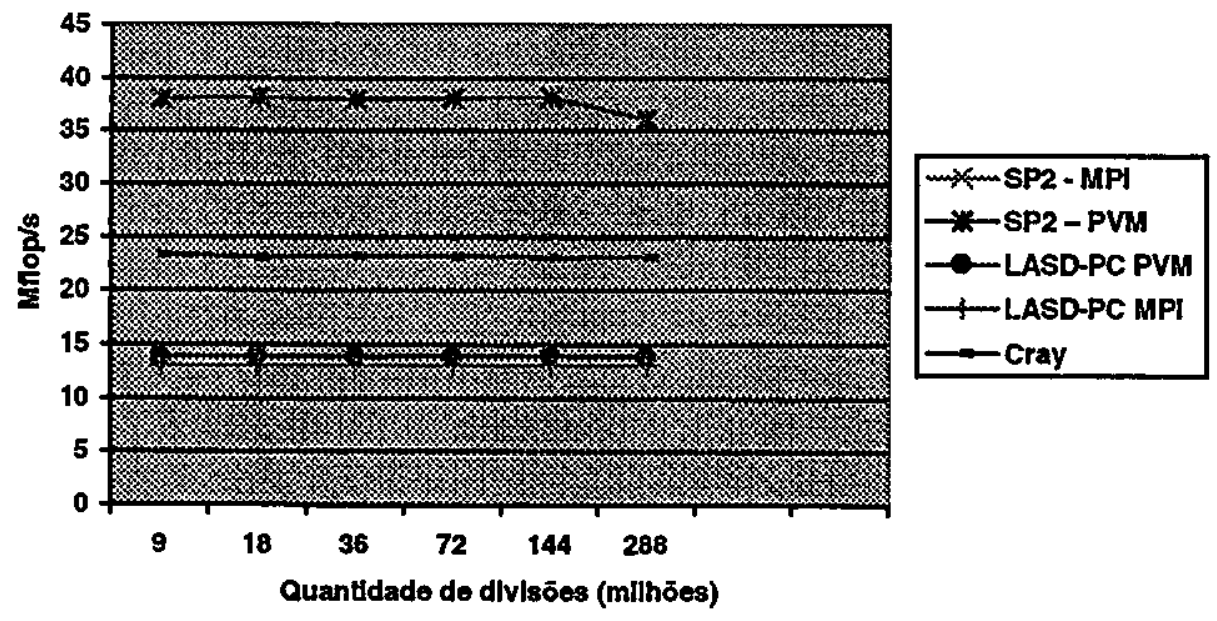

Novamente a arquitetura SP2 utilizando o PVMe teve um desempenho maior. O comportamento do PVM no LASD-PC também foi superior ao do MPI. Isso deve-se a eficiência do compilador ao gerar o código executável para as bibliotecas correspondentes.

\subsubsection{Resultado do algoritmo de Jacobi}

Esta seção apresenta os resultados obtidos executando o algoritmo de Jacobi. As linhas seguem o mesmo esquema das tabelas já apresentada. O cabeçalho das tabelas indicam o tamanho da matriz utilizada, por exemplo, 1200 indica que a matriz é de $1200 \times 1200$. 
As Tabelas 7.13 e 7.14 mostram os resultados encontrados na arquitetura SP2 utilizando a biblioteca de passagem de mensagem MPI.

Tabela 7.13 - Resultados encontrados no SP2 utilizando MPI com 3 processadores.

\begin{tabular}{|l|l|l|l|l|l|l|l|}
\hline & 300 & 600 & 900 & 1200 & 1500 & 1800 & 2100 \\
\hline 3 proc. & 0,0805 & 0,1132 & 0,3399 & 0,6328 & 0,9547 & 1,3414 & 1,8676 \\
\hline Serial & 0,0780 & 0,2688 & 0,6057 & 1,1595 & 1,6281 & 2,3461 & 3,1919 \\
\hline Speedup & 0,9689 & 2,3746 & 1,782 & 1,8323 & 1,7054 & 1,749 & 1,7091 \\
\hline Eficiência & 0,323 & 0,7915 & 0,594 & 0,6108 & 0,5685 & 0,583 & 0,5697 \\
\hline$R_{\mathrm{T}}(\mathrm{N})$ - sols/s. & 12,4224 & $\mathbf{8 , 8 3 3 9}$ & 2,942 & 12,4224 & 8,8339 & 2,942 & 1,5803 \\
\hline$F_{\mathrm{B}}(\mathrm{N})-$ Mflop & 0,4527 & 1,8054 & 4,0581 & $\mathbf{7 , 2 1 0 8}$ & 11,2635 & 16,2162 & 22,0689 \\
\hline$R_{B}(N, p)-$ Mflop/s & 5,6236 & 15,9488 & 11,9391 & 11,3951 & 11,7979 & 12,089 & 11,8167 \\
\hline
\end{tabular}

Tabela 7.14 - Resultados encontrados no SP2 utillzando MPI com 2 processadores.

\begin{tabular}{|l|l|l|l|l|l|l|l|}
\hline \multicolumn{2}{l}{300} & 600 & 900 & 1200 & 1500 & 1800 & 2100 \\
\hline 2 proc. & 0,3839 & 0,4002 & 0,5442 & 0,8227 & 1,1968 & 1,6505 & 2,2873 \\
\hline Serial & 0,0780 & 0,2688 & 0,6057 & 1,1595 & 1,6281 & 2,3461 & 3,1919 \\
\hline Speedup & 0,2032 & 0,6717 & 1,113 & 1,4094 & 1,3604 & 1,4214 & 1,3955 \\
\hline Eficiência & 0,1016 & 0,3359 & 0,5565 & 0,7047 & 0,6802 & 0,7107 & 0,6978 \\
\hline$R_{\mathrm{T}}(\mathrm{N})$ - sols/s & 2,6048 & 2,4988 & 1,8376 & 1,2155 & 0,8356 & 0,6059 & 0,4372 \\
\hline$F_{\mathrm{B}}(\mathrm{N})$-Mflop & 0,4527 & 1,8054 & 4,0581 & 7,2108 & 11,2635 & 16,2162 & 22,0689 \\
\hline$R_{B}(N, p)$-Mflop/s & 1,1792 & 4,5112 & 7,457 & 8,7648 & 9,4113 & 9,825 & 9,6485 \\
\hline
\end{tabular}

* $\mathrm{R}_{\mathrm{T}}(\mathrm{N})-$ Desempenho temporal

** $\mathrm{F}_{\mathrm{B}}(\mathrm{N})-\mathrm{Quantidade}$ de operaçōes em ponto flutuante

*** $R_{B}(\mathrm{~N}, \mathrm{p})$ - Desempenho do benchmark.

Como esperado, o tempo de execução em 3 processadores foi menor que o tempo para a execução em 2 processadores conforme mostra o Gráfico 7.13. Esta aplicação já não possui a mesma linearidade da aplicação anterior (algoritmo do trapézio). O algoritmo de Jacobi apresenta uma complexidade $n^{2}$, por esse motivo, a quantidade de operações em ponto flutuante cresce junto com o tamanho do problema e conseqüentemente o desempenho do benchmark $\left(R_{B}(N, p)\right)$ também é crescente.

Como esta é uma aplicação que executa um número maior de comunicaçōes (Figura 7.6) em comparação com as outras (trapézio e multiplicação de matriz) o speedup e a eficiência são números que devem ser utilizados com cautela para analisar o desempenho. $\mathrm{O}$ Gráfico 7.14 apresenta o speedup e a eficiência alcançados pela aplicação. Observa-se que para esse exemplo, obteve-se speedups razoáveis para os casos em que as matrizes de ordem mais elevadas foram consideradas. Mesmo para matrizes grandes, a eficiência não foi tão atrativa como nos outros exemplos. A maior quantidade de comunicação explica esses resultados. 


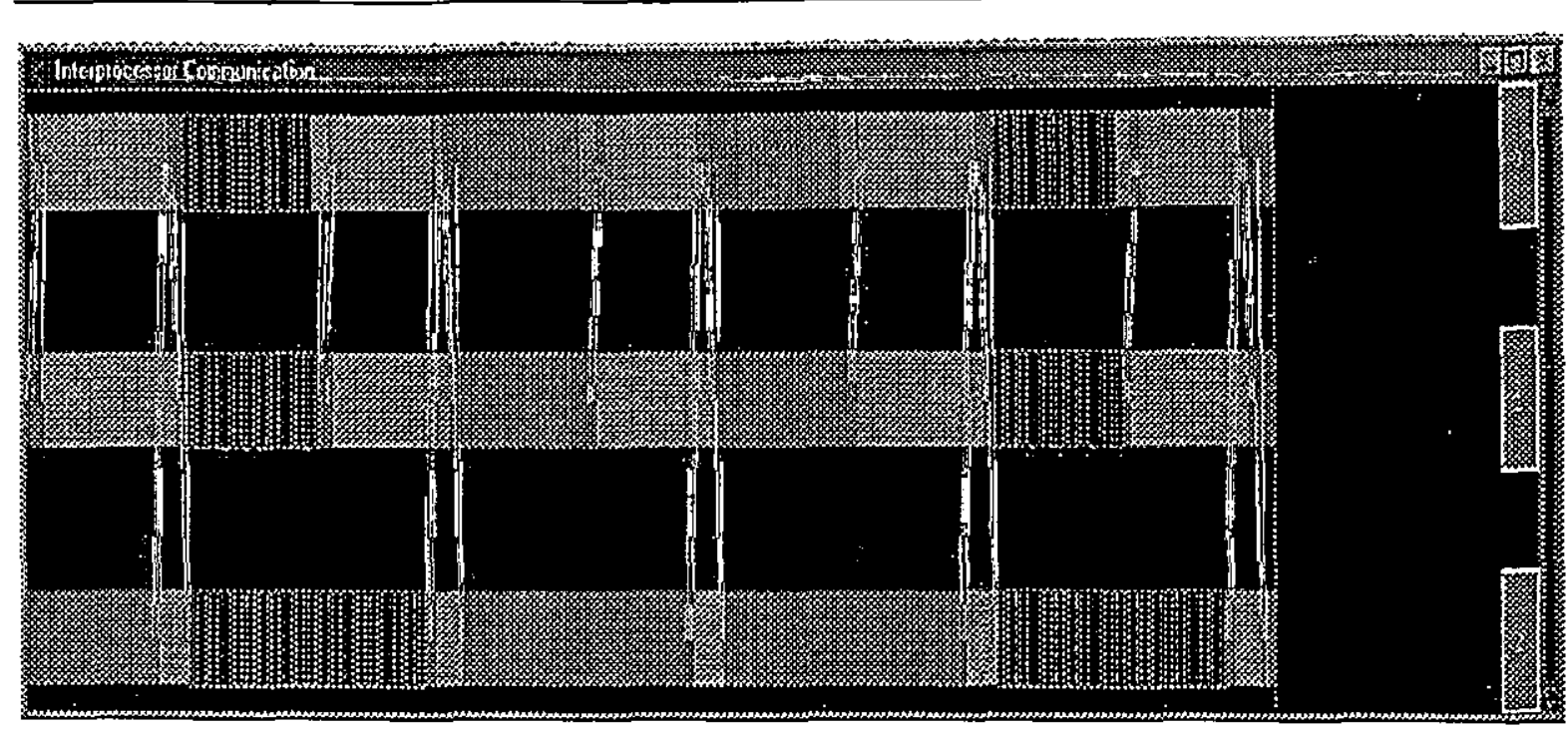

Figura 7.6 - Trecho final de comunicação no algorltmo de Jacobi.

Grátlco 7.13 - Tempo de execuçāo do algorltmo deJacobl no SP2 uttllzando o MPI.
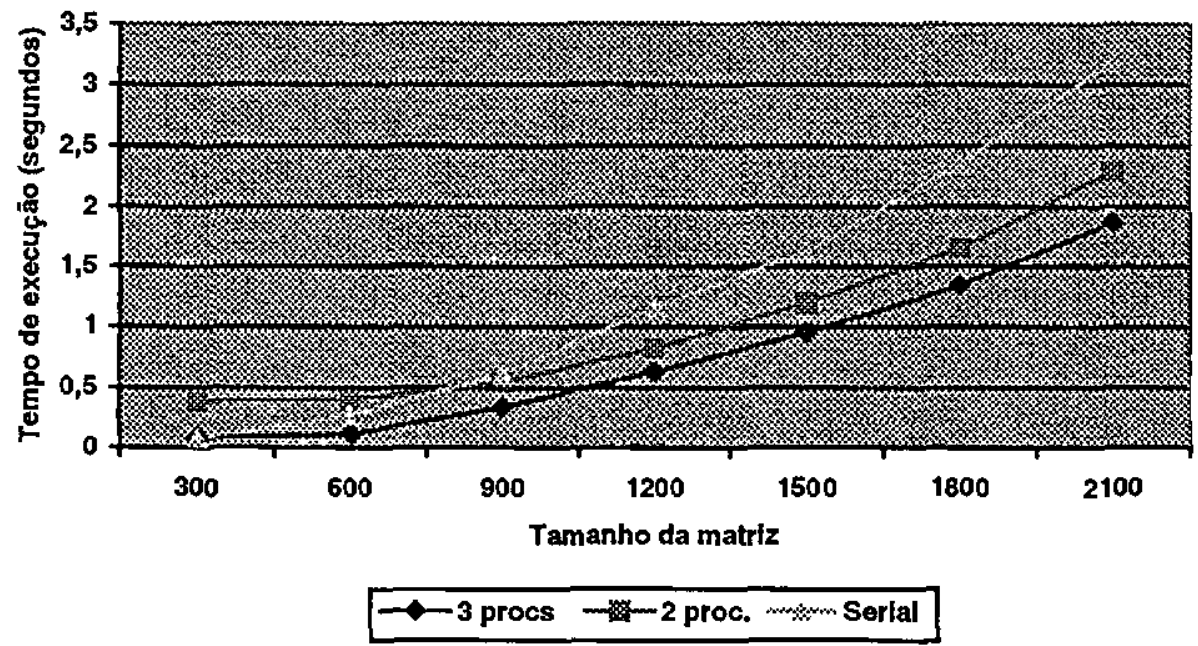

O tempo de execução serial, em 2 processadores e 3 processadores é praticamente o mesmo até uma matriz 600 x 600. Nota-se que a diferença cresce com o aumento do tamanho da matriz. Houve um encontro entre a execução com dois processadores com a linha serial para o tamanho da matriz de 900x900, isso é esperado já que a execução serial começou mais rápida que a com 2 processadores.

O Gráfico 7.14 apresenta o speedup e a eficiência mostradas nas Tabelas 7.13 e 7.14. 
Grafico 7.14 - Speedup e eficiência alcançados por 2 e 3 processadores no SP utilizando MPI.
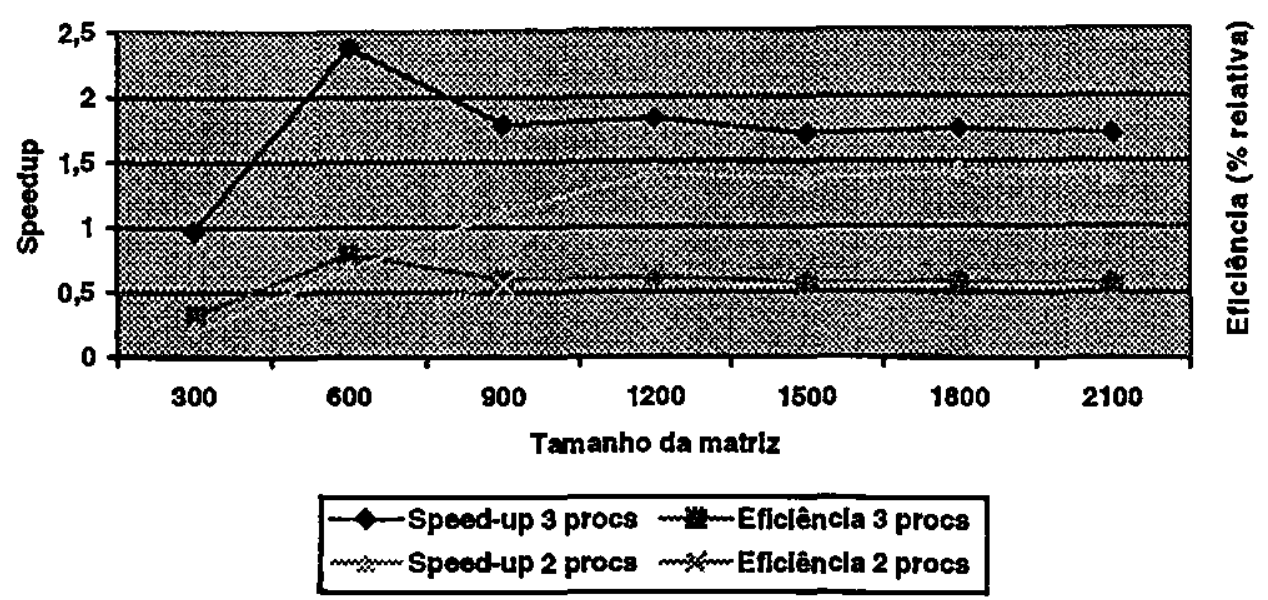

Pode-se observar que o gráfico já não é tão linear como os anteriores (algoritmo do trapézio). Isso deve-se ao fato de que a aplicação necessita de mais comunicação gerando assim mais sobrecarga (overhead), juntamente com este fator está a complexidade do problema. Novamente, deve-se ter cuidado com a eficiência que com dois processadores foi maior do que com três, mas não necessariamente foi a que teve melhor tempo de execução. Os speedups não apresentaram anomalias e conseqüentemente as eficiências também não.

A seguir, as Tabelas 7.15 e 7.16 apresentam os resultados encontrados quando o algoritmo de Jacobi é executado usando o PVMe no SP2.

Tabela 7.15 - Resultados encontrados no SP2 utilizando PVMe com 3 processadores.

\begin{tabular}{|c|c|c|c|c|c|c|c|}
\hline & 300 & 600 & 900 & 1200 & 1500 & 1800 & 2100 \\
\hline 3 proc. & 0,0541 & 0,4400 & 0,783 & 0,8301 & 1,2056 & 1,8218 & 1,9355 \\
\hline Serial & 0,0780 & 0,2688 & 0,6057 & 1,1595 & 1,6281 & 2,3461 & 3,1919 \\
\hline Speedup & 1,4418 & 0,6109 & 0,7736 & 1,3968 & 1,3504 & 1,2878 & 1,6491 \\
\hline Eficiência & 0,4806 & 0,2036 & 0,2579 & 0,4656 & 0,4501 & 0,4293 & 0,5497 \\
\hline$R_{T}(N)-$ sols $/ s$ & 0,4527 & 1,8054 & 4,0581 & 1,2047 & 0,8295 & 0,5489 & 0,5167 \\
\hline$F_{B}(N)-$ Mflop & 0,4527 & 1,8054 & 4,0581 & 7,2108 & 11,2635 & 16,2162 & 22,0689 \\
\hline$R_{B}(N, p)-$ Mflop/s & 8,3678 & 4,1032 & 5,1828 & 8,6867 & 9,3427 & 8,9012 & 11,4022 \\
\hline
\end{tabular}


Tabela 7.16 - Resultados encontrados no SP2 utillzando PYMe com 2 processadores.

\begin{tabular}{|c|c|c|c|c|c|c|c|}
\hline & 300 & 600 & 900 & 1200 & 1500 & 1800 & 2100 \\
\hline 2 proc. & 0,3839 & 0,4002 & 0,5442 & 0,9486 & 1,3184 & 2,1782 & 2,6366 \\
\hline Serial & 0,0780 & 0,2688 & 0,6057 & 1,1595 & 1,6281 & 2,3461 & 3,1919 \\
\hline Speedup & 0,2032 & 0,6717 & 1,113 & 1,2223 & 1,2349 & 1,0771 & 1,2106 \\
\hline Eficiência & 0,1016 & 0,3358 & 0,5565 & 0,6112 & 0,6175 & 0,5386 & 0,6053 \\
\hline$R_{T}(N)$ sols $/ \mathrm{s}$ & 0,4527 & 1,8054 & 4,0581 & 1,0542 & 0,7585 & 0,4591 & 0,3793 \\
\hline$F_{B}(N)-$ Mflop & 0,4527 & 1,8054 & 4,0581 & 7,2108 & 11,2635 & 16,2162 & 22,0689 \\
\hline$R_{B}(N, p)-$ Mflop/s & 1,1792 & 4,5112 & 7,457 & 7,6015 & 8,5433 & 7,4448 & 8,3702 \\
\hline
\end{tabular}

O tempo de execução para dois processadores foi superior até o tamanho de $900 \times 900$, fato que se deve ao tamanho relativamente pequeno da matriz. Quando o porte aumenta para $1200 \times 1200$ o desempenho em 3 processadores é nitidamente melhor. $O$ que fez com que o desempenho do benchmark aumentasse gradativamente foi a complexidade $n^{2}$ do problema.

O Gráfico 7.15 mostra a variação na execução do algoritmo de Jacobi para 1,2 e 3 processadores.

\section{Gráfico 7.15 - Tempo de execução do algoritmo de Jacobi no SP2 utilizando PVMe.}

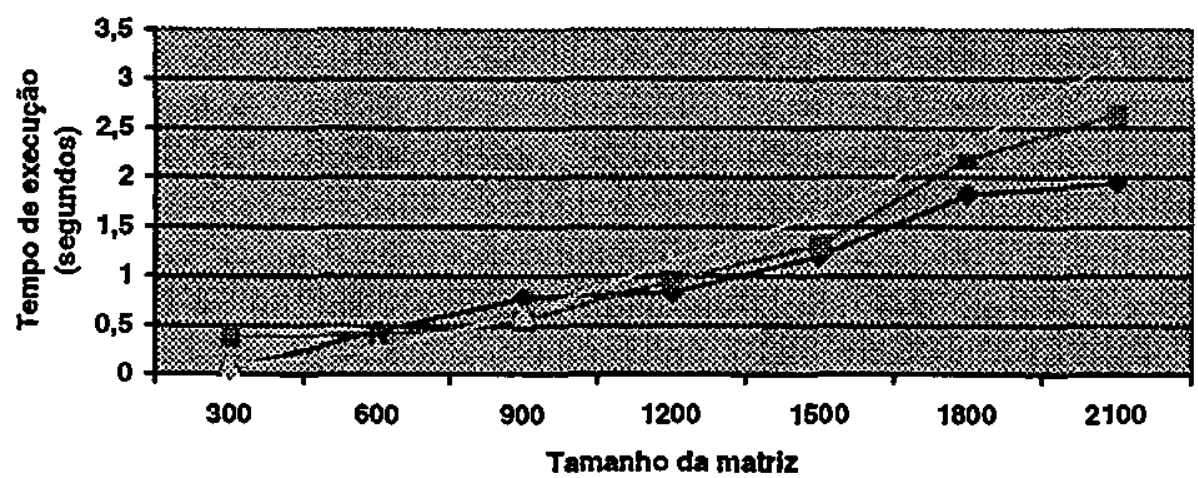

-3 proc. $-1+2$ proc. $m$ Serlal

Ainda no Gráfico 7.15 observa-se melhor a questão que envolve o tamanho das matrizes. Até 900 x 900 a sobrecarga na comunicação teve um fator decisivo no desempenho que nitidamente ficou melhor a partir da matriz de 1200 x 1200. O Gráfico 7.16 apresenta o speedup e a eficiência encontrados para 2 e 3 processadores conforme o tamanho do problema. Apesar do speedup ter sido melhor com 3 processadores ele está longe do ideal que seria 0 valor 3 (speedup=número_de_processadores). 


\section{Gráfico 7.16 - Speed-up e eficiência alcançados por 2 e 3} processadores no SP2 utilizando PVMe.

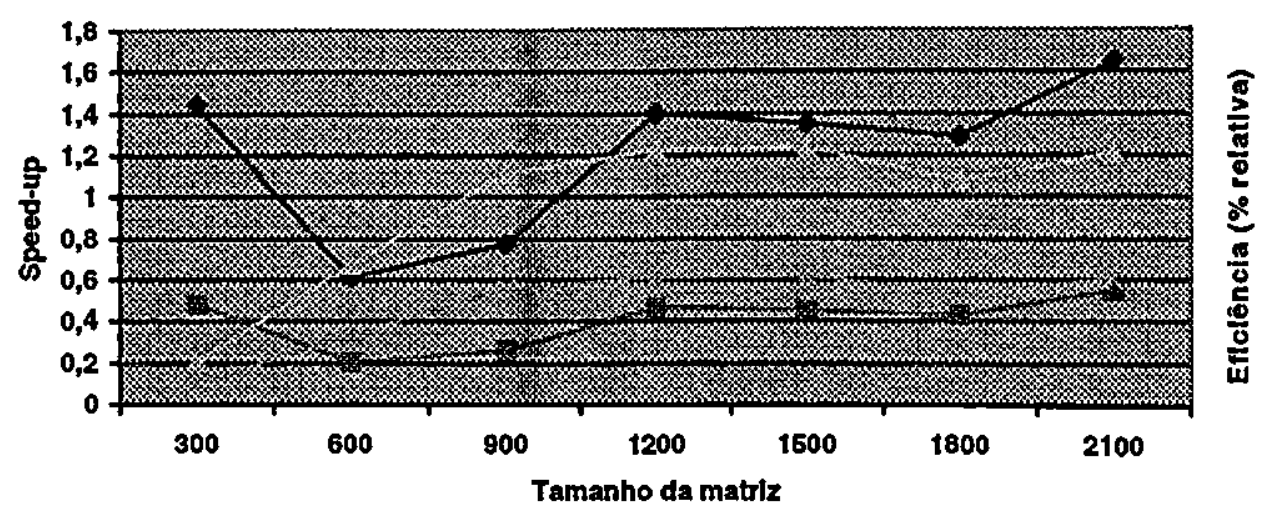

$$
\begin{aligned}
& \text { - - Speed-up } 3 \text { procs m minmeflelêncla } 3 \text { procs } \\
& \text { m.m.m Speod-up } 2 \text { procs maflelôncia } 2 \text { procs }
\end{aligned}
$$

As Tabelas 7.17 e 7.18 mostram os resultados obtidos utilizando-se o sistema distribuído (LASD-PC) com o MPI. O valor máximo para o tamanho da matriz foi de $1200 \times 1200$ sem alocação dinâmica, um teste com alocação dinâmica permitiu criar matrizes de até 2100 x 2100 , mas o ParkBench não permite a utilização de alocação dinâmica pois impede a comparação futura dos resultados obtidos com algoritmos implementados em Fortran 77.

\begin{tabular}{|c|c|c|c|c|}
\hline & 300 & 600 & 900 & 1200 \\
\hline 3 proc. & 0,2688 & 0,5966 & 0,8177 & 1,1772 \\
\hline Serial & 0,1159 & 0,4323 & 0,8874 & 1,7527 \\
\hline Speedup & 0,4312 & 0,7246 & 1,0852 & 1,4889 \\
\hline Eficiēncia & 0,2156 & 0,3623 & 0,5426 & 0,7445 \\
\hline$R_{T}(N)-$ sols $/ s$ & 0,19 & 0,1 & 0,05 & 0,02 \\
\hline$F_{B}(N)-$ Mflop & 0,4527 & 1,8054 & 4,0581 & 7,2108 \\
\hline$R_{B}(N, p)-$ Mflop/s & 1,6842 & 3,0261 & 4,9628 & 6,1254 \\
\hline
\end{tabular}

Tabela 7.17 - Resultados encontrados no LASD-PC utilizando MPI com 3 processadores.

\begin{tabular}{|c|c|c|c|c|}
\hline & 300 & 600 & 900 & 1200 \\
\hline 2 proc. & 0,3796 & 0,9556 & 1,0065 & 1,8197 \\
\hline Serial & 0,1159 & 0,4323 & 0,8874 & 1,7527 \\
\hline Speedup & 0,3053 & 0,4524 & 0,8817 & 0,9632 \\
\hline Eficiência & 0,1527 & 0,2262 & 0,4409 & 0,4816 \\
\hline$R_{T}(N)-$ sols $/ \mathrm{s}$ & 0,14 & 0,07 & 0,03 & 0,02 \\
\hline$F_{B}(N)-M f l o p$ & 0,4527 & 1,8054 & 4,0581 & 7,2108 \\
\hline$R_{B}(N, p)-$ Mflop/s & 1,1926 & 1,8893 & 4,0319 & 3,9626 \\
\hline
\end{tabular}

Tabela 7.18 - Resultados encontrados no LASD-PC utllizando MPI com 2 processadores. 
O desempenho do sistema distribuído foi muito baixo em relação a execução seqüencial. A única execução que teve um desempenho um pouco melhor, foi a execução em 3 processadores para uma matriz de 1200 × 1200. Apesar disso, o ganho foi tão pequeno que não valeria a pena investir em três máquinas para ter um resultado tão pouco eficiente. $O$ baixo desempenho verificado pode ser justificado pela grande quantidade de comunicação do algoritmo em questão e da ineficiência da comunicação da rede ethernet de 10Mbits utilizada. O Gráfico 7.17 mostra mais claramente a velocidade de execução.

\section{Gráfico 7.17 - Tempo de execução do algoritmo de Jacobi no LASD-PC utilizando MPI.}

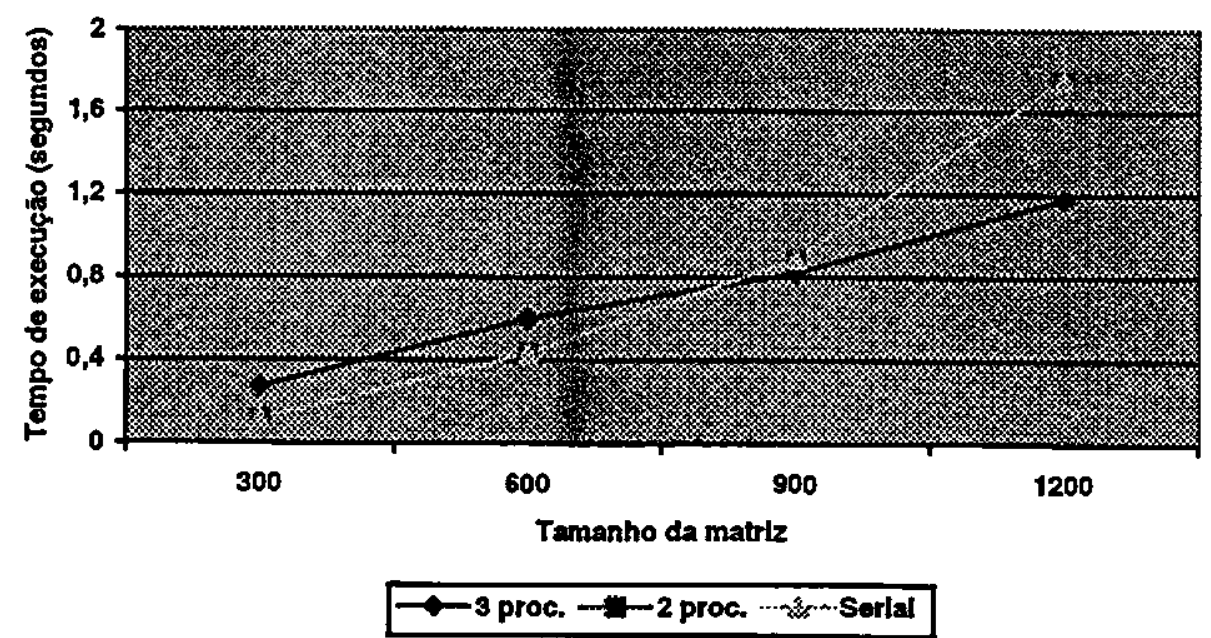

Quando o processamento com 2 processadores é comparado com o serial, o serial leva vantagem pois a execução do programa é muito rápida. Nota-se que para que haja um melhor desempenho o tamanho da matriz tem que ser igual ou superior a uma matriz de $900 \times 900$ em 3 processadores. Essa diferença é mais acentuada quando é utilizada uma matriz de $1200 \times 1200$, onde a distribuição de carga é mais notada. O Gráfico 7.18 mostra o speedup e a eficiência alcançados no sistema distribuído utilizando-se o MPI. 
Gráfico 7.18 - Speed-up e eficiência alcançados por 2 e 3 processadores no LASD-PC utilizando MPI.

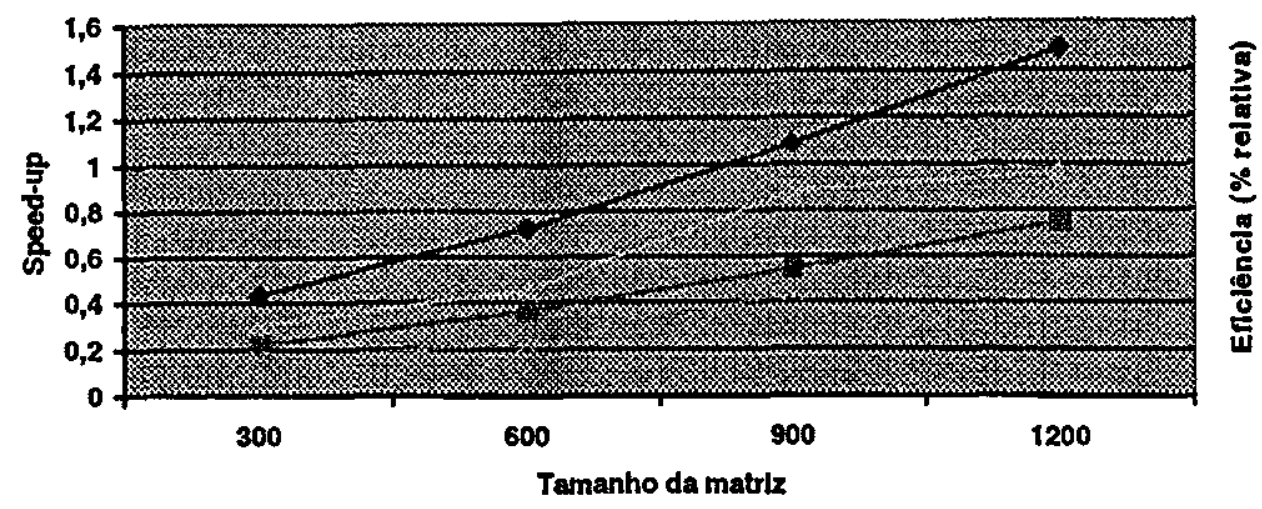

- Speed-up - 3 procs un min-Eflclêncla -3 procs mum Speed-up -2 procs un Efleléncia -2 procs

A eficiência para 2 processadores no Gráfico 7.18 é baixa considerando-se que ela deveria estar mais próxima de 1 para demonstrar um bom resultado. Com 3 processadores a eficiência só se torna atraente para uma matriz de tamanho de 1200 x 1200 já que está mais próxima de 1 . O speedup para 2 processadores mostra que o desempenho é pior que do serial já que ele está abaixo de 1 e o ideal serial que ele estivesse próximo de 2 . O speedup para 3 processadores também torna-se melhor utilizando-se uma matriz de $1200 \times 1200$, o que ainda é relativamente baixo, pois o ideal seria que ele estivesse próximo do valor 3 .

A seguir as Tabelas 7.19 e 7.20 mostram os resultado obtidos utilizando-se o sistema distribuído com a biblioteca de passagem de mensagem PVM.

Tabela 7.19 - Resultados encontrados no LASD-PC utilizando PVM com 3 processadores.

\begin{tabular}{|c|c|c|c|c|}
\hline & 300 & 600 & 900 & 1200 \\
\hline 3 proc. & 0,212 & 0,5839 & 1,6774 & 2,5729 \\
\hline Serial & 0,1159 & 0,4323 & 0,8874 & 1,7527 \\
\hline Speedup & 0,5467 & 0,7404 & 0,529 & 0,4906 \\
\hline Eficiência & 0,2734 & 0,3702 & 0,265 & 0,2453 \\
\hline$R_{T}(N)-$ sols $/ \mathrm{s}$ & 0,14 & 0,07 & 0,03 & 0,02 \\
\hline$F_{B}(N)-$ Mflop & 0,4527 & 1,8054 & 4,0581 & 7,2108 \\
\hline$R_{B}(N, p)-$ Mflop/s & 2,1354 & 3,092 & 2,4193 & 2,8026 \\
\hline
\end{tabular}


Tabela 7.20 - Resultados encontrados no LASD-PC utilizando PVM com 2 processadores.

\begin{tabular}{|l|l|l|l|l|}
\hline & 300 & 600 & 900 & 1200 \\
\hline 2 proc. & 0,258 & 0,6994 & 1,6797 & 2,4992 \\
\hline Serial & 0,1159 & 0,4323 & 0,8874 & 1,7527 \\
\hline Speedup & 0,5467 &, 6181 & 0,5283 & 0,7013 \\
\hline Eficiência & 0,2734 & 0,3091 & 0,2642 & 0,3507 \\
\hline$R_{\mathrm{T}}(\mathrm{N})-$ sols/s & 0,14 & 0,07 & 0,03 & 0,02 \\
\hline$F_{\mathrm{B}}(\mathrm{N})-$ Mflop & 0,4527 & 1,8054 & 4,0581 & 7,2108 \\
\hline$R_{B}(N, p)-$ Mflop/s & 1,7547 & 2,5814 & 2,416 & 2,8852 \\
\hline
\end{tabular}

O tempo de execução em 2 e 3 processadores foi muito pobre fazendo com que a execução serial tive-se um melhor desempenho. Grafico 7.17 mostra mais claramente os resultados encontrados no tempo de execução. A utilização do PVM mostrou-se neste exemplo, pior que a utilização do MPI na mesma plataforma de hardware, uma vez que em nenhum caso foi obtido um bom resultado.

Gráfico 7.19 - Tempo de execuçăo do algoritmo de Jacobl no LASD-PC utllizando PVM.

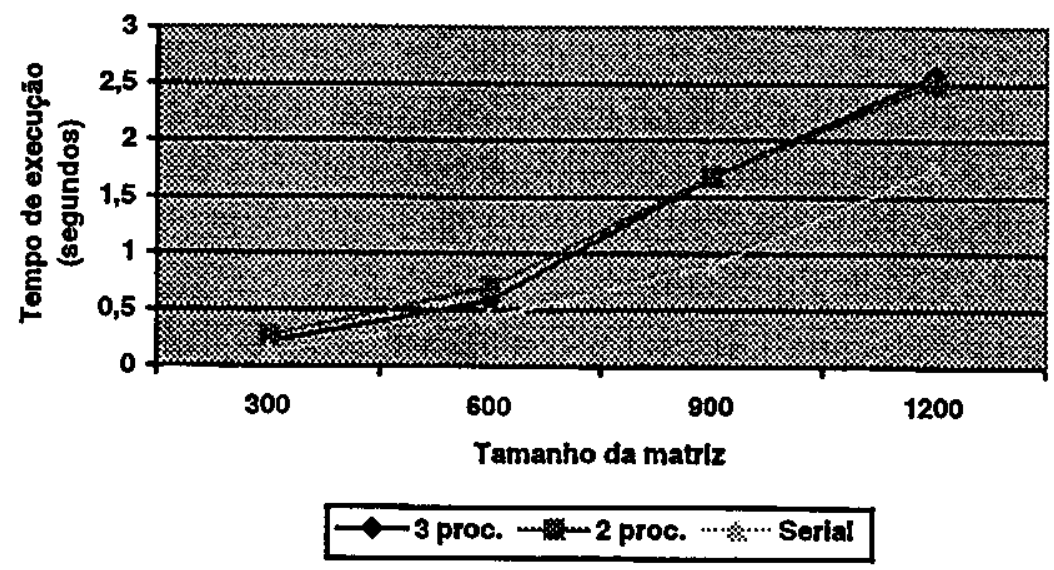

A execução serial foi nitidamente melhor que a execução em paralelo. Se o tamanho da matrix pudesse ser aumentado com certeza num determinado ponto essa situação se inverteria. A quantidade maior de comunicação nesse algoritmo foi o responsável pelo baixo desempenho. Neste caso o MPI (Mpich) teve um melhor desempenho na comunicação devido a sua capacidade de trabalhar bem com a comunicação de matrizes, vetores e estruturas complexas. $O$ Gráfico 7.20 apresenta o speedup e a eficiência alcançadas na execução. 
Gráfico 7.20 - Speed-up e eficiêncla alcançados por 2 e 3 proceseadores no LASD-PC utllizando PVM.
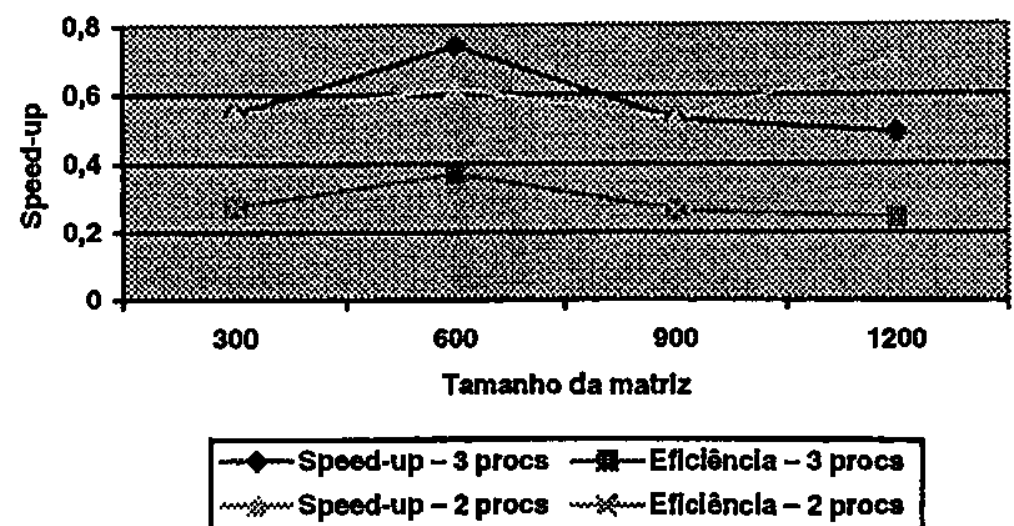

Verificando-se o eixo-y nota-se que todas as linhas estão abaixo do valor 1 , isso indica que o desempenho alcançado pela eficiência e pelo speedup foi inferior ao desempenho alcançado na execução serial.

As próximas tabelas (Tabela 7.21 e 7.22) apresentam os resultados encontrados na arquitetura Cray, mais precisamente na máquinas dolphin cujas características foram descritas no Capítulo 5.

Tabela 7.21 - Resultados encontrados no Cray uttilizando 3 processadores.

\begin{tabular}{|c|c|c|c|c|c|c|c|}
\hline & 300 & 600 & 900 & 1200 & 1500 & 1800 & 2100 \\
\hline 3 proc. & 0,0139 & 0,0325 & 0,0690 & 0,0948 & 0,1332 & 0,1687 & 0,2532 \\
\hline Serial vetorizado & 0,0112 & 0,0310 & 0,0680 & 0,0930 & 0,1288 & 0,1650 & 0,2174 \\
\hline Serial fi vetorizado & 0,2648 & 0,9728 & 2,1307 & 4,2008 & 5,5196 & 7,0303 & 9,3717 \\
\hline Speedup & 19,0504 & 29,9323 & 30,8797 & 44,3122 & 41,4384 & 41,6734 & 37,013 \\
\hline Eficlência & 6,3501 & 9,9774 & 10,2932 & 14,7707 & 13,8128 & 13,8911 & 12,3377 \\
\hline$R_{T}(N)-s o l s / s$ & 3,7764 & 1,028 & 0,4693 & 0,238 & 0,1812 & 0,1422 & 0,1067 \\
\hline$F_{B}(N)-M f l o p$ & 0,4527 & 1,8054 & 4,0581 & 7,2108 & 11,2635 & 16,2162 & 22,0689 \\
\hline$R_{B}(N, p)-$ Mflop/s & 32,57 & 55,551 & 58,813 & 76,0633 & 84,5608 & 96,1245 & 87,16 \\
\hline
\end{tabular}

Tabela 7.22 - Resultados encontrados no Cray uttlizando 2 processadores.

\begin{tabular}{|c|c|c|c|c|c|c|c|}
\hline & 300 & 600 & 900 & 1200 & 1500 & 1800 & 2100 \\
\hline 2 proc. & 0,0138 & 0,0326 & 0,0678 & 0,0963 & 0,1386 & 0,1706 & 0,2649 \\
\hline Serial vetorizado & 0,0112 & 0,0310 & 0,0680 & 0,0930 & 0,1288 & 0,1650 & 0,2174 \\
\hline Serial ñ vetorizado & 0,2648 & 0,9728 & 2,1307 & 4,2008 & 5,5196 & 7,0303 & 9,3717 \\
\hline Speedup & 19,1884 & 29,8405 & 31,4263 & 43,622 & 39,824 & 41,2093 & 35,3783 \\
\hline Eflciência & 9,5942 & 14,9202 & 15,7131 & 21,811 & 19,912 & 20,6047 & 17,6892 \\
\hline$R_{T}(\mathrm{~N})-\mathrm{sols} / \mathrm{s}$. & 3,7764 & 1,028 & 0,4693 & 0,238 & 0,1812 & 0,1422 & 0,1067 \\
\hline$F_{B}(N)-$ Mflop & 0,4527 & 1,8054 & 4,0581 & 7,2108 & 11,2635 & 16,2162 & 22,0689 \\
\hline$R_{B}(N, p)-$ Mflop/s & 32,8 & 55,38 & 59,854 & 74,8785 & 81,2662 & 95,0539 & 83,3103 \\
\hline
\end{tabular}


Novamente, nota-se um desempenho muito pobre no tempo de execução sem vetorização. Devido a implementação fazer uso exaustivo de vetores, a execução com vetorização teve um ganho excelente como pođe ser visto no Gráfico 7.21. Da mesma forma que na aplicação anteriores a vetorização em um único processador teve um desempenho superior aos demais, relembrando que esse ganho deve-se a utilização de registradores vetoriais, pipelines vetoriais e cache local. A comunicação entre processadores envolve acesso a memória RAM criando problemas de sincronização e limitando a utilização dos registradores vetoriais e dos pipelines vetoriais a alguns dados.

\section{Gráfico 7.21 - Tempo de execuçăo do algoritmo de Jacobi} na sistema Cray.

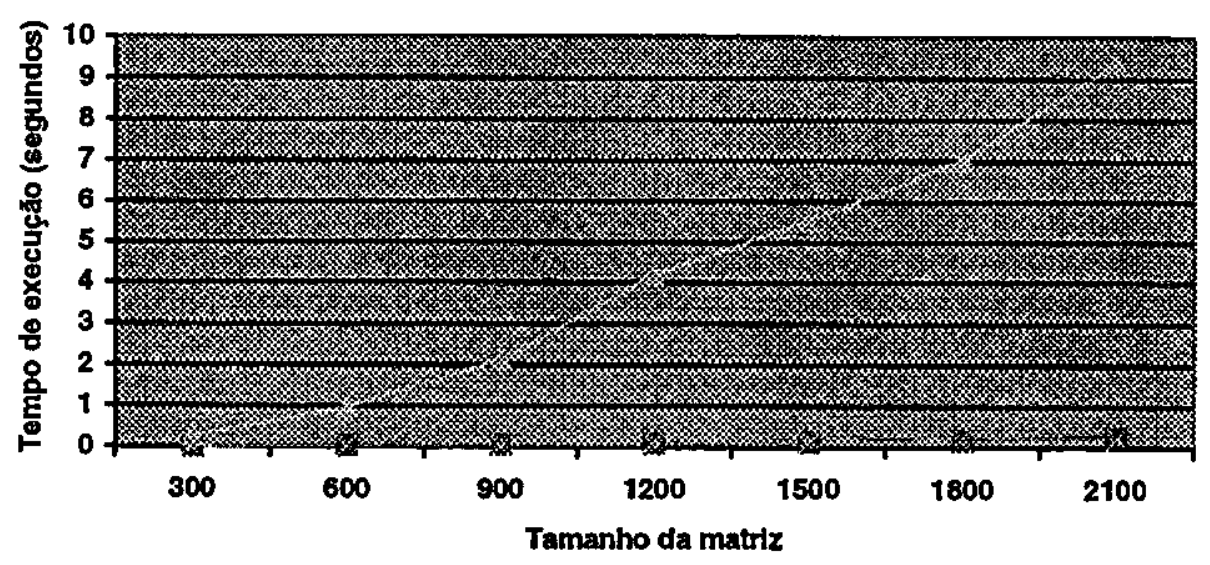

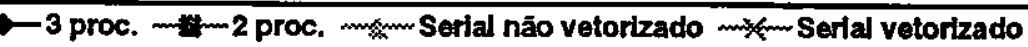

O Gráfico 7.20 mostra o speedup e a eficiência alcançada neste tipo de arquitetura. $O$ baixo desempenho da execução sem vetorização novamente foi o responsável pela anomalia de speedup e pela anomalia da eficiência. 


\section{Grafico 7.22 - Speedup e eficiência alcançados no sistema Cray.}

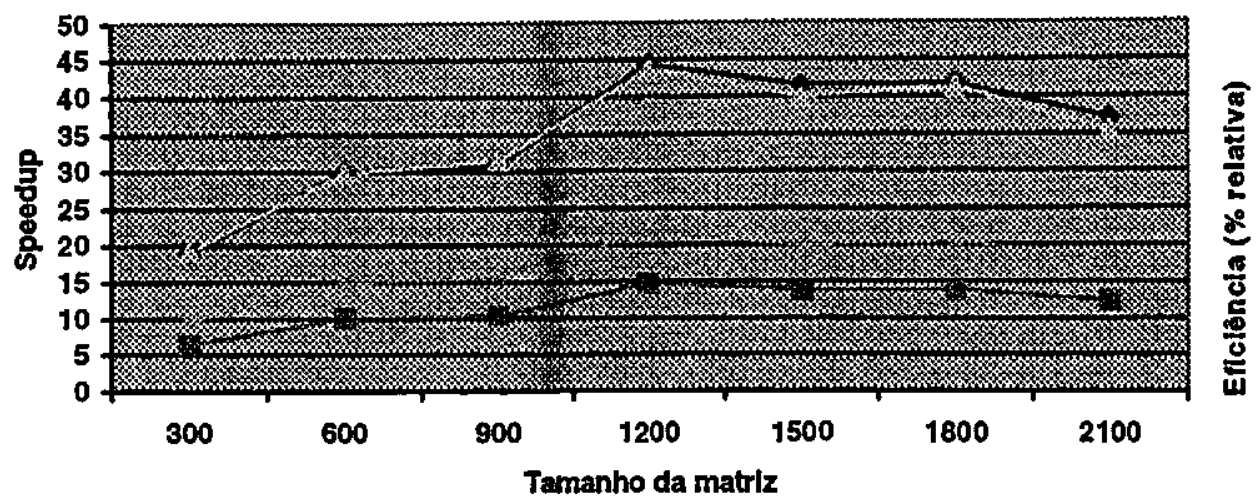

-Speed-up - 3 procs. - Exiclencla - 3 procs

Speed-up - 2 procs $m$ Strim Eficlencla -2 procs

\section{Comparação entre arquiteturas}

As Tabelas 7.23 e 7.24 resumem o desempenho do benchmark para o algoritmo de multiplicação de matrizes para 3 e 2 processadores respectivamente.

Observando-se o Gráfico7.23, nota-se o comportamento não linear da aplicação em todas as arquiteturas.

Tabela 7.23 - Desempenho do benchmark para 3 processadores.

\begin{tabular}{|l|l|l|l|l|l|l|l|}
\hline & 300 & 600 & 900 & 1200 & 1500 & 1800 & 2100 \\
\hline SP2 MPI & 5,6236 & 15,9488 & 11,9391 & 11,3951 & 11,7979 & 12,089 & 11,8167 \\
\hline SP2 PVMe & 8,3678 & 4,1032 & 5,1828 & 8,6867 & 9,3427 & 8,9012 & 11,4022 \\
\hline LASD-PC MPI & 1,6842 & 3,0261 & 4,9628 & 6,1254 & - & - & - \\
\hline LASD-PC PVMe & 2,1354 & 3,092 & 2,4193 & 2,8026 & - & - & - \\
\hline Cray & 32,57 & 55,551 & 58,813 & 76,0632 & 84,5608 & 96,1244 & 87,1599 \\
\hline
\end{tabular}

Devido a aplicação trabalhar intensivamente com vetores e a mesma ter sido gerada com um nível agressivo de vetorização, a arquitetura Cray teve nítida vantagem sobre as outras como pode ser visto no Gráfico 7.23 . 
Grafico 7.23 - Comparação entre arqulteturas com 3 processadores executando o algoritmo de Jacobl.

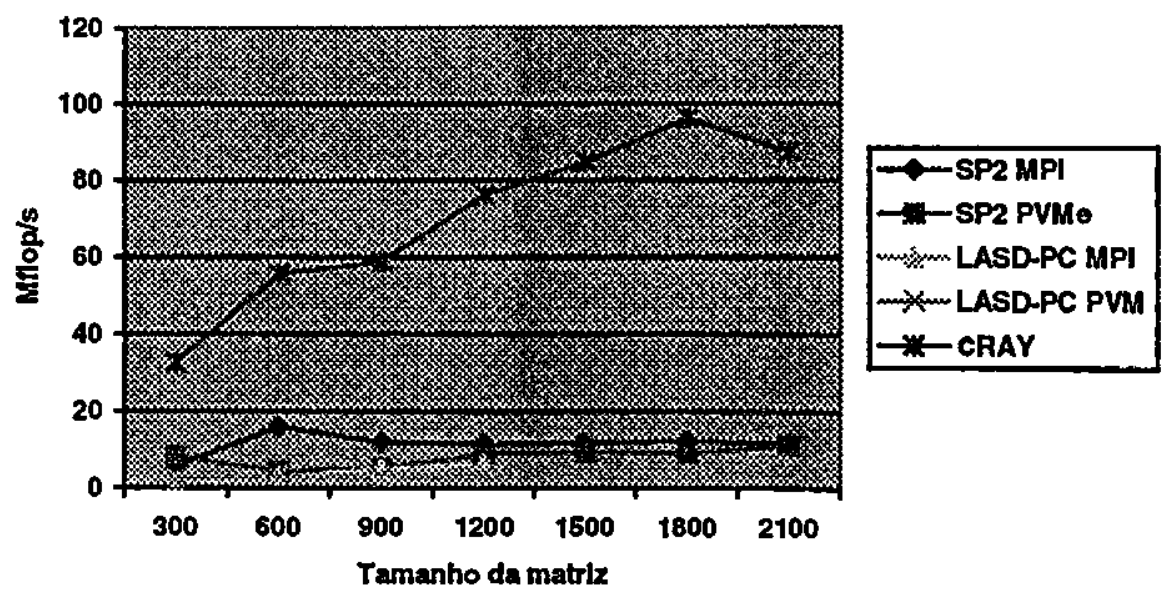

A Tabela 7.24 mostra um resumo do $\mathrm{RB}(\mathrm{N})$ para 2 processadores.

Tabela 7.24 - Desempenho do benchmark para 3 processadores.

\begin{tabular}{|c|c|c|c|c|c|c|c|}
\hline & 300 & 600 & 900 & 1200 & 1500 & 1800 & 2100 \\
\hline SP2 MPI & 1,1792 & 4,5112 & 7,457 & 8,7648 & 9,4113 & 9,825 & 9,6485 \\
\hline SP2 PVMe & 1,1792 & 4,5112 & 7,457 & 7,6015 & 8,5433 & 7,4448 & 8,3702 \\
\hline LASD-PC MPI & 1,1926 & 1,8893 & 4,0319 & 3,9626 & - & - & - \\
\hline LASD-PC PVMe & 1,7547 & 2,5814 & 2,416 & 2,8852 & - & - & - \\
\hline Cray & 32,8 & 55,38 & 59,8539 & 74,8785 & 81,2662 & 95,0539 & 83,3103 \\
\hline
\end{tabular}

Através do Gráfico 7.24 nota-se que o comportamento foi semelhante a execução com 3 processadores. E como era de se esperar, a aplicação vetorial levou nítida vantagem sobre as demais arquiteturas. 
Gráfico 7.24 - Comparaçăo entre arquiteturas com 2 processadores executando o algoritmo de Jacobi.

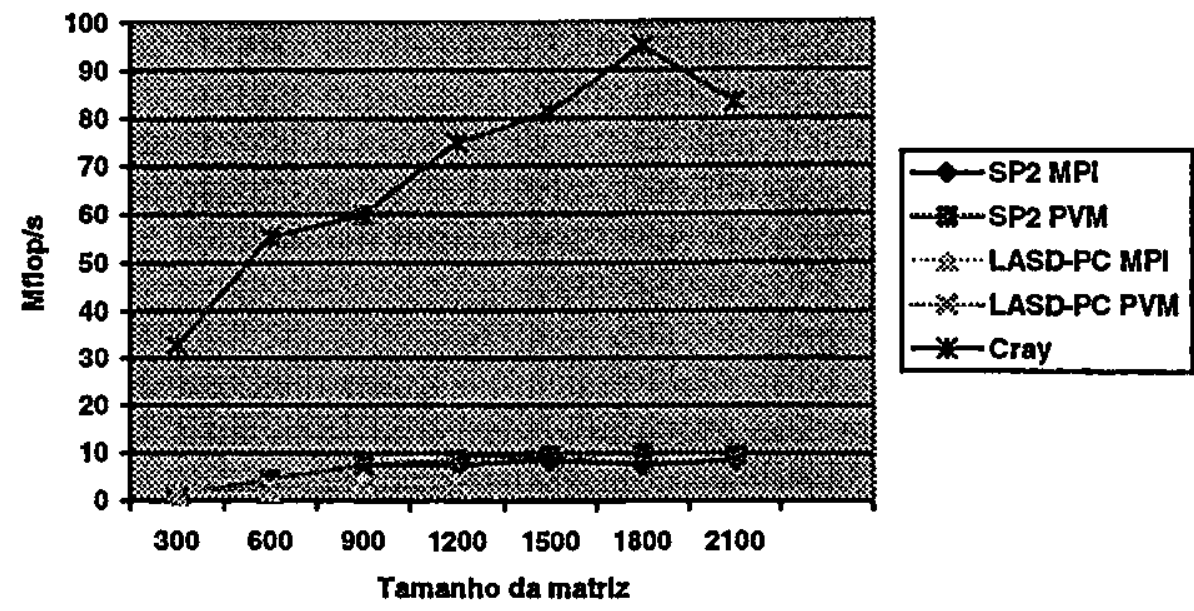

\subsubsection{Resultado do programa de multiplicação de matrizes}

Neste seção são apresentados os resultado obtidos na execução do algoritmo tradicional de multiplicação de matrizes apresentado no Capítulo 6.

As tabelas 7.25 e 7.26 mostram os resultados encontrados na execução do programa no SP2 utilizando o MPI.

Tabela 7.25 - Resultados encontrados no SP2 utillzando MPI com 3 processadores.

\begin{tabular}{|c|c|c|c|c|c|}
\hline & 90 & 180 & 360 & 720 & 1440 \\
\hline 3 proc. & 0,0167 & 0,1068 & 0,6697 & 58,621 & 667,416 \\
\hline Serial & 0,0431 & 0,3523 & 2,7995 & 278,723 & 1072,73 \\
\hline Speedup & 2,5808 & 3,2987 & 4,1802 & 4,7547 & 1,6073 \\
\hline Eficiência & 0,8603 & 1,0996 & 1,3934 & 1,5849 & 0,5358 \\
\hline$R_{\mathrm{T}}(\mathrm{N})-\mathrm{sols} / \mathrm{s}$ & 1,5803 & 1,0474 & 0,7455 & 0,5354 & 0,4174 \\
\hline$F_{B}(N)-$ Mflop & 2,4386 & 18,5014 & 143,9877 & 1135,818 & 9020.00 \\
\hline$R_{B}(N, p)$ Mflop/s & 146,024 & 173,2341 & 215,0033 & 19,3756 & 13,5148 \\
\hline
\end{tabular}


Tabela 7.26 - Resultados encontrados no SP2 utillzando MPI com 2 processadores.

\begin{tabular}{|c|c|c|c|c|c|}
\hline & .90 & 180 & 360 & 720 & 1440 \\
\hline 2 proc. & 0,0188 & 0,1321 & 0,9427 & 67,7456 & 689,2 \\
\hline Serial & 0,0431 & 0,3523 & 2,7995 & 278,723 & 1072,73 \\
\hline Speedup & 2,2926 & 2,6669 & 2,9697 & 4,1143 & 1,5565 \\
\hline Eficiência & 1,1463 & 1,3335 & 1,4849 & 2,0572 & 0,7783 \\
\hline$R_{T}(N)-$ sols $/ \mathrm{s}$ & 1,0542 & 1,5011 & 1,1226 & 0,8752 & 0,6945 \\
\hline$F_{B}(N)-M f l o p$ & 2,4386 & 18,5014 & 143,9877 & 1135,818 & 9020,00 \\
\hline$R_{B}(N, p)-$ Mflop/s & 129,7128 & 140,056 & 152,7397 & 16,7659 & 13,0876 \\
\hline
\end{tabular}

Os três primeiros valores de tempo de execução são baixos devido a comunicação com estruturas mais complexas através do MPI ser mais eficiente. Nota-se o crescimento do tempo de execução de acordo com a complexidade do problema que é de $n^{3}$. Logicamente, isso leva a uma queda de desempenho observada tanto no speedup quanto no desempenho do benchmark $\left(R_{B}(N)\right)$ a partir de uma matriz de 1440 x 1440 . Essa queda deve-se a grande quantidade de trocas de páginas entre a memória RAM e a memória cache. Nota-se que para cada matriz de 1440 x 1440 é exigido uma memória de aproximadamente 16 Mbytes e o SP2 possui uma memória cache de 256 Kbytes para o nó wide e 128 Kbytes para os nós thin. Dessa forma, uma matriz de 720 x 720 acessa muito menos a memória RAM do que uma matriz de 1440 x 1440. Essa diferença de memória exigida pelas matrizes, aliada a complexidade do problema, causa uma queda brusca de desempenho na matriz de 1440 x 1440 . O Gráfico 7.25 mostra mais claramente os tempos de execução.

Gráfico 7.25 - Tempo de execuçăo do algoritmo de multiplicação de matrizes no SP 2 utilizando MPI.

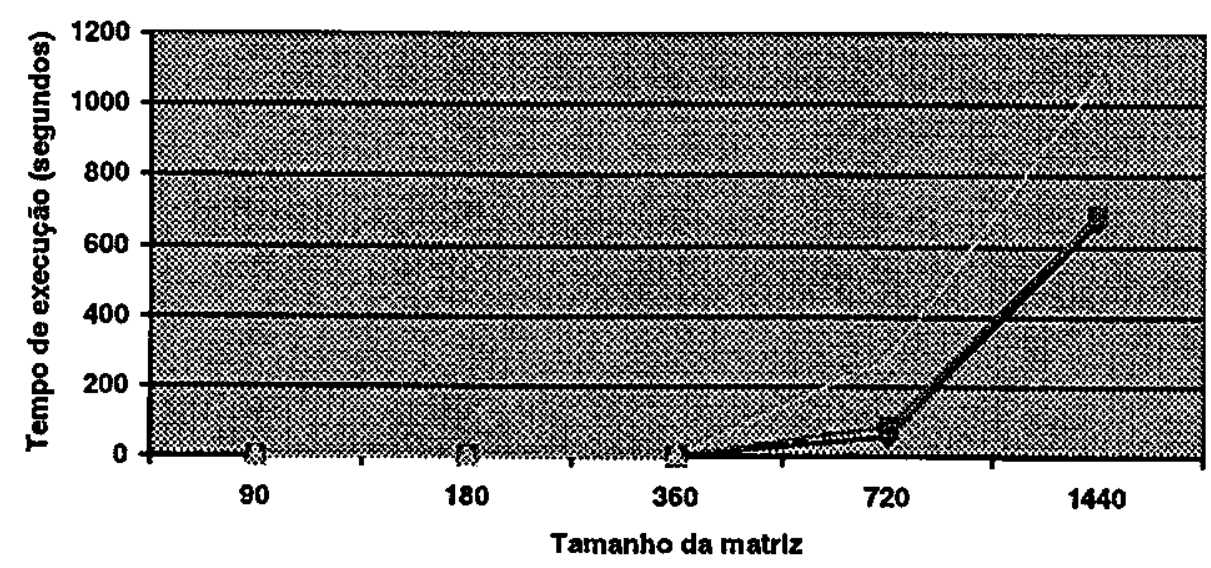

3 proc. $-2-2$ proc. muspers Serial 
Pelo tamanho das matrizes o tempo de execução é semelhante até um certo ponto, mais precisamente até uma matriz de $360 \times 360$. A partir da matriz de $720 \times 720$ a distribuição de trabalho entre os processadores já é nitidamente notada dada a diferença dos tempos de execução entre a versão paralela e a versão serial.

\section{Grático 7.26 - Speedup e eficiêncla alcançados por $2 \theta$} 3 processadores no SP2 utilizando MPI.
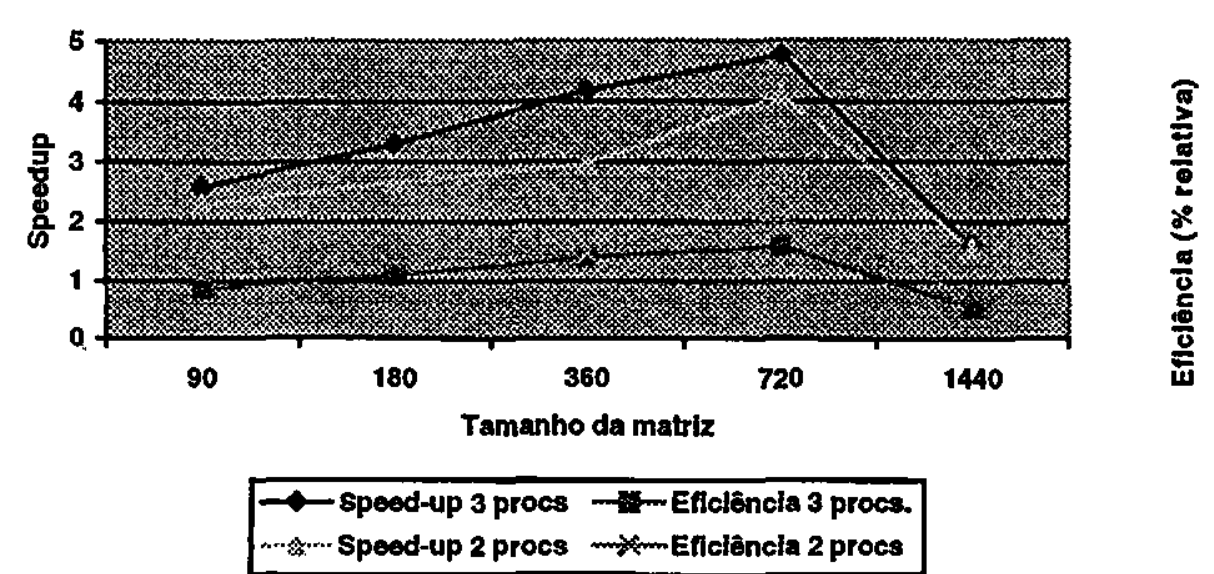

No Gráfico 7.26 é apresentado o speedup e a eficiência alcançados por 2 e 3 processadores. Para um problema de tamanho 1440 x 1440, há uma queda relativamente grande de speedup tanto para 2 como para 3 processadores, essa queda também deve-se a anomalia gerada nas matrizes de $180 \times 180$ a $720 \times 720$. Essa anomalia é gerada pelo tamanho relativamente pequeno dessas matrizes $(90 \times 90,180 \times 180$ e $720 \times 720)$ o que leva a um maior uso da memória cache. Como já mencionado, cada matriz de $720 \times 720$ ocupa aproximadamente 4 Mbytes de memória RAM e cada matriz de 1440 x 1440 ocupa por volta de 16 Mbytes. A queda de desempenho não é maior porque todas as matrizes são armazenadas na memoria. A grande quantidade de memória RAM disponível em cada nó do SP2 (128 Mbytes cada nó thin e 256 Mbytes o nó wide) permite que as três matrizes sejam armazenadas em cada um dos nós. Se a memória não fosse suficiente haveria acesso a disco e a queda seria ainda mais acentuada..

As Tabelas 7.27 e 7.28 apresentam os resultados encontrados na arquitetura SP2 utilizando-se a biblioteca de passagem de mensagem PVMe. 
Tabela 7.27 - Resultados encontrados no SP2 utillzando PVMe com 3 processadores.

\begin{tabular}{|l|lll|l|l|l|}
\hline & 90 & 180 & 360 & 720 & 1440 \\
\hline 3 proc. & 0,3442 & 0,4303 & 1,4285 & 102,144 & 684,692 \\
\hline Serial & 0,0431 & 0,3523 & 2,7995 & 278,723 & 1072,73 \\
\hline Speedup & 0,1252 & 0,8187 & 1,9597 & 2,728726 & 1,5667 \\
\hline Eficiência & 0,0417 & 0,2729 & 0,6532 & 0,909575 & 0,5222 \\
\hline$R_{\mathrm{T}}(\mathrm{N})$ sols/s & 0,197 & 0,1009 & 0,05 & 0,03 & 0,0128 \\
\hline $\mathrm{F}_{\mathrm{B}}(\mathrm{N})$ - Mflop & 2,4386 & 18,5014 & 143,9877 & 1135,818 & 9020,00 \\
\hline$R_{B}(\mathrm{~N}, \mathrm{p})$ - Mflop/s & 7,0848 & 42,9965 & 100,7964 & 11,1198 & 13,1738 \\
\hline
\end{tabular}

Tabela 7.28 - Resultados encontrados no SP2 utilizando PVMe com 2 processadores.

\begin{tabular}{|l|lll|l|l|l|}
\hline & 90 & 180 & 360 & 720 & 1440 \\
\hline 2 proc. & 0,2829 & 0,4703 & 1,3750 & 86,6146 & 826,723 \\
\hline Serial & 0,0431 & 0,3523 & 2,7995 & 278,723 & 1072,73 \\
\hline Speedup & 0,1524 & 0,7491 & 2,036 & 3,218 & 1,2976 \\
\hline Eficiência & 0,0762 & 0,3746 & 1,018 & 1,609 & 0,6488 \\
\hline$R_{\mathrm{T}}(\mathrm{N})$ - sols/s. & 1,0542 & 1,5011 & 1,1226 & 0,8752 & 0,6945 \\
\hline $\mathrm{F}_{\mathrm{B}}(\mathrm{N})$ - Mflop & 2,4386 & 18,5014 & 143,9877 & 1135,818 & 9020,00 \\
\hline$R_{B}(N, p)$-Mflop/s & 8,62 & 39,3396 & 104,7183 & 13,1135 & 10,91055 \\
\hline
\end{tabular}

O comportamento utilizando o PVMe no SP2 foi semelhante ao do MPI com a uma pequena vantagem para o MPI. Isso deve-se ao fato de que o PVMe não é otimizado para realizar a comunicação de matrizes e estruturas mais complexas. Através do Gráfico 7.27 observa-se que a distribuição de carga é notada a partir de uma matriz de $720 \times 720$ onde o tempo de execução em paralelo passa a ser melhor que o tempo de execução seqüencial. $O$ tempo de execução foi consideravelmente melhor a partir de uma matriz de 1440 x 1440.

Gráfico 7.27 - Tempo de execução do algoritmo de multipllcação de matrizes no SP2 utilizando PVM

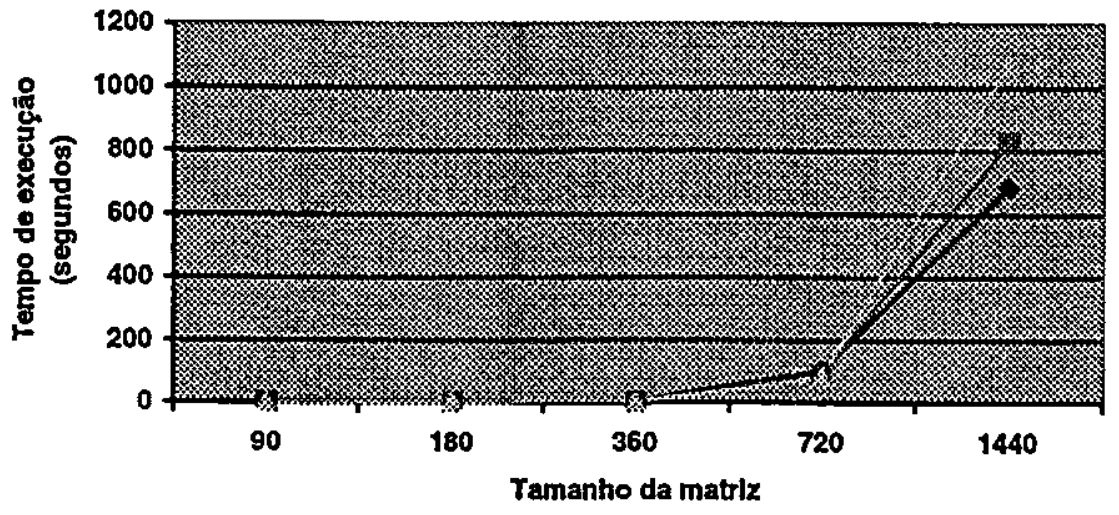

-3 proc. - 2 proc. 
O Gráfico 7.28 mostra o speedup e a eficiência alcançados pela execução do algoritmo de multiplicação de matrizes no SP2 utilizando o PVMe.

\section{Gráfico 7.28 - Speed-up e eficlência alcançados poe 2 e 3 processadores no SP2 utilizando PVMe}
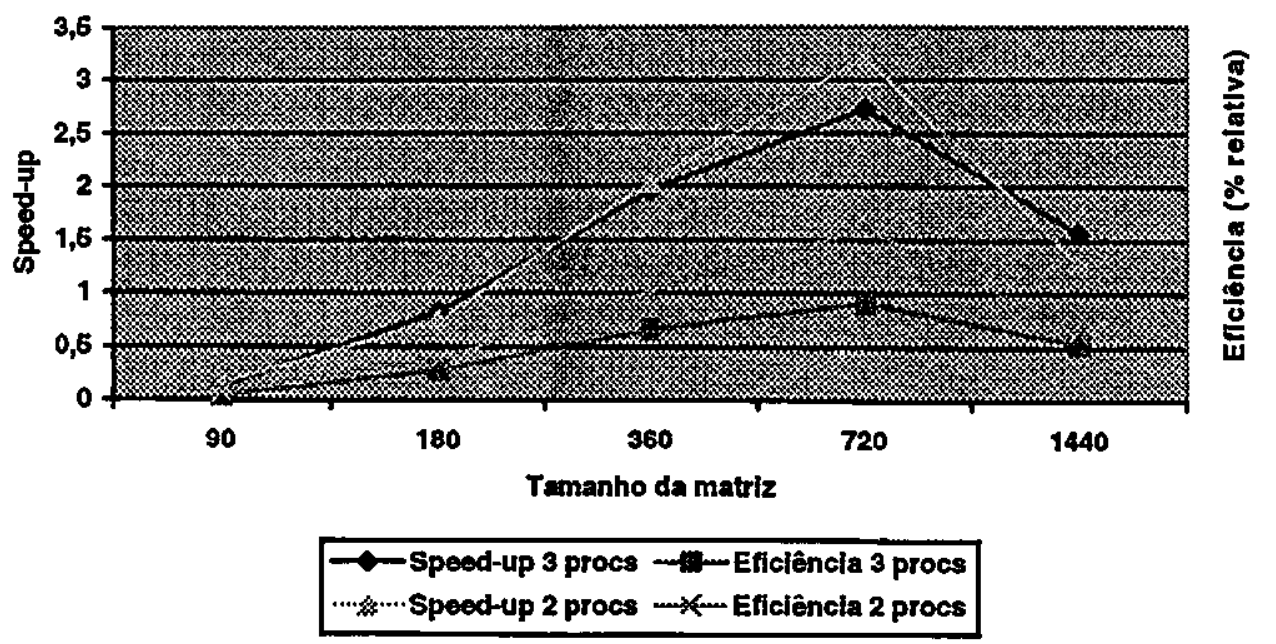

Os Gráficos 7.28 e 7.26 tiveram comportamentos semelhantes pelos mesmos motivos, ou seja, a memória cache foi a grande responsável pelo desempenho. Observa-se que no $R_{B}(N)$, também existe uma queda acentuada a partir de uma matriz de 720 x 720. Isso demonstra a influência da memória cache na obtenção de desempenho.

As Tabelas 7.29 e 7.30 mostram a execução do algoritmo de multiplicação de matrizes no sistema distribuído utilizando o MPI. Polo fato de que só foi utilizada alocação estática de memória, no sistema distribuído só foi possível multiplicar matrizes de até 360 x 360 . A alocação estática é utilizada pois o NAS não permite o uso de alocação dinâmica.

Tabela 7.29 - Resultados encontrados no LASD-PC utilizando MPI com 3 processadores.

\begin{tabular}{|c|c|c|c|}
\hline & 90 & 180 & 360 \\
\hline 3 proc. & 0,4136 & 5,2911 & 39,4338 \\
\hline Serial & 0,097 & 1,0429 & 17,9138 \\
\hline Speedup & 0,2345 & 0,1971 & 0,4543 \\
\hline Eficiência & 0,0782 & 0,0657 & 0,1514 \\
\hline$R_{\mathrm{T}}(\mathrm{N})-\mathrm{sols} / \mathrm{s}$. & 0,19 & 0,1 & 0,05 \\
\hline$F_{B}(N)-$ Mflop & 2,4386 & 18,5014 & 143,9877 \\
\hline$R_{B}(N, p)$ Mflop/s & 5,896 & 3,4967 & 3,6514 \\
\hline
\end{tabular}


Tabela 7.30 - Resultados encontrados no LASD-PC utilizando MPI com 2 processadores.

\begin{tabular}{|l|l|l|l|}
\hline \multicolumn{2}{|l}{90} & 180 & 360 \\
\hline 2 proc. & 0,5753 & 2,0973 & 39,4338 \\
\hline Serial & 0,097 & 1,0429 & 17,9138 \\
\hline Speedup & 0,1686 & 0,5308 & 0,4542 \\
\hline Eficiência & 0,0843 & 0,2654 & 0,2271 \\
\hline$R_{\mathrm{T}}(\mathrm{N})-$ sols/s & 0,14 & 0,07 & 0,03 \\
\hline$F_{B}(\mathrm{~N})-$ Mflop & 2,4386 & 18,5014 & 143,9877 \\
\hline$R_{B}(N, p)$ Mflop/s & 4,2388 & 8,8215 & 3,6514 \\
\hline
\end{tabular}

Para o sistema distribuído, este tipo de algoritmo executado sobre o MPI, tem um desempenho pobre se comparado com o PVM (Tabelas 7.31 e 7.32) além disso a execução seqüencial também foi mais rápida. Em relação ao PVM, seu baixo desempenho deve-se ao fato do MPI estar executando exatamente o mesmo código nos três processadores, ou seja, uma cópia de cada programa é enviada para cada processador e executada. O código é exatamente o mesmo até os programas reconhecerem quem é o mestre e quem são os escravos. No PVM isso não acontece, os programas escravos quando iniciados já sabem que são escravos e só possuem a parte do código necessária para a realizar a multiplicação.

Devido ao tamanho relativamente pequeno das matrizes, a diferença de velocidade dos processadores e a sobrecarga na comunicação (rede de velocidade baixa) a execução serial teve nítida vantagem sobre a paralela como mostrado pelo Gráfico 7.29.

\section{Gráfico 7.29 - Tempo de execução do algoritmo do trapézio composto no LASD-PC utilizando MPI.}

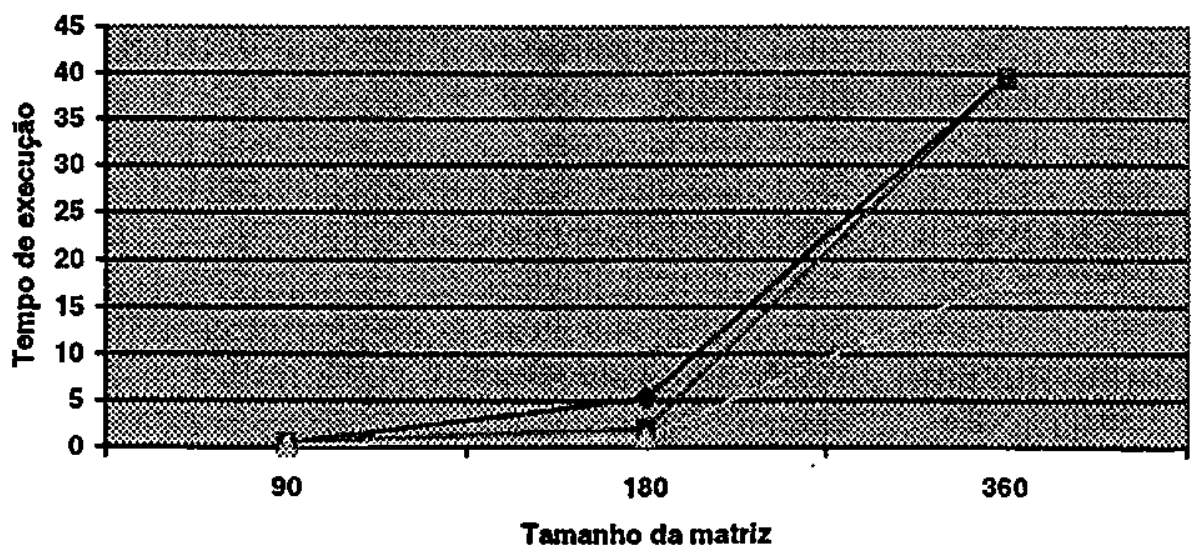

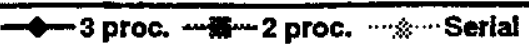




\section{Gráfico 7.30 - Speedup e eflciência alcançados por 2 e 3 processadores no LASD-PC utillzando MPI.}
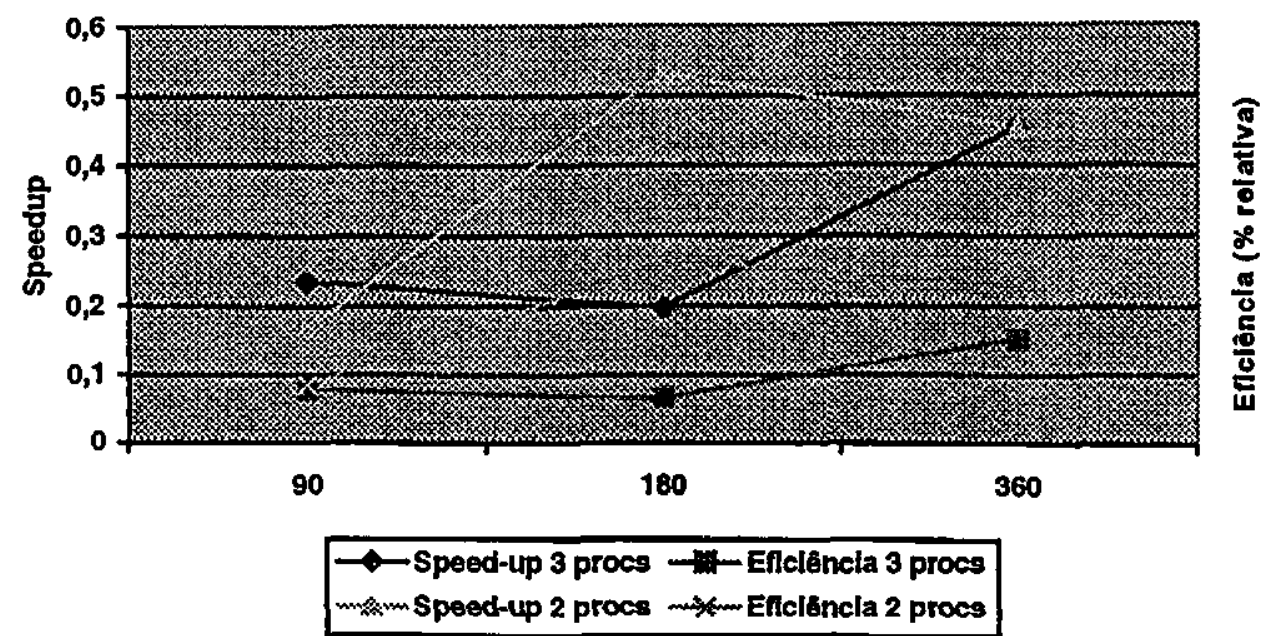

O Gráfico 7.30 de speedup e eficiência mostra o desempenho pobre do algoritmo no sistema distribuído já que os valores para o speedup estão abaixo de zero indicando que a velocidade de processamento foi melhor em 1 processador (seqüencial). E a eficiência não chegou a 0,3 que indica uma eficiência de apenas $30 \%$.

A seguir, nas Tabelas 7.31 e 7.32 são mostrados os resultados conseguidos no sistema distribuído utilizando o PVM.

Tabela 7.31 - Resultados encontrados no LASD.PC utillzando PVM com 3 processadores.

\begin{tabular}{|l|l|l|l|}
\hline \multicolumn{2}{|c}{90} & \multicolumn{1}{l}{180} & \multicolumn{1}{l}{360} \\
\hline 3 proc. & 0,5753 & 1,9646 & 10,8807 \\
\hline Serial & 0,097 & 1,0429 & 17,9138 \\
\hline Speedup & 0,1686 & 0,5308 & 1,6463 \\
\hline Eficiência & 0,0843 & 0,2654 & 0,8231 \\
\hline$R_{\mathrm{T}}(\mathrm{N})-$ sols/s. & 0,19 & 0,1 & 0,05 \\
\hline $\mathrm{F}_{\mathrm{B}}(\mathrm{N})-$ Mflop & 2,4386 & 18,5014 & 143,9877 \\
\hline$R_{B}(N, p)-$ Mflop/s & 4,2388 & 9,4174 & 13,2333 \\
\hline
\end{tabular}

Tabeia 7.32 - Resultados encontrados no LASD-PC utllzando PVM com 2 processadores.

\begin{tabular}{|l|l|l|l|}
\hline \multicolumn{2}{|c}{90} & 180 & 360 \\
\hline 2 proc. & 0,4052 & 2,066 & 13,6628 \\
\hline Serial & 0,097 & 1,0429 & 17,9138 \\
\hline Speedup & 0,2393 & 0,5047 & 1,3111 \\
\hline Eficiência & 0,119694 & 0,252396 & 0,6555 \\
\hline$R_{T}(N)-$ sols/s & 0,14 & 0,07 & 0,03 \\
\hline$F_{B}(N)-$ Mflop & 2,4386 & 18,5014 & 143,9877 \\
\hline$R_{B}(N, p)-$ Mflop/s & 6,0183 & 8,9552 & 10,5387 \\
\hline
\end{tabular}


Observando-se o Gráfico $7.31 \mathrm{e}$ analisando-se as Tabelas que apresentam os resultado (7.31 e 7.32)., vê-se a nítida vantagem do PVM sobre o MPI neste tipo de aplicação. Isso ocorreu porque apesar da programação usar a abordagem SPMD, todos os processadores não executam exatamente o mesmo código (como o MPI), ou seja, os escravos quando iniciados já sabem que são escravos, e a parte semelhante dos programas só é encontrada no algoritmo de multiplicação de matrizes. Nota-se também, que a execução em paralelo é mais rápida a partir de uma matriz de $360 \times 360$ onde a distribuição de carga passou a ter mais influência que a velocidade de comunicação.

Gráflco 7.31 - Tempo de execução do algorlitmo de multiplicação de matrizes no LASD-PC utilizando PVMe.

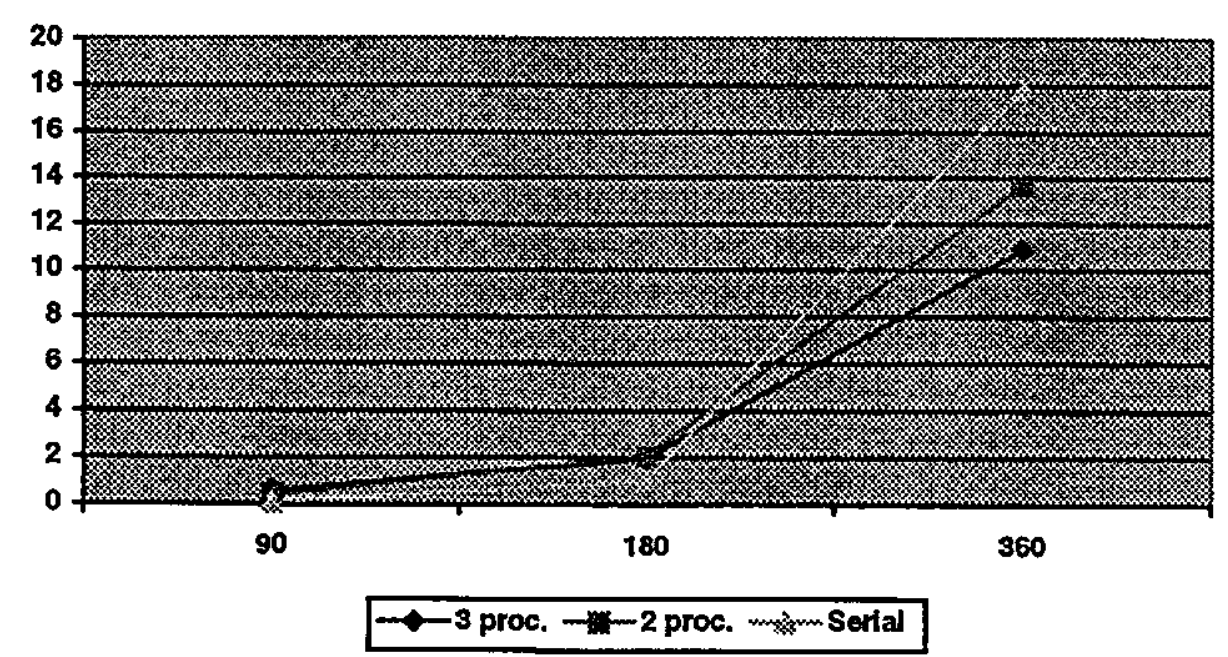

O Gráfico 7.32 mostra o speedup e a eficiência alcançados no sistema distribuído utilizando o PVM. Vê-se que o desempenho só se torna razoável a partir de uma matriz $360 \times 360$. Se uma matriz maior for considerada, com certeza esse desempenho iria aumentar. 


\section{Gráfico 7.32 - Speed-up e eficiência alcançados por 2 e 3 processadores no LASD-PC usando PVM.}
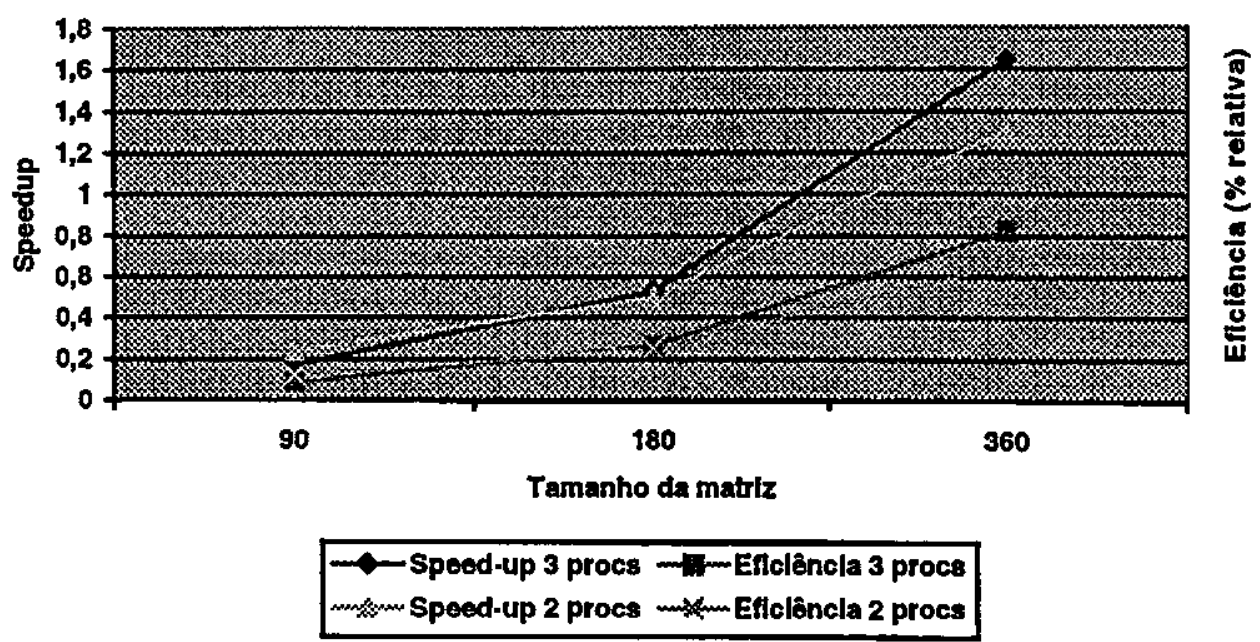

A seguir são mostradas as Tabelas 7.33 e 7.34 que exibem os resultado encontrados na arquitetura Cray.

Tabela 7.33 - Resultados encontrados no Cray utilizando 3 processadores.

\begin{tabular}{|c|c|c|c|c|c|}
\hline & 90 & 180 & 360 & 720 & 1440 \\
\hline 3 proc. & 0,0027 & 0,0162 & 0,1236 & 0,9731 & 7,6809 \\
\hline Serial vetorizado & 0,0035 & 0,0160 & 0,1229 & 0,9722 & 7,6719 \\
\hline Serial nāo vetorizado & 14,55 & 29,17 & 58,29 & 116,59 & 233,16 \\
\hline Speedup & 5388,8889 & 1800,6173 & 471,6019 & 119,813 & 30,3558 \\
\hline Eficiência & 2694,4445 & 900,3087 & 235,801 & 59,907 & 15,1779 \\
\hline$R_{T}(\mathrm{~N})-$ sols $/ \mathrm{s}$ & 0,19 & 0,1 & 0,05 & 0,02 & 0,01 \\
\hline$F_{B}(N)-$ Mflop & 2,4386 & 18,5014 & 143,9877 & 1135,818 & 9020,00 \\
\hline$R_{B}(N, p)-$ Mflop/s & 903,1852 & 1142,0617 & 1164,949 & 1164,949 & 1167,2161 \\
\hline
\end{tabular}

Tabela 7.34 - Resultados encontrados no Cray utilizando 2 processadores.

\begin{tabular}{|l|l|l|l|l|l|}
\hline 2 proc. & 90 & 180 & 360 & \multicolumn{1}{l}{720} & 1440 \\
\hline Serial vetorizado & 0,0029 & 0,0171 & 0,1222 & 0,9706 & 7,6809 \\
\hline Serial nāo vetorizado & 0,0035 & 0,0160 & 0,1229 & 0,9722 & 7,6719 \\
\hline Speedup & 14,55 & 29,17 & 58,29 & 116,59 & 233,16 \\
\hline Eficiência & 5017,2414 & 1705,848 & 477,0049 & 120,1216 & 30,3558 \\
\hline$R_{T}(\mathrm{~N})$ - sols/s & 2508,6207 & 852,924 & 238,5025 & 60,0608 & 15,1779 \\
\hline$F_{B}(\mathrm{~N})-$ Mflop & 0,14 & 0,07 & 0,03 & 0,02 & 0,01 \\
\hline$R_{B}(N, p)-$ Mflop/s & 2,4386 & 18,5014 & 143,9877 & 1135,818 & 9020,00 \\
\hline
\end{tabular}

Devido a vetorizaçāo alcançou-se um caso raro de eficiência. Como a multiplicaçāo tradicional de matrizes exige muitas operações vetoriais o desempenho desta arquitetura foi muito bom. A 
execução com vetorização utilizando um único processador, novamente foi mais rápido que com 2 e 3 processadores. Esse resultado deve-se novamente ao fato de que com um único processador em uso, a utilização de registradores e pipelines vetoriais é mais eficiente e não exige comunicação entre os processadores. O Gráfico 7.27 mostra mais claramente o tempo de execução.

\section{Gráfico 7.33 - Tempo de execução do algoritmo de multiplicação de matrizes no sistema Cray.}

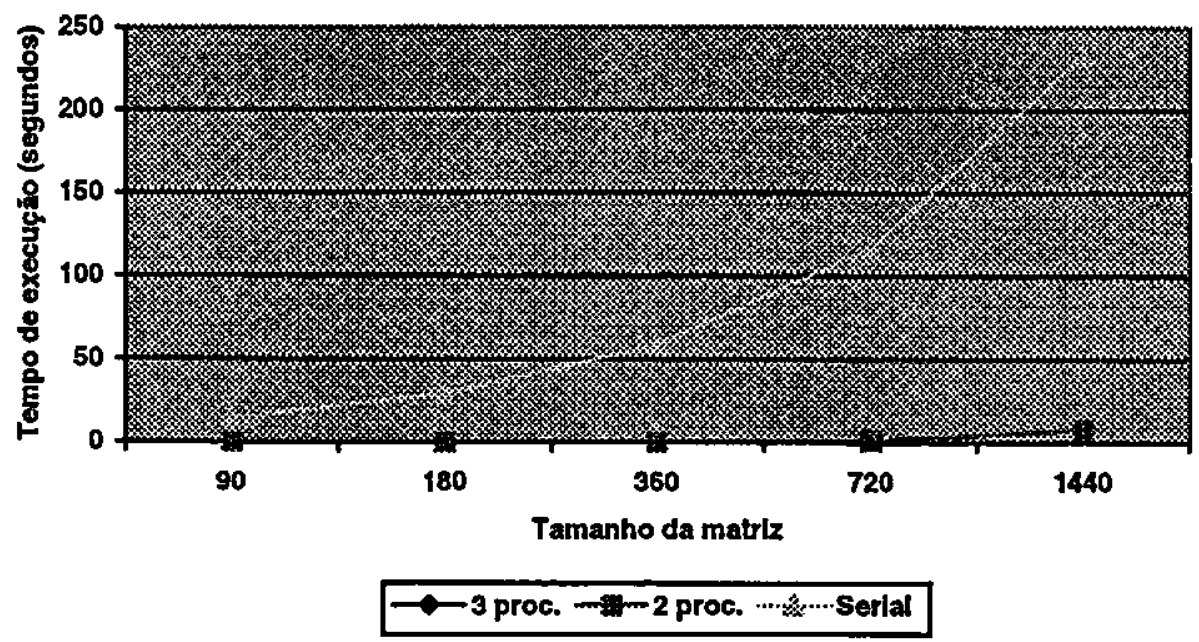

Para 2 e 3 processadores o tempo de execução não teve uma diferença que possa ser notada. A diferença extrema entre as versões vetorizadas e a seqüencial é explicada pelo fato que quando o compilador encontra uma multiplicação tradicional de matrizes, ele o substitui por uma biblioteca própria da arquitetura Cray que é totalmente vetorizável [Cra98a]. Utilizando o profview pode-se observar em termos estatísticos o quanto essa biblioteca influencia no tempo de execução. A Figura 7.7 mostra um gráfico que representa a execução da aplicação sem vetorização. 


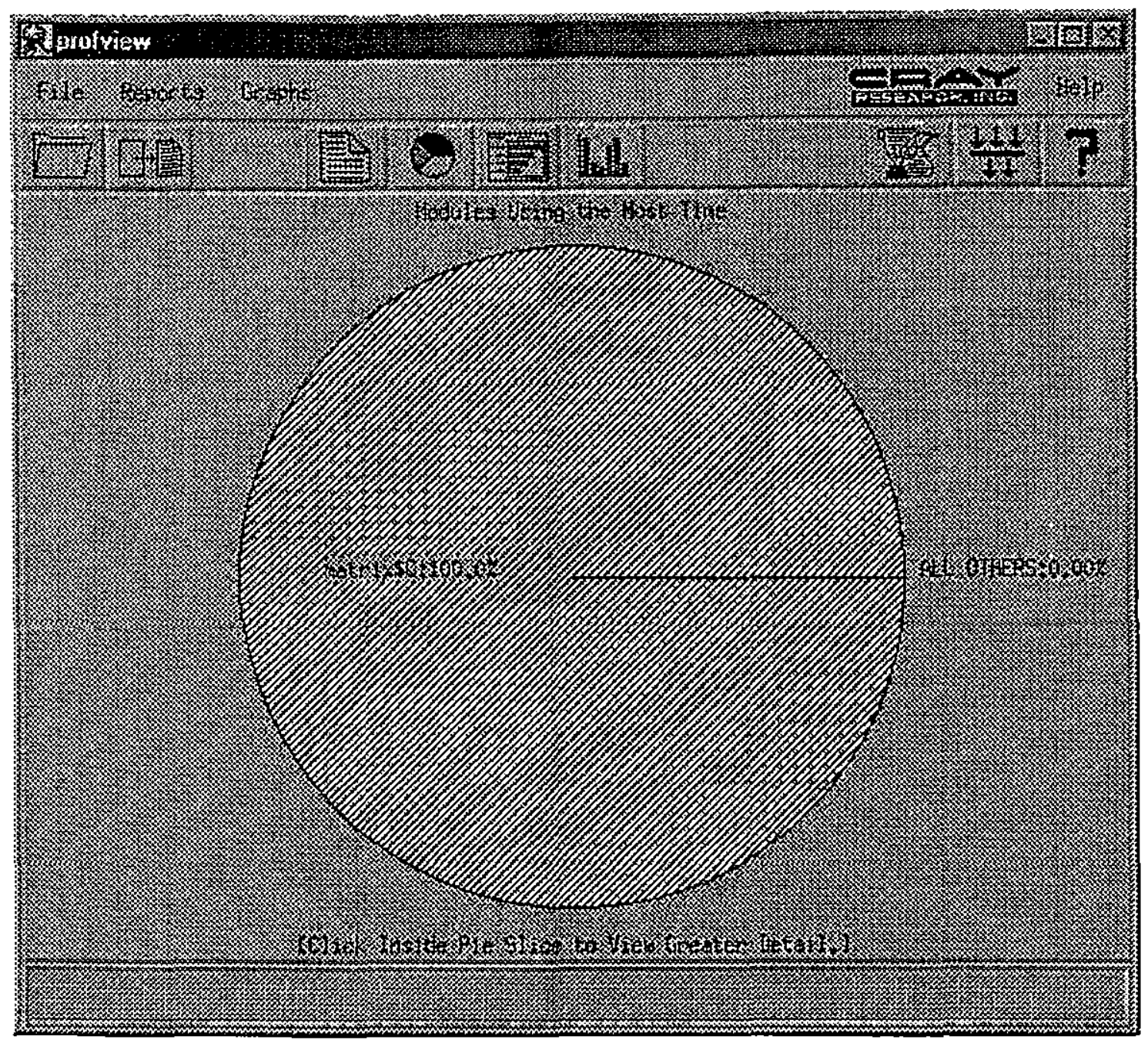

Flgura 7.7 - Execução do algoritmo de multiplicação de matrizes sem vetorização.

No centro do gráfico de Pizza vê-se a porcentagem da aplicaçăo que não foi vetorizada, ou seja, $100 \%$. A Figura 7.8, mostra a porcentagem que a biblioteca inserida pelo compilador tem dentro da execução total do programa observa-se que $78,3 \%$ do tempo total é gasto pela biblioteca, e o restante que inclui inicialização de variáveis, matrizes e demais operações não vetorizadas. 


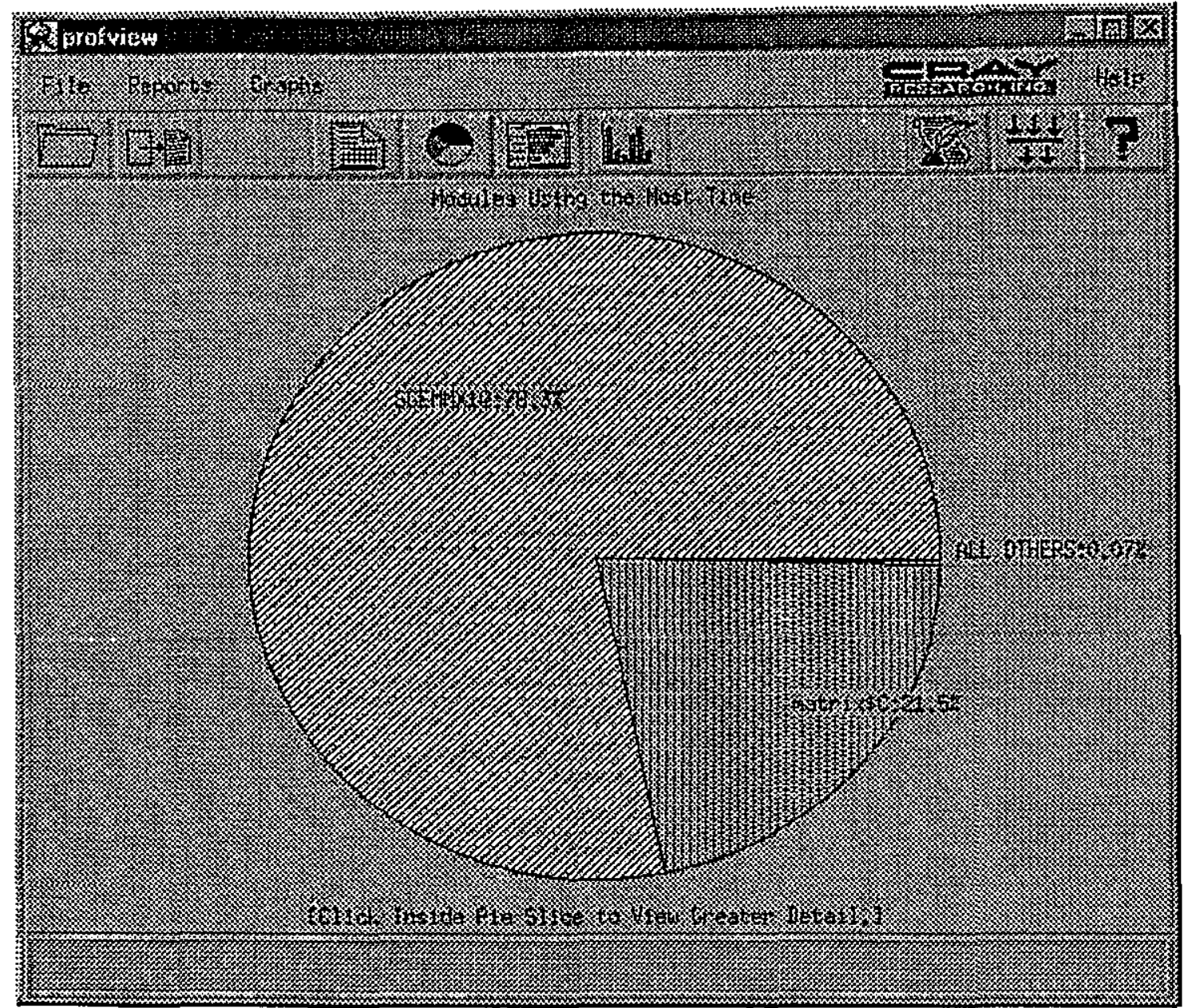

Figura 7.8 - Execução do algoritmo de multipllcação de matrizes com um nível agressivo de vetorização.

Nota-se que esses $21,5 \%$ da aplicação não vetorizada incluem trechos de código que não são contabilizados no tempo de execução do algoritmo. No algoritmo só é contabilizado o tempo necessário para solucionar o problema, neste caso o de multiplicação de matrizes. Dessa forma, o tempo de execução do algoritmo esta quase que totalmente dentro dos $78,3 \%$ da substituição. 


\section{Gráfico 7.34 - Speedup e eficiência econtrados no sistema \\ Cray.}

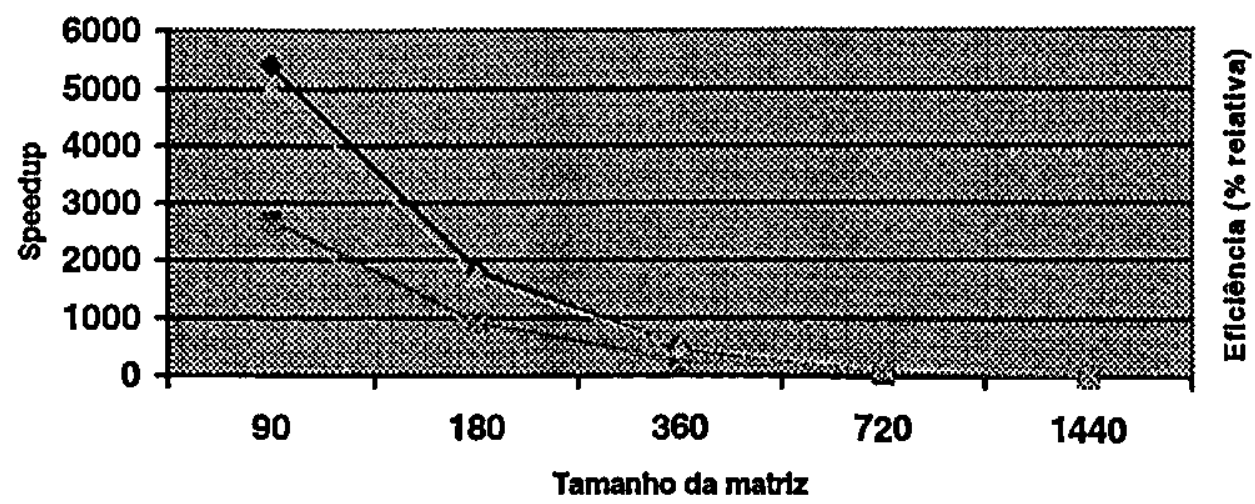

\section{-Speed-up 3 procs m-Eficlêncla 3 proces

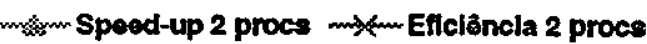

O Gráfico 7.34 mostra o speedup e a eficiência alcançados pelo programa que é decrescente devido novamente a complexidade do problema $\left(n^{3}\right)$. Observa-se também uma anomalia rara de speedup e eficiência devido a vetorização e a substituição do trecho de multiplicação das matrizes pela biblioteca proprietária do Cray. Essa anomalia diminui a medida que a matriz aumenta de tamanho, e continua sendo uma anomalia até a matriz de tamanho $1440 \times 1440$. Apesar desses valores de speedup e eficiência muito altos, quem teve menor tempo de execução foi a versão vetorizada para 1 processador.

\section{Comparação entre arquiteturas}

A Tabela 7.35 e o Gráfico 7.35 mostram um resumo dos desempenhos de benchmark encontrados.

Tabela 7.35 - Resumo do desempenho de benchmark para 3 processadores.

\begin{tabular}{|l|l|l|l|l|l|}
\hline$R_{\Xi}(\mathrm{N}, \mathrm{p})$ & 90 & 180 & 360 & 720 & 1440 \\
\hline SP2 - MPI & 146,024 & 173,2341 & 215,0033 & 19,3756 & 13,5148 \\
\hline SP2 - PVMe & 7,0848 & 42,9965 & 100,7964 & 11,1198 & 13,1738 \\
\hline LASD-PC PVM & 4,2388 & 9,4174 & 13,2333 & - & - \\
\hline LASD-PC MPI & 5,896 & 3,4967 & 3,6514 & - & - \\
\hline Cray & 903,1852 & 1142,0617 & 1164,949 & 1164,949 & 1167,2161 \\
\hline
\end{tabular}

No SP2 utilizando o MPI, os três primeiros valores crescentes são gerados pela grande velocidade de execução que é gerada pelo alto uso da memória cache, a medida que a matriz 
cresce o número de operaçōes em ponto flutuante começa a diminuir devido ao aumento no tempo de execução, lembrando que $R_{B}(N, p)=F_{B}(N) / T(N, p)$.

O desempenho do benchmark vai caindo gradativamente como pode ser visto mais claramente no Gráfico 7.28. Isso acontece deviđo a complexidade do problema $n^{3}$, ou seja, os custo das operações e diretamente relacionado com o tamanho da matriz.

\section{Gráfico 7.35 - Comparação entre arquiteturas com 3 processadores executando o algoritmo de multipllcação de matrizes.}

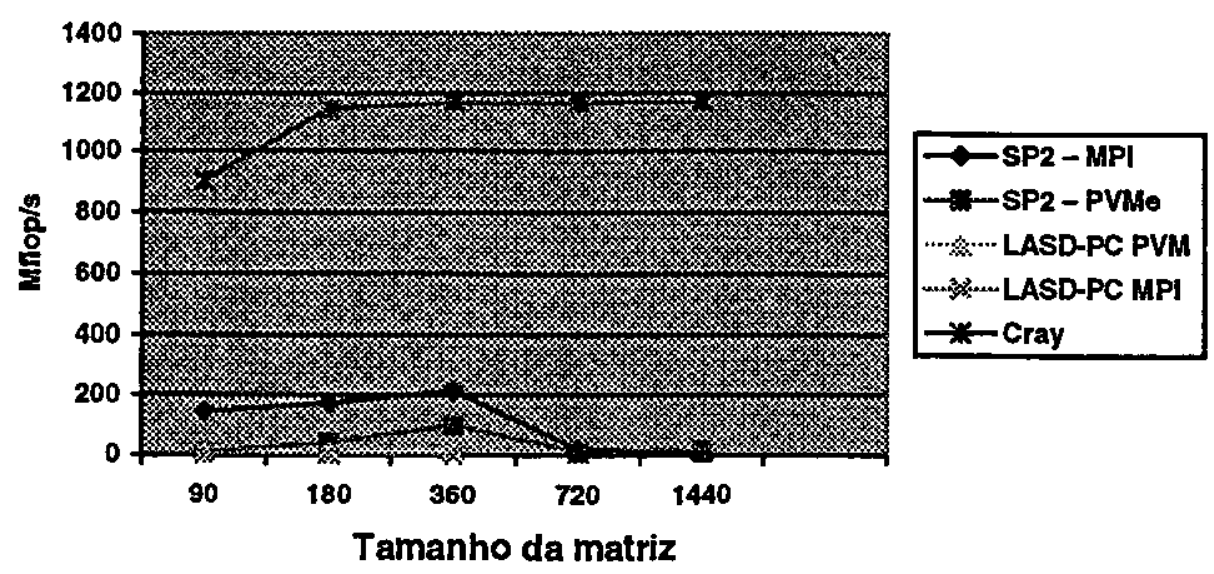

Devido a grande eficiência da vetorização e pela substituição por uma biblioteca própria da máquina, a arquitetura Cray levou uma vantagem mais que nítida sobre as demais. A substituição por essa biblioteca torna a comparação entre as arquiteturas injustas. Isso só seria possível se as demais arquiteturas também utilizassem bibliotecas proprietárias e mais eficientes. o Gráfico 7.36 mostra um melhor comparação entre as demais arquiteturas. 
Gráfico 7.36 - Comparação entre arquiteturas com 3 processadores executando o algoritmo de muitiplicação de matrizes excluindo o Cray.

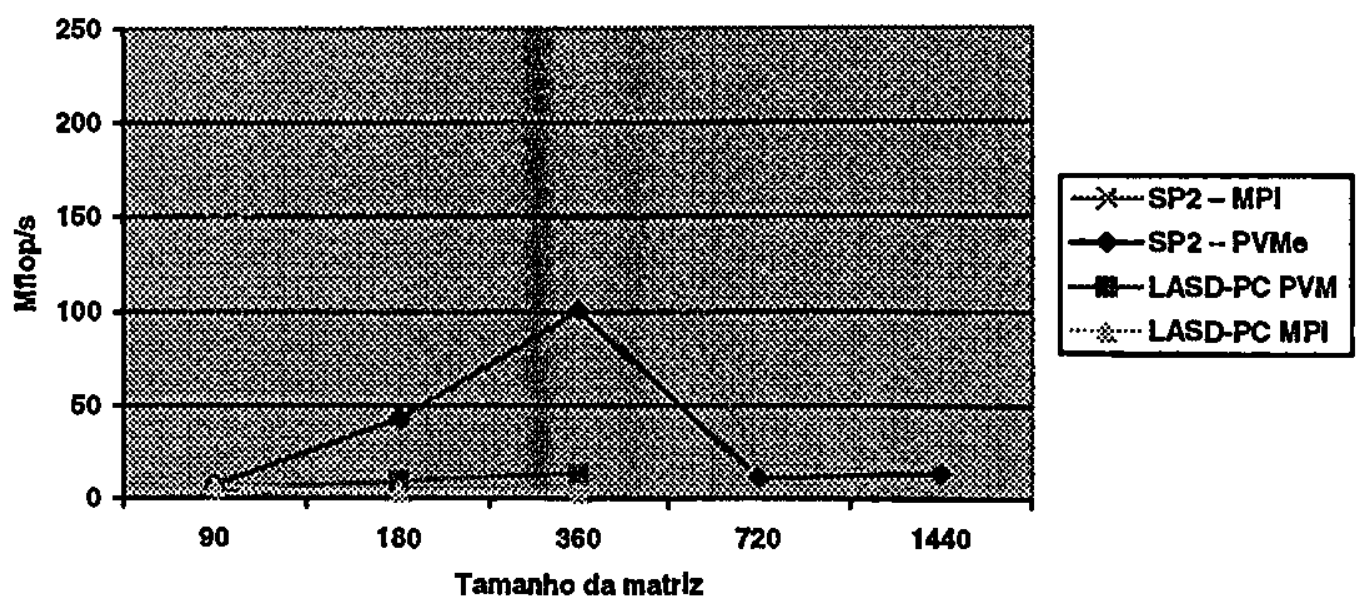

As matrizes de $90 \times 90$ ate $360 \times 360$ se beneficiam nitidamente pela utilização do cache que efetua poucas trocas de páginas entre a cache e a memória. A partir da matriz de 720 x 720 essa troca de páginas aumenta drasticamente. A diferença inicial de Mflop entre o PVMe e o MPI deve-se a diferença do tempo de execução. Essa diferença no tempo de execução deu-se por uma sobrecarga na execução dos escravos no PVMe.

Tabela 7.36 - Resumo do desempenho de benchmark para 2 processadores

\begin{tabular}{|l|l|l|l|l|l|}
\hline$R_{\mathrm{B}}(\mathrm{N}, \mathrm{p})$ & $\mathbf{9 0}$ & 180 & 360 & 720 & 1440 \\
\hline SP2 - MPi & 129,7128 & 140,056 & 152,7397 & 16,7659 & 13,0876 \\
\hline SP2 - PVM $\Theta$ & 8,62 & 39,3396 & 104,7183 & 13,1135 & 10,91055 \\
\hline LASD-PC PVM & 6,0183 & 8,9552 & 10,5387 & - & - \\
\hline LASD-PC MPI & 4,2388 & 8,8215 & 3,6514 & - & - \\
\hline Cray & 840,8966 & 1081,9532 & 1178,2954 & 1178,2954 & 1170,2225 \\
\hline
\end{tabular}

Para dois processadores o comportamento foi semelhante ao de três processadores como pode ser observado no Gráfico 7.37. 
Gráfico 7.37 - Comparação entre arquiteturas com 2 processadores executando o algoritmo de multiplicação de matrizes.

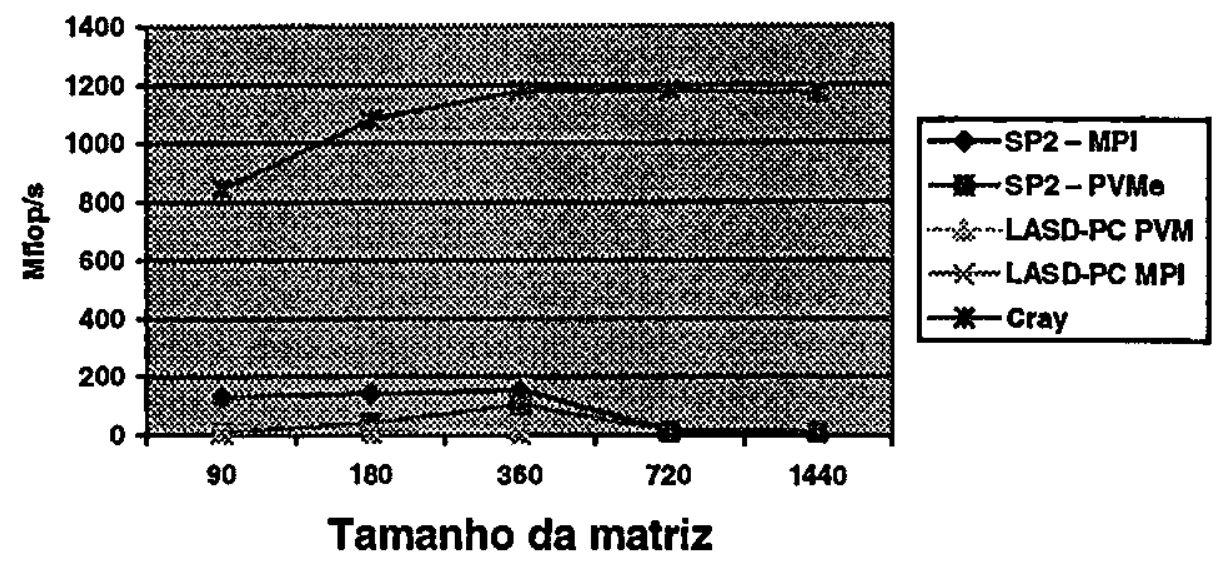

O Gráfico 7.38 mostra o desempenho para as arquiteturas SP2 e sistema distribuído já que novamente incluir a arquitetura Cray na comparação seria extremamente injusto.

\section{Grafico 7.38 - Comparação entre arquiteturas com 3} processadores executando o algoritmo de multiplicação de matrizes exclulndo o Cray.

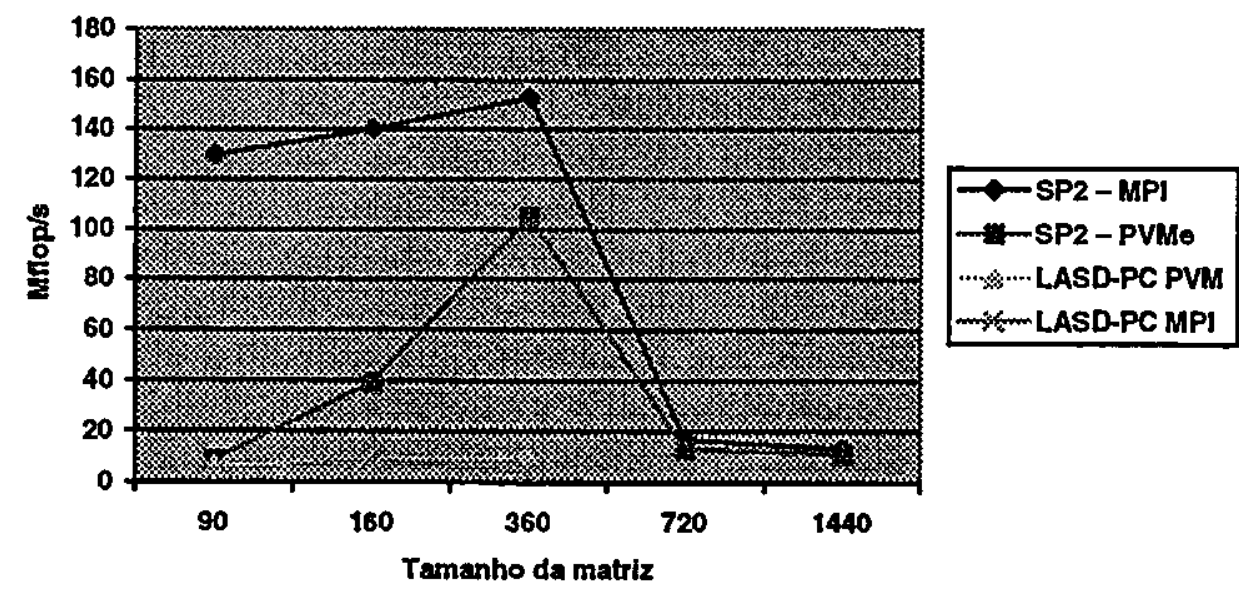

Assim como para 3 processadores, o desempenho do benchmark para 2 processadores teve o mesmo comportamento. O baixo desempenho do sistema distribuído deve-se a diferença de velocidade de processamento entre as máquinas aliado a baixa velocidade de comunicação (10 Mbits/s). 


\subsection{Comparação entre as aplicações desenvolvidas e o NAS}

As aplicações desenvolvidas seguem duas regras básicas do NAS:

- Não utilizar alocação dinâmica

- Os algoritmos iterativos desenvolvidos devem apresentar erro entre $1 \times 10^{-10}$ e $1 \times 10^{-25}$

A Tabela 8.1 mostra um resumo (de acordo com os tamanhos aproximados do problema executado) dos resultados obtidos na execução dos algoritmos e dos benchmarks utilizando 2 processadores sobre MPI. As três primeiras linhas representam os algoritmos numéricos desenvolvidos. As demais linhas representam os resultados encontrados na execução do NAS Parallel Benchmark.

Tabela 8.1 - Resumo dos resultados obtidos na execução dos algoritmos e dos benchmarks.

\begin{tabular}{|l|c|c|c|c|c|}
\hline Benchmark & $\begin{array}{c}\text { Tamanho do } \\
\text { problema }\end{array}$ & \multicolumn{1}{c}{ Erro } & No de iter. & $\begin{array}{c}\text { Tempo de } \\
\text { Execução(s) }\end{array}$ & Mflop/s \\
\hline Integral & 288.000 .000 & - & - & 175,80 & 36,04 \\
\hline Jacobi & 1500 & $1 \times 10^{-20}$ & 9 & 1,1968 & 9,4113 \\
\hline Matrix & 1440 & - & - & 689,2 & 13,0876 \\
\hline MG & $64 \times 64 \times 64$ & $0.1624 \times 10^{-18}$ & 40 & 7,9 & 76,22 \\
\hline EP & 536870912 & - & - & 447,86 & 1,20 \\
\hline FI & $128 \times 128 \times 32$ & - & 6 & 5,98 & 62,30 \\
\hline CG & 1400 & $0.8888 \times 10^{-14}$ & 15 & 1,47 & 62,96 \\
\hline
\end{tabular}

A primeira coluna mostra qual algoritmo e qual benchmark ou aplicação foi utilizado. A próxima coluna exibe o maior valor utilizado para o tamanho do problema. A terceira coluna mostra o erro alcançado quando este é utilizado. A coluna quatro apresenta a quantidade de iterações executadas. A penúltima coluna mostra o tempo de execução e a última coluna apresenta a quantidade de operações em ponto flutuante executados por segundo.

Nota-se que os valores encontrados para os Mflop e para o tempo de execução são bem diferentes. Os tempos de execução são bem variados e extremamente dependentes do algoritmo. Não há como fazer uma previsão de qual será o tempo de execựão.

Os erros encontrados também estão dentro do esperado que é de $1 \times 10^{-15}$ a $1 \times 10^{-20}$, segundo 0 exigido na documentação do NAS. Esse parâmetro é essencial nas aplicações que exigem uma alta precisão como as aplicações de astronomia e astrofísica. 
Para realizar uma avaliação utilizando-se o desempenho do benchmark, ou seja, a quantidade de operações em ponto flutuante por segundo é necessário saber exatamente que tipo de aplicação será executada numa determinada arquitetura. Por exemplo, se a aplicação a ser desenvolvida soluciona sistemas lineares como o CG (Conjugate Gradiente) do NAS ou como o algoritmo desenvolvido de Jacobi, pode-se utilizar o benchmark CG para prever o tempo de execução do algoritmo de Jacobi. Ao comparar as arquiteturas, o benchmark que tiver a maior quantidade de operações em ponto flutuante deve ser o escolhido.

A avaliação da arquitetura a ser utilizada as vezes não depende apenas do melhor desempenho. Outras variáveis estão inclứdas na avaliação como custo, erro desejado numa aplicação entre outras. Cabe lembrar que quanto maior o desempenho geralmente o custo da máquina é maior o custo.

Outra observação pertinente é que o tamanho do cache influencia diretamente na quantidade de operações em ponto flutuante executadas pela máquina.

\subsection{Considerações Finais}

Neste capítulos foram apresentados os resultados obtidos com a execução de três algoritmos numéricos nas 5 plataformas consideradas neste trabalho. Algumas considerações sobre os resultados obtidos são discutidas a seguir.

Os algoritmos numéricos considerados permitem a obtenção de um bom balanceamento de carga e consequentemente uma boa utilização da CPU. Para a implementação do algoritmo do trapézio houve uma média de utilização de 97,33\%. A implementação do algoritmo de Jacobi teve uma média de balanceamento de carga de $96,66 \%$. E a implementação do algoritmo de multiplicação de matrizes teve a melhor porcentagem de balanceamento de carga que foi de $98 \%$ no sistema SP2.

Quanto aos speedups e eficiência alcançados uma grande discrepância pode ser observada nos diferentes exemplos e principalmente nas diferentes plataformas.

As execuções nos sistemas distribuídos apresentam na maioria dos casos, speedups abaixo de um. Estes resultados podem ser explicados pela utilização da rede ethernet - 10Mbit/s. A comunicação lenta torna a execução paralela inviável. 
As execuções no SP2 apresentam na maioria dos casos bons resultados de speedups chegando próximo do caso ideal (speedup = número de processadores utilizados). Em alguns casos ocorreu a anomalia de speedup que gera a anomalia de eficiência devido a grande quantidade de memoria. Isso permite o armazenamento completo das estruturas utilizadas na memoria RAM. Quando essas estruturas eram pequenas podiam ser completamente armazenadas na memória cache. Aliado a essa característica, está também a grande velocidade de comunicação entre os processadores.

As execuções na máquina Cray apresentam otimos resultados para as versōes vetorizadas em aplicaçōes que fazem uso intensivo de matrizes e vetores. As versōes vetoriais monoprocessadas tiveram um melhor desempenho que as versōes multiprocessadas devido a comunicação entre processadores que causa um maior acesso a memória RAM (gerando sincronização) e restringe a utilização de registrados e pipelines vetoriais a dados locais. Ao contrário da versão monoprocessada que usa intensamente os registradores e os pipelines vetoriais.

Assim, as aplicações que fazem uso intensivo de vetores ou matrizes tiveram um desempenho nitidamente melhor que as demais especialmente no sistema Cray. Em especial o algoritmo de multiplicação de matrizes apresentou speedups elevados, que nos sistemas Cray, uma vez que este se utilizou de bibliotecas próprias para realizar a multiplicação disponível somente no Cray.

As métricas de speedup e de eficiência devem ser utilizados com muita cautela, principalmente quando se está efetuando comparação entre arquiteturas. Dessa forma, para comparar as plataformas utilizadas foi usada uma outra métrica, isto é, de operações em ponto flutuante por segundo (desempenho de benchmark)

Comparado o desempenho de benchmarks das aplicaçōes implementadas com os resultado obtidos pelo NAS (apresentado no Capitulo 6), os valores estavam dentro do esperado, não gerando nenhum valor absurdos nem fora do esperado. 


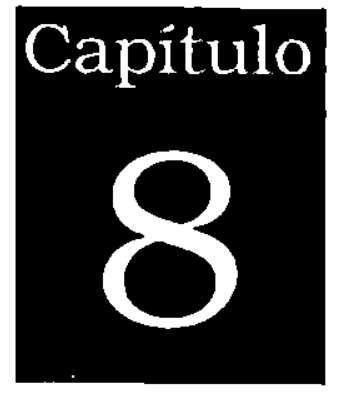

\section{Conclusões}

Este capítulo apresenta uma discussão final sobre o trabalho desenvolvido, abordando um análise da revisão bibliográfica, comentários sobre os ambientes utilizados e as conclusões baseadas nos dados obtidos no trabalho. As principais dificuldades encontradas são discutidas e sugestões para trabalhos futuros são propostas.

\subsection{Análise da revisão bibliográfica}

\section{Computação Paralela}

Os principais tópicos relacionados tanto às arquiteturas paralelas, quanto à programação dessas arquiteturas foram discutidos. Em termos de arquiteturas paralelas, vem sendo muito utilizado os sistemas distribuídos simulando uma arquitetura paralela virtual, também conhecida como arquitetura de cluster. Seu custo relativamente baixo tornou a computação paralela extremamente atrativa tanto para organizaçōes públicas, como universidades, ou particulares como pequenas e médias empresas que antes não tinham acesso a esse tipo de sistemas. 
Quanto a programação dessas arquiteturas paralelas, vem se tornando cada vez mais forte a utilização de programas MPMD e SPMD, fortemente apoiados pelas extensões paralelas de linguagens seqüenciais como o PVM e o MPI.

\section{Benchmarks}

Neste tópico foi apresentada a utilização de benchmarks como ferramenta para avaliação de desempenho em sistemas computacionais, em geral, e em particular nos sistemas paralelos. Para organizar a grande quantidade de benchmarks existentes no mercado foi criado o Parkbench Comitee, esse comitê ê responsável pela divulgação de novos benchmarks e pela divulgação dos resultados obtidos com a utilização dos já existentes. A área dos benchmarks paralelos é relativamente recente sendo que um dos mais conhecidos, e alvo de constantes estudos, é o NAS Parallel Benchmark desenvolvido pela NASA Ames Research Center. A maioria dos benchmarks conhecidos estão escritos em Fortran, os mais antigos encontram-se também em ALGOL, mas, pouco a pouco eles tem sido passados para a linguagem C. O principal motivo dos benchmarks estarem escritos em Fortran é que esta linguagem, por ser voltada para a matemática, trabalha com números de ponto flutuante mais rapidamente que as outras linguagens. Atualmente esse quadro vem sendo alterado drasticamente devido as otimizações de código feitas pelos compiladores $\mathrm{C} \mathrm{e} \mathrm{C}++$ disponíveis atualmente [Ve197]. Na verdade, nos dias atuais essas três linguagens estão competindo de igual para igual na manipulação de números de ponto flutuante.

A área de Bechmarks paralelos ainda é relativamente nova, sua utilização não é simples e exige um bom conhecimento sobre:

- Configuração das bibliotecas de passagem de mensagem;

- Utilização do sistema operacional do tipo Unix;

- Linguagem de programação em que foi desenvolvido o benchmark;

- Noções de cálculo numérico quando utilizados os benchmarks de núcleo.

A documentação para alguns benchmarks paralelos como o Genesis e o ParkBench é muito pobre e geralmente muito difícil de ser encontrada.

O NAS Parallel Benchmark, é o benchmark mais bem documentado por isso não gera muitas dificuldades para ser instalado e executado. 
Os resultados obtidos em benchmarks não dizem muita coisa sobre o sistema em teste, apenas dá um idéia do que se quer saber. Também não responde a questőes que não são analisadas pelo seu nível, por exemplo, um benchmark de núcleo não pode dar muitas respostas sobre o sistema de comunicação pois para isso existem os benchmarks de baixo nível.

\section{Algoritmos Numéricos}

Alguns exemplos de algoritmos numéricos e a possibilidade de paralelizá-los foram discutidos. Como em outras áreas, os algoritmos numéricos também têm se tornado cada vez mais complexos. Um exemplo disso é que atualmente o método de Gauss-Jacobi, que havia sido considerado obsoleto, pois convergia muito lentamente em sistemas lineares de grande porte, em relação a outros métodos diretos como o de Triangularização de Gauss, foi revivido pela computação paralela. Na área de Engenharia Elétrica, mais especificamente, na área de Sistemas de Potência, onde muitas vezes é necessário resolver sistemas lineares com matrizes de tamanho aproximado de 2000 x 2000, o método de Gauss-Jacobi e o de Jacobi são muito utilizados e muito se tem pesquisado devido a paralelização natural desses algoritmos.

A maioria dos algoritmos numéricos podem ser implementados tanto utilizando-se a abordagem de programação SPMD quanto MPMD. Sendo que a abordagem SPMD neste caso torna-se extremamente atraente por facilitar a programação e a manipulação dos dados.

\subsection{Comentários sobre os ambientes utilizados}

O aprendizado da utilização do ambiente SP2 não é trivial e exige um bom conhecimento sobre a operação do sistema operacional do tipo Unix. Para a biblioteca de passagem de mensagem MPI, existe um bom número de ferramentas gráficas que auxiliam no desenvolvimento das aplicaçōes. Já para o PVM/PVMe, a quantidade de ferramentas disponíveis é muito pequena e quando encontrada é baseada em caractere.

A utilização dos sistemas Cray não é muito complexa. Assim como no SP2, para utilizar o sistema é necessário conhecer a operação de um sistema operacional do tipo Unix. Em comparação ao SP2 o sistema de submissão de tarefas do Cray é mais simples e a quantidade de comandos essenciais para manipular a fila de execução é bem menor. 
A utilização do sistema distribuído é totalmente interativa, ou seja, não existem programas gráficos para auxiliar na execução dos programas paralelos. Dentre os três sistemas este é o que exige mais do usuário, já que o mesmo precisa estar acompanhando a execução da tarefa, seja para ver os resultados ou caso haja um travamento no sistema.

\subsection{Discussão sobre os resultados obtidos}

\section{Quanto aos ambientes utilizado}

Um estudo sobre a paralelização do algoritmo que será utilizado com o intuito de obter-se um bom balanceamento de carga é essencial para bons resultados. Várias versões do programa devem ser criadas e testadas até a obtenção de um balanceamento adequado. $O$ bom conhecimento sobre o ambiente que será utilizado e sobre o algoritmo a ser paralelizado ajuda na diminuição do tempo de desenvolvimento de um bom algoritmo.

O desempenho obtido em um algoritmo paralelo depende ainda da adequação da aplicação considerada ao ambiente utilizado.

Quando a aplicação não faz uso intenso de vetores, como no caso do algoritmo do trapézio composto, o desempenho nas máquinas Cray não é satisfatório, principalmente no que diz respeito a variável custo/beneff́cio. Neste caso o SP2 leva nítida vantagem.

O desempenho dos programas seqüenciais nas máquinas Cray é extremamente baixo. Isso quase sempre leva a uma anomalia de speedup e de eficiência. Essas anomalias não caracterizam um real ganho de desempenho. Dessa forma, conclui-se que essa métrica não deve ser a única para tirar conclusões sobre o desempenho de um sistema, principalmente se for um sistema vetorial.

As máquinas Cray apresentam ainda grande vantagem para aplicações em que bibliotecas proprietárias podem substituir trechos de programas. Um exemplo deste caso é a multiplicações de matrizes.

O SP2, representa uma máquina multiprocessada de alto desempenho e com grandes vantagens para aplicações genéricas que não façam uso intensivo de vetores. Com um balanceamento de carga adequado apresenta-se como uma excelente alternativa. Um exemplo deste caso é a resolução de integrais pelo método do trapézio composto. 
No sistema distribuído, a diferença de velocidade entre os processadores gera uma espera para a finalização da comunicação degradando o desempenho. Neste caso o balanceamento de carga deve ser revisto e alterado, ou seja, mais cálculos para o processador mais rápido e menos cálculos para os mais lentos. Um problema adicional observado no sistema distribuído é a comunicação muito lenta oferecida pela rede Ethernet a $10 \mathrm{Mbits} / \mathrm{s}$.

\section{Quanto as bibliotecas de passagem de mensagem}

Quanto ao desempenho das bibliotecas de passagem de mensagem, o PVM teve uma ligeira vantagem sobre o MPI, pelo fato de que o PVM foi projetado para rodar em sistemas distribuidos, isso aconteceu tanto no sistema distribuído como no SP2. O enfoque principal do MPI é a portabilidade, ou seja, o programa deve ser executado em qualquer máquina sem nenhuma modificação. Essa portabilidade do MPI foi notada pois os programas funcionaram tanto no SP2 como no sistema distribuído sem nenhuma alteração. Já o PVM exigiu a inserção de algumas rotinas para poder ser executado no sistema distribuído.

\section{Quanto a utilização de benchmarks}

A substituição de trechos envolvendo laços por bibliotecas proprietárias para o sistema Cray, torna o desempenho de benchmark $\left(R_{B}(N)\right)$ inadequado para comparação entre essas arquiteturas, a menos que cada um delas substitua os mesmos trechos por bibliotecas proprietárias. $O$ desempenho de benchmark demonstrou-se adequado para a comparação entre arquiteturas que utilizam o mesmo processo de paralelização.

Um dos grandes responsáveis pela obtenção de um bom desempenho em problemas de pequeno porte foi sem dúvida a memória cache.

A comparação entre sistemas de memória distribuída e de memória compartilhada deve ser feita com muito critério, a menos que as mesmas bibliotecas de passagem de mensagem sejam utilizadas. Como pode ser visto nos gráficos de comparação entre arquiteturas do Capítulo 7, as máquinas Cray quase sempre levaram vantagem devido a velocidade de comunicação entre os processadores.

O desempenho temporal $\left(R_{f}(N)\right)$ comportou-se de acordo com a complexidade do problema. 
Pelo fato dos benchmarks paralelos serem muito recentes, o melhor teste de desempenho ainda continua sendo a aplicação que se quer utilizar, ou seja, se o objetivo é utilizar um programa de análise de contingência já construído, a execução do próprio programa em cada arquitetura observando-se o tempo de execução ainda é o melhor benchmark.

Caso não se tenha a aplicação ainda pronta, deve-se primeiro saber que tipos de algoritmos essa aplicação utilizará. Em seguida escolher os benchmarks que mais se aproximam desses algoritmos e verificar os respectivos desempenhos.

\subsection{Dificuldades Encontradas}

Inicialmente um dos maiores empecilhos para $o$ andamento do projeto foi a configuração dos sistemas SP2 e Cray. No caso do SP2 do CISC a configuração e utilização foi mais fácil por encontrar-se localizado na própria região da pesquisa. $O$ maior empecilho neste caso é a quantidade máxima de processos que podem ser gerados nesta máquina que são apenas três, ou seja, a quantidade máxima de processos que podem ser criados $e$ igual ao número de processadores o que impede a implementação de algoritmos que gerem concorrência pelos processadores. A utilização do SP2 do LCCA tornou-se difícil devido ao grande número de usuários.

Quanto aos computadores da linha Cray, que se encontram no campus de São Paulo, o empecilho inicial foi a configuração dos sistemas que chegou a durar dias pois toda a comunicação com o suporte era feita através de $e$-mail.

Em relação a utilização de benchmarks, deve-se destacar a pouca documentação encontrada principalmente sobre instalação e utilização de alguns benchmarks. A utilização de benchmarks mostrou-se complicada exigindo muitos conhecimentos.

No desenvolvimento dos programas PVM, encontrar falhas na comunicação que provocavam o travamento da aplicação foi uma dificuldade encontrada, principalmente pela falta de ferramentas. Portar o programa em PVM do SP2 para o sistema distribuído causou dificuldades extras, pois no sistema distribuído o programa mestre utiliza a posição 0 (zero) do vetor de identificação de escravos para sua própria identificação, e no SP2 isso não ocorre. 
Pelo fato de que a utilização no sistema distribuído é interativa, obrigando o usuário a acompanhar a execução das tarefas, os testes nas aplicações desenvolvidas consumiu uma boa quantidade de tempo. A falta de ferramentas para depuração causou dificuldade extras.

Notou-se também uma falta tremenda de monitores de desempenho para as arquiteturas com memória distribuída.

\subsection{Sugestões para Trabalhos Futuros.}

- Desenvolver outros algoritmos numéricos para solucionar os mesmos problema abordados neste trabalho para validar a utilização da métrica desempenho temporal.

- Desenvolver uma ferramenta para monitorar o desempenho de máquinas com memória distribuída, contando todas as operações em ponto flutuante.

- Desenvolver uma ferramenta semelhante ao VT para um sistema distribuído com as funções de monitorar:

- Comunicação entre processos;

- Balanceamento de carga;

- Utilização de CPU;

- Acessos a disco;

- Comunicação entre a memória cache e a memória RAM.

- Fazer a comparação de algoritmos numéricos implementados em PVM, MPI, HPF e PARMACS.

- Desenvolver o MPI para o sistema operacional Windows comparando-o com a versão do PVM para Windows desenvolvida no LASD-PC. 


\section{Referências Bibliográficas}

[Alm94] Almasi, G. S.; Gottlieb A., "Highly Parallel Computing", 2a ed. The Benjamin Commings Publishing Company, Inc., 1994.

[Bai94a] Bailey, D.; Barszcz, E.; Barton, J.; Browning, D.; Carter, R.; Dagum, L.; Fatoohi, R.; Fineberg, S. ; Frederickson, P. ; Lasinski, T. ; Schreiber, R.; Simon, H.; Venkatakrishnan, V.; S. Weeratunga. "The NAS PARALLEL Benchmarks", http://science.nas.nasa.gov/Pubs/TechReports/RNRreports/dbailey/RNR-94007/htm//npbspec.html, NASA Ames Research Center, RNR Technical Report RNR-94-007, Março 1994.

[Bai94b] Bailey, D.; Barszcz, E.; Barton, J.; Browning, D.; Carter, R.; Dagum, L.; Fatoohi, R.; Fineberg, S. ; Frederickson, P. ; Lasinski, T. ; Schreiber, R.; Simon, H.; Venkatakrishnan, V.; S. Weeratunga. "Simulated CFD Application Benchmarks", http://science.nas.nasa.gov/Pubs/TechReports/NASreports/NAS-94001/section3 4.html, NASA Ames Research Center, RNR Technical Report RNR94-007, Março 1994.

[Beg94] Beguelin, A.; Geist, A.; Dongorra, J.; Jiang, W.; Manchek, R.; Sunderam., "PVM: Parallel Virtual Machine. A User Guide and Tutorial for Networked Parallel Computing". The MIT Press, 1994.

[Ber91] Berry, M.; Cybenko, G.; Larson, J., "Scientific Benchmark Characterizations", Parallel Computing, vol. 17, pp. 1173-1194, 1991.

[Ble94] Blech, R. A., "An Overview of Parallel Processing", slides, Parallel Computing with PVM Workshop, Nasa Lewis research Center, 1994.

[Cen97] Centurion, A. M., "Análise de Desempenho de Algoritmos Paralelos Utilizando Plataformas de Portabilidade", Mini-dissertação, ICMSC/USP, novembro, 1997.

[Cis98] Centro de Informática de São Carlos, "IBM Scalable POWERParallel System", http://www.cisc.sc.usp.br/servicos/sp2.html, 1998

[Cla94] Claudio, D. C. e Marins, J.M. "Cálculo Numérico Computacional: Teoria e Prática", São Paulo: Atlas, 1994. 2 ed. 460p. 
[Cra98a] Cray Research Inc., "Cray C/C++ Reference Manual", http://www.Cray.com/cgibin/mph-dweb/dynaweb/t90_ieee_fp/004-2179-001/@Generic_BookTextView/ 7207.

[Cra98b] Cray Research Inc., "Optimizing Code on Cray PVP Systems", http://www.Cray.com/cgi-bin/nph-dweb/dynaweb/t90_ieee_fp/004-2179001/@Generic_BookTextView/ 7207.

[De195] Dell Computer Corporation, "Server System Benchmarks", Advanced Tecnology Group, 1995.

[Don87] J. Dongarra, J. Martin, and J. Worlton, "Computer Benchmarking: Path and Pitfalls", IEEE Spectrum, pp. 38-45, Julho 1987.

[Don96] Dongarra J., Mucci, P., Strohmaier, E., "ParkBench 2.0: Release Notes and Run Rules", http://netlib2.cs.utk.edu/parkbench/, May, 1996.

[Dun90] Duncan, R. "A Survey of Parallel Computer Arquitectures", Computer IEEE, Fevereiro de 1990.

[Emi96] Emilio G. H., "A Methodology for Design of Parallel Benchmarks", Thesis submitted for the degree of Doctor Philosophy, University of Southampton, Dezembro 1996.

[Fos95] Foster, Y., “Designing and Building Parallel Programs: Concepts and Tools for Parallel Software Engineering", Addison-Wesley Publishing Company Inc., 1995.

[Geh89] Gehani, N., e McGettrick A. D. "Cuncurrent Programming", Cornwall: International Computer Science Series, 1989.621p.

[Gei94] Geist, A., Beguelin, A., Dongarra, J., Weicheng, J., Manchek, R., Sunderam, V., 'PVM 3 User's Guide and Reference Manual", Oak Ridge National Laboratory, 1994.

[Gle94] Glendinning, I., "The GENESIS Distributed-Memory Benchmark Suite Release 3.0". High Performance Computing Centre. University of Southampton, 1994.

[Gus86] Gustafson, J. L., Hawkingson, S., "A Language_Independent Set of Benchmarks for Parallel Processors", http://www.scl.ameslab.gov/Publications/6-pack/6pack.html. Ames Laboratiry, Departament of Energy, ISU, Ames, Iowa, 1996.

[Hay82] Haynes, L. S.; Lau, R. L., Siewiorek, D. P., "A Survey of Highly Parallel Computing", Computer IEEE, Janeiro 1982.

[Hei84] Heidelberg, P. e Lavemberg, S. "Computer Performance Evaluation Methodology", IEEE Transaction Computer, vol C.-33, $\mathrm{n}^{\circ} 12$, pp. 1195-1220, 1984.

[Hoc96] Hockney, R. W., "The Science of Computer Benchmarking", Philadelphia: 
society for Industrial and Applied Mathematics, 1996.

[Hwa84] Hwang, K. Brigs, F. A., "Computer Architecture and Parallel Processing", McGrawHill, 1984.

[Hwa93] HWANG, Kai. “Advanced Computer Architecture: Parallelism, Scalability, Programmability". Illinois: McGraw-Hill, 1993.

[Ibm95a] IBM Corporation, "IBM Parallel Environment for AIX: Operation and Use Version 2.1.0”, IBM Departament 55JÁ, 1995

[Ibm95b] IBM Corporation, "IBM PVMe for AIX User's Guide and Soubrotine Reference Version 2, Release 1", IBM Departament 55JÁ, 1995

[Ibm95c] IBM Corporation, “LoadLever User's Guide Release 2.1", , $\mathrm{ftp}: / / \mathrm{ftp}$.usp.br/pub/lcca, 1995

[Ibm98] IBM Corporation, "SP2 High Performance Switch Overview", http://aixport.sut.ac.jp/advsys/mhppc/ibmhwsw/switch.html, 1998.

[Int98] INTEL Corporation, "Why Should You Care About Performance?", http://pentium.intel.com/procs/perf/intro/bintro.htm, 1998.

[Kir91] Kirner, C., "Arquiteturas de Sistemas Avançados de Computação", Anais da Jornada EPUSP/IEEE em Sistemas de Computação de Alto Desempenho, pp. 307$353,1991$.

[Mac94] MacDonald, N., Minty, E., Harding, T., Browa, S., "Writing Message-Passing Parallel Programs with MPI - Course Notes". The University of Edinburgh, 1994.

[Mah88] McMahon., F. H., "The livermore Fortran Kernels test of the Numerical Performance Range.". Performance Evaluation of Supercomputers, pp. 143-186. Elvier Science B. V., North-Holland, Amsterdan, 1988.

[Men97] Meng, X., 'Parallel Computing CSCI 6356", http://bahia.cs.panam.edu/ meng/Course/CS6356/Notes/master/node20.htmi\#SEC TION00520000000000000000, Texas: Department of Computer Science University of Texas - Pan American, 1997.

[Mis89] Misra, C. "Parallel Program Design: A Foundation", Texas: Addison-Wesley Publishing Company, 1989. 516p.

[Nav89] Navaux, P. O. A., "Introdução ao Processamento Paralelo". RBC - Revista Brasileira de Computação, v. 5, nº 2, pp.31-43. Outubro, 1989.

[On198] OnLine Knowledgment Home Page, "Types of benchmarks", http://www.systemhouse.mci.com/shltdemo/segments/lds00001/method/tech/mq30 6/mq307nd4.htm, 1998. 
[Tan95] Tanenbaum, A. S., "Distributed Operating Systems", Pretince Hall International Inc., 1995.

[Ve194] Velde, E. F. Van De, “Concurrent Scientific Computing”, New York: SpringerVerlag, 1994. 328p.

[Ve197] Veldhuizen, T., "Scientific Computing: C++ Versus Fortran", Dr. Dobb's Journal, $n^{\circ} .271$, pp. 34-38, Novembro, 1997.

[Wai95] Wainner, S., "Benchmarks FAQ 6", http://hpwww.epfl.ch/bench/bench.FAQ.html, 1995.

[Wa194] Walker, D. W., "The Design of Standard Message Passing Interface for Distributed Memory Concurrent Computers"., Parallel Computing, vol. 20, pp. 657-673, 1994.

[Wei91] Weicker, R. P., "Detailed Look at Some Popular Benchmarks", Parallel Computing, vol. 17, pp. 1153-1172, 1991.

[Zan94] Zandt, J. V., "Scientific Computing Paradigm", NASA Ames Research Center, RNR Technical Report RND-94-002, Janeiro, 1994. 